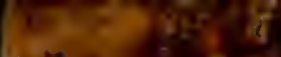

2yore

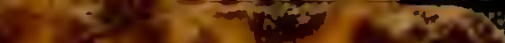

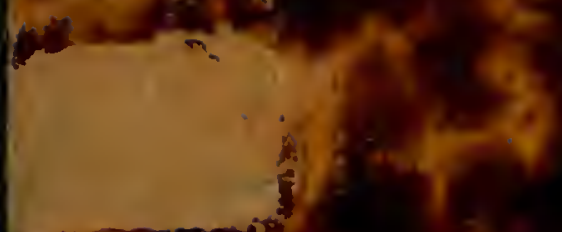

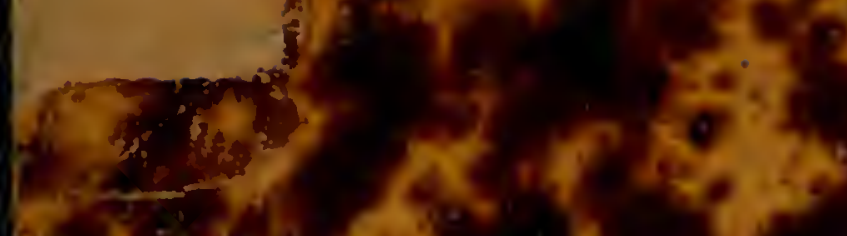

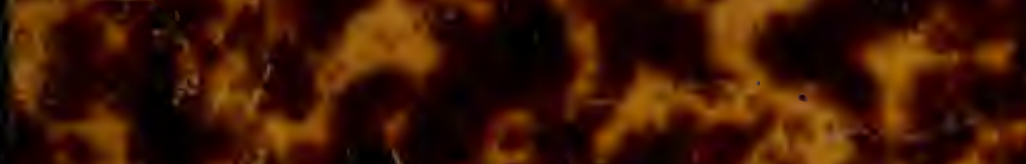

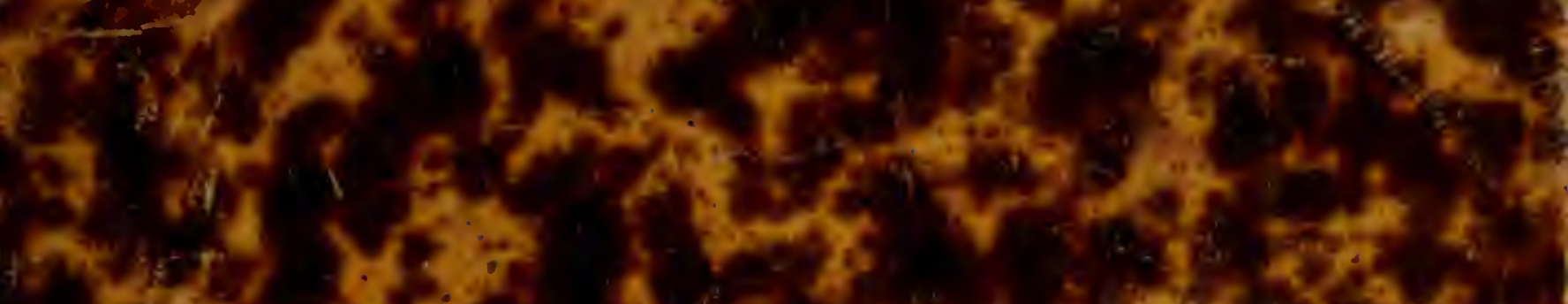

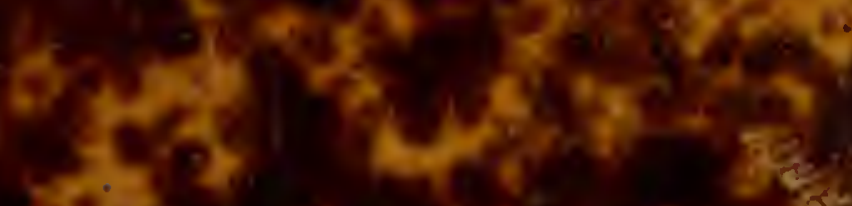

$(x+2)+2$

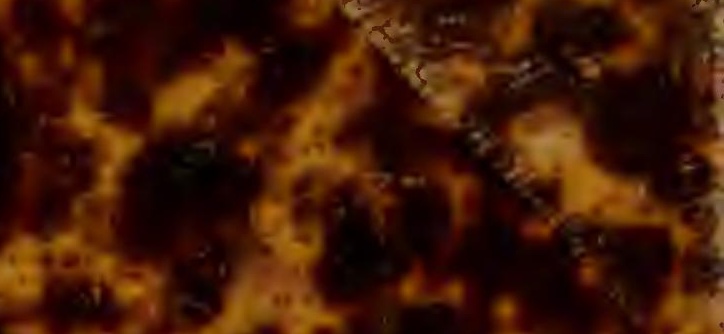

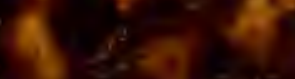

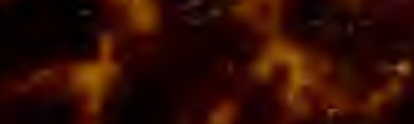

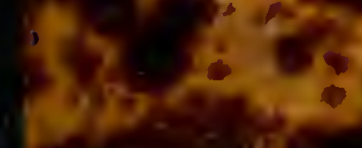

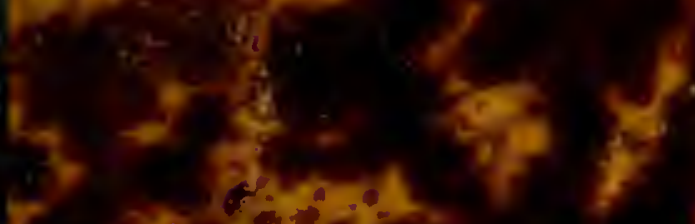

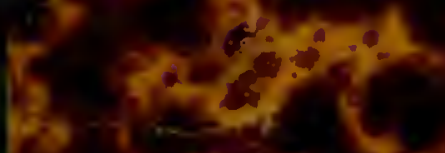

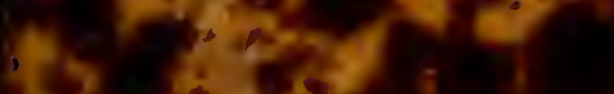

$8 \sqrt{15}$

to.

not

mins

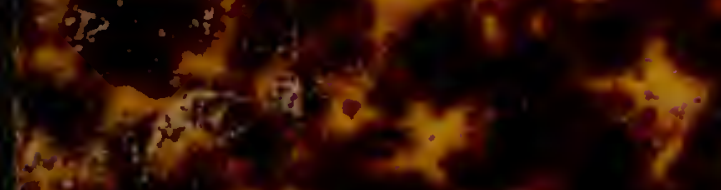

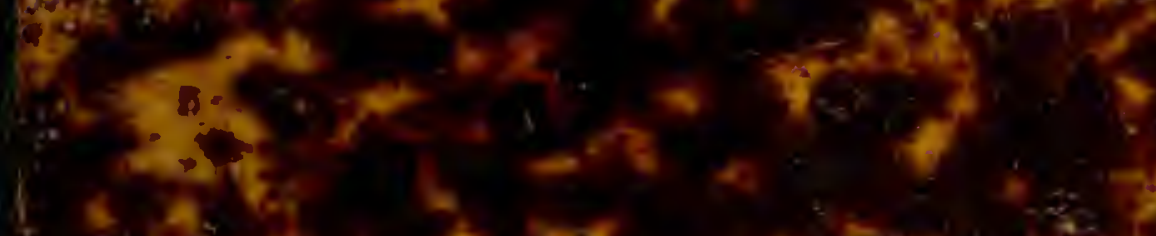

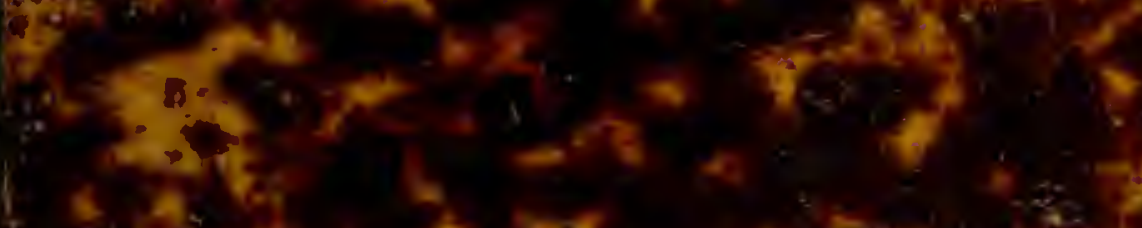

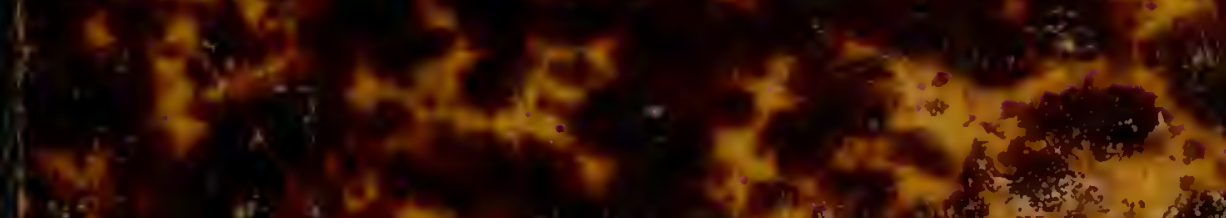

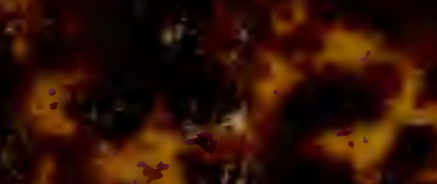

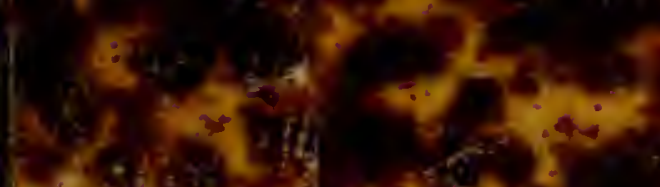

gits.

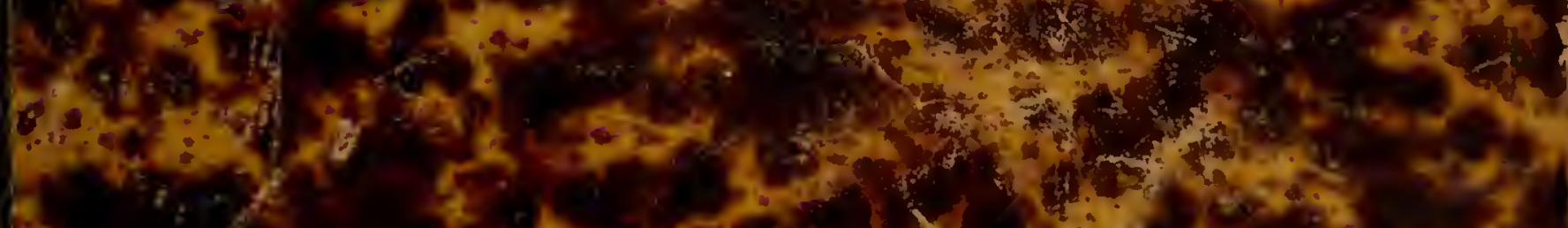

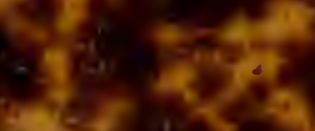

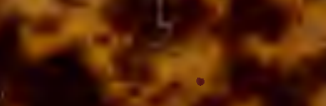

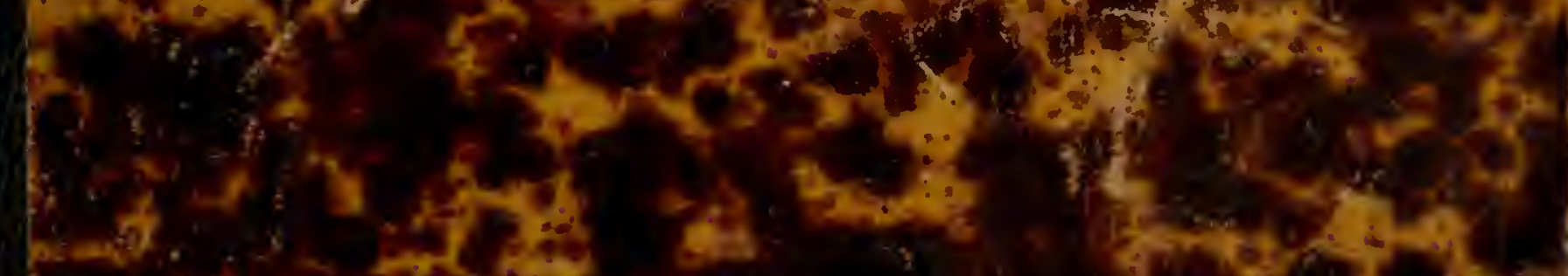
bians?

(4. $3 t^{2}$

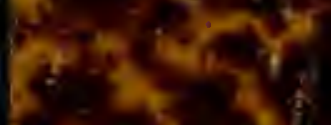
- $3 x$

$\rightarrow y$ कात

$=\infty$

ke $4^{2}+4$

il ?

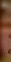




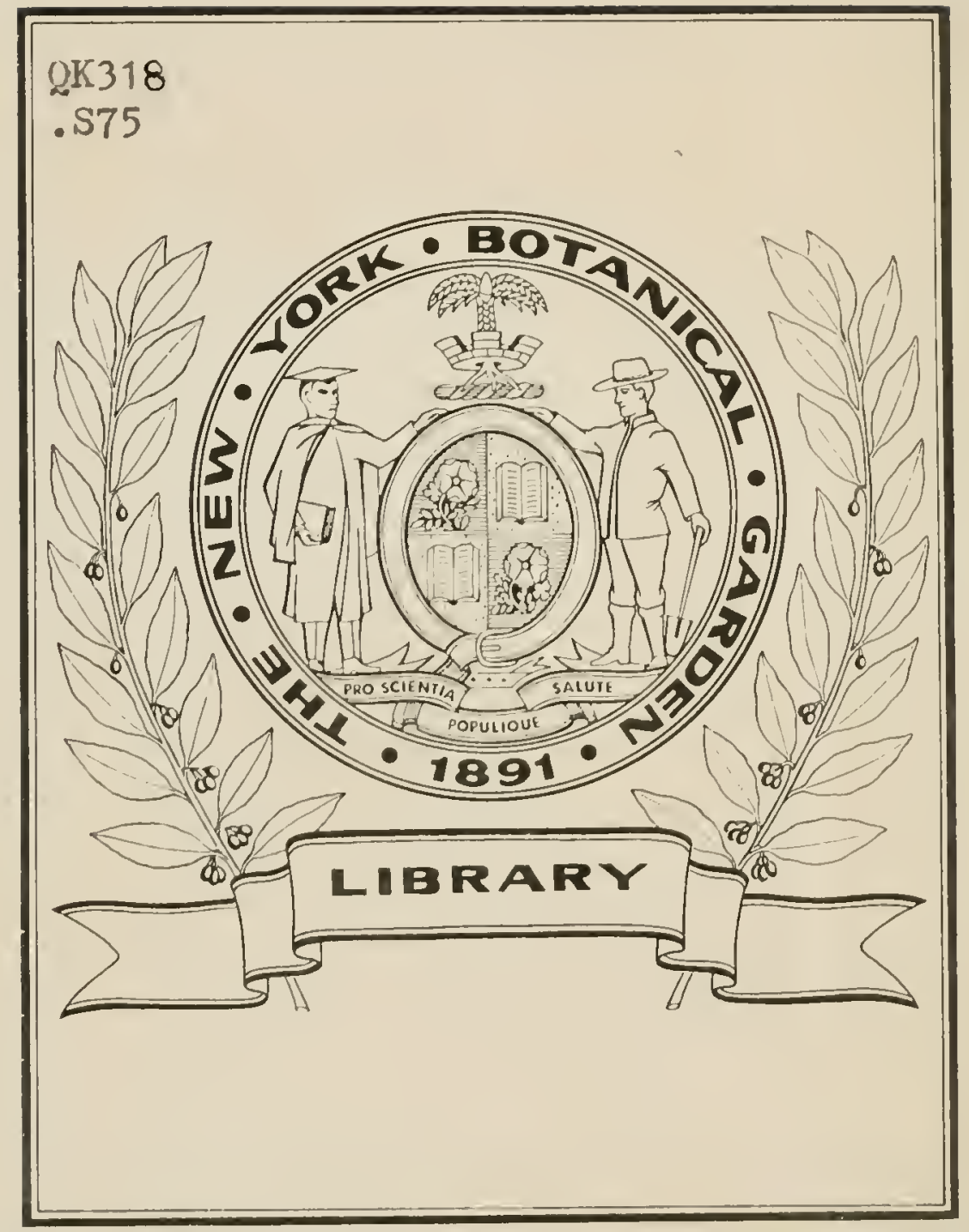


$-$

$=$

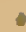

. 



\section{Ein und dreissigster}

\section{Jahres - Bericht}

us

\section{kaiserl. königl. Obergymnasiums}

$7 \mathrm{U}$

\section{MEETKR.}

Alm Schllusse des Sclulljabres 1881 veröffentlichl

vom

Direktor des Gymnasiums

\section{Isidor KrenI.}

I n h a I t:

I. Flora von Admont, von Professor P. Gabriel Strob I.

II. Nekrolog, von Professor Dr. Berthold $\mathrm{H} \subset \mathrm{ffer}$.

III. Schulnachrichten, vom Dire c t o r.

WIEN, 1881. 



\title{
Flora von Admont.
}

\author{
Von \\ Professor P. Gabriel Strobl.
}

111 


$$
\begin{array}{r}
9 \times 315 \\
.575
\end{array}
$$


Das alte Hofgericht Admont umfasste nicht blos das untere Eunsthal (etwa von Liezen bis Hieflan), sondern. auch das Paitenthal nebst den zum Wassergebiete der beiden Flüsse gehörigen Höhen; in diesem weiteren Sinne wurde von den älteren Admonter Botanikern die Flora von Admont stets aufgefasst, in dieser Ausdehnung war vor dem Brande 1865 das Herbarium Admontense angelegt, wurde es seit dem Brande von mir wieder hergestellt, und dieselbe Ausdehnung bildet auch das Object vorliegender Arbeit. Viele Mitglieder des Stiftes Admont (besonders hervorzuheben sind $\dagger$ P. Ignaz Sommerauer, P. Mauritius de Angelis, P. Anton Hatzi, $\dagger$ P. Gabriel Strobl sen., mein seliger Oheim, $\dagger$ P. Hartnid Dorfmann, $\dagger$ P. Theodor Gassner, † P. Thassilo Wegmayr, $\dagger$ P. Friedrich Schäfer, P. Blitmund Tschurtschenthaler) haben sich mit der Erforschung dieses Gebietes beschäftigt und bedeutende Herbarien angelegt, mehrere von ihnen, vorzüglich die drei zuerst genannten und Gassner haben auch Tauschverbindungen angeknüpft und mit den Resultaten ihrer Forschungen grössere botanische Werke, wie Maly (Flora von Steiermark), Koch und Martens, Koch Synopsis, Reichenbach (Flora und Icones) bereichert; iu der Regensburger "Flora" finden sich auch mehrere selbststindige Artikel Sommerauer's und in Wegmayr's "der Tourist in Admont" eine kleine Aufzählung besonders interessanter Pflanzen aus unserem Gebiete. Eine genane 1)arstellung der Admonter Flora aber wurde von keinem der genannten Capitularen in Augriff genommen.

Vom Jahre 1866 bis 1872 beschäftigte ich mich eingehend mit der Erforschung des Gebietes und stellte in diescr Zeit das Herbarium Admontense im Naturalienkabinet des Stiftes Admont wieder her; seither komute ich allerdings nur in den Ferien ver- 
einzelte Excursionen unternehmen. Ansserdem studirte ich die Herbarien, in denen grösseres Materiale aus der Admonter Flora angesammelt war, besonders das grossartige Maly'sche Herbarium der Flora Styriaca im Johanneum zu Graz (66 Fascikel), die äusserst instructiven Sammlungen des Prof. P. Anton Hatzi, des verstorbenen Gymnasialdirectors P. Theodor Gassner, meines verstorbenen Oheims G. Strobl, die aus dem Brande geretteten und die seitdem neu angelegten Sammlungen des emeritirten Priors und Kŕreisdechants M. de Angelis und die Sammlungen des Stiftes S. Lambrecht, dessen Capitular Raimund Steyrer ebenfalls viel um Admont botanisirt hatte. Auch das Herbar Oberleitner's, Pfarrers in S. Pankraz, enthält vieles aus unserem Gebiete, namentlich vom Pyrgas. - Die einschlägige Literatur beschränkt sich - abgeschen von meinen Arbeiten in der österr. bot. Zeitschrift (Jahrgang 1869, 1870, 1871, 1873), im „österr. 'Tourist“ (1871), im „österr. Alpenverein" (1873) und meiner „Flora der Hallermauern" (1878) - auf einige kleinere Artikel in der Regensburger "Flora“, in der "steiermärkischen Zeitschrift" (1828), Wilhelm Schleicher's „Aus den obersteyrischen Bergen", einzelne Notizen in den Werken Stur's, Gebhard's alphabetisch geordnete Flora von Steiermark und die zwei Auflagen der „Flora von Steiermark“ Maly's (1838 und 1868); doch ist zu beachten, dass Maly niemals in unserem Gebiete botanisirte, sondern seine Angaben von den oben genannten Capitularen Admonts stammen und nicht selten umrichtig oder zu allgemein wiedergegeben wurden. - Alle Angaben, hinter denen kein Findername steht, beruhen auf eigener Beobachtung und das Zeichen ! hinter einem Findernamen bedeutet Antopsie der Exemplare.

Bevor ich zur Aufzählung der in unserem Gebiete indigenen oder häufig kultivirten Arten nach Endlicher's „Genera plantarum" übergehe, dürfte es von Nutzen sein, die häufiger vorkommenden Fundorte in topographischer Ordnung nebst einigen Notizen über geognostische Unterlage vorzufülıren. Die Höhenangaben in Fuss sind Gobanz und Zollikofer, die in Metern der Generalstabskarte entnommen.

Das Ennsthal. Die Ebene desselbeu von Liezen (Westen, 2023 ${ }^{\prime}, 659^{\mathrm{m}}$ ) bis zum Beginne des Gesäuses (Osten, 1900', 600 ${ }^{\mathrm{m}}$ ) ist fast ausschliesslich Alluvium. Am linken Ufer folgen sich die 
Gemeinden Reithal, Ardning, Franenberg. (Mühlan), Hall, Weng; am rechten Selzthal, Aigen, Admont, Tíruman. Botanisch wichtig sind besonders die grossen Torfmoore (mit mehr als 500 Joch); ron Westen nach Osten kommen: das Selzthaler-, Ardninger-, Frauenberger-, Wolfsbacher-, Hofmoor (mmittelbar bei $\Lambda$ dmont), Krumauermoor (152. Joch, zwischen Admont und Gesäuss). Die wichtigsten Zufflüsse der Enns sind: Die Palte (bei Selzthal), der Ardningbach bei Ardning, der Lichtmessbach und die Essling (auch Oessling) bei Adimont. Seen fehlen; die wichtigeren Teiche sind: der Bichelmayrteich bei Frauenberg, der Temmelteich zwischen Franenberg und Admont, der grosse und die kleinen Stiftsteiche im Stiftsgarten, der Scheiblteich (36 Joch) in der Krumau. Sonst noch bäufiger rorkommende Fundorte aus der nächsten Umgebung Admonts sind: das Oberloffeld, Frauenfeld, Hoffeld, die Schultering (= Hofwiese, unterhalb des Hoffeldes), die Sautratte (eine mit Weiden bewachsene Fläche zwischen der Enns und einem stagnirenden Ennsarme), die Griesmayrlache und die Griesmayrwiesen (zwischen Admont und Weng), das Mühlauerwäldehen unmittelbar vor Mn̈hlau (Untergrund Kalkgerölle).

Die nördliche Begrä̈zung des Ennsthales wird von Liezen bis Admont durch mässig hohe, meist kuppelförmige oder in sanften Linien fortlaufende Berge aus Werfnerschiefer gebildet; die wichtigsten derselben sind: der Saalberg bei Liezen $\left(1395^{\mathrm{m}}\right.$, ausnalımsweise Grauwacke), der Franenberg $=$ Kulm $\left(766^{\mathrm{m}}, 2476^{\prime}\right)$, die Plesch $\left(1718^{\mathrm{m}}, 5413^{\prime}\right)$ und der Leichenberg $\left(1068^{\mathrm{m}}\right.$, zunächst Admont). Bci Ardning schneidet sich der Arduinggraben (mit dem Ardningbache) tief in dieses Gebirge ein und hier bant sich hinter den Schieferbergen ein hohes, ausserordentlich steiles, botanisch noch fast unbckauntes Kalkgebirge, der Bosruck $\left(2009^{\mathrm{m}}, 5943^{\prime}\right)$ auf. Von Admont bis Weng wird das jetzt viel breitere ( $3 / 1 /$ Meilen) Thal nördlich begrenzt von den berühmten Hallermanern, einem 6-7000' hohen manerartigen Kammgebirge aus Dachsteinkalk (in tieferen Regionen auch wohl Dachsteindolomit, am Fusse der Kette anch vereinzelte Lagen ron Werfnerschiefer und Belvedèreschotter). Die Kette beginnt westlich mit dem Pyrgas $\left(2244^{\mathrm{m}}, 7199^{\prime}\right)$, welchen der tiefe Ardningsattel (= Arling, 4471',1461 ${ }^{\mathrm{m}}$ ) vom Bosruck scheidet; von der Plesch scheidet iln das „Pyrgasgatterl * = Pyrgassattel 
$\left(1348^{\mathrm{m}}\right)$, ein vielbenützter Uebergang von Admont nach S. Spital am Pyrn. An den Pyrgas schliesst sich der Scheiblstein (= Scheiblingstein, $2200^{\mathrm{m}}, 6932^{\prime}$, mit der tief gelegenen Gstadtmayrvoralm und der hoch gelegenen Gstadtmayrhochalm), die Kreuzmaner (2079 $)$, der Hochthurm (1959 ${ }^{\mathrm{m}}$ ), der Hexenthurm (= Bärenkarmauer 2181 ${ }^{\mathrm{m}}$, $\left.6618^{\circ}\right)$, der Natterriegel $\left(2064^{\mathrm{m}}, 6548^{\circ}\right)$, getrennt durch das Grabnerthörl vom Grabnerstein $\left(1843^{\mathrm{m}}, 5820^{\circ}\right)$. An den Abhängen dieser Kette folgen sich die wichtigeren Fundorte: Folkernotgraben mit dem Mühlauerwasserfall (= Mühlawerfall), die Kóochenalm an Fusse des „Mühlanerstadls" $\left(1701^{\mathrm{m}}\right)$, der Waschenberg $\left(1454^{\mathrm{m}}\right)$ und die Griesweberalm unterhalb des Hexenthurms, der tief eingerissene Schwarzenbachgraben, der fast isolirte Dörflstein (= Pitz, 1063 ${ }^{\mathrm{m}}$ ), hinter demselben die üppigen Pitzweiden und das Lürcheck $\left(1495^{\mathrm{m}}\right)$, alle drei links vom Rabengraben am Aufstiege zum Natteriegel, die Moseralm und Grabneralm unterhalb des Grabnerthörl. Bei Weng werden die Hallermauern durch die ausserordentlich tiefe Depression der Buchan $\left(850^{\mathrm{m}}\right)$, eines Ueberganges nach S. Gallen, vom Buchstein geschieden; dieser Berg gehört schon zum Gesäuss.

Die siidliche Grïnze des Enusthales wird rom Durchbruche des Paltenbaches in das Ennsthal bis nach Admont gebildet durch ein waldreiches, sanft gewölbtes und meist geradlinig fortlaufendes Mittelgebirge aus silurischen Gesteinen (meist Grauwacke, seltener silurischer Kalk, Talkschiefer, Quarzblöcke, Conglomerate). Der höchste Punkt desselben ist das Dürrenschöberl $\left(5430^{\circ}\right)$ ob Aigen (mit der Messneralm an der Südseite); andere Höhen sind: der Blahberg (mit der Pesendorfer Siderit-Erzgrube) westlich davon, der Klosterkogel (4932') mit dem auf einem Kalkvorsprunge desselben liegenden Schlösschen Röthelstein $\left(817^{\mathrm{m}}\right)$ und der Lichtmessberg $=$ Dittmannsberg, beide unmittelbar ob Admont; über letzteren führt eine Fahrstrasse nach Kaiserau und in's Paltenthal. Von der Höhe des Ueberganges (c. 4340') gegen Admont hinab zieht sich der romantische Veitlgraben, an dessen Ausgange das Sensenwerk Adam liegt, und östlich von der Fahrstrasse zieht sich durch einen Wald der schattige „Schafferweg", welcher in das Oberhoffeld und Franenfeld mündet.

Oestlich rom Lichtmessberge verengt sich dei Grauwackenzug und zieht sich etwas südlich, während die unmittelbare Thalgrenze durch eine grossartige Dachsteinkalk-Gruppe gebildet wird. Un- 
mittelbar ob Admont beginnt diese Gruppe mit der sehroften Bärnkoppe (unterhalb derselben die Stumpfuagleralm = Saupichleralm) links, dem grotesken Hahnstein und der Kemetenwand rechts; zwischen beiden zieht sich eine tiefe, gewundene Schlucht, in deren Tiefe der Scheibleggerbach rauscht, empor. An den tieferen Abhïngen wäre noeh zu erwähnen der Admonter Kalkofen, die Weberalm und die Scheibleggervoralm, von der ein Pfad zum Schafferweg führt. Die erwähnte tiefe Schlucht fiihrt zur Scheibleggerhochalm; von da erreicht man das Scheibleek, die Höhe des Grates $\left(1708^{m}\right)$, und gelangt lüngs desselben auf geführlichem Stiege zur Schafleithen, von dieser endlich zur bekanntesten Erhebung der Gruppe, zum Kalbling $\left(6300^{\prime}\right)$, welchen ein grünes Kahr (der „Speikboden“) ron dem noch höheren Sparafeld (7083') scheidet. Ausserdem führen noch drei Wege auf den Kalbling: der erste zweigt sich als sogenannter "Almweg" in halber Höhe der Lichtmessberger Fahrstrasse nach Osten $a b$, führt an der Siegelalm vorüber zu einer Schäferhütte und ron da als "Schafweg“ zwischen Gerölle nnd Felsmauern zur südlichen Abdachung der Schafleithen empor. Der zweite beginnt in dem 108 Joch grossen Thale der Kaiserau (4320'?), welches beim Nagelschmied- und Kaiserauerteiche auf der Höhe des Lichtmessberg-Ueberganges anfängt und noch ganz in der Grauwackenzone liegt; verfolgt, am Schlosse Kaiserau, später an einem Kalkofen vorüber, allmählig ansteigend, das ganze Thal nach Osten, und führt zu einem Jagdhause (daher der Jägerweg genannt); von da ersteigt er zwischen Krummholz und Krummholzwiesen die niedrigste Stelle der Kalblingrormaner und zieht sich um die hohe Kalblingmaner allmählig aufwärts, bis er auf der Einsattlung zwischen Schafleithen und Kalbling mit den zrei früher beschriebenen Wegen zusammentrifft. Der vierte, fast nie benützte Aufstieg zum Kalbling beginnt in der Krumau und führt, anfangs dureh das Gaisenthal, am Nordabhange der Schafleithen empor. - Oestlich vom Sparafeld, durch die "böse Seharte" getrennt, erhebt sich der fast unersteigliche, botanisch noch wenig erforschte ,Admonter Reichenstein“ (6829'): zwischen ihm und dem Sparafeld beginnt der Flietzengraben und Flietzenbach, der südwärts in's Paltenthal mündet. Südlich rom Reichenstein liegt die 'Treffneralm, über welche man ron Kaiserau nach Johusbach gelangt. 
Das Gesäuss und seine Gränzen. Etwa 1/4 Stunde östlich von Admont beginnt das Gesäuss (1900', 600 ${ }^{\mathrm{m}}$ ), der berïhmte, hochromantische Engpass der Enns und dauert bis Hieflau (1366'). Ausser dem Schienenwege durchieht ilm noch eine Kunststrasse und rom Eingange ( dem oberen Stein") führt zum „unteren Stein“ bis Gstatterboden ein stellenweise gefährlicher Fusssteig. Das Gesäuss wird zu beiden Seiten von kolossalen Dachsteinkalkmassen begränzt, im Norden zuerst von der Buchsteingruppe, später vom Damischbachthurm, im Süden zuerst von den Auslänfern und Vorbergen des Reichenstein, dann von den wiłdzerrissenen Johnsbachermauern (= Kammgebirge).

$\mathrm{D}$ er $\mathrm{B}$ u c h s te in (7020) ist ron rielen kleineren Kalkbergen umringt; unter ihnen sind hervorzuheben gegen das Ennsthal hin der Stockerkogel und Augenstein, gegen das Gesäuss hin der direct am Eingange liegende Himbeerstein $\left(1183^{\mathrm{m}}\right)$, weiter drinnen der Bruckstein mit dem interessanten Bruckgraben, dessen Höhe Brucksattel lıeisst; über diesen führt ein Pfad durch den Rauchboden- und Laffawald (= Laferwald) nach Weng; an der Nordseite des Buchstein (gegen S. Gallen hin) liegt ein grossartiges KalkGeröllbett, die „Buchauerschütt." Der Damischbachthurm (6408') wurde nur wenig erforscht und dürfte kaum Seltenheiten besitzen.

Von den Vorbergen des Reichenstein ist hervorzuheben die Heindlmauer $\left(1415^{\mathrm{m}}\right)$, welche, dem Himbeerstein gerade gegenüber, den Eingang in's Gesüuss begrenzt und das Kaderalbl, ein Fussweg, der über Vorgebirge vom Heindl zum "Amtmannsgalgen" (2 isolirten Felssäulen) im Johnsbachgraben führt. - Etwa in halber Weglänge zwischen dem Gesäusseingange und der Bahustation Gstatterboden öffnet sich nach rechts der äusserst romantische, vom Johnsbache durchiströmte Johnsbachgraben und von nun an wird die südliche Gesäussgränze gebildet von den Johnsbacherma ern. Sie sind auf dieser Seite mersteiglich. Um sie zu ersteigen, geht man in der Tiefe des eine Stunde langen Johnsbachgrabens zum Dörfchen Johnsbach (2314'), verfolgt das schön begrünte, links von den kahlen Johnsbachermaueru, rechts von üppig bewaldeten Grauwackenbergen umrahmte Johusbachthal bis zum Wolfsbauern ( $1 / 2$ Stunde), steht so im Rücken der Johnsbachermauern und steigt neben dem $100^{\prime}$ hohen Wolfsbauer-Wasserfalle 
in die Höhe. Die höchsten Gipfeln der Kette sind ron West nach Ost: der Oedstein, der Festkogel, das Hochthor (7200'), der Zinödl. Tiefer liegen die ofters erwähnten Fundorte: Der Rinnstein, Gamsstein, der "untere, mittere und obere Boden", die Kaderalm, Farchneralm, der Hund, das Sulzkahr; von letzterem gelangt man, den schroffen Lugauer (6952') rechts lassend, durch den Hatlersgraben an der Seite des Hatlersbaches zwischen Gstatterboden und Hieflau wieder in's Gesäuss; ein anderer Weg führt durch den Waaggraben und mündet unterhalb Hieflan.

Das Paltenthal. Es erstreckt sich ron Sïdost nach Nordwest und führt seinen Namen von der Palte, einem bedentenden Zuflusse der Enns. Am rechten Ufer liegen die Gemeinden Gaishorn, Dittmanmsdorf (= Lichtmessdorf), Bärendorf, Büschendorf, (das ehemalige Schloss Grünbüchel), Vielmannsdorf; am linken liegt Trieben, S. Lorenzen, Singsdorf, S. Georgen, die Stadt Rottenmann (2136'), das Gewerke Klamm. Die ergiebigsten Fundorte liefert der obere Theil; besonders reich ist die Umgebung des von der Palte durchströmten Triebnersee's (= 'Triebnermoor) und des Gaishornsee's. Die Tiefe des Thales ist Alluvium, die nächst angränzenden Höhen sind beiderseits grösstentheils Grauwacke. D i e $\mathrm{Nor}^{\circ} \mathrm{gränze}$ des Thales bildet derselbe Grauwackenzug, der zugleich die Südgränze des Eunsthales bildet; er wurde schon oben besprochen und ist botanisch ron geringem Belange.

Als Sürlgräuze hingegen thürmen sich die hochinteressanten „niederen Tanem", hier speziell Rottemmanncrtanern genannt, z.u bedeutenden Höhen anf. Die Vorberge bestehen theils aus silurischem Kalke, besonders der Berg, auf welchem Schloss Strechau (2537'), umschlossen von dem "Hauswalde", liegt; ferner eine Felspartie in der Klamm, eine Partie am Steinamandl ob Rottenmann, Partieen an der Hochhaide und einige mïchtige Felspartien unterlalb Hohentauern, die als Sunk und Triebenstein (5711') bekannt sind; theils bestehen sie aus ïchten Grauwackengesteinen, wie im Oppenbergerthale, in der Strechen, zwischen S. Lorenzen und Wald bis hinauf nach Hohentanern; theils aber reicht das Hauptgestein des Taueruzuges, der Gneiss (öfters auch Granit und Glimmerschiefer) bis in's 'Thal herab.

Die wichtigsten Fundorte und Berge dieses Zuges sind ron Westen nach Osten: der Klammgraben (unterhalb Strechau), welcher 
sich tiefer innen in zwei Gräbèn theilt, den Strechen- und Oppenbergergraben; letzteren bewässert die Gulling, die sich aus der Weiss- und Schwarz-Gulling zusammensetzt; im innersten Winkel des Grabens liegen die Ursprungsstellen und der Lärchkahrsattel $(=$ Plinten $=$ Plintensattel $)$. Im Strechengraben erreicht man, an einer Menge grüner Alpen und Berge (z. B. dem „Blahberg in der Strechen") vorüber, schliesslich die Reiteralm, den Reitersee (5600`) und den pflanzenreichsten Berg des ganzen Tauernzuges, den Hochschwung (c. 6800'). Unmittelbar ob Rottenmann liegt das Steinamandl $\left(6445^{\prime}\right)$ und der Kanpl; oberhalb Singsdorf die terrassenförmig anfsteigenden Singsdorferalpen mit der gleichnamigen Alm, dahinter die Hochhaide; das Thal zwischen ihr und dem Steinamandl heisst Globuke. Von Lorenzen steigt man auf zur Pfarrerhub, von da links zur Hölleralm, zu den „Kothhïtten", zum Ochsenkahr und "gefrornen See*; mehr rechts zur Bacheralm (und Pesendorferalm), höher hinauf zum Grünsee, Gemeinsee, Mitterstein, endlich zur Hochhaide und zu den dreizackigen „drei Strecken“ (c. 7300').

Von Trieben führt ein breiter Fahrweg und der romantische "Wolfsgraben" gegen Hohentauern empor; beim Ausgange der Schlucht kann man entweder längs des Fahrweges oder durch das Kalkgebiet der Sunk auf einem kleinen Umwege das Dorf Hohentauern und somit die Passhöle (3957') erreichen; vom Fahrwege zweigt sich tiefer unten (nahe am Gasthause „Brodjïger“") nach links das langgestreckte Triebenthal ab, in dessen Hintergrunde als Gränzen gegen das Sekanergebiet die Ketterthaleralm, Schaunitzeralm, der Grieskogel und der noch wenig erforschte Griesstein (7379') liegen.

Von Hohentauern führt, an den Tauernteichen vorïber, ein Weg zur Scheiplalm, zum grossen (15 Joch) und kleinen Seheiplsee; hinter ihnen thürmen sich die höchsten Erhebungen des Zuges: der Hengst, das Hauseck, der kleine und der grosse Bösenstein (7784'), letztere durch ein langgestrecktes Hochalpenkahr von einander geschieden.

M e lk, 31. Mai 1881. 


\section{Phanerogamae.}

\section{Fam. Con iferae Juss.}

1. Taxus baccata L. In Bergwäldern des Ennsthales auf Kalk und sil. Schiefer hie und da, sehr selten und vereinzelt: Bei Hall, Röthelstein, am Schafferwege.

2. Juniperus commmuis I. Auf trockenen Haiden, dürren Waldrändern der Ebene und Vorberge bis an und über die Gränze der nana sehr häufig, vorzïglich auf Kalkschotter: Im Wäldchen vor Mühlau, im Gesänss, Rauchboden, um die Gstattmayrvoralpe, am Almweg des Kalblingvorgebirges etc. Bildet das „Kranawetterwäldchen " bei Rottenmanu.

3. Juı. alpiua Clus. (nana W.) Auf steinigen oder buschigen Plïtzen der höheren Berg- und Voralpenregion bis 6000' sehr häufig im Kalk-, Gneiss- und Schieferzuge, in den ticferen Regionen nicht selten neben communis und theilweise in dieselbe übergehend; a Kalk: Am Almweg des Kalbling zuerst mit communis, dann alleinig, ebenso am Jägerweg, unter der Bärnkoppe, Scheibleggerhochalpe, um die Gstattmayrvoralpe am Scheiblstein und hoch hinauf, um die Griesweberalm, Hölleralm, im Sunk etc. $\beta$ Gneiss: Um den Scheiplsee, ob der Bacheralm zum Grünsee hinauf, am Bösenstein, Steinamandl, Kampl, Hochschwung; $\gamma$ Werfner Schiefer: auf der Plösch. Häufig auch anf dem Hofmoose im Ennsthale.

4. Jun. Sabiua 1. "Am Kalbling (Angelis)" Maly, Fl. v. Steiermark. Ist dem „Finder" selbst nicht mehr erinnerlich, wurde auch von mir niemals daselbst beobachtet; wird übrigens in Bauerngärten häufig cultivirt.

5. Piums silvestris L. Auf kalkschotterigen Flächen des Ennsthales, in Torfmooren, auf steinigen Bergen der Kalk-, Schieferund Centralzone bis 3000', selten höher': Bildet ziemlich reine Bestände im Mühlauerwäldchen, auf dem Krumanermoore, am oberen Ende des Schafferweges; mehr vereinzelt am Rottenmannertauern, z. B. am Kampl noch bei $5600^{\circ}$.

6. Piums Muglus Scop. Auf den steinigen Abhängen, Felskämmen und Kuppen aller Kalkalpen bis 6000' äusserst gemein 
und oft die grössten Flāchen n̈berdeckend, selten höher hinauf; sehr häufig jedoch in den Schuttbetten und längs der Giessbäche bis in die Ebeue herabsteigend, z. B. im Sehwarzenbachgraben, Bruckgraben, Gesäuss, Johnsbachgrabeu, am Mühlauerbach, auf der Buchauerschütt. Ferner sehr häufig (als r. uligiuosa Koch) auf Torfmooren (Hof-, Krumaner-, Frauenberger-, Ardninger-, Triebnermoor); endlich auch ziemlich häufig auf Schiefer- nnd Gneissgebirgen, z. B. Plösch-Kuppe. ron der Plinten zum Sattel hinauf, ob der Bacheralm, am Grinn- und Scheiplsee; ob der Kettelthaleralm sogar gemeiu.

7. Pinus Cembra L. Auf höheren Bergen und Voralpen des Gneisszuges zerstreut, bisher nur ron Hohentanern zum Scheiplsee und ron da gegen den Bösenstein hinauf, sowie ron den Kothhütten aufwärts in grosserer Nenge beobachtet: am Lichtmessberg ob Bärndorf fraglich. Hie und da gepflanzt, z. B. 4 Bäıme im Stiftsgarten und eine sehr lange. uralte Allee hinter Schloss Strechau.

S. Alies pectinata (Lam.) DC. In Berg- und Voralpenwäldern des Kalk-, Schiefer- und Gneisszuges bis 4000' zwar häufig, aber zwischen Fichten, Buchen etc. zerstreut. nie in reinen Beständen.

9. Ahies excelsa (Lam.) DC. Auf Kalk, Schiefer und Gneiss ron der Ebene bis an die Baumgrảnze änsserst gemein und die grössten Wälder bildend.

10. Larix enropaea DC. In Berg- und Toralpenwäldern des Kalk- und Schieferzuges, einzeln oder truppweise zwischen anderen Holzarten sehr gemein, nicht selten auch in eigenen Beständen, z. B. am Bruckstein, Buchstein, im Laffawalde.

\section{Fam. Gramineae Juss.}

11. Zea Iais L. Sehr selten cultirirt, z. B. bei Trieben.

12. Digitaria sangninalis (L) Scop. Auf bebautem Boden in Gârten und Aeckern sehr selten, z. B. in Gemuึsegärten um Rottenmann.

13. Setaria viridis (L) Br. Auf wüsten Plätzen, sandigen oder unbebauten Aeckern, an Strassemrändern sehr häufig, z. B. am Triebnerbache, am Wege nach Frauenberg, auf Aeckern um Admont. Glauca wurde im Gebiete noch nicht gefunden.

14. Phalaris al'undinacea L. In Sümpfen, Gräben, an Flüssen und Teichen sehr gemein.

15. Antloxanthum odoratum I. Auf Wiesen, Feldern, Waldplätzen und grasigen Abhängen bis in die Alpenregion des Kalk-, besonders aber des Urgebirges sehr gemein.

16. Alopecurus pratensis L. Ist in einem alten Verzeichnisse der Admonter Flora angeführt, doch kamen mir Exemplare nie zu Gesicht; übrigens ist das Vorkommen wahrscheinlich.

17. Al. fulvis Snı. An lehmigen Ennsufern, in Lachen der Torf- und Wiesenflächen, im Schlamme abgelassener T'eiche stellen- 
weise massenhaft, z. B. in Stiftsteichen, in Lachen beim Ziegelstadl, am Hofmoore, an der Enns unterhalb Aigen.

18. Phleum Michelii All. Anf Voralpen- und Alpenwiesen des Kalkzuges bis zur aberen Kirummholzgränze sehr häufig am Pyrgas, Scheiblstein (- 6500'), Kalbling, ob der Scheibleggerhochalpe, am Reichenstein (Angelis), Gamsstein (Hatzi), vom Mitterboden auf den Hund etc.; anch am Hochschwung (Gneiss, 5.500-6400') häntig.

19. Phleum alpinum L. Auf T'riften und Weiden der Voralpen bis hoch in die Alpenregion der Tauern- und Kalkkette überall sehr gemein, besonders um die Almhintten; höchster Standort im Kalkzuge der Speikboden des Kalbling (circa 6200); im Tauernzuge steigt es noch viel höher.

20. Phlemu pratense L. a. caespitosum Nlr. u. i nodosum (L) Gd. a. Auf Wiesen, Feldern, Rainen, Grasplätzen bis in die Voralpen der Kalk- und 'Tanernkette äusserst gemein; $\gamma$ besonders an steinigen Wegrändern im Gesüuss etc., aber auch an fenchten Wiesengräben der Schnltering; 'F stoloniferum (Host) wurde noch nicht beobachtet.

21. Agrostis stolonifera L. o. coarctata Hffm. (floribus albis et coloratis) und F diffisa Nlr. (dazu die sehr üppige Form A. gigantea Rth.) a: An sandigen, steinigen Wegrändern, trockenen Rainen; $\beta:$ Auf Wiesen, Mooren, an Ufern und Lachenründern gemein: die Riesenform besonder's auf Getreideäckern des Enusthales sehr häufig.

22. Agr. vulgaris With. Auf Wiesen, Feldern, Rainen, in lichten Wäldern der Schieferberge bis in die Voralpen höchst gemein; besonders massenhaft auf Sumpfwiesen des Paltenthales.

23. Agrr. caniua L. Auf Wiesen der Krruman, auf grasigen subalpinen Abhängen der Gneisskette, \%. B. beim Aufstieg zu den Kothhütten, beim Steiner im Triebenthale (Angelis!), von der Bacheralpe zum Gemeinsee (Angelis!); nirgends hüufig.

24. Agr. alpiua Scop. Auf felsigen und steinigen Alpentriften $\left(5500-7500^{\circ}\right)$ der Kalk-, sowie der Tanemkette (Gneiss, Glimmerschiefer) stellenweise sehr häufig; a. Talk: Von der Schafleithen bis auf das Sparafeld $\left(6-7000^{\circ}\right)$, sehr hänfig mit der schönen Spielart var. aurata (All.), vom Fusse bis auf die Höhe des Hund $\left(5-5500^{\prime}\right)$; F: Am Kamme des Bösenstein $\left(6-7600^{\prime}\right)$ s. hfg., ım den Grünsee und hinauf zur Hochhaide ziemlich häufig, am Steinamandl seltener; auch v. aurata wurde von Angelis am Tauern gesammelt.

25. Agr. rupestris All. Auf Alpen- und Hochalpentriften der Kalkkette nicht hänfig, z. B. am Scheiblstein (6500'), Pyrgas (Angelis!), Kalbling, Hund bei Johnsbach $\left(5500^{\prime}\right)$; höchst gemein aber auf allen Gneiss- nnd Schieferbergen von $4000^{\circ}$ bis auf die höchsten Spitzen, z. B. Bösenstein, Hochhaide, Steinamandl, Hochschwung, Plintensattel, Plősch; var. virescens (eine ganz grünährige Spielart) findet sich zwischen der Normalform und in sie übergehend häufig am Steinamandl etc.

26. Agr. Spica Venti L. Auf Aeckern unter Getreide bei Admont selten, auch zwischen Lorenzen und Trieben (Angelis!) 
27. Calamagrostis littorea (Sclird.) DC. F laxa (Host.) An niedrigen, sandigen Ufern der Enns in der Sautratte und Krumau äusserst gemein, auch an der Essling, an Bächen bei Trieben und Lichtmessdorf; die Normalform mit mehr zusammengezogener Rispe selten auf Kalkgries im Gesäuss.

28. Cal. Halleriana DC. In Wäldern, zwischen Strauchwerk ron der Berg- bis in die Alpenregion der Schieferberge (Grauwacke, Gneiss, Werfnel- und Glimmerschiefer) meist sehr häufig, z. B. im Wolfsgraben bei Trieben (2200-2600'), von der Schaunitzeralpe im Triebenthale zur Seckauergrïnze (Angelis!), um Hohentauern, vom Scheiplsee auf die umliegenden Höhen bis $6500^{\prime}$, um die Bacheralpe, am Steinamandl, Kampl, Hochschwung, auf der Plösch unter Krummholz; var. mutica milhi: Ziemlich häufig zwischen Krummlıolz am Scheiblstein ob der Gstattmayrroralpe (Kalk).

29. Cal. tenella (Schrad.) Host $\propto$ mntica. In Voralpenwäldern und auf Alpentriften der Gueisskette ron 4000'-5500' selten: Ob der Singsdorferalm am Aufstiege zur Hochhaide, unterhalb des gefrornen See's am Bösenstein, von der Pfarrerhub ob Lorenzen zur Bacheralm (Angelis!), ron der Schaunitzeralm im Triebenthal gegen die Seckanergränze (Angelis!).

30. Cal. Mnontana DC. A uf Kalkgries, an steinigen, buschigen Abhängen, in Schluchten und lichten Wiildern des Kalkzuges (2-5000') gemein, z. B. durch's Gesäuss, im Rauchboden, Laffawalde, Schwarzenbachgraben, am Mühlanerwasserfalle. Scheiblstein, Pyrgas, Aufstieg zur Kemetenwand, Hochthor, in der Klamm, im Sunk etc.

31. Cal. arundinacea (L) Rotli. In Schlıchten, Holuschlägen und Wälden der Schieferberge (Werfner-, Grauwackenschiefer und Gneiss, 2000-4000') sehr häufig: Auf der Plüsch, im Wolfsgraben, an der Tauernstrasse, am Aufstiege zum Steinamandl. von der Klamm in den Strechengraben (hier auch die üppige var. pyramidalis (Host) Rchb.).

32. Milium effusum I. In feuchten, schattigen Schluchten und Wäldern, an Waldbächen $\left(2500-5000^{\prime}\right)$ zerstreut: Sehr häufig im Hatlersgraben ror Hieflau (Kalk), im Arlninger- und Wolfsgraben (Schiefer), am Aufstiege zur Farchneralm in einer Seitenschlucht (Kalk); höchster Standort ob dem Grünsee um die Felswände der Hochliaide (Gneiss, c. 5500').

33. Plhragmites commmmis Trin. In Sümpfen, Lachen, an Flüssen und Teichen beider Hauptthäler höchst gemein; an sandigen Ufern oft mit $6-10^{\mathrm{m}}$ langen Wurzelstöcken.

34. Sesleria coerulea (L) Ard. Auf Felsen, steinigen, buschigen Abhängen, in lichten Wäldern der Kalkzone überall von 2000-5000' gemein, vereinzelt sogar bis über $7000^{\prime}$, z. B. ain Festkogel, Sparafeld, Natterriegel : auch sehr häufig an Felspartieen des Hochschwung (5500-6000' auf Kalkglimmerschiefer?).

35. Sesl. microcephala (Hffmo.) IOC. An Felsen und felsigen Abhängen der Hochalpen $\left(6-7100^{\prime}\right)$ selten: Am Pyrgas (Strobl sen.), Kalbling, hier am Nordabhange der Schafleithen und des Sparafeldes häufig (Kalk); zerstreut auch am Hochschwung (Glimmer- 
schiefer, circa $6000^{\prime}$ ); am Rottenmannertauern (Maly Flor. v. Steierm.).

36. Sesl. disticha (Wlf.) Pers. Anf Triften, Haiden und steinigen Höhen der Gneisskette (5-7500') sehr gemein, z. B. rom Scheiplsee auf die umliegenden Höhen, auf der Hochhaide, am Steivamandl, Hochschwung, Plintensattel: auch häufig am Rücken und im Speikboden des Kalbling (Dachsteinkalk).

37. Koeleria cristata (L.) Pers. Auf trockenen Wiesen und steinigen Abhäugen des Ennsthales bis auf die Voralpen nicht bäufig: Bei der Griesmayrlache an der Wand, auf der Wirthswiese, in der Essling (Angelis!), auf Wiesen beim Laftawalde.

38. Deschampsia caespitosa (L.) Beaur. Auf Wiesen, Waldplätzen und grasigen Abhängen bis in die Alpenregion der Kalk-, besonders aber der Schiefer- und Gueissberge sehr gemein.

39. Desch. flexuosa (L.) Gris. In Wäldern, Holzschlägen, an trockenen Abhängen der Schiefer- und Gneissgebirge von 2000 bis 7000' sehr gemein, z. B. Plösch (Werfner Schiefer), Lichtmessberg, Röthelsteiner Wäldchen, Strechengraben (Silur. Schiefer), Bösenstein, Hochhaide, Steinamandl (Gneiss); viel seltener auf Dachsteinkalk, \%. B. am Kalbling, unter der" Farchneralm bei Johnsbach; ziemlich selten auch in der Thalsohle, z. B. unter den Eichen des Hoffeldes; in der Alpenregion meist var. montana (L) mit dunkler, zusammengezogener Rispe.

40. Holcus lanatus L. Auf Wiesen, Rainen, an Wegen bis $4000^{\prime}$ sehr gemein.

41. Holcus mollis L. Auf sonnigen, buschigen Rainen, an Bergabhängen, in Holzschlägen (2-3000') stellenweise häufig: Am Wege nach Frauenberg (Werfner Schiefer), am Südabhange des Lichtmessberges, innerhalb der Klamm gegen die Strechen hinein (silur. Schiefer).

42. Aprhenathermu elatius (L.) M. K. Auf Wiesen, Grasplätzen, an Wegrainen gemein, auch gebaut.

43. Arena sativa L. Allgemein gebaut, selbst noch sehr häufig um Hohentauern $\left(4000^{\prime}\right)$; an Wegrändern und wüsten Plätzen auch oft verwildert.

44. Avena pubescens L. Auf Wiesen, an Wegen und Rainen nicht häufig: Von Lorenzen gegen Bärndorf (Augelis!), im Stiftsgarten (Hatzi).

45. Ar. pratensis L. Auf dem Franenfelde bei Admont ron Hatzi und Angelis gesammelt!.

46. Ar. Sehenchzeri All. Auf trockenen Weiden und steinigen Abhängen der Centralkette $\left(5-7500^{\prime}\right)$ höchst gemein, z. B. ob der Kettenthalalm im Triebenthal, am Griesstein (Hatzi!), rom Scheiplsee auf die umliegenden Höhen, rom Grünsee auf die Hochhaide, am Steinamandl, Hochschwung, Plintensattel; auch häufig am Kalbling unter der hohen Mauer, am Speikboden und hinauf zum Sparafeld $\left(5-7000^{\prime}\right.$, Dachsteinkalk).

47. Ar. Hostii Boiss. (sempervirens Host, non Vill.) Auf Triften und steinigen Abhängen der Kalkalpen ron $6000^{\circ}$ bis in die Krumm- 
holzregion lierab sehr häufig am Pyrgas, Scheiblstein, Kalbling, Hochthor, Gamsstein, Hund; am Hund auch var. viridis mihi (mit einfach gelblichgrünen Aehrchen) zwischen der riolett gescheckten Normalform häufig.

48. Trisetum flarescens (L) Br. Auf trockenen Wiesen, an Grasplätzen, im Stiftsgarten ziemlich häıfig.

49. Tris. alpestre (Host) Br. Auf Kalkgries, steinigen Abhängen und an Felsen der Kalkkette (2-6000') sehr gemein: im Gesäuss, Johnsbachgraben, auf der Pitz, am Wege nach St. Gallen, im Laffawald, - am Scheiblstein, Pyrgas, Hochthor, Hund etc. Auf Alpen sind die Aehrchen zierlich gescheckt, an Bergfelsen aber ganz oder beinahe grün und die Pflanze fast in nichts ron flavescens verschieden: daher wohl Varietït derselben.

50. Danthonia decumbens $\left(\mathbf{L}_{i}\right)$ I)C. Auf Rainen, Waldwiesen, besonders aber in Wäldern der Schiefer- und Gneissberge (2-4000') überall sehr hänfig, z. B. auf der Plösch, arn Lichtmessberg, unter Röthelstein, am Aufstieg zum Pitz, von der Kemetenwand zur Scheibleggervoralpe. in der Tauernkette bis um Hohentanern; auch im Wäldchen ror Mühlan häufig (Kalkschotter).

51. Melica untans L. Zwischen Gebüsch, an steinigen Waldrändern der Berg- und Voralpenregion auf Dachstein- und Granwacken-Kalk (2-4000') ïberall sehr häufig, z. B. im Gesäuss, Johnsbachgraben, Rauchboden, Laffawald, am Scheiblstein, Kalbling, Aufstieg zur Scheibleggervoralpe, - in der Klamm, im Sunk etc. Selten auf Alluvium und tertiärem Gerölle, z. B. im S'tiftsgarten.

52. Briza niedia $I_{\text {. }}$ Auf Wiesen des Enns- und Paltenthales stellenweise sehr häufig, wie in der Sautratte, bei den Eichen des Hoffeldes, um Rottenmann; an schattigen Waldstellen ror Johnsbach auch mit ganz grünen Aehrchen.

53. Poa anmı L. An Wegen, Rainen, Grasplätzen, in Gürten, Feldern und Triften überall höchst gemein bis auf die Alpen des Kalk- und Urgebirges, hier hesonders um die Almhütten. In alpinen Regionen sind die Aehrchen meist bunt geschecht (v. varia Gd.), z. B. schon um die Kaiserau.

54. Poa laxa Haenke. Auf Alpentriften der Gneisskette von $5500^{\prime}$ bis auf die höchsten Kuppen meist sehr gemein, z. B. ob der Schaunitzer- und Kettenthaler-Aln, rom Scheiplsee anf den Bösenstein, ob der Bacheralm, auf der Hochhaide, am Steinamandl, Hochschwung etc. Blüten gescheckt, selten (z. B. am Steinamandl) grün.

5.5. Poa minor Gil. Auf Gries, Felsschutt und steinigen $A b-$ hängen hoher Kalkalpen stellenweise sehr häufig, z. B. an Hochthor (5.500-6500'), Scheiblstein (6500', unter der letzten Erliebung), unter der hohen Kalblingmaner und am Uebergang rom Scheibleck zur Schafleithen, von hier anch sehr häufig hinabgeschwemmt bis in die Triften der Kaiseral $\left(4000^{\prime}\right)$, ebenso am Nordabhange des Kalbling s. hfg. im Gaisenthale (Angelis); von den Hallermanern durch den Schwarzenbach und die Fssling nicht selten sogar bis in's Ennsthal herabgeschwemmt. 
56. Poa alpina $L$. und F vivipara (W.) Auf Triften, steinigen Abhängen und im Gerölle der Kalkkette ron $2500^{\prime}$ bis $6000^{\prime}$ beide Varietäten höchst gemein, besonders um die Almhütten; steigt sogar, z. B. am Scheiblstein, bis $7000^{\prime}$ und ist anch (aber meist var. $\beta$ ) sehr häufig auf Kalkschotter des Ennsthales vor Mühlan, im Gesäluss etc.; in der Gneisskette findet sie sich riel seltener, z. B. ob der Kettenthalalm, ron der Bacheralm zur Hochhaide, am Steinamandl, Hochschwung, am 'Tauernbache.

57. Poa nemoralis I. In Hainen, Vorhölzerı, an Rainen und Bachrïndern, sowie auf Felsen und Triften ron der Fbene bis in die Voralpenregion der Kalk-, Schiefer- und Gneissgebirge sehr verbreitet. Variirt ausserordentlich: Auf schattigen, feuchten Orten z. B. unter den Linden des Stiftsteiches, im Wolfs-, Veitl-, StrechenGraben etc. sind die Halme diunn, schwach, die Rispen weit ausgebreitet und überhängend (= $\%$ rulgaris Koch); an sonnigen, trockenen Stellen sind die Halme steif, die Rispen aufrecht, spärlicher mit reicherblüthigen Aehrchen besetzt ( $=\%$ firmula Gd. Koch); auf subalpinen, steinigen Abhängen del Kalkzone sind die Halme schlank mit langen, zusammengezogenen Rispen (v. montana Koch); auf Schiefer-Toralpen ist die Pflanze dunkler grün mit meist reichblüthigen, zierlich gescheckten Aehrchen, z. B. ob der Pfarrerbub bei Lorenzen ( $r$. glauca Koch ?): dieser ähnlich ist auch eine äusserst armährige, niedrige Form (var. subuniflora Rchb. 403), welche sich am Reiterbach unterhalb des Hochschwung häufig findet; sie scheint einen Uebergang zu bilden zu Poa glancescens Kerner, welche ich im Gebiete noch nicht, wohl aber in südlichen Seitenthïleru des oberen Ennsthales melirmals antraf.

58. Poa serotiua Ehrh. Auf sumpfigen Wiesen (z. B. Hofwiese), an Grasplätzen, Wegrändern (in der Krumau, gegen Frauenberg, um Lorenzen etc.), an sandigen oder überschwemmten Uferstellen der Enns und Palte meist häufig.

59. Poa lỵbrida Gil. In Hochwäldern, an steinigen, buschigen Abhängen, 2 wischen Krummholz der Kalkkette $\left(3-4500^{\prime}\right.$ ) stellenweise häufig. Im Hatlersgraben vor Hieflau sehr häufig, ob der Gstattmayroralm am Scheiblstein z. hfg., am südwestlichen Fusse der Kemetwand bei $4000^{\prime}$ häufig, um die Kalblingrormauern, unterhalb der Schäflerluütte. Auch in der Voralpenregion des Blahberges in der Strechen an üppigen, buschigen Stellen häufig (Gneiss).

60. Poa trivialis L. Auf Wiesen, Grasplätzen, zwischen Gebiisch gemein bis in die Voralpenregion des Kalk-, Schiefer- und Gneissgebirges.

61. Poa pratensis L. \% rulgaris Gd., $\beta$ latifolia humilis (Ehrh.) und $\gamma$ angustifolia (L) Sm. Auf Wiesen und Weiden bis $4000^{\prime}$ höchst

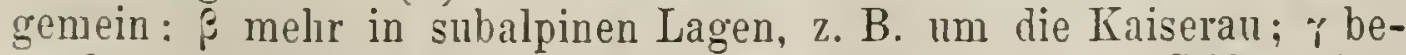
sonders typisch unter den Eichen des Hoffeldes und im Stiftsgarten.

62. Poa distichophylla Gd $\%$ cenisia All. (Die Form mit gedrungener Rispe). Selten im Kalkschutte des Schwarzenbachgrabens bei Hall (c. $2500^{\prime}$ ). 
63. Poa compressa L. $\alpha$ contracta Nlr. An sandigen Uferstellen bei Trieben, am Einflusse der Essling, bei der Johnsbacherbrïcke (Angelis!), anf trockenen Rainen, z. B. bei der Schlageralm. im Laffawald (Kalk), auch auf Schieferfelsen der Central-Voralpen hie und da, meist truppweise.

64. Glyceria fluitans (L.) R. Br. An Sümpfen, Teichen, Gräben, Waldbächen bis in die Voralpen sehr gemein.

65. Catabrosa aquatica (L.) Bv. An Lachenrändern beim Uebergange unterhalb des Griesmayrhauses sehr häufig.

66. Molinia coerulea (L.) Mnch. Auf Mooren, Torf- und Sumpfwiesen äusserst gemein, sehr häufig auch in Wäldern, an Bächen und feuchten Bergabhängen bis in die Voralpen des Kalk-, Schieferund Gneisszuges.

67. Dactylis grlomerata L. Auf Wiesen, Grasplätzen und Rainen sehr gemein; bei Trieben fand ich auch spärlich var. vivipara mihi.

68. Cyuosurus cristatus L. Auf Wiesen und Grasplätzen bis in die Voralpen, z. B. am Pyrgasübergange.

69. Festuca ovina L. Unter den Birken der Schultering auf trockenen, torfigen Stellen, im unteren Stiftsgarten beim Schutthügel und in Holzschlägen gegen den Strechengraben häufig.

70. Fest. Halleri All. A uf Triften Ind steinigen Abhängen der Kalkalpen $(5-6500$ ); gemein am Kalbling, Hochthor, Festkogel, Hund, Scheiblstein, Hexenthurm etc.

71. Fest. duriuscula L. var. alpestris Godr. Auf Triften und steinigen Abhängen der Gneisskette (6-7700') sehr häufig; z. B. am Bösenstein, Hauseck, Steinamandl, Hochschwung, auf der Hochhaide; sehr selten var. vivipara.

72. Fest. glanca Lam. Auf Felsen der Klamm bei Rottenmann und einwärts gegen den Strechengraben häufig (silurischer Kalk und Schiefer).

73. Fest. heterophylla Lam. $\alpha$ laxa Nlr. (Schlaff, mit langen, feinen Blättern, überlıängenden Rispen und grünen Aehrchen). Nicht häufig an Waldrändern um Admont und auf üppigen Rainen unterhalb der Pfarrerhub bei Lorenzen.

$\beta$ rigida (Steifer, mit kürzeren, dickeren Blättern, gerader Rispe, violett überlaufenen Aehrchen, vielleicht = rubra var caespitosa Hackel.) An Kalkblöcken um den Gamsstein bei Johnsbach und auf Schiefervoralpen, selten.

74. Fest. violacea (Gd \& major Hackel (nigrescens Lam.). Auf feuchten Alpenwiesen der Gneisskette sehr häufig, so z. B. vom Scheiplsee auf die umliegenden Höhen, von der Bacheralpe aufwärts, am Hochschwung.

75. Fest. rulora L. a repens Hackel. Auf Triften, Grasplätzen, Rainen, an Weg- und Waldrändern bis in die Voralpenregion der Kalk-, Schiefer- und Gneissberge fast überall sehr häufig, z. B. unter den Linden des Stiftsteiches, an den Rändern des Hoffeldes, am Wege in's Gesäuss, am Lichtmessberge, von Lorenzen zur Bacheralm, durch den Strechengraben etc. Variirt sehr in der Länge der Aus- 
läufer, in Farbe und Indument der Achrchen, \%. B. bald kahl, bald weichhaarig (var. villosa Kich.), im Schatten grïn, an der Sonne etwas gescheckt.

76. Fest. Varia Huke. Auf Felsen, an steinigen Abhängen, auf 'l'riften der Gneisskette von $5000^{\prime}$ bis anf' die höchsten Kuppen sehr gemein, z. B. vom Selieiplsee und Grïnsee anf die umliegenden Höhen, am Steinamandl, Hochschwung, Plintensattel, Blahberg. Sehr gemein auch im Kalkgebirge am Hund, läufig anch am Kalbling $\mathrm{zwischen} \mathrm{Scheibleck} \mathrm{und} \mathrm{Schafleithen,} \mathrm{sowic} \mathrm{am} \mathrm{nordöstlichen} \mathrm{Ab}$ hange vor den Schneegruben, am Sparafeld sogar über $7000^{\prime}$ hinauf mit pumila.

77. Fest. alpestris R. S. (varia $\gamma$ crassifolia Huter, varia v. mutica mihi in lıerb.) Sehr häufig an Waldfelsen ob dem Wolfsbauer bei Jolnsbach (Dachstein-Dolomit, c. 3000'); stimmt genau mit 'Iyroler Exemplaren.

78. Fest. pumila Vill. Auf steinigen Triften der Hochalpen im Kalkzuge (55-7000') sehr gemein: Am Kalbling, Scheiblștein, Pyrgas, Natterriegel, Hochthor, Festkogel etc. Viel seltener im Gneisszuge: Auf den höchsten Abhängen des Bösenstein $\left(7500^{\circ}\right)$ und am Hochschwung.

79. Fest. Schenchzeri Gd. Auf Kalkgries und Kalkschutt in der höheren Krummholzregion der Kalkalpen: Sehr gemcin unter den Felswänden der Schafleithen und des Kalbling. zwischen Pyrgas und Scheiblstein, von der 'lreffneralpe zum Reichenstein (Angelis), am Fusse des Rinnstein bei Johnsbach; die Essling schwemmt sie bisweilen bis in das Ennsthal herunter. Im Gneisszuge bisher nur auf Felspartien des Hochschwung (6000') beobachtet.

80. Fest. pratensis Hds. Auf Wiesen, Feldern, Grasplätzen und Rainen iiberall höchst gemein; an sonnigen Stellen mit gefärbten, an schattigen mit grünen Aehrchen.

81. Fest. grigantea (L.) Vill. In schattigen Anen, an buschigen Wegrändern, in Holzschlïgen, Hainen und Wäldern anf Kalk und Schiefer sehr lıäufig, z. B. im Stiftsgarten, am Weg in's Gesïuss, Aufstieg zur Suheibleggervoralpe, in Erlenwäldchen bei Trieben, Holzschlägen innerhalb der Klamm.

82. Brachypodium pimatım (L.) Bv. $\alpha$ vulgare, Koch $\beta$ rupestre (Host.) Auf buschigen Rainen, an Waldrändern, in Holzschlägen, Hainen und lichten Wüldern sehr gemein auf Kalk, seltener auf Schiefer und tertiärem Gerölle; $\beta$ seltener, z. B. Kruman (Angelis !).

83. Bracli. sylvaticum (I)C.) Bv. An schattigen Uferstellen, auf Rainen, in Holzschlägen, Hainen und Wäldern bis $3000^{\circ}$, besonders auf Kalkschotter sehr verbreitet, z. B. im Rauchboden-, Laffa-, Mühlauer-Walde, ob der Gstattmayrvoralpe, am Wege in's Gesäuss, Aufstieg zur Scheibleggervoralpe, an Ufern der Enns, des 'I'auernbaches etc.

84. Serrafalcus secalinus (L.) Godr a microstachys Godr. Auf Aeckern unter Getreide, an Grasplätzen und wïsten Stellen hie und da, z. B. im Franenfelde, Hoffelde. 
85. Serr. arrensis (L.) Godr. An Eisenbahndänmen im Hoffelde, am Stationshause beim Reitmeier, am Bachfluder zu Admont (Angelis!); scheint von der Bahn eingeschleppt zu sein.

86. Serr. mollis (L.) Parl. An wüsten Wegrändern, auf Aeckern und Schuttplätzen hie und da, z. B. am Wege nach Frauenberg, um Dittmannsdorf.

87. Brounts asper L. fil. An waldigen Bachrändern ob dem Kalkofen beim Aufstiege zur Kemetenwand häufig (Kalk, c. 2800').

88. Brom. erectus Hols. und 89. inermis Leyss. Beide ron Angelis um Admont spärlich gesammelt, doch sah ich nur erstere.

90. Triticum vulgare Vill $\alpha$ aestivum, $\beta$ hybernum L. Im Enns- und Paltenthale häufig kultivirt.

91. Trit. repens L. $\beta$ filmum Presl. An Wegen, Rainen, Grasplätzen, Sümpfen und auf Wiesen sehr gemein.

92. Trit. caninum (I.) Hds. An denselben Standorten, wie Brachypodium sylvaticum, doch seltener.

93. Secale cereale L. Viel häufiger, als der Weizen, gebaut; steigt bis $4300^{\prime}$ und verwildert anch häufig. gemein.

94. Lolimm perenne L. Auf Grasplätzen, an Wegen und Rainen garten.

95. Lol. italicum A. Br. Häufig auf Grasplätzen im Stifts-

96. Lol. temulentum L. a. macrochaeton A. Br. Unter Getreide, auf rersandeten Aeckern bei Admont, Lichtmessdorf etc. ziemlich häufig.

97. Nardus stricta I. Auf der Hofwiese, in Torfmooren der Krumau, auf dürftigen Ablängen und Waldplätzen der Centralkette, (z. B. am Bösenstein, Steinamandl, Hochschwung, Blahberg, auf der Hochhaide), auf der Plösch (Werfner Schiefer), auf Schiefereinlagerungen der Kalkkette (z. B. am Kalbling, besonder's am Almsteig; auf der Höhe des Brucksattels), stellenweise liöchst gemein und weite Strecken überziehend; geht bis $5500^{\prime}$.

\section{Fam. Cyperaceae DC.}

98. Cyperus flavescens $\mathrm{L}$. Anf nassen, sumpfigen Wiesen, besonders an den hindurchführenden Fusssteigen, an Lachen und auf Mooren stellenweise löchst gemein, z. B. im Selzthale beim Kornberger, im Hofmoore (Angelis!).

99. Cyp. fuscus L. $\alpha$ nigricans, $\beta$ virescens Hffm. An überschwemmten Stellen, Lachenrändern, in Mooren hie und da: An lehmigen Ufern der Ennsarme östlich von der Sautratte n. s. häufig, im Hofmoore (Angelis !). Sehr häufig in abgelassenen kleinen Stiftsteichen mit Uebergängen zu $\beta$, die blos als cine blasse, auf schlammigen Grunde entstandene Schattenform zu betrachten ist, wälrend an ausgetrockneten und der Sonne stark ausgesetzten Stellen die Aehrchen schwarzbram erscheinen (var a.). 
100. Rlyuchosporar albil (L) Vialu. Auf allen T'orfinooren und Moorwiesen des Hons- mo Paltenthales äusserst gemein, \%. B. im Krmmaner-, Hof-, Arlningermonre, bei liezen, liottemmann, Trieben, Gaishorn.

101. Holpochatris palustris (L) R. Br. In S'ümpfen. Isachen, an 'Jeichen. Wassergräben, schlammigen Fluss- mon Bachufem n̈berall sehr gemein bis auf die Voralpen, \%. B. Pyrgasgatter.

102. Hel. mnighmis link. In Sümpfen, Lachen, an Uferstellen und Moorrändern bei Gaishorn, 'L'rieben, Lorenzen, Admont, Kruman laäufig (Sommeraner, Angelis, Strobl).

103. Hol. ovata (Roth) R. Rr. In Teichen und Sümpfen nm Acimont selten. um Gaishorn (Verbniak!).

104. Hal. acicularis (h) R. Br. An überschwemmten Uferstellen, in halbausgetrockneten Lachen und an 'T'eichen um Admont selten (Augelis, Strobl sen.); ich selbst fand sie nur eiumal spärlich au den Eunsarmen der Krumau.

105. Scirpus caspitosus 1. Auf moorigen oder sumpfigen Stellen, an nassen Abhängen, anf triefenden Felspartien der Tauemkette sehr häufig, besonders $u m$ den Scheiplsee und rechts von der Bacheralpe hinauf zum Felsgehänge (Gueiss, c. 5000').

106. Sc. pauciflorus Liugti. Auf Mooren, nassen Wiesen, an Sümpfen, lachen, quelligen Stellen des Funs- und Paltenthales bis auf die Voralpen zerstrent, z. B. bei Lorenzen, Trieben (Sommeraner, Angelis), im Hofmoor (Ang.), unterhalb des Griesmayr, am Pyrgasübergange (Schiefer c. $4500^{\prime}$ ).

NH. Die Angabe, dass Se. mucronatus L. in Sümpfen úm Admont rorkomme, beruht auf einem Irrthume.

107. Sc. lacustris L. in 'Teichen, Seen und versumpfenden Wasserarmen des Linns- und Paltenthales sehr gemein, z. B. im Gaishorn- mnd Triebner-See, im Bichelmayr-, Temmel- und Krumaner-Teiche, an Linusarmen.

108. Sc. Taberuacmontani (im. Am Südrande des 'Temmelteiches bei Admont mit voriger nicht selten.

109. Sc. llaritimus L. o. compactus Ḱrock. Im nordwestlichen Winkel des grossen Stiftsteiches ron Admont nicht häntig.

110. Sc. sylvaticus 1. Auf Smmpt- und Waldwiesen, an Lachen, Wassergräben, 'Teich-, Whuss- und liachufern gemein; besonders iippig am grossen Stiftsteiche.

111. So. воmpressus (L.) Pers. In Sumpfwiesen, an Lachen, Wassergräben, quelligen Abhïngen der Berge und Voralpen des Kialk- und S'chieferzuges sehr häutig, \%. B. bei Bärndorf', in der Kruman, beim Griesmayr (s. gemein), am $\Lambda$ ufstieg zur Pitz, Kemeten, rol Kíaiseran.

112. Eriophorum alpinum l. Auf dem Hofmoore an einigen Stellen sehr gemein, im 'Triebnermoore (Angelis), auf Sumpfwiesen um die Sägernühle ror Kaiserau (Schiefer c. $4300^{\prime}$ ).

113. Lir. varinatum L. Auf Torfmooren (z. 13. im Hof- und Ardningermoore) höchst gemein, auch in Sümpfen und Hochwäldern 
der Gneiss- und Schieferzone, z. B. um den Scheiplsee sehr häufig, am Dürrnschöberl ob der Messneralm häufig zwischen Fichten unter Heidelbeeren (c. 5000').

114. Er. Schenchzeri Hoppe. Auf moorigen oder sumpfigen Stellen, an Lachen der mittleren Alpenregion (5-6000') im Gneisszuge zerstrent: Gerade unter der Höhe des Kampl bei Rottenmann an moorigen Abhängen (6000') häufig; an Lachen unterhalb des Hochschwung s. hfg.; von der Plinten bei Oppenberg zum Lärchkahrsattel s. hfg.; auch in der Schwarzgulling bei Oppenberg (Gebhard in Maly. 1838).

115. Er. latifolinm Hoppe. Auf Sumpf- und Torfwiesen von der Ebene bis in die Voralpen gemein auf Kalk, Schiefer etc. z. B. beim Griesmayr, vor Kaiserau, ob dem Sunk.

116. Er. angustifolium Rth. Auf Sumpf- und Torfwiesen, in Mooren, an feuchten Abhängen von der Ebene bis in die Voralpen des Kalk-, Schiefer- und Gneisszunges höchst gemein, z. B. bei Bärndorf, Büschendorf, beim Griesmayr, im Hofmoos, Bruckgraben, nuterhalb der Kothhütten, ob der Reiteralm.

117. Carex Davalliana Sm. Auf nassen Wiesen, an Wassergräben, Bächen und quelligen Abhängen von der Ebene bis in die Voralpen gemein, z. B. Hofwiese, Sautratte, Hofmoos, Kaiserau, Pyrgasübergang, Voralpen des Kalbling, Hochschwung, Bösenstein ; meist Schiefergrund.

118. C. panciflora Lightf. Auf Torfmooren, moorigen und sumpfigen Wiesen des Enns- und Paltenthales sehr häufig, besonders im Hofmoos, in der Krumau und um den Bichelmayrteich bei Franenberg; seltener in Voralpeu- und Alpensümpfen, z. B. um die Scheiplseen am Rott. Tauern.

119. C. curvula All. Auf dürren, steinigen Alpenhöhen der Tauernkette: Am Bösenstein von der Scheiplalpe hinauf $\left(6-7000^{\prime}\right)$ sehr gemein, seltener auf der Hochhaide (Gneiss). Wurde nach Hatzi auch am Kalbling (Kalk) von Angelis eimmal gesammelt.

120. C. muricata L. $\alpha$. densa, $\beta$ interrupta Wllr. Auf sonnigen, buschigen Rainen, Hügeln, Wiesen, an Zäunen und Waldrändern ist var. a. mit häufigen Uebergängen zu $\beta$ (einer bleichen, unterbrochen-ährigen Schattenform) sehr verbreitet, z. B. vor'm Admonter Ziegelstadl, am Wege in's Gesäuss, nach Frauenberg; ausgesprochene $\beta$ findet sich sehr häufig unter Spalieren im unteren Stiftsgarten,

121. C. vulpiua L. $\alpha$ densa Nir. $\beta$ nemorosa Reb. ( $=\beta$ interrupta Nhr.). Auf Bergen, in Hainen von Hatzi gesammelt; $\beta$ in feuchten Gebüschen bei Trieben.

122. (\%. teretinscula Good. "Auf nassen Wiesen im Enns- und Paltenthale" (Maly 1868): von Angelis früher in der Hofwiese angegeben, doch kann er sich nicht mehr erinnern.

123. C. paradoxa W. Auf Sumpf- und Moorwiesen: „Im Ennsund Paltenthale" (Maly 1868); bei Admont (Strobl sen); Hatzi erhielt sie von Angelis, aber ohne Angabe des Fundortes.

124. C. paniculata L. Auf Sunpf- und Moorwiesen, an Bächen 
land Wassergräben, sowie in Sümpfen bis anf die Voralpen sehr häufig, besonders in der Krumau, Schultering und vor Kaiserau (c. 4000').

125. C. brizoides $\mathrm{I}_{\text {. }}$. Auf nassen und trockenen Abhüngen, an Wegrainen. Waldrïndern des Enns- und Paltenthales sehr häufig, z. B. ob der Santratte unter Eichen, am Hohlwege der Krumau, am Nordrande des Hofieldes ol der alten Emms, an den kleineren Stiftsteichen, bei Bärndorf etc.

126. C. l'emota L. An Lachen, Quellen, Bächen und sonstigen fenchten Stellen der Bergwälder auf Schiefer sehr häufig, z. B. vom Lichtmessberg nach Dittmannsdorf hinab, am Maxbichl bei Lorenzen, auf der Pitz, beim Kiohlenbau im Laflawald s. gemein; seltener auf Kalk, z. B. am Brucksattel, ob dem Franenfelde am Schafferwege.

127. C. echinata Murr. Auf Mooren, Sumpfwiesen, an sumpfigen oder quelligen Abhüngen, sowie an Bach- und Seeründern bis in die Alpen des Urgebirges sehr gemein, z. B. in der Kruman, im Hofmoos, bei Dittmannsdorf, am Pyrgasübergang (Schiefer), an den Taurer- und Scheiplseen, ob der Bacher- und Reiteralm, am Steinamandl, vor Kaiserau (Schiefer); auf Alpenhöhen werden die Aehren braun, dic Fruchtschnäbel theilweise krumm, nach Koch $=v$. grypus Sehk.: doch unterscheiden sich meine Schweizerexemplare (Grimsel-Lagger) durch reichfrüchtige, elliptische, intensiver gefärbte Aehren, längliche Früchte und konstant gekrümmte, längere Schnäbel, so dass sie spezifisch von unserer Alpenform verschieden scheinen.

128. c. leporina 1. Auf nassen Wiesen, an Grasplätzen, Rainen, Waldwegen des Enns- und Paltenthales ziemlich häufig, z. B. bei dem Torfhütten des Krumauer Moores, auf Wiesen daselbst, im Stiftsgarten beim Neugebäude in der blassen Form $\beta$ argyroglochin (Horu) Relıb., bei der Jagdhütte des Kalbling (Angelis!), sehr häufig jedoch auf Bergen, Voralpen und Alpen des Schiefer- und Gneissgebirges, z. B. Plösch, Lichtmessberg, Strechen, Steinamandl, Aufstieg zur Bacheralm.

129. C. Mlongata L. Auf feuchten Wiesen, au kleinen Bächen, Wassergräben zwischen Gröbming und Admont" (Gebhard); ,im Enns- u. Paltenthale" (Maly 1868). Ich sah es bisher nur von Aussee.

130. C. canescens L. An Tümpeln, Wassergräben, auf' 'Torfwiesen und Mooren beider Hauptthäler bis auf die Voralpen: sehr häufig im Hofmoos, am Wege ron Trieben nach Dittmannsdorf (Sommerauer) und um die Tauernteiche.

131. C. Persomii Sieber. An sumpfigen und moorigen Stellen der Gneiss- und Schieferalpen $\left(5-6000^{\prime}\right)$ ziemlich hänfig: Um die Scheiplseeen, unter den Felsen der Hochhaide, unter der Kamplhöhe bei Rottenmann s. hfg., am Steinamandl, ob der Reiteralm, um die Almhütten der Plösch; schon von Hatzi am Hengst gesammelt, aber nicht erkannt.

132. C. mucronata All. Auf Felsen, steinigen Abhängen und dürren Triften der Kalkkette in der Voralpen- und Krummholzregion bis $6000^{\prime}$ sehr hänfig, seltener in die Bergregion herunter- 
geschwemmt: $\Lambda \mathrm{m}$ Kalbling, Pyrgas, Scheiblstein, zur Kochenalm hinauf, im Schwarzenbachgraben, auf der Pitz (Hatzi), an der Bärnhoppe, im Gesänss, Johnsbachgraben, am Gamsstein, Hund etc.

133. C. stricta Gool. Anf Mooren, in Sümpfen, Sumpfwiesen, an Lachen und Wassergräben dureh's Enns- und Paltenthal lö̈chst gemein, z. B. Hof-, Krumauermoor, Schultering, Santratte, Griesmayrsümpfe, bei Trieben, zwischen Bärn- und Büschendorf.

134. C. vulgaris Fr. Auf Mooren, torfigen oder sumpfigen Wiesen, an Lachen, Seen, Bächen, bis in die Voralpenregion der Gueiss- und Schieferkette höchst gemein, z. B. Hof-, Wolfsbacher, Krumauermoos, Griesmayr-, Trieben-Siimpfe, am Scheiplsee, ob der Reiteralm; var. turfosa (Fr.) in der Kruman (Angelis!).

135. C. acuta L. In Sümpfen, an Fluss- und Teichnfern sehr häufig, z. B. in den Griesmayr- und Krumausümpfen, in der Sautratte, an Ennsarmen, den Stiftsteichen, an der Palte.

136. C. nigra All. (atrata \% conglomerata Nlr.) Auf mageren, steinigen Hochalpentriften, besonders an Schneefeldern und Schneegruben des Kalkgebirges nicht gemein, noch viel seltener im Tanernzuge : a. am Scheiblstein von 6000 bis 7000' sehr häntig mit atrata, am Kalbling in gleicher Höhe ziemlich selten; $\beta$ ror dem Grünsee der Hochlaide (c. 5500', Gneiss).

137. (. atrata L. (= $\beta$ laxa Nlr.) Auf üppigen und mageren, feuchten und dürren 'Triften der Kalk- und T'anernkette, von der Krummholzregion bis zu den Hochgipfeln sehr häufig, z. B. Kalk: am Scheiblstein mit nigra und in sie übergehend gemein, am Pyrgas bis zur Pyramide $\left(7199^{\prime}\right)$, Kalbling, auf der Scheibleggerhochalpe, rom unteren Boden bis auf den Hund. Gneiss: Am Hengst (Hatzi), von den Scheiplseen anf die umliegenden Höhen, von der Bacheralpe zum Gemeinsee, am Hochschwung. Die C. aterrima Hpp. bilden eben die vom Urgebirge dunkler gefürbten Exemplare der atrata, besonders wenn sie anf fetten Triften sich ïppig entwickeln, wobei die Halme meist mehr oder minder rauh erscheinen; doch gibt es im Tanernznge auch lı̈ufig ganz glatte Ex., sowie die von Kalkalpen stammenden auch öters etwas rauh sind.

138. C. linnsi L. Auf Torfmooren und sumpfigen Wiesen des Enns- und Paltenthales nieht sehr selten: Ennswiesen bei Admont (Hatzi!), Ardningermoos (Angelis!), Paltenmoore bei Trieben (Sommeraner!).

NB. C. irrigna Sur. wird in Maly 1868 ,im Enns- und Paltenthale, bei Spadeck (Angelis)" angregeben, fehlt aber in unserem Gebiete, da Angelis sie blos anf dem Spadeck fand, dieser Berg aber ausserhalb unseres Gebietes liegt.

139. C. pilulifera I. Auf Wiesen, in W:ïlern und Holzschlägen bis auf die Voralpen der Schieferzone häufig, z. B. in der Schultering s. hfg.. im muteren Stiftsgarten, anf Wiesen östlich ron der Sautratte, rom Fuss bis zur Höhe des lichtmessberges lı̈口fig, von Lorenzen bis gegen die Bacheralpe, ob der Reiteralm vor"m Hochschwung. 
140. C. tomentosil L. Auf nassen Wiesen, an Lathen mom Admont ziemlich selten: Am liande eines Sumpfes ron der Ziegelbrennerei gegen die Sautratte hinab nicht selten: am nordöstlichen Ufer der Griesmayrlache (Hatri!), ann Oberhofleldbache und am Wege zu den Stiftswirthwiesen (Angulis!) : auch im Paltenthale.

141. (. montana 1. Wurde bein alten Kalkofen oberhalb des Franenfeldes in einem älteren Verzeichnisse angegeben; diurfte woh! einheimisch sein, da sie sich bei Bruck und Judenburg noch findet.

142. ('. praceox Jacq. Auf Wiesen, Rainen, an Waldrändern überall sehr gemein.

143. C. Hullnosa Host. Auf buschigen Rainen und nassen Wiesen selten: In der Krumau und Schultering (Angelis!); neben der Lichtmessdorfer Paltenbrücke auf einer rassen Wiese, unter Buschwerk neben dem Wege von Lichtmessdorf nach Gaishorn, etwa beim Prechtler (Angelis!), am Ufer der Enns im Sande (Altes Verzeichniss).

144. C. hnmilis Leys. Auf sonnigen Felshöhen gegen die Stumpfnagleralm hinauf, wo ein grosses Felsstiick herabgerollt ist (Hatzi!), im Gesäuss (Angelis!).

N3. C. Halleriana Asso wird in einem alten Verzeichnisse rom Kalbling angegeben, wurde aber in neuerer Zeit nie daselbst gefunden.

145. C. ornithopodioides Hausul. Auf hohen Kalkalpen selten: An einem Schneefelde des Hochthor (c. 6000') selten, ebenso selten in der Hochilpenregion des Pyrgas, Natterriegel und Buchstein.

146. C. or unithopoda W. Auf Wiesen, an buschigen Kalkrainen, an Waldrändern und in lichten Föhrenwäldern bis in die Voralpenregion der Kalkkette sehr gemein, z. B. auf Wiesen neben der alten Enns östlich von der Sautratte, durch's Gesänss, im Johnsbachgraben, am Schafferwege, der Esshing entlang durch den Föhrenwald bis Mühlau, zur lochenalm, zur Farchneralm bei Johnsbach; selten im Tauernzuge: An Waldrändern ob der Pfurrerhub bei Lorenzen; auch von Hatzi am Tauern gesammelt.

147. C. digitata L. (besser als Var. zur vorigen zu ziehen.) Unter Spalieren und Linden des Stiftsgartens häufig, sehr gemein im Walde vor dem Himbeerstein und am Schafferweg. NB. Dass Nr. 146 und 147 keine echten Arten, sondern kaum Varietäten, eigentlich blos Standortsformen sind, beweisen die zahlreichen Uebergänge, besonders am Schaflerwego, wo man nebst den typischen formen auch zahllose findet, an denen das Verhältniss der Frucht zum Balge, die Zusammeusetzung des Fruchtstandes und der Habitus röllig schwankt; interessant ist anch, dass Reichenbach in seiner Flora 1846 die Frucht kürzer, als den Balgy angibt, während die übrigen Autoren das Gegentheil sagen.

148. C. alba S'cop). In Wäldern, Holzschlägen und an buschigen Ablängen von der Ebene bis in die Voralpen sehr gemein, aber nur auf Kalk, \%. B. durch's Gesïuss, im Johnsbachgriben, im Rauchboden, Laftawald, auf der Pitz, ob Mühlau, am Schaflerweg, Aufstieg zur Scheibleggerhochalpe etc. 
149. C. pilosa Scop. Unter dem Hainbuchen-Spalier des unteren Stiftsgartens sehr gemein - wahrscheinlich ursprünglich wegen ihrer schönen Rasen kultivirt, soust nirgends „im Enns- und Paltenthale" (Maly 1868).

150. C. panicea L. Auf sumpfigen Wiesen des Enns- und Paltenthales bis in die Voralpenregion der Schieferzone sehr häufig, z. B. beim Griesmayr, an Lachen unterhalb der Ziegelhütte, in der Sautratte, vor'm Hofmoos, ror Kaiserau (Schiefer 4300') s. gemein, ob der Reiteralm vor'm Hochschwung (Gneiss) etc.

151. C. Hacca Schreb. (glanca Scop.) In Sümpfen, nassen Wiesen, an Bächen, Rainen, Waldrändern, besonders in der Berg- und Voralpenregion der Kalkkette höchst gemein; viel seltener im Urgebirge, z. B. bei der Strechenbrïcke. In höheren Regionen, besonders zwischen Krummholz am Scheiblstein, tritt sie mit dickeren, mehr keulenförmigen, braunschwarzen A ehren auf $=\mathrm{C}$. clavaeformisHoppe.

152. (\%. pendula Huds. In einer feuchten, bachdurchrieselten Schlucht des Laffawaldes zwischen Kohlenbau und Bruckgraben spärlich.

153. C. pallescens L. Auf Wiesen, nassen Abhängen, buschigen Hügeln, in Hainen und Wäldern bis auf die Voralpen des Kalk- und Schieferzuges sehr häufig, z. B. Hofwiese, Raine ob der alten Enns, Käferwäldchen, Voralpen des Kalbling, ob dem Sunk, ob der Bacherund Reiteralm.

154. C. capillaris L. Auf Triften, steinigen Abhängen der Kalkalpen (45-6000') sehr häutig, z. B. am Pyrgas, Scheiblstein, Kalbling (schon an Waldrïndern hinter Kaiserau), um die Scheibleggerhochalpe. unter der Farchneralm, am Hund, im Sulzkahr etc. Seltener an quelligen oder sumpfigen Stellen der Gneisskette: bei der Gruberhütte in der Plinten s. hfg., ob der Reiteralm vor'm Hochschwung, am Bösenstein (Hatzi!).

155. C. fuligrinosa Schk. Auf steinigen Triften, zwischen Granitblöcken in der Hochalpenregion $\left(6-7000^{\prime}\right)$ des Gneisszuges: Sehr häufig am Bösenstein, besonders im Kahr zwischen dem grossen und kleinen B., häufig von der Singsdorferalm dem Viehweg entlang auf die Hochlaide. "Im Johnsbachthale (Gebh.)" Maly 1838 ist umrichtig.

156. C. Prigila All. An Bächen, in Sümpten und auf nassen Abhängen der Gneisskette (4-5500') häufig: an den Zuflüssen des Scheiplsee's, ehemals sehr hüufig sogar bis 'Trieben hinabgeschwenmt (Angelis!), an Hauseck beim Scheiplsee (Hatzi), von der Hölleralm zu den Kothhütten (Angelis), an Bächen ob der Bacheralm, ob der Reiteralm am Hochschwung, hier stellenweise fast gemein.

157. C. selipervirens Vill. An grasigen und steinigen Abhïngen der Kalk- und Urgebirge von der Voralpen- bis in die höhere Alpenregion $\left(4-6600^{\prime}\right)$ gemein, z. B. Kalk: Pyrgas, Scheiblstein, Natterriegel, Kalbling, ob der Treffneralm am Reichenstein, am Hochthor, Hund, im Gesiunss; Gneiss: Ob dem Scheiplsee, der Bacheralm, auf der Hochhaide, am Steinamandl, Blahberg, Hochschwung.

158. C. firma Host. Auf Felsen, steinigen Abhängen und Triften der Kalkkette von der Krummholzregion bis anf die höchsten Spitzen 
(des Pyrgas, Scheiblstein, Natterriegel, Kalbling, Reichenstein, Buchstein, Hochthor, Hund ete. ete.) ïusserst gemein und oft weite Strecken, besonders die Bergrïcken, polsterförmig überziehend: steigt auch sehr häufig in die Kalkschluchten und auf die Felsen der Seitenthäler herunter, z. B. am Mühlanerwasserfall, im Wäldehen vor Mühlan, im Schwarzenbachgraben, Johnsbachgraben, Gesäuss.

159. C. ferruginca Scop. Auf grasigen oder steinigen Plätzen, in Wäldern, an nassen Abhängen und Giessbachrändern von 3500 bis 5000' der Kalkkette sehr häufig: Am Pyrgas, Scheiblstein, ob der Kochenalm und hinabgeschwemmt bis zum Mühlauerfall, rom Schwarzenbachgraben zur Griesweberalm, am Unterkalbling (vorzüglich im Walde unterhalb der Schäferhütte und gegen die Jägerhütte hinauf), von der 'I'reffineralm auf den Reichenstein, im Gesäuss (Angelis), gegen die Farehneralm, ob dem Hund etc.

160. c. temuis Host. Anf steinigen, fenchten Abhängen, Felsen, an Giessbächen und in Sehluchten von der Voralpen- bis in die mittlere Alpenregion meist sehr häufig, auch oft tiefer herabgeschwemmt: Am Pyrgas, Scheiblstein, um den Mühlauerwasserfall, seltener zur Kochenalm hinauf, nicht häufig an Pitzfelsen, am Schafund Schafterweg, hfg. an Aufstieg zur Scheibleggerhochalpe, s. hfg. durch's Gesäuss, im Johnsbachgraben, am Hochthor und Hund.

161. C. flava $\mathrm{I}$. Auf Torfmooren, nassen Wiesen, an sumpfigen Abhängen, Bach- mnd Seerïndern bis in die Voralpen des Schiefer-, Gneiss- und Kalkgelinges gemein, z. B. Hofmoos, Hofwiese, Sautratte, Griesmayrsïmpfe, Pyrgasübergang, Scheibleggerbach, Kaiserausümpfe, Strechengraben bis $5000^{\prime}$.

162. C. Oederi Ehrl. Auf Torfmooren, an sumpfigen Teichund Lachenränderu des Enns- und Paltenthales: Selır gemein stellenweise im Hofmoos, hänfig an Griesmayrlachen, am Bichelmayrteich vor Franenberg, um Trieben und Gaishorn.

163. C. Hornschuchiana Hoppe. Im Hofmoos (Angelis!).

164. C. distans L. Auf fenchten Wiesen beim Griesmayr mit Primula farinosa sehr hänfig, auch in der Hofwiese und im Paltenthale.

165. C. silvatica Huds. In Hainen, Bergwäldern, schattigen Schluchten, bis auf die Voralpen des Kalk- und Urgebirges sehr häıfig, z. B. unter den Spalieren des unteren Stiftsgartens, beim Kohlenbau des Laffawaldes, ror'm Mühlanerfall, in Wäldern rings ob dem Franenfelde, im Wolfsgraben ob 'Trieben.

166. \% ampullacea Good. An Wassergräben der 'Torfmoore, an moorigen Sümpfen des Fnns- und Paltenthales sehr gemein, z. B. Hof- und Krumauermoos, um den Triehnersee; sehr häufig auch an Lachen, Teichen und Bächen bis in die Voralpen des Schicfer- und Gneisszuges, z. B. Sautratte, Griesmayrlachen, Kaiseranerteich und Bäche daselbst, Strechengraben, Ränder des Scheiplsee's.

167. '. resicaria I. An 'Teichen, Lachen, Sümpfen, Bächen, Wassergräben des Enns- und Paltenthales sehr häufig, besonders an den Stiftsteichen, in der Sautratte, in der Krrumau und an der Palte; selten an Moorründern, z. B. am Nordrande des Hofmoores. 
168. C. paludosa Good. $\alpha$ vnlgaris Nlr. und $\beta$ Kochiana (DC) Gd. In Sümpfen, auf nassen Wiesen, an Fluss- und Teichrändern des Enns- und Paltenthales sehr häufig; z. B. an der Enns, am Stiftsteiche, in der Krumau.

169. C. filiformis I. In tiefen Sümpfen des Enns- und Paltenthales (Angelis!).

170. C. lirrta I. a. vera Nlr. und $\beta$ hirtaeformis (Pers.) Nlr. Auf feuchten, sandigen oder lehmigen Uferstellen der Bäche, Lachen, Sümpfe und Teiche, auf Wiesen, Grasplätzen bis in die Voralpenregion häufig, z. B. an den Ennsarmen, bei der Griesmayrlache, an Stiftsteichen, am Wege zur Scheibleggerhochalpe, am Unterkalbling. Ganz glatte Exemplare (var. $\beta$ ) sehr häufig in abgelassenen Stiftsteichen, doch sind auch die Ex. anderer Standorte meist wenig behaart.

\section{Fam. Juncacene Agardh.}

171. Juncus couglomeratus I. An Gräben, Lachen, auf Sumpfund Moorwiesen bis auf die Voralpen sehr häufig, z. B. Hofwiese, Hofmoos, Krumanermoos, Lachen beim Ziegelstadl, Triebnermoor.

172. J. efliusus 1. An Gräben, Lacheu, Bächen, Teichen, auf sumpfigen und moorigen Wiesen bis anf die Voralpen überall höchst gemein.

173. J. glaucus Ehrl. An Grüben, nassen Rainen, auf sumpfigen Wiesen häufig, z. B. an der Emns, in der Krumau, bei Lorenzen.

174. I. filiformis L. In 'T'orfmooren, Sumpfwiesen, besonders an quelligen Stellen, auf sumpfigen Abhängen, Lachen- und Seerändern der Voralpenregion im Gneiss-, Schiefer- und Kalkzuge, z. B. Hofmoos, Schultering, am Kalbling hinter Kaiseran, bei der Treffneralpe, um den Scheiplsee am Bösenstein, ob der Reitəralm am Hochschwung.

175. J. Jacyuini L. Auf sumptigen Stellen am Speikboden des Kalbling (c. 6200') von Angelis! luäufig gesammelt, von mir daselbst stets vergebens gesucht.

176. J. castaneus Sur. An quelligen und sumpfigen Stellen zwischen der Reiteralm und dem Hochschwung oberhalb des ersten Gürtels links sehr hänfig mit Carex frigida (Schiefer, c. 5000').

177. J. trigrlumis L. An nassen, sandigen Wegrainen bei der Gruberhütte in der Plinten hinter Oppenberg häufig (Schiefer c. 4000').

178. J. trifidus L. Auf Felsen, steinigen Höhen und kurzgrasigen 'Triften der höheren Urgebirge (5-7500') sehr gemein, z. B. am Hauseck, Bösenstein (schon rom Scheiplsee an), von der Bacheralpe zur Hochhaide, zum Ochsenkahr etc., am Steinamandl, Kampl, Hochschwung, Plintensattel.

179. J. monanthos Jeq. Auf Felsen, steinigen Abhängen und dürren Höhen der Kalkgebirge (5-7000') selır gemein, z. B. von den Vormauern des Kalbling an, um die Kemetwand, am Pyrgas, 
Scheiblstein, Rimnstein, Hochthor, Hund; anch häutig herabgeschwemmt in den Schwarzenbach, Johnsbachgraben und in's Gesäıss.

180. J. lamprocarpus Elılı. An Gräiben, Lachen, äberschwemmten Uferstellen, auf Torfmooren und nassen Wiesen höchst gemein; anch in feuchten, schattigen Bergwällern, \%. B, beim Steinkohlenban im Laffawald; sogar, aber seltener, anf' Voralpen (um die Kemetwand, am Unterkalbling, ob der Reiteralm an Hochschwung). Variirt mannigfach: An sonnigen, vertrockneten Stellen aufrecht starr, an sehr feuchten Orten kiriechend und aufsteigend, oft mit grïnlichen Perigonen; seltener sprossend (= valr. vivipara, \%. B. in Lachen beim Griesmayr, am Südlende des Hofmooses); in Wäldern hoch und sehlank.

181. J. ilpinus Vill. Auf Sumpfiviesen des Enns- und Paltenthales, an leuchten Waldstelien, quelligen Abhängen, an Bächen der Berg- md Voralpenregion (Kalk, Schiefer, Gneiss) gemein, \%. B. Triebnermoor, beim Griesmayr, in der Krunan, am Mühlanerfall, Pyrgas - Uebergang, Aufstieg zur Scheibleggerhochalm, Kaiseranerteich, Bruckgraben, ob dem Sunk, unterhalb der Kothhütten etc.

182. J. compressus Jicy. Auf nassen Wiesen, an überschwemmten Uferstellen, an Lachen, Gräben und Wegen häufig, \%. B. ron Admont in's Gesïuss, vom Moser zum Nagelschmied, am Brucksattel-Quell.

183. .J. hufonius I. An lehmigen Lachenrändern, überschwemmten Uferstellen, auf sumptigen Wiesen, im Schlamm abgelassener Teiche etc. sehr gemein.

184. Iuzula flavescens (Host) Gid. In allen Berg- und Voralpenwäldern his $4500^{\prime}$ an feuchten, moosigen Stellen auf Kalk, Schiefer und Gneiss sehr häufig. \%. B. unter Röthelstein, am Aufstieg zur Pitz, Scheibleggerhochalpe, am Schafferweg, Lichtmessberg bis zum Nagelschmied, Pyrgas, Scheiblstein, Kalbling, bei der Treftneralpe, bis zur Bacheralpe am Rott. 'Tauern; sehr gemein auch unter den Teichlinden des Stiftsgartens.

185. I. pilosa (I.) WV. Auf schattigen Grasplätzen, in Wäldern, Holzschlägen und Hainen sehr häufig, \%. B. im Stiftsgarten, unter Röthelstein, am Beginn des Schafferweges etc., meist auf Schiefer, oft mit roriger, aber viel sparsamer.

186. I. maxima (Ehrlı.) 1)(. Gemein unter Krummholz der Kalkgebirge und tiefer herab in die Voralpenwälder, z. B. aun Pyrgas, Scheiblstein, Hochthor. Hund, Kalbling his zu den KaiseraucrWeiden herab. inter der Scheibleggerhochalpe, im Sunk ete.

187. L. gralurata Hoppe. Anf steinigen Abhängen, unter Krummholz, an Schneefeldern der Kalligebirge (4500-6.500') häufig, besonders am Pyrgas, zwischen P. und Ścheilolstein, am Aufstiege rom unterun Boden zur Farchneralm bei Jolnsbach s. hfg., ob dem Hund, an Hochthor, unter Finmmhol\% vor der Scheibleggerhochalpe, am Speikibulen des Kalbling (6500') und tiefer.

188. L. spadicea I) . Auf grasigen oder steinigen Abïngen, an Bächen, Seen, Schneefeldern, sowic auf kahlen Bergrücken der Taurerkette (5-7500') sehr gemein, 7. 3. vom Scheiplsee und der Bacheralpe zu allen umliegenden Hühen, am Griesstein im 'l'ricben- 
thale, Steinamandl, Hochhaide, Hochschwung etc. Auch auf sumpfigen Orten ob dem Pyrgasgatterl, wie es scheint, an einer SchieferFortsetzung der Plösch.

189. L. albida (Hffm.) DC. Auf Wiesen, Rainen, Waldrändern, in Wäldern, Holzschlägen und auf buschigen Abhängen der Berge bis in die Alpenregion der Urgebirge höchst gemein (Gneiss, Schiefer, seltener Kalk). Variirt besonders in der Perigonfärbung bedentend: In der Ebene und auf niederen Hügeln (z. B. am Nordrande des Hoffeldes, Wege nach Frauenberg, Aufstieg zur Pitz) sind die Perigone meist weiss mit einem Stiche in's Röthliche ( $\beta$ rubella Hoppe), seltener rein weiss ( $\alpha$ vera), auf Bergen und Alpen aber (Lichtmessberg, Steinamandl, Hochschwung, Plintensattel etc.) mehr oder weniger intensiv roth (\% cuprea).

190. L. campestris DC. Auf Rainen, Wiesen, sonnigen Hügeln schon im ersten Frühjahre sehr gemein, seltener auf Berg- und Alpenwiesen (Kalk).

191. L. erecta Dsv. 1808 (multiflora Lej. 1811) a nemorosa. Auf buschigen, üppigen Abhängen, in Hainen, Holzschlägen, Torfmooren, Wäldern bis auf die Voralpen sehr häufig; $\beta$ pallescens Sw. im Hofmoore, unter den Linden des Stiftsteiches.

192. L. congesta Lej. a genuina und $\beta$ nigricans Dsv. (die lockerblüthige Form). Auf Triften, kahlen Abhängen und steinigen Höhen der Alpen (4500-7000') im Kalkzuge selten (z. B. Unterkalbling, Flitzen, Treffineralpe), im Urgebirge gemein, z. B. vom Scheiplsee zum Bösenstein, um die Bacheralpe und aufwärts zum Grünsee, Gemeinsee, Mitterstein, zur Hochhaide, am Steinamandl, Hochschwung etc.

NB. Es dürfte sich empfehlen, 190-192 zusammenzuziehen, da wohl 190 die Rain- und Wiesenform, 191 die Wald- und Hainform, 192 die Alpenform des Juncus campestris L. zu bilden scheint.

193. L. spicata (L.) DC. Auf grasigen und felsigen Abhängen, sowie auf kahlen Rücken der Urgebirge (5-7000') sehr liäufig, z. B. ob der Kettenthalalm, am Bösenstein, Hengst, von der Bacheralpe zum Gemeinsee, vom Mitterstein zur Hochhaide, am Steinamandl. Auf dürren, hochgelegenen Abhängen ist die Aehre köpfchenartig $=\beta$ conglomerata Mielichh., z. B. am Bösenstein.

\section{Fam. Melanthaceae R. Br.}

194. Colchicum autmmale L. Auf feuchten Wiesen, grasigen Rainen sehr gemein, z. B. Hofwiese, Griesmayrwiese, bei Johnsbach, Wiesen im Reithmairmoore etc.

195. Veratrum album L. Auf Sumpf- und Waldwiesen, Rainen und grasigen Abhängen von der Ebene bis auf die Voralpen und Alpen $\left(2-6000^{\prime}\right)$ höchst gemein in der Kalk- und Gneisszone, z. B. noch am Hund und am Grünsee. 
196. Tofichlia calyculata (L) Whll. Auf Wiesen, fenchten, steinigen Hïgeln, in Schluchten, an felsigen oder grasigen $\Lambda$ bhïngen von der libene bis auf die hüchsten Gipfeln der Kalkalpen seh" gemein, z. B. Griesmayrwiesen, Gesiluss, Johnshachgraben, Hund, Hoehthor, Ranchboden, Bruckgraben, Laflawald, Mühlauerfall, Schafferweg, Scheiblstein, Pyrgas, Kalbling bis $7000^{\prime}$; seltener im 'Tauemzuge, wie an Biichen ob der Bacheralpe, am Fuss des eigentlichen Hochschwming, hier s. lifg.

NB. An tieferen Standorten ist die Traube lang und oft unterbrochen; an höheren wird sie kïrmer und gedrumgener, anf den Hochgipfeln oft kopflörmig (glacialis Gd. capitata Hpp.), doch anch hier meist mit verlïngerten gemischt. Selten finden sich Abnormitäten mit ïstigem Blïthenstande, der bei 'Thalformen (z. B. Gesänss) rispig, bei Alpenformen (am Scheiblstein (6500') doldenförmig wird. (var. ramosa $\mathrm{Hpp.}$.).

197. 'T'. lon'ralis Whlh. Auf grasigen Abhängen der höchsteu Kalkalpen selır selten: Am Speikboden des Kalbling (c. 6200') auf einen dichten Rasen zinsammengedrïngt anno 1836 von Angelis in Menge gefunden, seitdem stets vergebens gesucht, am Pyrgas, Scheiblstein, Natterriegel selten (Hatzi!), am Bnchstein. Andere Angaben beziehen sich wohl auf die Alpenform der vorigen.

\section{Fam. Liliaceae Lindl.}

198. Fritillaria Maleagris L. Am grossen Stiftsteiche (Sommeraner, 12. Mai 1821); war gewiss blos verwildert und ist seitfem verschwinden. "In Gesïmss (Haffner)" Maly 1868. Gilt wohl dasselbe.

199. Lilinm bulbifer'um L. Auf Bergwiesen, buschigen Rainen und an Waldrïndern stellenweise hänfig (Śchiefer, selten Kalk) z. B. Anf Wiesen im Triebenthal (Hatzi!), von Hohentanern (4000') nach S. Johann sehr häufig, ebenso im .Johusbachthale; zerstreut auch ob dem Moser auf Rainen des Lichtmessberges und unter Gestrïnch am Leichenberge.

200. L. Martagou I. Auf grasigen Ablüngen, in lichten Wäldern und Holzschlägen der Kalkvoralpen bis zur Krummholzregion sehr häufig, z. B. Auf Voralpen des Kalbling, Pyrgas, Scheiblstein, im Walde östlich von der Griesweberalm, am Aufstieg zur Bärnkoppe und Kemetwand hie und da, im Gesänss selten, unterhalb des Gams- und Rimnstein, gegeu die Farchneralm etc. Auf Gneiss nur an buschigen Stellen des Blahberges in der Strechen entdeckt.

201. Lloydia serotina (L) R(hlh. An felsigen Stellen der Noriseite des Hochschwung hie und da (c. 6000', Glimmerschiefer'); nach Stur auch am Bösenstein (7700', Gueiss.)

202. Anthericum yamosum L. Auf Felsen, steinigen, buschigen Ablängen, seltener an grasigen Stellen, der Berge und Voralpen anf Kalk häufig: \%. B. Im. Gesäuss zwischen Johnsbachbrïcke und Gstatterboden, am Gamsstein, im Ranchboden, Laflawald, am Dörfl- 
stein ob Hall, ob dem Mühlanerfall, zwischen Gesträuch ob der Gstadtmayrvoralpe am Futterweg, an Pyrgasfelsen beim Aufstieg 7um Scheiblstein.

203. Ornithogalıu nubellatum L. Sehr häufig an Wegen und Spalierrïndern im unteren Stiftsgarten, sonst höchst selten.

204. 0. mutius I. Im Obstgarten und an der Gartenmanel von Burg Strechau verwildert gefunden (Strobl sen.!).

205. Gacea minima (L.) Schult. Auf Grasplätzen um die Almhiïtten der 'Tanernkette: Un die Hölleralm sehr häufig (Angelis!), anch um die Bacher- und Pesendorferalm (c. 4500').

206. G. Intea ( $\mathbf{L}_{1}$ S Schult. In Auen, Obstgärten, an buschigen Stellen und Waldrändern riemlich häufig bei Admont (z. B. Stiftsgarten), Weng, Rottenmann, Johnsbach, im Gesïuss mit Lencojum vernum, auch um die Scheibleggerhochalmhïtte (Kalk, c. 5000') und auf Alpenwiesen des Unterkalbling (Sommeraner!).

207. Scilla anoena T. Unter Obstbäumen beim grossen Stiftsteiche im Mai 1820 von Sommeraner verwildert gefunden, seitdem verschwunden (teste Angelis).

208. Sc. bilolia I. Unterhalb der Johnsbachbrïcke im Gesäuss nicht weit rom Reithmayrluntlfeld links linunter nicht selten auf einer Waldan (Angelis!, Hatzi!); „im Paltenthal" (Maly 1868)?.

209. Allium Victorialis L. Auf felsigen und steinigen Abhängen der Kalkalpen, meist in der Krummholzregion, nicht länfig: Ob dem Hund-Uebergange bei Johusbach hfg., 'miter den Schuttfeldern des Hochthor s. hfog., an F'elswänden ob Weng, am Pyrgas, Kalbling zerstrent.

210. All. "Ixinum 1. Auf Wallboden unter dem Dörflstein bei Hall (Hatzi !), am Lichtmessberg (Angelis).

211. All. montalum Nohur. Aul' Felsen und steinigen, buschigen Abhängen der Kalkroralpen ziemlich gemein, \%. B. um den Gamsstein, die Kemetwand, an Schal- und Schafferweg, Hmod, auf Mühlauer- und Ardningerhöhen, am Aufstieg zum Strinamand, in der Klamm (c. 2100', tiefster P'mlit).

212. All. angulosmu $\mathrm{L}_{\text {. }}$ (arutangulum Schrd.). „Auf Wiesen bei Admont (Angelis)" Maly $1838^{\circ}$ und 1868. Sah es niemals aus dem Gehiete.

213. Mll. carluatum L. Auf Wiesen, an buschigen Rainen und an Zäunen selten: Beim Nenwirth bei Admont (Angelis!), im Gesäuss (Strobl sen.), vor'm Griesmayr. Jenseits der Buchau bei S. Gallen, Altenmarlit ctc. viel häufiger.

214. MII. sibiricum I. (Schoenoprasum \& alpinum Gd.) Auf subalpinen Wiesen sehr selten: Höhın ob Ardning, Höhe des Neuhurgs bei Johnsbach an Stadleld (Hatri!).

NB. All. Schocnoprasum L, sativum L, Porrum L, Cepa L und fistulosum \& werden in Gärten kultivirt.

215. Muscari botryoides (L) IOC. Anf Wiesen an der alten Eums in der Nähe der Sautratte, auf der Fuchsweide (Angelis!, Hatzi!), im alten Schlossgarten bei Streclian wild (Hatzi!). 


\section{Fam. Smilaceat R. IBr.}

Asparagus oflicinalis I. Hänfig knttiv., besond. im Stiftsgart. 216. Paris quadrifolia L. In Inanen mol schattigen Bergwäldern bis auf die Voralpen zerstrent, stellenweise sehr häntig, besonders nuter den Spalieren des Stiftsgartens, im Sunk mol oberhalb desselben gegen Holuntanern hinanf; seltener um Mïhlan, am Scheiblstein ol, iler Gstatfmayrvoralpe, am Schafweg des Kalbling, im Gesïuss, Ranchborlen ete. Kalk, seltener Schiefer.

217. Streptopus amplexifolius (L) I) : An fenchtem, buschigen oder waldigen Stellan der höheren Bergregion selten: Boi Lorenzen rereinzelt (Hatri!), am Lichtmessberg neben dem lïindorfer Fusssteige gleich Anfangs an Zämnen nicht selten (Schiefer, 3500'), im Hatlersgraben hoch oben unter Fichten selten (Kalk, 3000').

218. (onvallaria rerticillata I. An fenchten, sehattigen Rainen, in Wïhlem mol Hol»schlïgen der Berge bis anf die Voralpen der Kalkgebirge seh" hïufig, \%. B. mm den Mühlanerfall, am Scheiblstein, Pyrgas, unterlalb der Griesweberalm, am Aulstieg zur Scheibleggerhochalpe, Schafweg, Schallerweg, Waldrïnler hinter Kaiseran, Gesïuss, Rauchboden, vor'm Hochthor, im Sunk; seltener anf'Schiefer (auf der Buchan, vor der Pfinrerhub ob Lorenzen, ob dem Scheiplsee, am Blahberg in der Strechen). Auch hie und da in der Ebene, \%. B. im Höpflingerlelde, muter Spalieren des Stiftsgartens.

219. Conv. Polygonafum I. An steinigen, buschigen Stellen der Kalkvoralpen häntig: Durch's Gesïuss, besonders am unteren Stein, im Johnshachgraben, Rauchboden, an Gamsstein, ob dem Mühlanerfall, der Gstaltmayrvoralpe am Scheiblstein, im Sunk.

220. Conv. multillora I. An feuchten, schattigen Stellen, in Hainen und Wäldern des Fnns- und Paltenthales: Sehr gemein unter den Spalieren des Stiftsgartens, seltener am Bach der Oberhofmühle (Angelis!), im Gesäıss (Strobl sen.) ete.

221. ('nur. majalis L. An steinigen, buschigen Stellen und an Waldrändern Her Kalkkette (2-4000'), meist truppweise, häufig: Im Gesünss his Gstatterboden hie und da, am lingange in den Schwarzenbachgraben, ob dem Mühlaucrfall s. hfg., zwischen Strauchwerk ob der Gstattmayrvoralpe ete.

222. Majanthemum hifolium (1.) I)C. In scliattigen Bergwäldern auf Kilk und Schiefer gemein, \%. B. unter Röthelstein, am Schafferweg, im Haller Wäldchen, Gesäuss, Ramchboden, gegen den Kalkofen bei Admont, ron Sunk nach Hohentanern; vereinzelt sogar noch auf der Kante les Steinamandl (Gneiss, 6000').

\section{Fam. Amaryllideae R. Br.}

223. Sincissus puäticus 1 . Auf Thal- mol Bergwiesen an wenigen Punkten, aber massenhaft: In der Schultering bei Admont, anf einer Waldwiese hinter Strcchan $7 n$ 'Tansenden (Kalk, c. 2600'). 
224. Leucojum vermum L. An feuchten Waldrändern und Bergabhängen, in Obstgärten, auf Feldrainen und sumpfigen Wiesen des Enns- und Paltenthales höchst gemein, vorzïglich auf Schieferboden, etwa bis $3000^{\prime}$.

\section{Fam. lrideae R. Br.}

225. Crocus alliflorus Kit. ж albiflorus, $\beta$ violaceus. Auf Bergund Waldwiesen im Enns- und Paltenthale strichweise sehr gemein, besonders in letrterem, z. B. bei 'T'rieben, ob der Ledererhube bei Rottenmann, am Lichtmessberg neben dem Fusssteige nach Bärndorf hinab, auf der Buchau neben den Teichen. Variirt mit blanen, weissen und gescheckten Blïthen und zwar wachsen diese Varietäten meist nebeneinander.

226. Iris Psendacopus L. In Wassergrïben, Sümpfen, an Lachen und Teichen sehr häufig, vorzüglich zwischen Schilfrohr am Scheiblteich.

227. Iris sibiricia L. Auf saturen Wiesen, an Schilfrändern des Enns- und Paltenthales stellenweise sehr häufig; vor den Ennsarmen der Kruman erscheinen zur Blüthezeit weite Strecken blau gefärbt; auch in der Schultering und ror Franenberg tritt sie massenhaft auf.

\section{Fam. Orehileac R. Br.}

228. Orehis militaris L. Auf Wiesen und an grasigen Waldrändern nicht häufig: Schultering, Griesmayrwiesen, Kruman (Angelis!), Gesïuss (Strobl sen!).

220. 0. tridentata Scp. Auf buschigen Grasplïtzen der Berge und Vorilpen sehr selten: Am Schaflerweg und mm die Moseralpe (Angelis); sah sie nicht aus dem Gebiete.

230. 0. nstulata 1. An Waldrïndern, anf Triften der Berge und Voralpen nieht selten im Kalligelirge: Im Mïhlanerwäldchen zerstreut, am Schafferweg (Strobl sen.!), im Johusbacigraben, am Neuburg bei Johnsbach (IIatzi!), hinter Kaiserau gegen den Kalbling hin, um die Kochenalm.

2:31. O. corioplonal T. Anf nassen Wiesen des Eimnsthales selten: Neben der Griesmayrlache ziemlich hünfig, am Wege nach Franenberg und beim Abdecker seltener.

232. 0. crlobosa L. Auf Wiesen und Bergen der Voralpen bis $5000^{\circ}$ sehr hälnfig im Kalkznge ( $\%$. 13. vom unteren Boden zur Farchnerahn bei Johnsbach, an Scheiblstein, Pyrgas, Kaibling und dessen Vorbergen bis zor Kemetwand, an Natterriegel, auf der Ardning): viel seltener im Urgebirge, nur ob der Bacheralpe an ïppigen Abhängen rechts rom Grüusee häutig.

233. 0. Morio I. Anf einer Wiese des Lichtmessberges beim Drummer von Angelis cinmal gesammelt.

2:34. 0. pallens L. Im Dechantthale auf der Buchan (Altes Verzeichniss), auf der Moseralpe am Natterriegel (Tschurtschenthaler!): „im Eums- und Paltenthale* (Maly 1868). 
235. 0. sambucina 1. . Anf dem Vorgehirge (wahrscheinlich bei Hall) von 'I'schurtschenthaler gusammelt" (Her). Matri!).

236. 0. Inascula l. y speciosa (Hst.) Köh. Aul ïppigen Bergund Voralpenwiesen des Kalkzuges bis zur lírummliol\%egion sehr zerstreut und riemlich selten: Gegen die Stumpfuaglalm (Hatzi!), im Gesäuss (Strob] sen.), zwischen lirummlıol\% aun Pyrgas s. sellen, ziemlich lıäılig im Sulzkalı ob der Schälferhütte.

237. (). maculata 1. Gemein anf Inschigen oder waldigen Grasplitzen der Beroe und Voralpen anf Kalk, Schiefer, seltener Gneiss, \%. 3. Im Gesäuss, hauchborlen, am Scheiblstein, Pygas, Schatlerweg, Aufstieg zur Soheiblegrgerhochalpe, hinter Kaiserau, am Mühlanerfall etc. Ob der Bacheralpe anf folsigen 'l'riften rechts vom Grinusee ziemlich läutig (Gueiss).

238. (). latilolia 1. Auf Sumpf- mul Moorwiesen, atuch an schilfigen Sumplrïndern im Huns- mul Yaltenthale gemein; geht vielfach ïber iu die spouter blühende Varietät (†)

239. (). incalnata 1. Auf sumpligen Wiesen beim Griesmayr, um das Woltisbichermoos, zwischen Aigen und Framenberg sehr häufig mit voriger.

240. Anacamptis pramilalis (l.) Rich. Auf einer sonnigen, felsigen Bergwiese an der Haberl - Alm ob der Bucliau (Kalk) mit Cephalantera pall. zicmlich häufig (Hatzi!).

241. Hymmalemia conopsea (I.) R. Br. Auf nassen Wiesen der 'Thäler, Berge und Voralpen bis 5000' im Kalkgebiet gemein, viel seltener im 'l'anernzuge, z. B. a. Griesmayrwiesen, Gesäuss, um den Gamsstein, gegen die Farchueralm, am Scheiblstein, Pyrgas, Kalbling, im Sunk. $\beta$ Ol) der Bacheralm auf telsigen 'lriften rechts vom Grünsee häutig. Bisweilen, wie un die Griesweberalm, auch var. albiflori.

242. Gyum. odoratissima (J.) Rich. Auf Hriften, sowie au steinigen, buschigen Stellen der Berge und Voralpen im Kalkzuge bis 5000' mit der vorigen sehr häutig, z. B. in Gesïuss, Jolnsbachgraben und am Schafferwege sogal vorwicgend, seltener am Aufstieg zur Śchcibleggerhochahm, aul Vorbergen des Kalbling, an Scheiblstein, Pyrgas (bes. unter Krommholy), vou der 'Treflneralpe zum Reichenstein, in Schwarzenbachgraben etc.

243. liymu. albidal (1.) Rich. Auf 'lriften, buschigen oder waldigen Grasplätzen der Kalk- und Urgebirge (3500-6000') an vielen Stellen, aber selten in srösserer Anzalil, oft mit der folgenden, z. B. o. an Unterkalbling liälig, vom mnteren Boden zur Farchneralm. 8 an Waldrindern hinter Kaliserau (silus. Suhiefer), am Kanpl, un die Felsen der Hochlaide ob dem Griunsee häufigr, un den Sehciplsee, zun Böscustein himanf (Gneiss).

244. Coclughlossum viricle (1.) Hrtur. Fast ïberall auf 'Iriften und buschigen Abhängen des Kalk-, Schiefer- und Gneisszuges in der höheren l3erg- bis Alpenregion (- 6000), alyer meist sehr vereinzelt, z. B. \%. Kalbling, Scheiblstein, Pyrgas, Schaflerweg, Aufstiegr zur Scheibleggerhochalm, Hochthor, Farchueralı, Hund, Sumk. P Hoch- 
schwung. ๆ Strassenränder hinter Hohentanern, ob der Bacheralpe, ob dem Scheiplsee, ain Bösenstein.

245. Platanthera bifolia (L. p. p.) Relıb. Auf üppigen Bergwiesen, an Waldrändern und buschigen Stellen häufig auf Kalk, seltener auf Schiefer, z. B. durch's Gesäuss, im Johnsbach- und Bruckgraben, ob der Gsattmayrvoralpe, am Aufstieg zur Scheibleggerhochalpe, an grasigen Waldrändern ob dem Franenfelde, am Schafferweg etc.

246. Nigritella angustifolia Rich. $\Lambda$ uf Wiesen und grasigen Abhängen der Voralpen und Alpen bis $6000^{\prime}$ sehr häufig im Kalkgebirge, vorzüglich an krummholzumschlossenen Stellen, z. B. von der Hundslı̈lıe links in's Sulzkahr hinah, am Natterriegl, Scheiblstein, Pyrgas, Kalbling, von der 'Treffneralpe zum Reichenstein; stellenweise anch häufig im Urgebirge (\%. B. von der Scharte des Hochschwung bis zur Spitze am Südabhange s. hfg., ob der Bacheralpe, rechts vom Grünsee, vom Gemeinsee gegen die Kante der Hochhaide linauf), hier aber mit schwarzpurpurnen Blüthen (v. atropurpurea), während die des Kalkzuges karminroth sinı.

247. Nigruit. suavoolens (Vill.) Koch. „Am Rottemmanner Tauern (Hatzi)" Maly Flora 1868. Die von mir gesehenen Ex., welche Oberleitner anf Alpenwiesen ob der Bacheralpe gesammelt und als suav. bestimnt hatte, waren vorige; auch in Hatzi's Herbar sah ich aus dem Gebicte blos vorige; suaveolens find Hatzi nur am Hochwart; dieser Berg liegt allerdings der Gränze ziemlich nahe und dürfte daher die Art auch im Gebiete anfzufinden sein.

248. Oplurys muscifora Ilds. Auf selattigen Grasplätzen dè Kalkvorberge un Admont selten: Am lä̈ufigsten auf Abhängen ob der Siegelalm und von dort zerstreut bis zum Schafferweg, wo an einer Stelle noch eine kleine Gruppe sich findet; sonst hie und da ein Exemplar in Walde unter der Pitz, im Johusbachgraben ete.

249. Chantanolehis alpiua (L) Rich. Auf steinigen, kurzgrasigen Ablı̈ngen der Kalkhochalpen sehr selten: An Kalbling von Hatzi einmal in ziemlicher Menge, am Pyrgas von Oberleitner mehrmals, am Scheiblstein von mir einmal gesammelt.

250. Herminimm Monorchis (L) R. Br. Auf sumptigen Wiesen, schattigen Rainen und Weiden, an Waldrändern, bis in die Voralpen auf Kalk und Schiefer zicmlich häufig: Sumpfwiesen an der Enns, lei Röthelstein, beim Galgen vor'm Griesmayr, Raine gegen Weng, Waldränder vor dem Gesïuss (hier hfg.), Weiden vor dem Wolfsbacherwasserfall, auch im Gesïuss, am Schafferweg (Angelis) etc.

251. Fpipogum aphyllum (Schm.) Sw. Auf einem faulenden Baumstrunke am Schafferwege vou Steyrer cinmal gefunden, seitdem vergebens gesucht; auf nadelbestreutem Waldbodeu ob der Weberalm am Aufstiege zur Kemetwand selı selten.

252. Cephalantlera grandiflora (Scop.) Bab. Auf buschigen Abhängen und in steinigen Bergwäldern der Kalkzone nicht selten: Vor dem Pitzfelsen im Waldboden bis gegen die erste Pitzhöhe ziemlich häufig, am Aufstieg zur Sclieibleggerhochalpe ob dem Kalk- 
ofen selten, auf einer steinigen Bergwiese der Buchan an der Haberlalm (Hatzi), vom Wolfsbacher durch den Wald zum "unteren Boden" nicht selten; vereinzelt auch unterhalb der Kochenalm ete.

253. Ceph. Xiphophyllum (I. f.) Rehb. In Wäldern auf Kalkboden sehr selten, nur hie und da ein Exemplar, z. B. im Gesäuss (Strobl sen., Angelis) beim ,unteren Stein" im Gesïuss, unterhalb der Kochenalm, im Lafliwald (Tschurtschentlıaler); ,am Kalbling" (Maly 1868).

254. Coph. rulura (I.) Rich. Noch seltener als vorige, an ähnlichen Standorten. Im Laffiawald (Augelis), in einem Tichtenwalde des Johnsbachurahens yon der ersten Kohlhiitte einwïrts aul Kalkschotter sehr spärlich.

255. Epipactis ruliginosa (Cr.) Gd. An steinigen, buschigen oder waldigen Stellen der Berge und Voralpen im Kalkznge fast überall, aber selten in grösserer Menge: durch's Gesiuuss, im Johnsbachgraben, Rauchboden, Bruckgraben, Lafficwald, unter der Griesweberahn \%. hifg., im Hühlanerwäldehen, am Scheiblstein, Pyrgas, Schatlerweg, anf' allen Vorbergen des Kalbling, um den Gamsstein, im Sunk ete.

256. Ip. Iatifolia All. In schattigen, steinigen Wälderu der Kialkvorberge schr zerstreut und vichleicht spätblïbende Schattenform der vorigen: Vom Schafterweg zur Scheibleggervoralpe nicht selten, an Aufstieg zur Scheibleggerhochalpe, zur Pitz, zur Gstittmaylvoralpe, am brocksattel, im Hanswalite unter Strechan ete.

257. Ey. palustris Cr. Auf Sumpl- und Moorwiesen der Kruman, an den linusarmen daselbst, um die Griesmayrlache sehr häufig, ebenso im Paltentliale (Angelis!); seltener anf fenchten Triften der Berge und Voralpen, z. B. vor Gstatterboden im Gesäıss, am Kalbling, Pyrgas.

258. Listera ovata $\left(\mathbf{I}_{3}\right)$ R. Br. Auf fenchten 'Thal- und Bergwiesen, besonders an schattigen Stellen, bis anf die Voralpen sehr häufig, z. B. neben den Eunsarmen unterlaalb der Sautratte, im Stiltsgarten (vorzinglich un die Schiessstätte), durch's Gesïuss, im Lichtmessberge, zwischen Stranchwerk ob der Gstattmayrvoralpe ete.

259. List. cordata (L) R. Bir. In feuchten, moosigen Wählern, an Rändern schattiger Hohlwege hie und da, besonders anf Sehiefergrund, doch ziemlich selten: Am Beginn des Schallerweges im Hohlweg, vom oberen Ende des Veitlgribens gegen den Nigelschmied, besonders am linken Wegrande (Hatzi), im Veitlyrabun (Angelis), neben der Fihrstrisse nach Lichtmessilorf hinal, rom biarndorfer Wegzeiger an ziemlich lıäntig, „an Kalbling" (Nlaly 1868), ob der Lorenzuer Pfarrerhub in Fichtenschatten neben dem bilche selten, rom innersten Wiukel des Triebenthales durch den Wald zur Kettenthalalm hinauf n. slt.

260. Teottial nilus avis (L.) Rich. In fenchten Fichteuwildern der Berg- und Voralpenregion anf Kalk und Sehiefer nicht selten: Am Schallcrwege ziemlich häufig, am Aufstieg zur Scheibleggerrorund -hochalpe, im Johnbachgraben. 
261. (ioodyeri repens (L.) R. Br. In moosigen, feuchten Fichtenwälder'n der Berg- und Voralpenregion anf Kalk und Schiefer meist truppweise, nicht selten: Im Dolomitgerölle des Schwarzenbach's (Stur), am Weg in's Gaisenthal (Angelis), im Gstatterboden und am Kaderalbl (Hatzi), am Aufstieg zur Scheibleggerhochalpe z. hfg, rom Schafierweg zur Scheibleggervoralpe, im Sunk selten, am Steinamandl neben dem Almwege zur Globuke (Gneiss).

262. Corallorrhiza imata R. Br. In fenchten, moosigen Fichtenwäldern der Voralpenregion im Kalli- und Tanernzuge sehr zerstreut und vereinzelt, obwoll an vielen Standorten, z. B. Am Aufstieg zur Scheibleggervor- und -hochalpe, Almsteig, Niederkalbling, vor'm Mühlanerfall (Angelis), am Pyrgas (Oberleitner und Hatzi), ob der Lorenzener Pfarrerhub am Standorte der Myosotis variabilis ete.

263. Malaxis paludosa (L.) Sw. In 'Torfmooren des Ennsund Paltenthales auf schwammigen Sphagneen-Polstern sehr selten: Im Paltenmoore bei Trieben ziemlich häufig, schon von Sommerauer und Stur gesammelt, im Hofmoore bei Admont nur in 1 Ex. entdeckt.

264. Microstylis monophyllos (L.) Indl. An moosigen, schattigen Abhängen der Berge und Voralpen, besonders an Waldrändern und in Wäldern fast im ganzen Gebiete, aber sehr zerstrent und die Standorte wechselnd, so dass man sie an vorjährigen Fundorten oft vergebens sucht; wurde gefunden am Eingange in's Gesäuss, am Fusssteige ïber das Kaderalpl (Hatzi!), im Johnsbachthale (Sommerauer), im Bruckgraben, beim Kolılenbau des Lafiawaldes, am Schafferweg (Hatzi!), hinter Kaiseran und am Wege zur Stumpfuagleralm (Angelis), in Waldrindern neben der Strasse nach Aigen und ausser der Klaus gegen die Kapelle himauf häufig (Schiefer), im Hauswald unterhalb Strechau, besonders gegen Lassing hinaus, häufig, am Blahberg und im Walde ob dem Sunk.

265. (ypripedium Calceolus L. An steinigen, buschigen Stellen, an Waldrändern und in Wäldem der Berge nud Voralpen bis in die Krummholzregion durch die ganze Kalkzone, aber meist vereinzelt oder in kleinen Gruppen: Durch's Gesäuss, besonders um den Ausgang des Bruckgrabens und vor der Johnsbachbrücke häufig, im Johnsbachgraben s. selten, durch den Schwarzenbachgraben und zur Griesweberalm hinauf nicht selten, an Mühlauerfall (Angelis), von der Gstattmayrvoralpe durch den Futterweg zum Scheiblstein slt., am Aufstieg zur Scheibleggerhochalpe z. hfig., am Schafferweg und zur Scheibleggervoralpe s. slt., hinter Kaiserau selten, anı Unterkalbling (Angelis!), durch die Flietzen (Angelis!).

\section{Fam. Najadeae Rich.}

266. Potamogeton matans L. In Lachen, Sümpfen, Teichen und stagnirenden Wasserarmen des Enirs- und Paltenthales häufig, z. B. in den Enusarmen der Krumau, im Scheiblteich, Triebnersee etc., höchster Standort: die Tauernteiche. 
267. Pot. rufescens Schall. In dem rou der Palte durchflossenen 'Triebnersee sehr häufig; .im Ennsthale* Maly 18 is ist wohl unrichtig.

268. Pot. Incens I. In Teichen und Lachen des Eunsthales: Im Stiftsteiche sehr häufig, im Scheilulteich der Krumau. in einer grossen Lache westlich von del Schultering.

269. Pot. perfoliatus 1. Ceberzieht in den stagnirenden Ennsarmen der Kruman weite Strecken.

270. Pot. (rispus l. In den kleineren Stiftsteichen sehr häufig. ebenso im Scheiblteich der lírumau, besonders neben der dbzugshütte.

271. Pot. jusillus L. F rulgaris Koch. In stehenden oder langsam fliessenden Gewässern ziemlich selten: Im Triebnersee (Angelis!), in einer von Weiden umsäumten Lache am ostlichsten Ende der Griesmayrfelder neben der Enus, in den Enmsarmen westlich ron der Marktschiessstätte häufig.

272. Zanichellia palnstris $\mathrm{L}$. An und in dem Bache, welcher von der Griesmayrlache ostwärts fliesst, besonder's bei der Brücke häufig: an tieferen Stellen lang fluthend, an den Rüuderu kriechend.

\section{Fam. Lemnaceae Endl.}

273. Lemna minor L. In Wassergräben, Lachen, Teichen sehr gemein, z. B. am Südrande des Hofmooses, bei der Ziegelbrennerei, in dem grossen Stiftsteiche.

274. L. polyrrliza I. In Lachen und Teichen sehr häufig zwischen der rorigeu.

\section{Fam. Aroideae Juss.}

275. Arum maculatum L. Unter den Spalieren des Stiftsgartens ron Admont sehr gemein, wahrscheinlich einst eingeführt.

276. Calla pahustris L. An schattigen morastigen Stellen der Torfmoore sehr selten: Am Nordrande des Hofmoores in etwa 20) Exemplaren: im Unterholz höherer Fichten östlich rom Bichelmarrteich bei Frauenberg (Hatzi, Strobl sen.): anch in Torfmooren des Paltenthales nach Sommeraner (Herb. Joinnei).

277. Acorns Calamis L. In der Wolfsbacherlache (Altes Verzeichniss), an Wassergräben ror dem Scheiblteiche der hírumau.

\section{Fam. Typhaceae DC.}

278. Typla latifolia L. In Sümpfen und Teichen stellenweise: sehr bäutig am Ansgange des Triebnersee's, auch im hirmmauerschilf und in der Griesmarrlache (Angelis!).

279. T. angustifulia L. In Sümıfen, Teichen, an Ufern stellenweise: sehr bāutig in Scheiblteich der Liruman zwischen Schilfrohr. 280. Sparganium raunsum Hds. In Wassergräben, Lachen und Suimpfen häufig: Am Südrande des Hofmoores, unterhalb des Griesmayr beim Bretterübergange s. hfig. etc. 
281. Sparg. simplex Hds. In Wassergräben, Lachen, Sümpfen, Morästen des Enns- und Paltenthales nicht häufig: Am Nordrande des Hofmoores, beim Blasschnstergïtl b. Admont (Strobl sen.), in der Krumau; s. häufig im und um den Triebnersee, hier oft mit fluthenden Blättern.

282. Sparge. natans l. In einer kleinen Lache am Berge Loibner bei Johnsbach (Hatzi!).

\section{Fam. Alismaceae R. Br.}

283. Alisina Plantago I. In Sümpfen, Jachen, Wassergräben, sowie an schlammigen Uferstellen sehr gemein, z. B. bei der Ziegelbrennerei, in der Krumau, Schultering, im Hofmoos, gegeu Frauenberg, an Eunsarmen. Gewöhnlich a latifolium G. G., seltener (z. B. in den Enusarmen der Kruman) \& lanceolatum (With).

284. Scheuchyeria palustris $\mathbf{~ L . ~ A n ~ s c h w a m m i g e n , ~ t r u ̈ g e r i s c h e n ~}$ Stellen der Moore des Lims- und Paltenthales auf Sphagneen, z. B. im Hof-, Ardninger- und Triebner-Moore häufig.

285. Triglochin palustro L. Auf nassen Wiesen, feuchten Bergtriften und Waldwiesen, an Wassergräben und Sümpfen des Emns- und Paltenthales bis 3500' sehr häufig, \%. B. Vor'm Hofund Krumaner-Moore, an der Strasse zur Buchan und zum Nagelschnied, anf der P'itz, am Anfstiege zum Admouter Kalkofen, am Kaiseramerteiche, Gaishomsce etc.

\section{IVI. Fam. Callitrichineae Lev.}

286. Callitriche verua (L) Kt\%. In Lachen der Alpeu und Voralpen: Auf der Moseralpe (Angelis! = vir: minima Hoppe), am Wege zu den $\Lambda$ mhnïtten der Plösch häulig, um den Scheiplsee am Rottenmanner T'anem.

287. Gall. Iammlata Kitz. In stehenden Gewässern um Admont (Hatzi!); zicmlich häufig am südlichen handgraben des Hofmoores.

NB. „Call. autumnalis L. im Enns- und Paltenthale (Angelis)" Maly Flora 1868 ist höchstens eine linealblättrige Form der verna, etwa v. minima Hрp., aber jedenfills nicht die Pllanze Linné's.

\section{F'all. Betulacene Brtl.}

288. Betula verrucosa Ehrli. (alba subsp. 1. verruc. Regel DC. Pr.) Auf buschigen Hügeln, in Berg- und Voralpenwälderu des Kalk-, vorzïglich aber des Schiefergebirges sehr luäufig, aber meist gemischt mit anderen laub- und Nadelbäımen, selten in grösseren Gruppen.

289. Bet. alba 1. (alba sulssp. VII. pubescens DC Pr.) Auf Mooren, häufig am Nordrande des Holmoores neben einem Wassergraben.

NB. Bet. nana L. findet sich nach Maly Fu. 1868 „Auf den Gipfeln der Admouter Alpen (Gebhard)", in der 1. Aullage 1838 
steht blos .Judenburger Alien"; im Herbar des .Tohanneum liegen lixemplare mit der Etiquette "Almont"; dessungeachtet ist mir das Vorkommen in Gebiete mglaublich.

290. Mluns viridis (Vill) I)C. Auf somnigen Hïgehı, an Waldräudern des Paltenthales, anf Bergen und Voralpen des Sehieferund Gneissgebirges, besonilers dem Lante der Bäche ent\}ang bis zur Stranchgränze (etwa 6000') äusserst gemein, \%. B. lichtmessberg, Trieben, um den Scheiplsee, ob der Bacheralm, in der Strechen, Weissgulling ete.

291. Aluns corylifolia liomer. (Klemfriehtige líalk-Race der vorigen). '/wischen kirmmmholz der Kialkalpen ziemlich selten, z. B. am Buchstein, Scheiblstein, Kalhling.

292. Alı. inrinil (h) W. An Bach- unil Flussufern, in Auen höchst gemein, sehr häulig anch auf sonnigen Jïgehn und in Waldrändem; bildet die meisten Vorlölzer mil Haine.

293. Mlı. unhtinosa Girn. Auf Sumpfwiesen mu Mooren, sowie an den Rändern derselben hie und da häntig, im Allgemeinen aber viel seltener, als vorige: Selır hüulig im Wolfsbichermoore und in den nahen sumplwiesen, ebenso im Hofmoore, ziemlich häufig und in selır schönen txemplaren nahe den bichen des Hoffeldes, einige holıe Büume anch inn Westrande des oberen Krumanormoores.

\section{IVIII. Fam. Cupuliferac Rich.}

294. Fanus silvatica J. In Berg- und Voralpenwäldern der Kialk - und S'chiefer\%one bis ïber $4000^{\circ}$ sehr häulig, aber oft rerkrüppelt und meist vereinzelt unter Narlelhol\%. Selı schöne Bänme im Rauchboden, Bruckgraben und Lafterwald; reine, weun anch kleine Bestände ob dem Wolfsbaner und ror der liochenalm bei Mühlaı.

295. Quercus pedunculata Ehrh. Zwisthen Weidengebüsch an der Emus, auf sonnigen Willläudern bei Rottenmamu ete. ziemlich häufig. In der Lichelan und am Hoffelde bei Admont in sehr schönen Exemplaren gepflanzt.

NB. Q. sessiliflora Sm., die uach Maly 1868 ,in Obersteier ganze Waldungen bildet", (in iler 1. Auflage steht aber ,in Untersteier"), wurde im Gebiete nicht beobachtet.

296. Corylus Arellana L. Auf somnigen Hïgeln, an Bälehen, Waldrändern bis in die Krummholzregion der Kalkalpen, in tieferen Regionen sehr gemein.

297. Cirpinus Betulus L. Bildet grösstentheils die nach altfranzösischem Gesebmacke in Stiftsgarten gezogenen mäehtigen Spaliere, scheint aber im Freien nirgends vorzulommen.

\section{Fam. Ulmaceate Mirb.}

298. Limms montana With. (cannestris L. suec, major Rehb. f. 1335). In Hainen und Bergwïldern um Adment auf Kalk und 
Schiefer selten: Am Eingang in's Gesäuss zu beiden Seiten der Enns, links ob dem alten Kalkofen am Weg zur Weberalm, am Lichtmessberg unter der Ruppwiese ete.

\section{Fam. Urticaceae Endl.}

299. Urtica uresss I. Auf wüsten Gras- und Schuttplätzen, an Häusern und Wegen sehr gemein.

300. Lrt. dioica L. \% vulgaris DC Pr. Auf wüsten Plätzen, an Wegen, Züunen und Gebäuden höchst gemein, auch noch um die Hüiten der Voralpen. Bisweilen selbst am Fusse von Kalkfelsen der Alpenregion, aber wahrscheinlich von Schafen hinaufverschleppt.

\section{Fam. Cannabineac Endl.}

301. ('annabis sativa $\mathbf{I}_{\text {. }}$. Hie und da gebant, anch nicht selten auf wüsten Plätzen, Erdauswürfen, an Zăunen und in der Nähe mensehlicher Wohnungen rerwildert.

302. Humulus Lupulus I. An Gebüschen, Hecken und Zännen ziemlich häufig, z. B. an den Enusufern.

\section{Fam. Salicineae. Rich.}

303. Salix Babylonica I. Im Friedhofe von Rottenmann mehrere Ex. kultivirt.

304. S. albal L. (und \& vitellina L.) An niederen Uferstellen, auf Weiden- und Wiesenrindern, an Wegen, selnr gemein im Ennsund Paltenthale, besonders in der Sautratte, Krrumau und bei Lichtmessdorf; $\partial$ coerulea (Sm.), deren fast kahle ältere Blatter bis auf den minderen Glanz mit S. Russeliana Sm. nach Koelischen Originalen ganz übereinstimmen, ist hänfig von der Ennsbrücke bei Admont gegen die Essling linauf und bei der Brücke im Studentenbad. fragilis L. fehlt im Gebiete.

30.5. s. triandrat L. o. discolor Kocl. An Uferstellen, in Auen, auf sumptigen Wiesenränden sehr häufig im Enns- und Paltenthale, z. B. längs der Enns und Palte, am Triebnerbache, am Hoffelde. is concolor fehlt.

306. S. daphnoides Vill. An Ufern, Zämen, auf Weiden-, Wiesen- und Waldründern bis anf die Berge sehr verbreitet, aber mehr vereinzelt, z. B. an Ennsarmen unterhalb des Hoffeldes, in der Sautratte und Krumau, gegen Mühlau, Weng, Gesïuss, am Lichtmessber. und durch's Paltenthal. Liefert die "Palmbuschen" und ist deshalb um Banernhöfe häufig angepflinzt.

307. S. purpurea L. An überschwemmten Orten, Ufern der Flüsse und Bäche, Wegen und Zäunen der Tief- und Bergregion (z. B. um die Gstattmayrvoralpe) sehr gemein.

308. S. incana Sclirk. Auf überschwemmten Niederungen, auf Kalkschutt der Giessbäche, an Fluss- und Bachuferu, besonders des 
Ennsthales und seiner Seitenschluchten schr gemein, anch noch um die Gstattmayrvoralpe.

309. S. cinelea L. Auf sumpfigen Wiesen, an Wassergräben, Sumpf-, Moor- und Fhssrïndern gemein; Angelis sammelte Rxemplare, an denen die Fruchtknoten in Staubblüthen übergehen ( $f$. degenerans); ror dem Hofmoore fand ich einen Strancl mit lichten, meist verkehrt-eirunden Blättern (nach Rchb. Ic. $=₹$ aquatica Sm.)

310. S. nigricans Sur. * lejocarpa. An Ufern der Funsse und Bäche, an Wiesen- und Moorrändern, auf waldigen Hügeln gemein, vorzüglich auf Schieferkrume, seltener auf Kalkschutt; steigt selten bis in die Krummholzregion, wo sie, z. B. ob der Kochenalm an einer Schütt, in glahra Scop. überzugehen scheint. Dic Blätter rariiren ganz ausserordentlich, oft anf demselhen Stranche von grasgrïn bis seegrün, von lanzettlich bis eirund, von kahler bis filziger Unterseite.

311. S. silesiaca W. An einem Alpenhache ol, dem Scheiplsee (Gneiss c. 5000') am Aufstiege zum Bösenstein; Bestimmung noch etwas zweifelluaft. da ich nur Blattexemplare fand.

312. S. Erandifolia Ser. Auf buschigen Hiigeln, felsigen und sandigen Abhïngen, in Schluchten, Berg- und Voralpenwäldern der Kalkzone bis unter das Krummholz äusserst gemein und formenreich; selten in Schieferschluchten (z. B. Wolfsgraben, zur Bacheralpe hinauf). An fencliten, schattigen Orten ist der Stranch hoch, die Aeste schlank und geschmeidig, die Plätter gross. länglich, dmmkelgrinn: anf durrem, somnigem Kalkboden nierrig knorrig mit nur 1-11/2" langen, olivengrünen, verhältnissmïssig hrciteren Blättern mil nicht selten anch flammigen Aestchen: am Mühlanerfall sogar Exemplare mit theilweise granflammigen Ḱnospen, ebenda ein Stranch mit schmal-lanzettlichen Blätter", vielleicht ljastard mit incana: zwischen den Lxtremen zahlreiche Mittelformen.

313. S. Caprea I. An Bächen, auf buschigen Stellen, am Rande der Vorhülzer und Wälder dureh's Enus- und Paltenthal häufig: An der Enns ron der Schultering an. hinter Röthelstein, in Aigen, Franenberg gegenüber, 7. B. ob dem Prrgasgatterl hïufig. ob der Schäferlun̈tte am Kalblingbache zwischen arbuseula und glabra rereinzelt: Sommeraner sammelte sie am Flitzenbache am Fusse des Kalbling als rar. "sphacelata W. (Herb. Joannei).

314. S. andita L. An Wiesen- und Waldrändern, anf buschigen Hügeh fast selten: Stumpfnagleralm, Weg in 's Gesïmss (Angelis), "Hoffehl, Wiesen bei Armont" (Strobl sen.!), neben der grossen Kalkschütt ob der Kochenalm in einer schmalblïttrigen Abart selten. häufig rom Farchner nach Franenberg längs der Fahrstrasse.

315. S. crlahua scop. Auf steinigen Abhängen, im Felsschutt der Voralpen und ihrer Giessbäche, besonders in der Krummholzregion des Kalkzuges gemein, häufig auch herabgewandert in die Schluchten der Vorberge: meist var. 1. latifolia And., doch auch val. 2. angustifolia Anu. nicht selten: z. B. Kemetrand, Kochenalm, Mühlanerfill. 
316. S. lasstata L. 3 subalpina And. An grasigen, steinigen Abhängen in der mittleren Alpenregion des Kalk- mnd Tauernzuges an wenigen Punkten: Auf der Ostseite des Hund-Ueberganges zwisehen Krummholz gegen die Schutthalden hinab häufig (Kalk); zwischen den Felspartieen des Hochschwung (Gl. Schiefer, 5000') auf üppigen Triften häufig: im Herh. Hatzi sah ich anch Exemplare ron "Felsen der Pitz".

317. S. angustifolia Wlf. In ansgetrockineten Wassergräben der Schultering ror dem Hofmoore. Stimmt ganz mit Rubb. Abb. TA. 58s. Fg. 1238 ïberein.

318. S. repens L. \& rulgaris Koch. Anf Sumpfwiesen und Mooren des Enns- und Paltenthales häufig, z. B. Schnltering, Hofmoos, Tolfshachermoos, Triebnersümpfe, Kaiserauer- Wiesen.

319. S. Arbuscnla L. a erecta And. 2. oralifolia And. (Waldsteiniana W.) Auf steinigen oder buschigen Abhängen, sowie im Felsschutt der mittleren Kalkalpenregion, besonders zwischen Krummholz, sehr hänfig, steigt nicht tiefer herab; im Gineisszuge nur bei $5500^{\prime}$ an der Norlostseite des Hochschwung (nicht selten) beobachtet.

NB. S. Lapponm L. "Anf der Griesmayralpe (Widtermann)" Maly 1868. „Am Fusse des Kalbling" Maly 1838. Beruht wohl auf irriger Bestimmung.

320. S. Jaequiniana $\mathrm{W}^{r}$. Anf grasigen, steinigen und felsigen Abhängen der höheren Kalkalpen (5-7000') hänfig: An Felsen unterhalb der Schatleithen bis anf den Rücken des Kalbling, am Bach der Scheibleggerhochalpe, an den höchsten Erhebungen des Scheiblstein und Prrgas n. slt., gemein am Fuss des "Hund " bis über die Sattellı̈he und in's Snlzkahr hinab an grasigen Stellen: sehr selten herabgeschwemmt rom Buchstein in die Buehanerschn̈tt. Reife Kapseln stets kahl, grïn bis jmrpursehwarz.

321. S. peticnlata I. \% typica glabra And. Anf steinigen und felsigen Alhängen, seltener auf Triften, ler Kalk- md Gneissberge $\left(5-6500^{\prime}\right)$ ziemlich hïnfig: Ob dem, Hund", auch schon weit unterhalb der Farchnerahm gegen den rechts sichtbaren kleinen Wasserfall, am letzten Absatze des Scheiblstein, ant der Scheibleggerhochalpe, am Schafweg des Kalloling muter den Felsen der Schatleithen z. hfg.; sehr länfig an den nordustlichen Ablängen des Hochschwung (Gneiss, $\left.5-6000^{\prime}\right)$.

322. S. petusa L. Auf steinigen und felsigen Abhängen der Kalk - und Urgebirge $\left(5-7500^{\circ}\right)$ is rulgaris Koch und $\gamma$ Kitaibeliana (IV) schr gencin, oft in Ciesellschaft und in einander ïbergehend: $\alpha$ serpyllifolia (Scop.) viel seltener, auf den höchsten Felskämmen, anch üfters mit $\vec{i}$ und $i$, aher ohne merkliche Uebergänge, z. B. am Rï̈eken der Hochhaile rom Mitterstein hinanf, Bösenstein, Kalblingrücken, Hochschwung, in den Jolnsbacheralpen.

323. S. herbacea L. Auf steinigen Abhängen der höchsten Alpenregion des Büsenstein sehr selten (Gueiss): wrirle ron Strobl sen. auch auf der Spitze des Pyrgas (Kalk, 7200') angegeben, ich fand aber daselbst nur '/wergocemplare der retusa $\hat{\beta}$ Vulgaris; anf den Gneissalpen des oberen Ennsthales etwas hänfiger. 
324. Populus tremula L. In Auen, auf buschigen Hügelu, an Waldrändern hie und da, meist vereinzelt: An der alten Einns bei Admont, am Westende der Schultering an Schilfrändern häufig stranchartig, am Aufstieg zur Pitz, auf Hügeln zwischen Dittmannsdorf und Gaishorm, im Stiftsgarten.

325. Pop. nigrpal I. An Eunsufern \%wischen Wcidengesträuch häufig unterhall des Hofleldes, in der Sautratte und Krumau, an Wegrändern ron der Enusbrücke \%ur Essling etc., doch stets stranchartig.

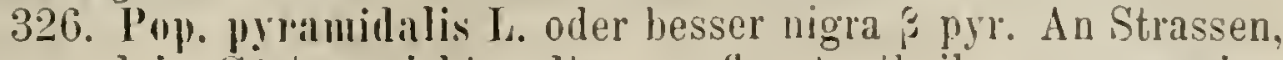
Wegen und in Giilten nicht selten geptlanzt, theils gruppeuweise, theils in Alleeen, z. B. Stiftsgarten, Thallof, ron St. Georgen zum Bahnhof: hänfig anch an Kapellen und Statuen: selten rereinzelt. gleichsam wild.

\section{Fam. Chenopodeae Vent.}

327. Chenopodium hỵhridum I. An Wegen, Höusern, auf Schuttpliitzen und in Gïlten ziemlich häufig, z. B. um die Klamm bei Rottenmann, im Stiftsgarten, im Dechantgarten ron Rottenmann.

328. Ch. Irloicum L. \% deltoideum (Lam.) Auf Schutplätzen, wüsten Stellen, an Häusern, Wegen selten: Von der Ennsbrücke gegen den Abdecker linab, ror der Stiftskirche (Strobl sen.!).

329. ('l. allım I. Auf Schutt, wïsten Grasplätzen, an Häusern, Wegen, Zäunen ïusserst gemein.

330. Cl. polyspermum L. In Gürten, Feldern, anf Grasplätzen, an Wegen häufig, z. B. bei den Zirbelbälumen les Stiftsgartens, in Hausgiilten $1 \mathrm{~m}$ Adimont.

331. (H. bomus Henricus L. Auf Sehuttplätzen, an Hüusern, Wegen, Zïunen sehr gemein, häutig auch 1 m die Almhütten der Kalkkette, z. B. Gstattmayralpe, Stumpfnagleralm; steigt aber noch viel höher bis ïber $10000^{\prime}$, z. B. häutig in Erdfïllen des Scheiblstein mit Aronicum seorpioides, am Fusse der Felswäude links ob dem Hund bei Johnsbach ete.

NB. murale L, Vulvaria L, glancum $\mathrm{L}_{\text {, }}$ nach Maly in ganz Steiermark gemein, wurden im Gebiete nirgends beobalitet.

332. Blituı capitatum L. Auf Gartenauswïrfeı, an wïsten Plitzen hie mul da rerwildert, z. B. hinter der Ziegelbrennerei ron Armont, an dor Nagelschmiele des Lichtmessherges, in Stiftsgarten.

338. Beta rulgaris L. In Ginten sehr häufig kultivirt.

334. Spinacia uleracea L. In Gïrten häufig als Geınūse gebaut. 335. Atriplex hortensis 1. Wie rorige, hisweilen anch $\beta$ rubla Hrt.

336. Atı. patula I. \% genuina G. G. Auf Schuthauten, wiisten unl bebauten Stellen, an Wegen, Hänsern, Rainen selı häufig, z. B. im Uinkreise der Stiftsmaner, in den Stiftshölen, um Armont, Rottenmann. 


\section{Fam. A maranthacene R. Br.}

337. Amaranthus retroflexus T. An Schnttplätzen und Strassengräben bei 'Trieben (Hatzi, Strobl sen.!).

\section{Fam. Polygoneate Juss.}

338. Rumex maritimus I. Im zweiten kleinen Stiftsteiche auf Schlamm anno 1867 sehr häufig gefunden, selten unter Hafer am Westende des Hoffeldes vor dem Hofmoosstiegl; an Sümpfen (Strobl sen.).

339. R. conglomeratus Murr. Auf Weiden, wüsten Stellen, an Häusern, Wegen, Sümpfen sehr gemein; steigt bis auf die Voralpen, wo er um die Almhïtten hïufig sich findet.

340. R. crispns L. Auf Sumpfwiesen, an Gräben, Teicheu, Wegen und wïsten Stellen gemein.

341. R. olotusifolius L. Im Gehiete selten, bisher nur von Angelis in der Schulteringwiese gesammelt!, und in einem alten Verzeichnisse ohne näheren Standort aufgeführt.

342. R. aquaticus I. An Ufern, Wassergräben, in Sümpfen häufig: An den Rändern der Ennsarme in der Krumau s. hfg., auf Sumpfwiesen unterhalb der Ziegelbrennerei, an Wassergräben beim Temmelteich, von Aigen in's Selzthal an verschierlenen Stellen hfg., im Triebnermoos.

343. R. a]piums I. Auf feuchten Grasplïtzen der Alpen, vorzüglich um die Almhütten, wo er meist gepflant ist, sehr gemein, im Kalk- und Urgebirge, oft auch schon um die Hütten der Voralpen, z. B. vor Kaiscrau unter der Vogelbeerallee, um die Weberalm, Farchneralm.

344. R. scutatus $\mathrm{L}$. Auf steinigen Ablängen und im Schutte der Kalkalpen überall sehr gemein, von den Giessbächen häufig bis in die 'Thalschluchten herabgeschwemmt, z. B. im Bruckgraben, Gesäuss, Johnsbach- und Schwarzenbachgraben, am Mühlauerfall. Auch anf ähnlichen Stellen des Hochschwung sehr häufig, sonst im Gneisszuge seltener. Im Kalkznge meist var. $\beta$ glaucus (Jcq), seltener, im Gneisszuge aber immer, $\alpha$ viridis; in Gesäuss anch häufig var. monstrosus Meisu. Im Stiftsgarten aneh kultivirt.

345. R. alrifolius All. An fenchten Abhängen, auf üppigen Wiesen der Voralpen und Alpen im Kalk-, sowie im Gneisszuge sehr hänfig, z. B. $\alpha$ In der Waldschlucht zwischen Stumpfnaglund Scheibleggerhochalpe (bes. am Bache), unter Krummholz am Scheiblstein und besonder's gemein in Schneegruben zwischen Scheiblstein und Pyrgas, am Kalbling, vom "mittleren Boden" zur Farchneralm und an Hund bei Johnsbach ete. $\beta$ Ob dem Grünsee $11 \mathrm{~m}$ die Felswände der Hochhaide, auf Höhen im Umkreis des Scheiplsee's, in der Flietzen.

346. R. Acetosa I. Anf Wiesen, Feldern, Grasplititzen, an feuchten und buschigen Stellen sehr gemein bis in die Krummholz- 
region der Kalkgebirge und die Grünerlengebüsche der Tanernkette, z. B. Scheiblstein, Kalbling, Bösenstein, Steinamandl.

347. R. Acetosella I. Auf Feldern, Weiden, Torfmooren, Wegrändern, trockenen Abhängen, im Kalkschutt bis auf die Alpen (z. B. Spitze der Pïösch, Hölleralm, unter der liohen Kalblingmancr 5500') sehr hüufig, meist $\alpha$ hastatus Nlr.; $\beta$ angustifolius Koch fast ausschliesslich anf 'Torfmooren und im Kalkschutt.

348. Oxyria digyna (L.) Campd. Auf feuchten, felsigen Abhängen der Nordseite iles Hochschwung (Glimmerschiefer 6-6400') hie und da nicht selten, nach Stur auch am Bösenstcin (Gneiss); "Admonter Alpen" Maly 1868 ist unrichtig.

349. Poly'unum Bistorta I. Auf fenchten Wiesen im Ennsund besonders in Paltenthale gemein, z. B. Hofwiese, bei Bruckmühl, Bärndorf; seltener auf Bergen und Voralpen, z. B. Wiesen ob dem Sunk.

350. P. viviparum I. An Waldrändern des Ennsthales auf Kalkschotter (vor'm Gesäuss, vor Mühlan, durch's Gesäuss), auf Wiesen, Weiden und steinigen Abhängen der Kalkvoralpen bis in die Hochregion $\left(-7000^{\prime}\right)$ gemein; seltener im Schiefer- und Gneissgebirge, z. B. um den Kaiserauerteich, am Hochschwung, Bösenstein, rom Mitterstein zur Hochhaide hinauf.

351. P. amphibimm L. $\alpha$ natans Mnch, $\beta$ coenosum Kch, $\gamma$ terrestre Leers. In Lachen, Teichen und stagnirenden Flussarmen

๙ gemein, z. B. Ennsarme, Stiftsteiche, Scheiblteich, Frauenbergersümpfe; oft anch ( $\beta$ und $i$ ) an trockneren Orten.

352. P. tomentosum Schrk. (lapathifolium Aut., non L.) Auf Feldern, Aeckern, an Wegen, wüsten Plätzen, Teich- und Sumpfräudern $\alpha$ viride überall höchst gemein, $\beta$ incanum $(W)$ im Schlamme der Stiftsteiche und Ennsarme sehr häufig.

353. P. Persicaria I. An überschwemmten Stellen, Wassergrïben, anf feuchten Aekcrn und wüsten Plätzen selı häufig.

354. P. minus Hils. An Teich- und Sumpfrändern, Wassergräben, Erdauswürfen, feuchten Wegrändern häufig, z. B. um die Ziegelbrennnerei, am Temmelteich, an Ennsarmen, in Bassin's des Stiftsgartens, bei Trieben, Lorenzen.

355. P. Hydropiper I. An feuchten Sumpf-, Teich-und Bachrändern, an Wassergräben gemein, bisweilen massenhaft, z. B. in abgelassenen Stiftsteichen.

356. P. aviculare I. Auf Aeckern, Weiden, wïsten Stellen und an trockenen Wegrändern ausserst gemein; variirt im Habitus von \% prostratum bis $\beta$ erectum, nach den Blättern von $\alpha$ angustifolium bis $\beta$ latifolium (bis 5 "Breite), in den Blüten von $\alpha$ sparsiflorum bis $\beta$ densiflorum.

357. P. Courolvulus L. Auf Saatfeldern, an Feldrainen und Wegen gemein, besonders ïppig auf Lehmboden der Ziegelbrennerei von $A$ dmont.

358. P. dumetorum I. An Zäunen um Admont (Strobl sen.), bei Dittmannsdorf, häufig auf Strauchwerk am Westende der Schultering. 
359. Fagopyrum esculentum Mnch. In neuerer Zeit auf dem Hof- und Franenfelde bei Admont gebaut.

\section{Fam. Santalaceae Br.}

360. Thesium alpinmm L. Auf grasigen Abhängen und steinigen Triften der Kalkkette von $6000^{\prime}$ abwïrts sehr luäufig, besonders in der Krummholzregion, aber nie gesellig; anch tiefer herab an Waldund Giessbachrändern, sowie auf Kalksandhügeln ziemlich hänfig, z. B. durch's Gesïnss, am Mühlanerfall, im Schwarzenbachgraben; seltener im Gneisszuge: un den Scheiplsee, von der Bacheralpe zum Grünsee unter Felswänden.

\section{Fam. Daphnoideae Vent.}

361. Daphue Mezereum L. Zwischen Gebüsch, in feuchtschattigen Schlnchten, an Wahlrändern von der Ebene bis in die Voralpenregion des Kalk- und Schieferzuges sehr lı̈̈nfig, z. B. Sautratte, Schaflerweg, Weg nach Mühlau, Aigen, Aufstieg zur Scheibleggerhochalpe, zur Höllerahm, im Ranchboden, un Strechan.

362. 1). C'ncor'mu L. Anf steinigen Abhängen und lichten Waldstellen am Fusse der Kalkgebirge hie und da häufig: Am Fuss des Himbeersteines in Gesä̈uss, ron Gistatterboden bis Johnsbach, auf der Pitz am Dörflsteiı.

363. 1). Laureola L. In einem Walde zwischen S. Gallen und Lausach, allerdings schon etwas ausserlall, des Gebietes, spärlich.

\section{Fam. Aristolochieae Endl.}

364. Asarum emropaenm T. Unter Gebüsch, an Waldrändern, auf schattigen Rainen und Hügeln häufig (Kalk, Schiefer und Allnvium), \%. B. unter Alleeen im Conventgarten, von der Ennsbrïcke gegen die Essling unter Weiden, in der Santratte, am Mühlanerfall, Anfstieg zur Pitz, im Heindlfeld.

\section{Fam. Plantagineae Vent.}

365. Plantago major L. An Wegen, Uferm, Rainen, auf wüsten Stellen selı gemein; die Zwergform Pl. minima DC. vorzüglich an schlammigen Fluss- und Teichrändern, z. B. an Stiftstcichen, Ennsarmen, im Hofmoore.

366. Pl. media I. Auf Wiesen, Grasplätzen, an Wegen und Rainen änserst gemein bis auf die Alpen; rar. ramosa beim Neubauern am Schafferwege selten.

367. Pl. lanceolata L. \% vulgaris. Anf Wiesen, Triften, an Wegen und Rainen äusserst gemein; $\beta$ pumila Kch. viel seltener auf sonnigen Hïgeln, auch noch auf Grasplätzen um die Bacheralpe (Gneiss, 4500'). 


\section{XxX. Fam. Plumbagineae Vent.}

368. Armeria alpina (Нр).) W. Seheint in unserem Gebiete zu fehleu; die nächsten Standorte sind: Griesstein bei Wildalpen (Angelis!), Reiting bei Mautern (Hatzi!), Hochwart bei Irdning.

\section{Fam. Valerianeae DC.}

369. Valeriana oflicinalis $I_{\text {. }}$ \% major Keh. Auf feuchten Wiesen, an Sümpfen zwischen Schilf, in Bergwäldern sehr hüufig; $\beta$ minor Keh. An lehmigen Ufern der Ennsarme in der Krumau hänfig; in Bergwäldern (z. B. im Ranchbodenwalde) geht sie in die grössere Form über.

370. V. sambucifolia Mik. An Bächen der Hochwälder, auf iippigbegrasten, fenchten Alpenwiesen und unter Krummholz im Kalkzuge nicht selten, z. B. am Scheiblstein von der Gstadtmayrvoralpe aufwïrts dureh das Unterholz und von der Gstadtmayrhochalpe zum Scheiblstein, ron der Stumpfnagleralm durch den Wald zum Seheibleggerbach und zur Kemetwand, am Kalbling, Hochthor, Gamstein bei Johnsbaeh, im Sunk (Angelis !).

371. V. dioica L. Auf Sumpf- und Moorwiesen, an Wassergräben sehr häufig, z. B. Schultering, Griesmayrsümpfe.

372. V. tripteris I. An schattigen, feuchten Stellen der Bergwälder und Voralpen im Kalkzuge gemein, ebenso in Kalksehluehten der Tiefregion, z. B. am Mühlauerfall, im Gesäuss, Schwarzenbachgraben; seltener in der Tauernkette, wie von der Pfarrerhub ob Lorenzen gegen die Bacheralpe hinauf, um die Felsen des Hochschwung etc.; var. simplicifolia m. selten mit der Hauptform, z. B. am Lichtmessberge neben der Fahrstrasse.

373. V. intermedia Hoppe. Rchb. D. Fl. Abb. 1425. Am Schafferwege beim Bäehlein häufig.

374. $\mathrm{V}$. montana $\mathrm{I}_{\text {. An }}$ sehattigen, meist sandigen oder steinigen Stellen der Voralpen und höheren Bergwälder aller Kalkgebirge gemein; steigt seltener, als tripteris, in die Tiefregion der Kalkschluchten (z, B. Mühlauerfall, Sehwarzenbachgraben, Gesäuss, Klamm); auch $v$. albitlora hie und da.

275. V. saxatilis I. An felsigen Orten aller Voralpen und Alpen im Kalkgebirge gemein, auch in Kalkschluchten der Tiefregion (z. B. am Mühlauerfall, im Sehwarzenbachgraben, Gesäıss) sehr häufig.

376. V. elongata I. In Felsspalten und im Felssehutt der mittleren Kalkalpenregion nicht gar häufig, z. B. an der gefährlichen, steinfelsigen Nordseite der Schafleithen, auf Schnttabhängen des Sehafweges am Kalbling, unter der hohen Kalblingmauer, am Natterriegl, an Felsen ror der Farchneralm, unter der Hochthorscharte (hier sehr häufig), ob dem Hund (Hatzi!).

377. V. celtica L. Anf grasigen und steinigen Abhïngen der Hochalpen $\left(6500-7100^{\prime}\right)$ im Kalkzuge sehr häutig (an der letzten Erhebung des Scheiblstein, unter der Spitze des Pyrgas, in der 
Kreuzschlucht zwischen Kalbling und Sparafeld, anf der Höhe des Buchstein, am Natterriegl); im Tanernzuge aber $\left(6-7500^{\prime}\right)$ ïberall selı gemein.

378. Valeriauclla olitoria (I.) Much. Auf bebantem Boden selır hïufig, besonders gemein im unteren Stiftsgarten und auf Acckern beim Griesmayr.

379. Val. cariuata Lois. Auf bebautem Boden im Stiftsgarten (Angelis!).

380. Val. Morisonii DC. v. lejocarpa DC. Auf Aeckern unter Getreide, z. B. in Frauenfelde.

\section{FaII. Dipsacene Juss.}

381. Dipsacus silvestris Mill. Auf wïsten Plätzen, besonders an Zäunen und Wegen hänfig: Bei der Ziegelbrennerei, gegen Frauenberg, Weng etc.

382. Konautia sylvatica (I). Dub. Rchl,. Abb. 1350. In Bergwäldern bis in die Voralpen des Kalkzuges zerstrent; var. dipsacifolia (Host, Rchb. Abb.). Im Gesäuss, in Bergwäldern und anf Voralpenwiesen des Kalkzuges gemein, z. B. Anfstieg zum Brncksattel, zum Scheiblstein, Pyrgas, Kalbling, zur Scheibleggerlochalpe, am Schafferweg; hilufig anch in Tanernzuge, wie im Strechengraben, an Bachrändern und hochgrasigen Felstriften ob der Bacheralpe, an den Höhen des Ochsenkahr's.

383. Kn. longifolia (WK). Zwischen Krummholz am Scheiblstein ein Ex., das sich aber von den Tiroler Ex. durch abstehend behaarten Stengel (wie bei Nr. 382) mnterscheidet, daher var. pilosa mihi.

384. Kon. arvensis (L) Coult. Anf trockenen Wiesen, Feldern und Rainen gemein.

385. Succisa pratensis Much. Auf fenchten Wiesen und Feldern sehr häufig, z. B. in der Krumau, im Hoffelde, in der Schultering, im Triebnermoore.

386. Scabiosa lucila Vill. Auf Rainen und Waldhügeln, anf Wiesen der Ebene bis in die Alpenregion des Tanern-, vorzüglich aber des Kalkzuges überall sehr luäufig und vielgestaltig, in der Hochalpenregion des Kalbling, Festkogel etc. oft kaum spannenlang.

\section{Fam. Compositae Vaill.}

387. Enpatorium cannibinum T. An fenchten Wald- und Uferstellen, in Gebïschen hüufig, z. B. am Eingang in's Gesänss, bei den Ennsarmen der Krumau, im Rauchboden, bei Bärndorf, von der Klamm in den Strechengraben.

388. Adenostyles alpina (Jeq) Bl. u. F. Auf Kalkboden von der Ebene bis $6000^{\prime}$ sehr gemein, besonders in lichten Wäldern; var. flore albo am Wege zom Sumk (Angelis!). 
389. Ad. alhifroms (I) Rehl.. An fenchten, schattigen Stellen der Hoelswälder, Voralpen und niederen Alpen im Kalk- und Tanernzuge fast überall schr lïulig, olt sogill massenhaft.

390. Homoerve alpina (L) Cass. In 'T'orfinooren, anf moosigen Bergabhängen, in Vorilpenwïldern bis zu den höehsten Spitzen der Kalk-, noch melı aber der 'T'mern-Kette seln' gemein.

391. H. discolor (Jeq) C'ass. Von der Krmmmholzregion der Kalkalpen bis über $7000^{\prime}$ an trockenen $\Lambda$ bhängen sehr lüuligg; steigt läugs del Giesshäche anch oft fast bis zur' 'Tiefiegion (\%. B. Sehallerweg, Buchanerschütt) hermer.

392. Tussilago Farlatra I. Aul wïsten, lehmigen, sandigen oder steinigen Plitzen bis in die Voralpen sehr gemein.

393. Petasites oflicinalis Mnch. Auf lehmigen Feldern, an Bächen sehr häufig, z. B. aun Wege nach Weng, auf der Buchau, beim Ziegelstadl, muterhalb des Adam, ob dem Admonter Kalkofen; besonders gemein und iippig im oberen Hatlersgraben.

394. Pet. allıs (L) Girtı. An Bäclıen, in feuchten Schluchten, in Holzschlägen. anl Bergabhüugen sehı häufig, meist anf Schiefer, z. 13. innerhalb der Klamm zum Strechengraben, im Wolfsgraben, vom Nagelsehmied abwärts durch den Veitlgraben, ob dem Kalkofen gegen die Kemeten; selten auf' Kalk, wie im Gesänss (Strobl (sen.), beim Mïhlauerfall (Hatzi!).

395. Pat. nivens (Vill.) Bmg. Aut' steinigen Ablï̈ngen, Geröllfeldern, an Bergstrümen der Kallikette von aler kbene bis in die Krummholzregion selı gemein, besonders im Gesänss, Johnsbachund Schwarenbachoraben, am Kalbling, Pyrgas, Scheiblstein, bei der Bärnkoppe und Kemetwand.

396. Aster alpiuns I. Aul felsigen Stellen nuter der Spitze des Hochschwung sehr lı̈̈nfig; , am Bösenstein anf Gueiss, der auf einer Stelle eine kanm 3" "licke Kalkschichte eingelagert enthält" (Stur); im Kalkzuge nu ob iler Linns in der Nähe des Himbeerstein (Ierider) und an Hund bei Johnsbach spärlich beobachtet.

397. Bellidlastrum Michelii Cass. Auf Grasplät\%en der Toralpen und in lichten, steinigen Bergwäldern der Kialklette äberall, bisweilen äusserst gemein; steigt am Festliogel sogill bis gegen $7000^{\prime}$ und geht lïngs der Giessbïche bis in die Ebenc; anf Alpenwiesen der 'Tanernkette ziemlich selten, nur an Hochsehwung mul in des Umgebung des Gemeinsee hïulig. vill. radio rubro unterhillb des Himbeerstein inı Gesänss.

398. Bellis frommis l. Aul Grasplaitzen überall sehr gemein; meist flore albo, selteller roseo.

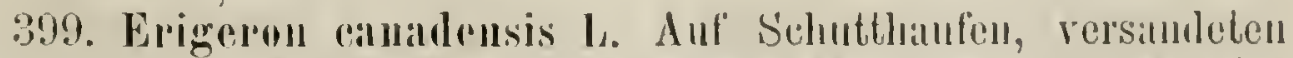
Feldern, an Fisenbahndämmen und wüsten Wegrändern strichweise sehr gemein.

400. Er. aceris L. und var. serotinus (Weilue). Mn sandigen Bachrändern, an Wegen, in lichten Bergwäldern der Kalkkette hie und da, nicht gerale hïutig, \%. B. Bei lichtmessdorf, Hall, am Schafweg, Brucksattel, Aulstieg zur Scheibleggerhochalpe. 
401. Er. Mröbachensis Mill. An den Stufen des Pavillons im Stiftsgarten, an sandigen und lehmigen Ufern der Enns unterhalb des Griesmayr und im Studentenbade, auf den Johnsbacheralpen und an der Johnsbachbrïcke im Gesäuss.

402. Er. alpinus L. Auf Grasplätzen der Alpẹn und angränzenden Voralpen im Kalkzuge zerstreut, z. B. um die Almhïtten des Pyrgas, am Pyrgasgatterl, Scheiblstein, Kalbling; var. hirsutus grandiflorus (Hoppe) nicht häufig auf üppigen Wiesen des Hochschwung (Südseite, 6000', Gneiss).

403. Er. glabratus Hpp. Auf Grasplätzen der Kalkalpen und angränzenden Voralpen viel häufiger, als vorige, besonders gemein am Hochthor; auch am Kalbling, Damischbachthurm, Scheiblstein, Pyrgas, auf der Höhe der Ardning, des Neuberg etc. häufig.

NB. In einem alten Verzeichnisse wird anch Er. uniflorus L. am Pyrgas angegeben, den ich bisher nur auf hohen Schieferalpen des oberen Ennsthales antraf.

404. Solidago virga anrea I. An sandigen Ennsufern, zwischen Gebüsch, in Holzschlägen und lichten Wäldern der Berge und Voralpen (hier meist in der Zwergform var. alpestris (W. K.) überall gemein.

405. Buphthahmm salicifolinm L. und $\beta$ angustifolium. Auf steinigen, buschigen Plätzen, in lichten Wäldern von der Ebene bis in die Voralpen ïberall, wo Kalk, sehr gemein.

406. Inula Heleninm L. In Grasgärten der Landlente, an Banernhäusern hie und da verwildert, z. B. um Admont (Angelis!), am Aufstiege zur Pitz.

407. In. salicina L. Im Reitthal in Sümpfen „unter'm Saal“ am 6. August 1845 von Angelis gesammelt!

408. In. Conyza DC. Vor'm Krippeunacher in der Klamm am Fusse der Kalkfelsen ziemlich häufig, im Walde ob Bärndorf spärlich; nach Angelis auch am Kalbling, Damischbachthurm und beim Bichelmayr vor Frauenberg.

409. Pulicaria dysenterica (I) Grtn. Auf sumpfigen, freien Waldplätzen am Aufstiege zur Pitz (von der Weng-Seite ans) massenhaft, selten auf Rainen vor Weng; beim Schauersberger (Altes Verzeichniss).

410. Bidens tripartita L. a inradiata. An Gräben, Sümpfen, in abgelassenen Stiftsteichen, im Hofmoos etc. sehr häufig.

411. B. cermua L. 3 radiata DC. An Gräben, Sümpfen, Teichen, Mooren sehr häufig, z. B. gegen Frauenberg, im Griesmayrsumpfe, im Hofmoos.

412. Filago germanica I. „Auf sandigen Aeckern, Braclıfeldern, trockenen Hïgeh: Bei Admont" (Maly 1868); ich sah nur Exemplare Sommerauer's im Herbar des Johamneum mit der Etiquette: "Fil. gallica. Admonter Alpen."

413. Fil. arvensis I. An schieferhältigen Wegränderu des Lichtmessberges ob Dittmannsdorf selten; „Fil. minima Fi. Auf dem Lichtmessberge" Maly 1838 dürfte damit wohl zusammenfallen. 
414. (inaphalimu silvaticum L. In Wäldern und Holzschlïgen bis anf die Voralpen ïberall gemein, auch aul' 'Torfmooren; nicht selten sind Uebergangsformen zur folgenden.

415. Gin. nor rergicun biun. Aut' grasigen Ahlängen der Voralpen und Alpen in 'Tanemzuge häntig: An Bachrändern um den Scheiplsee und tiefer, an haillentrigen Abhängen ob der Bacheralpe, um die Felsen der Hochhide, mnter der Höhe des Steinamandl und Kampl auf ïppigen 'T'riften und muter Stranchwerk sehr häulig und schön, auf Wiesen des Hochschwung; im Kalkzuge ziemlich selten, wie am Kalbling (Herb. Johannei!, Maly 1868). Kleine, breit- und schmal-blittrige Uebergangsformen 'zu' folgenden (Varictat?) fand ich am Fusse des Bösenstein in Ochsenkahr.

416. Ain. Iloppeanum Koch. Auf grasigen, steinigen Abhängen der Alpenregion sehr selten: Am Unterkalbling (Strobl sen.!), am Bösenstein.

417. Gu. supinum L. und $\beta$ subacanle Whlb. In lichten Hochwäldern, auf haideartigen Alpenhöhen, anch an feuchten Stellen und am Rande der Schneefelder in 'Tanernzuge bis $7700^{\prime}$ gemein; seltener in der Kalkkette, z. B. am Unterkalbling, in der Schlucht zwischen Sparafelı und Kalbling, in Sulzkihr (Hatzi!), am Festkogel (7000', hïnfig).

418. (in. uliginosum I. Auf fenthten, sandigen Aeckern bei Trieben, an schieferhältigen Wegrändern ob Dittmannsdorf, um die

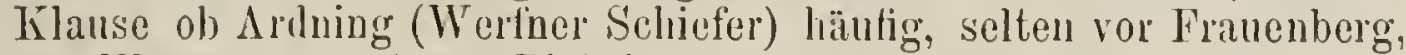
am Wege zum unteren Bichelmayr etc.

419. Antenuaria calpathica (Whll,) Bl. F. Auf feuchten, üppigen Alpenwiesen un die leksen des Hochschwung sehr häufig, seltener im übrigen 'Tanernzuge, z. B. anf der höehsten Spitze der ,drei Stecken" (Strobl sen.!), vom Gemeinsee gogen die Hochhaide hinauf (Angelis!), am Rottemmanner 'Tanern (Angelis!); selnr selten auf den Admonter und Johnsbacher Kalkalpen (Hatzi!).

420. Ant. dioica (l.) Grtn. \% nivea, $\beta$ rosea. Aul' somigen Rainen, in lichten Wäldern, Holzschlïgen, Haiden, anf' trockenen Ablü̈ngen der Alpen his über 6500' im lialk- und 'l'mernzuge gemein, gewöhnlich in grossen Rasen; bisweilen anch anf 'T'orfmooren und sumpfigen Wiesen.

421. Iemutoporlium alpinmm Cass. Anf lelsigen Stellon am Griesstein im 'Triebenthal mol in einer Folsschlucht an der Sïdseite des Hochschwung nicht hänlig (Gneiss, 5500'); soll anch an Zinödl in den Johnsbacher Kalkalpen rorkommen.

122. Artentisia Mutallina Vill. An Felsen des Hochsehwumg sehr selten, ich erhielt $4 \mathrm{Ex}$. von cinem Jïger.

423. Art. Alsinthinm I. Auf Schutt, an wïsten Plätzen, mm Bancmhäuser hie und la rerwildert; seh" gemein mud wirklich wild auf der lisslingalpe bei Altenmalkt, doch schon ausserhall, mnseres Gebietes.

424. Irt. vulgatris I. Auf Feldern und wïsten Pliitzen um Trieben äusscrst gemein, läulig aluch an Getreidefeldem gongen 
Franenberg, unterhalb der Adnonter Ziegelbrennerei, an Eisenbahndämmen, um den Stiftsmaierhof.

425. Tanacetum vulgare $\mathrm{L}_{\text {. }} \mathrm{Ob}$ dem Röthelsteiner Banern vor dem Walde an einem Zaune sehr häufig, hänfig anch vor dem Friedhofe rou Rottenmann und in Banerugärten.

426. Achillea Clavenna L. Auf felsigen Orten aller Kalkgebirge in mittlerer Höhe gemein; auf Gneiss nur an einem Seitenberge des Hochschwung entdeckt.

427. Acl. moschata Wlf. An Gebirgsbächen und überhaupt an feuchten Stellen der mittleren Alpenregion des Tanernzuges stellenweise sehr häufig, z. B. ob der Bacheralpe gegen das Ochsenkahr, den Grün- und Gemeinsee hinauf, um die Felsen der Hochhaide: ob der Singsdorferalm, am Grieskogel, Bösenstein etc.

428, 429. Ach. atrata L. und Chusiana Tsch. Auf felsigen Abhängen, an fenchten Rändern der Schneefelder, in Mulden und grubenförmigen Vertiefungen der Kalkalpen bis $7000^{\prime}$ fast überall gemein, oft in Gesellschaft und bald die eine, bald die andere vorwiegend, oft riesige Polster bildend.

430. Ach. Millefolium I. Auf Wiesen, Feldern, Aeckern sehr gemein, weiss- und rosablüthig; anf Voralpenwiesen, z. B. am Hochschwung, Kalbling, fast nur rosa ( $=\mathrm{v}$. alpestris W. Gr.).

431. Antluemis alrensis $\mathrm{I}$. Auf Feldern, wüsten Plätzen, an Wegen häufig, z. B. gegen das Gesäuss hinab, am Taurerbache bei Trieben.

432. Autlı. Cotula L. Auf wüsten Plätzen, an Wegen, vor Häusern gemein.

433. Matricaria Chamomilla L. Auf wüsten und bebauten Plätzen, an Wegen verwildert, besonders in der Nähe grösserer Ortschaften; auch sehr häufig kultivirt.

434. Lelcanthemum vulgare Lam. Auf Wiesen, Feldern, Hügeln gemein bis in die Voralpen; $\beta$ atratum Koch an Bächen und felsiggrasigen Abhängen der T'auernkette in der mittleren Alpenregion häufig, z. B. ob der Bacheralpe, ob dem Gemeinsee, im Ochsenkahr, am Steinamandl.

NB. Leuc. montanum (L) DC. wird in einem alten Verzeichnisse am Kalbling angegeben.

435. Lenc. coronopifolium (Vill.) ». genuinum G. G. Anf Wiesen, steinigen Abhängen, in Giessbachbetten der Voralpen und Alpen des Kalkzuges um Admont und Johnsbach sehr hïufig; zerstreut unter der gewöhnlichen Form und selten findet man Exemplare mit tief fiederspaltigen Blättern = var. ceratophylloides (All.) G. G., z. B. am Kalbling.

436. Pyretlirum alpinum ( $\left.\boldsymbol{I}_{4}\right)$ Wr. Auf feucliten Alpenböhen, besonders an Bächen und Schneefeldern, auf steinigen Abhängen in der ganzeu Urgebirgshette $\left(5-7700^{\prime}\right)$ sehr hänfig, meist sogar gemein.

437. Pyr. Parthenium (L) Sm. An wïsten Plätzen, auf Schutt um Häuser hie und da, z. B. um Admont, Ardning.

438. Pyr. inodorum (H) Sim. An Lisenbahndämmen bei $\Lambda d-$ 
mont nïehst dem haltenbrunner (Angelis!), erst ron Her Bahn eingeschleppt.

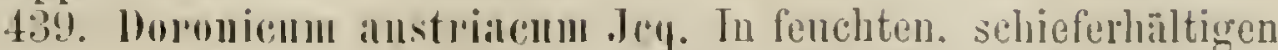
Sehluchten, in Berg- und Voralpenwäldern auf halk und Urgestein häufig, z. B. im Veitl-. Wolfs-, Strechengraben, am Scheihlstein. Schalferweg, unterhalb der Scheibleggerhochalpe, ob dem Sunk am Hohentauen, ob dem Scheiplsee zwischen Grünerlen, unterhalb der Bacheralpe, am Kampl, Blahberg in der Strechen; selten anf Sumpfwiesen des Ennsthales, \%. B. Westende der Schultering.

440. Aronicum Chusii (All.) Koch. Auf steiniggrasigen Abhängen der höheren Urgebirge hänfig, \%. l3. ob dem Scheiplsee am Bösenstein bis $7700^{\prime}$, im Ochsenkalır, rom Vitterstein zul Hochhaide, beim Gemeinsee, am Hochschwung.

441. Ar. arlaciale (IVlf.) Richl. Am Pyregas ron der Spitze bis zum Krummholz herab sehr häutig, ebenso am Scheiblstein, bei Johnsbach rom untereu Boden zur l'arehneralın hinauf (Dachsteinkalk).

442. Ar. scorpioides ( $h_{\text {) }}$ Kinch. An Schneefeldern und in muldenfürmigen Vertiefungen hoch ob der Gstadtmarrvoralpe am Scheiblstein, sowie zwischen Scheiblstein und Pyrgas sehr gemein, viel seltener am Kalbling (Angelis) und anf der Höhe des Neuberges bei Jolnnsbach (Hatzi!).

443. Arnica muntana ( $\mathrm{L}$ ) Auf dürren Bergabluängen, in lichten Hochwäldern, auf haideartigen Alpenhöhen im Kalkzuge selten (Kalbling, Treffineralm am Reichenstein), hingegen fast ïberall im Werfnerschiefer-, Granwacken- und Gneissgebirge bis 6000'; ron Hatzi auch selten auf Moorwiesen des Eunsthales gesammelt!

444. Cimeraria crispa (L) Jcq. o. genuina und $\beta$ rivularis Rehb. Auf Wiesen der Ehene, in Berg- und Voralpenwäldern bis in's Krummholz zerstrent, z. B. bei Bärndorf (Angelis $\beta$ !), nnter Gestrïuch der Sautratte ( $($ ), am Pyrgas, Kalbling, Scheiblstein, rom Wolfsbanern anf die Firchneralm ete; oft Uebergänge zur folgenden (Art:).

445. Cin. alpesíris Ilppe. In Hochwäldern, auf Voralpenwiesen, zwischen Krummlolz im Kalkzure sehr häufig, besonders am Pyrgas, Scheiblstein, Kalbling, in den Johnsbacher Alpen; seltener in der Tanernkette, \%. B. an Bächen nm die Bacheralm, um die Kothliütten, im Strechengraben bis zum Hochschwung: Früchte fist durchgehends kahl, selten etwas flaumig.

446. Senreio vulgalris I. Auf Schntt, an wiisten und bebauten Stellen der 'Tiefrexion sehr gemein.

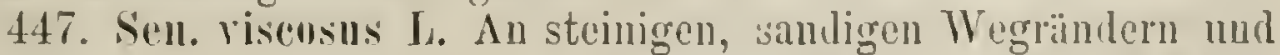
Uferstellen, in Lichtungen ler Wälder selı häufig. \%. B. am Wege mach Frauenberg, am Lichtmessbache miterhalb des Adam, rom Lichtmessberge gregren Dittmannsilorf hinal,, an Strassen des Paltenthales.

44S. Sen. silvaticus L. In Wäldem und Holzschlägen sehr bäufig, \%. B. am Lichtmessberge, Pyrgas. im Sumk.

449. Sen. pupestris W. K. An Häusern, auf steinigen, sehattigen Stellen der Ebene, der Berge und Voralpen an vielen Orten, doch 
selten in grösserer Anzahl (z. B. im Stiftsgarten, an Gewerken Triebens, der Klamm, im Schwarzenbach- und Veitlgraben, beim Steinbruch unterhalb der Kemetwand, auf der Pitz, im Sunk); sehr gemein um die Stumpfnagleralm.

450. Sen. abrotanifolius L. Anf grasigen Abbängen der Kalkvoralpen, besonders zwischen Krummholz, häutig: Am Schafweg des Kalbling, unter der Kalblingvormaner, am Aufstieg zur Scheibleggerhochalpe, am Pyrgas, Scheiblstein, Damischbachthurm, Hochthor, Hund, im Sulzkahr; selten im Sunk.

451. Sell. Jacobaca 1. "Auf Wiesen, an Rainen" (Altes Verzeichniss der Admonter Flora).

452. Sen. carniolicus $\mathbf{W}$. \% virescens $\beta$ incanescens $\mathrm{Km}$. Auf grasigen Abhängen der Tauernkette von $6000^{\prime}$ bis über $7700^{\prime}$ sehr häufig, besonder's am Bösenstein, anf Höhen ob der Bacheralpe, auf der Hochhaide, am Hochschwnng. „Sen. lyratifolius Reich. Am Rottenmannertanern (Host)" Maly 1868 gehört wohl anch hieher oder zur folgenden.

453. Sen. subilpiums Kocl. Auf grasreichen Orten, besonders an Bächen der Berge und Voralpen im Kalkzuge sehr häufig, noch viel gemeiner aber anf Schieler- und Gneissalpen.

NB. In Maly 1868 wird anch cordatus Koch um Admont angegeben, doch fand und sah ich aus dem Gebiete immer umr vorige.

454. Sen. nemorensis l. $\alpha$ genuinus (Hülle fast kahl, Geruch schwach) und $\beta$ odoratus Koch = Jacquinianus Rehb. (Hülle dicht gewimpert, Geruch stärker). In lichten Wäldern der Berge und Voralpen, im Kalkznge selten, im Wolfs-, Strechengraben ete. der 'Tauernkette gemein.

455. Sen. saracenicus L. non Koch (Fuchsii Gmel) a ovatus (W), $\beta$ salicifolins (Wllr.). In Bergwäldern und aul Voralpen del Kalkkette äusserst gemein, seltener im Tanemzuge; meist $\beta$.

456. Sen. paludosus $1 . \beta$ glabratus Koch. In der Wolfsbacherlache bei Admont (Sommeraner), zwischen Schilf an Wege vom Blahberger zur Mödringerbrïcke bei Frauenberg (Angelis!), sehr häufig zwischen Schill am Südrande des Gaishornsee's, im Paltenthale (Angelis).

457. Cinsinm lanceolatum $\left(\mathrm{I}_{4}\right)$ Scp. An Wegen, Rainen, wüsten Orten, aul freien Waldplätzen der Berge bis in die Voralpen selsr gemein.

458. Cirs. eriophorum ( $\left.1_{4}\right)$ Scop. Auf Bergen und Voralpen an buschigen Stellen vereinzelt: Am Pyrgasübergange, anf der Moseralm, am Kalbling (Maly 1868); nicht selten am Wege von Hohentauern nach St. Johamn.

459. Cirs. palustre (L.) Scop. Auf Sumpfwiesen, an Gräben, Bächen, in Waldwiesen bis anf die Voralpen sehr gemein.

460. Cirs. pauciflopun (W. K.) Spreng. Auf grasigen $\mathrm{Ab}$ hängen, in Schluchten der Bergregion ann Rottemmannertanern einzeln oder truppweise: Beim Stege im Wolfsgraben ob Trieben, anf Rainen unterhalh der Ortschaft Hohentauern, im Strechengraben. 
161. Cims. cannolirom Sorop. Gegen den Fuss des Hochthor (Kalk $5500^{\prime}$ ) zwischen hilummholz riemlich häulig, links hinauf am Hund (5000') seltener, anl' der Rückeniöhe desselben (5:500') häufig.

462. Cirs. benteense Treninfels (die Cirsien Tyrols) $=$ spinosissimo $\times$ carniolicum. Im imnersten Winkel des Hochalpenthales, das sich zwischen dem grossen und kleinen Bösenstein hinaufzieht, mit Cirs. spinosiss. und Myosotis variabilis am 30. August 1867 ziemlich häufig gefunden (Gneiss, 7:200'); im uäehsten Jaln'e am 17. Angust vergehens gesucht.

463. (ij's. spinosissimum (I) Scop. An fenchten Stellen der Kalk-, vorzüglich aher der Urgebirgsalpen, besonders an Bächen, Schneefeldern und üppig begrasten Abhängen unterhalb der höchsten Gneissmauern; Kalk: Am Kalbling und Scheiblstein, nach Kerner auch am Buchstein; Gneiss: Zwwisehen dem grossen und kleinen Bösenstein sehr gemein, ebenso im Ochsenkahr, an liusse der drei Stecken, um den Grünsee, Gemeinsee, von der Schannitzeralpe im 'Triebenthal bis zur Seckanerkette, am Strechenbach ron den Almhütten bis zu den Fèlsen des Hochschwung.

464. Cirs. Erisithales (L) Scp. In Bergwäldern und auf feuchten Bergwiesen der Kalkkette bis auf die Voralpen sehr häufig, ebenso ant ISalkvorlagen der 'T'anernkette.

465. Cirs. leterophyllum (L) All. a indivisum, $\beta$ incisum DC. Auf grasigen Abhüngen, vorzüglich an Aeckerrainen und anf Wiesen der Berge und Voralpen im 'Tanernzuge höchst gemein, auf Gneiss, Scliefer und Grauwacke, doch nie auf Kalk; steigt am Kampl bis $5500^{\prime}$ und findet sich anch in der 'Thalebene, z. B. um Rottenmann und an der Strasse nach Liezen.

466. Cirs. oleracen!n ( $\mathrm{L}_{4}$ ) Scop. Anf nasseu Wiesen und Bergabhängen ïnsserst gemein.

467. Cirs. subalpinm (idl. (palustri-rivulare Naeg.). „Auf dem Kalbling bei Admont (Angelis)" Maly 1868; mir aus dem Gebiete ebenso mbekanut, wic rivulare.

468. Cirs. hybrilum Kolı. (palustri-oleracenm recedens Näg.). Auf feuchten Wiesen, in Gräben von 'Trieben auf die Höhe des Tanermpasses selten; Blätter seicht - bis tief zertheilt.

469. lirs. alrense (L) Scop) \% horridum W. Gr. Seln gemein an wästen Plätzen, Wegen, freien Waldplätzen und in Holzschlägen bis auf die Voralpen; $\beta$ mite W. Gr. libenfalls gemein, loch meist unter Getreide; $\gamma$ integrifolimn. Im Paltenthale (Maly 18:38).

470. Cauduns aciuthoides 1. An Wegrändern und wüsten Plätzen höchst gemein.

471. Card. Pel'sunata Jcy. An schattigen, fenchten Orten der Hluene bis anf die Voralpen des Kalk- mol Tanemzuges ziemlich häufigg, z. B. unter Bäumen im Gesäuss vor der Johnshachbrïcke, anf Wiesen am oberen Ende des Hartelgrabens sehr häufig, ebenso am oberen Ende des Franenfeldes, bei Röthelstein, am Lichtmessberg, Kalbling, im Strechen-, Oppenberger-, Wolfsgraben, von Lorenzen zur Bacheralm, un Hohentamern ete. 
472. Card. defloratus $\mathbf{l}$. Nach der Blattform kömnte man unterscheiden: $\alpha$ dentatus (angustifolius und latifolius), $\beta$ lobatus, $\gamma$ pinnatifidus integer (= alpestris WK.) o pinnatifidus lobatus (die Fiederabschnitte nochmals lappig zertheilt). Diese vielgestaltige Pflanze kommt überall an waldigen, sonnigen, steinigen Ablängen des Kalkzuges und der Kalkvorlagen des 'T'anernzuges vor' und ist von der Ebene bis auf die Voralpen äusserst gemein, zumal $\beta$ und $\gamma$, seltener $\alpha$; $\delta$ ist nicht häufig, $z$. B. an sandigen Abhängen unter den Felsen der Schalleithen am Schafweg des Kalbling.

473. Lappa major Grtı. Auf wüsten Plätzen, an Wegen häufig, z. B. in's Gesäuss, nach Weng. gemein.

474. L. tomentosa Lam. Auf wüsten Plätzen, an Wegen sehr

475. I. minor 10(. Auf wüsten Plätzen, an Wegen seltener : Bei Aigen, vor'm Gesäuss häufig, gegen Mühlau, am Fusse der Klammfelsen ete.

476. Carlina acaulis I. Auf trockenen, unfouchtbaren Hügeln der Ebene, an kurzgrasigen Bergabhängen bis in dic Voralpen des Kalkzuges sehr lıäutig, z. B. Raine beim Griesmayr, vor Frauenberg, Aufstieg zum Brucksattel, zur Stumpfnagleralm, zum Pyrgas; seltencr im Urgebirge (am Steinamandl, aut haideartigen Ablıängen ob der Bacheralm etc.); $\beta$ caulescens DC. An hoehgrasigen, schattigen Plätzen ob der Bärnkoppe und der Gstaltmayrvoralpe nicht häufig.

477. Carl. vulgaris $\mathrm{I}_{\text {. }}$ Auf unfruehtbaren, somnigen Rainen und grasigen Hügeln der Ebene häulig, z. B. beim Griesmayr mit voriger, vor der 'liegelbrennerei.

478. Sanssurea alpina DC. Auf Alpentriften des Hochsehwung, besonders unter der Scharte, ziemlich häufig (Glimmersehiefer, 5500').

479. S. discolor DC. An steinigen Abhängen des Sulzkahres gegen den 'Linödl hinauf (Hatzi!); nach einem alten Verzeichnisse auch am Rottenmannertauern.

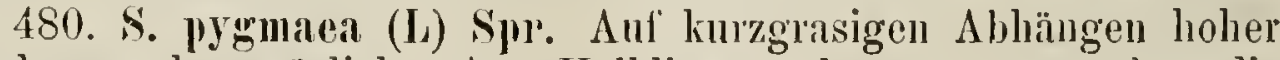
Kalkalpen sehr spärlich: Am Kalbling und zwar quer über die Felsen am Rücken hinauf selten (Angelis!), am Scheiblstein und 'Zinödl (Hatzi!), am Buchstein $\left(6-7000^{\prime}\right)$.

481. Centamea Jacea L. Auf Wiesen, Feldern, Rainen schr gemein, in Wäldern bis auf die Voralpen häufig: an dürren Waldrändern vor Mühlau oft kaum zollhoch und einblüthig.

482. C. psendo-phryaia Meier (phrygia Aut.) Auf Thal- und Bergwiesen, f'eldern (auch unter Getreide), zwischen Schilf an Sümpfen, sehr gemein im Enns- und Paltenthale bis 4000', z. B. Hoffeld, Franenfeld, Schultering, 'Trieben, ob der Pfarrerhub bei Lorenzen, um Hohentauern, zwisehen Krummholz der Johnsbacher Alpen; hicher gehören anch die Angaben Maly's 1868 über anstriaca W. aus unserem Gebiete; die echte fehlt.

483. C. montana I. Auf Berg- und Voralpentriften, an schattigen, feuchten Stellen des Kalkzuges bis in die Ebene herab, fast überall, aber ziemlielı zerstreut und selten in grösserer Menge. 
484. C. Cyanıs I. Auf Aeckern unter Getreide häıfig.

485. C. Scalhiosa 1. Auf Wiesen und Felder'n sehr häıfig: steigt in einer gedrungenen, grossköptigen Form (alpestris Heg.) am Scheiblstein vom Futterweg der Gstaltmayrvoralpe bis zum oheren Ende des Krummliolzes in Menge auf.

486. Lapsana communis L. Auf Feldern, Aeckern, in Gemüsegäirten, au Wegen gemein.

487. Aposeris foetida $\left(\mathrm{L}_{4}\right)$ Luess. ,An fenchten, buschigen Stellen der Berge bei Admont, Liezen, Rottenmann (Gebhard)" Maly 1838 und 1868. Feh fand es nur am Dachsteingebirge.

488. Cichorimm Lutyhus I. Auf Feldern, an wïsten Wegrändern: Im Flanenfelıle lı̈̈ntig, sonst ziemlich spärlich.

489. Tenntolon antumualis I. Auf Wiesen, Feldern, Rainen und an Wegen seln gemein lis in die Voralpen, wo eine schmächtige und oft einköpfige '/wergform besonders $1 \mathrm{~m}$ die Almhütten alle Weiden bedeekt; die Blïtter gezülnnt bis fiederspaltig, die Hüllen fast kahl bis dicht weichhaarig ( $\beta$ pratensis Koch); letatere Form gewöhnlich auch höher und stärler.

490. L. Taraxaci ( $\mathbf{L})$ Jois. Anf Triften und felsigen Abhäugen höherer Kalkalpen selten: Im Sulzkahı (Hatzi 1845!), am Scheiblstein; am häufigsten unterhalb der hohen Kalblingmauer gegen den Reichenstein hinüber, seltener in dem Kahre zwisehen Kalbling und Sparafeld.

491. T. pyreuaicus Gou. Auf grasigen Alpenhöhen des Kalkund Gneisszuges $\left(5-7000^{\prime}\right)$ nicht gemein; a: Krummholzwiesen um die Vormanern des Kalbling, Triften am Scheiblstein, Umgebung der Scheibleggerhochalpe, der Farehneralm bei Johusbach ete., höchster Standort im Kalre zwischen Kalbling und Sparafeld mit voriger bei $6600^{\prime}$; b: ob dem Gemeinsee, Scheiplsee, am Steinamandl, Bösenstein, anf der Hochlaide ete. Variirt von ganzrandigen bis stark gezïlnnten Blättern ( $\gamma$ pinnatifida Koch), ferner kahl bis stark behart (beide Formen oft mit einander wachsend und allmählig in einander übergehend); Blüthe gelb, selten am Tanern safranfärbig (= croceus Huk).

492. T. lıastilis T. Anf Wiesen, Feldern, Rainen, sandigen und steinigen Orten sehr gemein, vom üppigsten bis auf den dürrsten Standort, rom 'Thale bis auf die mittleren Alpenhölien. Ich schied in meinem Herbar folgende Formen:

a pratensis (Form der 'Thal- und Bergwiesen). Sehlaft, langblättrig, hocli, ïppig, meist fiederspaltig, kahl (= b. glabratus Koch) oder steifhaarig $(=\mathrm{v}$. hispidus vulgaris Koch p. p.).

b. alpinus (Form der Alpenwiesen). Wie vorige, aber mit weniger gespaltenen, breiteren, steif aufrechten Blättern, sehr dicht steif behaarten Hüllen mo dickem, strammerem Schafte. Sehr gemein auf Krummhol\%wiesen ob der Gstarltmayrvoralpe am Scheiblstein, ebenso am Pyrgas, Kalbling, von der Bacheralpe anfwärts, auf üppigen Triften um die Felsen der Hochhaide, des Hoelsschwung etc.; unter Krmmmholz oft sehr hoch und langblittrig. 
c. collinus (Form der trockenen, steinigen Wegränder und Raine rom Thal bis anf die Berge). Mager, kahl, mit kürzeren, schmäleren, dickeren, blos gezähnten Blättern. Raine vor Weng, steiniger Waldboden unterhalb des Brucksattels etc. Geht ïber in

d. dubins (Ipp.) (Form der Voralpen-Geröllfelder im Kalkzuge). Blätter ebenfills lanzettlich, noch mehr lederartig, glänzend, regelmïssig fiederspaltig, meist ausgebreitet rosettig, Köpfchen grösser. Variirt kahl bis steifhaarig. Auf der grossen Schütt im Bruckgraben, im Johnsbachgraben, ob der Gstattmayrvoralpe, im Gaisenthal, am Kalbling, selten herabgeschwemmt zum Mühlanerfall. Geht über in die üppigere

•. opimus Bisch. Blïtter breiter, blos gezähnt bis eingeschnitten gezühnt, fettglünzend, Köpfchen noch grösser. Ebenfalls auf Felsschutt, doch höher hinauf, besonders am Schafweg des Kalbling unter den Felsen der Schafleithen. Variirt kahl oder blos die Hülle spärlich behaart oder iiberall behaart; in letzterem Falle verläuft sie allmählig in die Form b.

493. L. incauns ( $\mathrm{I}_{i}$ Schrk. An felsigen Orten und im Felsschutte der Kalkvoralpen sehr häufig, besonders im Gesäuss, Bruckgraben, Gaisenthal, auf der Pitz, von Mühlau auf die Kochenalm, von der Gstadtmayrvoralpe zum Scheiblstein, am Kalbling unter der hohen Maner, an der Kemetwand; auch auf Kalkvoralpen des Tanernzuges.

494. Picris crepoides Saut. Auf Feldern im Ennsthale sehr häufig, z. B. im Hoffelde bei den Eichen, in Frauenfelde, vor Hall, in der Krumau, bei Johnsbach.

495. Tragopogon orientalis L. Auf Wiesen, Feldern und Grashügeln gemein.

496. Hypochaeris madicata L. An Wegen, auf Rainen, Hügeln, Grasplützen, in Waldlichtungen und Holzschlägen von der Ebene auf die Berge fast überall, aber äusserst sparsam; häufig nur unterhalb Frauenberg vom Farchner zur Mödererbrïcke an Strassenrainen und von der Höhe des Lichtmessberges gegen Dittmannsdorf hinab (Grauwackenschiefer).

497. H. uniflora Vill. Auf etwas steinigen Abhängen nud üppigen Triften der Urgebirgsalpen nicht häufig: Ob der Bacheralpe den rechts unterhalb des Grünsee's liegenden Abhang hinauf, auf der Hochhaide hie und da, am Hauseck ob dem Scheiplsee, an der rechten Kante des Bösenstein von $6500^{\prime}$ an zerstreut, am Blahberg in der Strechen nicht selten: häufig an der Südseite des Hochschwung (c. 6000').

498. Willemetia apargioides Less. Auf nassen Wiesen, an sumpfigen Waldstellen, an Bächen und Schilfseen der Voralpen, anf Krummholzwiesen, riemlich häufig im Kalk- und Tanernzuge: Sumpfwiesen der Santratte, der Griesmayrlache, im "Moos" bei Bärndorf (Angelis!), vor Kaiserau, um die Kalblingvormauern, in den Johnsbacheralpen (Hatzi!), bei der Treffneralm (Angelis!), ob der Bacheralm, bei den Kothhütten, um die Almhïtten des Hochschwung; am häufigsten wohl um die Scheiplseeen. 
499. Tamaxacum officinale Wigg. \% gemnimm. Auf Wiesen, Feldern, an Wegen änsserst gemein his an die Alpen, \%. B. hoch ob der Gstaltmayrvoralpe in muldenförmigen Vertiefungen des Selıciblstein in 'Thalformgrösse.

B alpium (Hoppe). Auf 'lriften, an Selmeefeldern der Hochalpen im Kalk- und 'lanernzuge selten: Jm Kahre z,wischen Kalbling und Sparafeld, um die Scheibleggerhochallu, am Pyrgas, im innersten Wiilkel der Hochalpenschlncht zwischen dem grossen und kileinen Bösenstein $\left.(7300)^{\prime}\right)$.

Y paludusum (Sonp.) = livilnm WK. Anf Snmpfwiesen des Ennsthales beim Griesmayr sehr hänligg, im Paltenthale bei Bärndorf gemein (Angelis).

500. Premanthes pmrpurea I. Im Sehatten der Berg- und Voralpenwillder last iiberall. doch selten in grosser Menge, anf Kalk, Schiefer und Gneiss; bei der Hüllerahm an Rott. Tanern anch rar. foliis integerrimis.

501. Lactuca muralis I. Im Schatten der Wälder, in Sehieferschlnchten, anf steinigem, besonders kalkhältigem Borlen überall hänfig.

502. Sonchus oleracens L. o integrifolius, $P$ triangularis, $\gamma$ lacerus Wllr. Auf wïsten mul bebanten Stelien sehr gemein, besonder's an Wegen mul auf Selntt.

503. S. asper. Vill. a inermis, $\beta$ pungens Vill. An denselben Orten, wie rorige, mul elenso gemein.

504. S. arvensis 1. Anf Selnutthanfen, an Wegen, vorzüglich gemein aber auf Aeckern mer Getreide, z. B. Hofteld.

505. Mulgedium alpimmu (L.) Less. In Hochwäldern, zwischen Krummlıol\% im Kalk- und Grünerlen im Tauernzuge, in Schlnchten, an Bächen, auf üppigen Alpeuwiesen, im Felsschatten, wohl an vielen Standorten, gemein aber nur unter Erlen mn den Scheiplsce, auf Triften ob dem Gemeinsee bei den Felsen der Hochliaide und rom Sulzkalı' zum Hatlersbach hinab.

506. C'repis amra (L.) Cass. Auf Wiesen der Alpen und Voralpen im Kalkznge bis $6600^{\prime}$ sehr gemein, seltener im Tanernzuge, z. B. $\mathrm{mm}$ den Scheiplsee, $\mathrm{mm}$ die Felsen der Hochhaide ob dem Gemeinsee (s. hfg.), an Hochschwing (gemein).

507. Cr. alpestris (Jeq.) Tsch. Anf Voralpenwiesen ma zwischen Krummholz der Kalkkette, selten höher hinanf: Zwischen Pyrgas und Scheiblstein sehr hïufig (variirt hier $\%$ dentata, $\beta$ runcinata mit Uebergängen), an Gamsstein (Hatzi!), Unterkalbling, Uebergange vom Scheibleck zur Schatleithen his 6000'.

508. (M. birmuis $\%$ dentata $\beta$ runcinata. Anf Wiesen, Feldern, an Wegen und Rainen beide Var. gempin, \%. B. Franenfeld, Weg nach Weng, Franenberg ete.

509 . ('r. virems L. o dentata Bisch., F runcinata 13isch., \% pectinata Bisch., o algrestis (W. K.) Biseh. Auf Wiesen, Feldern, Rainen, an Wegen und Ufern meist zerstrent, aber doch sehr hüntig im Enns- und Paltenthale, z. B. bei Trieben, Lorenzen, Admont. \% und $\beta$ an mageren Standorten, $\gamma$ und $\delta$ anf Kileefoldern und Wiesen. 
510. Cr. Jacquini Tsch. An Felsen und im Felsschutt der Kalkkette in mittlerer Höhe bis in's Krummholz herab ziemlich häufig: Ton der Gstadtmayrhochalpe gegen den Scheiblstein hin, am Natterriegl, unter der Kemetwand (selten), ob der Scheibleggerhochalm gegen die Schafleithen hin; am Schafweg, unter der hohen Kalblingmaner, am Rinnstein und Hund in deu Jolnnsbacheralpen.

511. C'r. paludosa (L) Mnch. Auf Sumpfwiesen, an Gräben, Bächen, nassen, schattigen Bergabhängen, unter Krummholz, von der Ebene bis 5500' im Kalk- nnd Tauernzuge sehr häufig.

512. Cr. suceisaefolia (All.) Tsch. F nuda Gr. God. Auf buschigen Voralpenwiesen in Kalkzuge, besonders zwischen Krummholz am Pyrgas (Zehenter) und Scheiblstein gegen den Pyrgas hin häufig.

513. (. blattalioides (L.) Vill. In Hochwäldern, zwischen Strauchwerk und Krmmmholz der Kalkalpen im ganzen Gebiete, besonder's lıäufig in den Johnsbacheralpen, an Pyrgas, Scheiblstein und Kalbling.

514. Cr. lyyoseridifolia Tsch. Auf steinigen Abhängen hoher Kalkalpen $\left(6-7000^{\circ}\right)$ : Am Fusse der letzten Erhebung des Scheiblstein und Kalbling und aufwärts ziemlich häufig, ebenso am Sparafeld; am Hund im Sulzkahr (Hatzi!).

515. Hieracium Pilosella L. Auf trockenen Rainen und Hügeln der Ebenen, Berge und Kalkroralpen sehr gemein: var. eflagellare häufig auf subalpinen Ablängen, z. B. vou der Kemetenwand zur Scheibleggerroralpe. Eine niedliche, kleimblättrige und kleinblumige Abänderung mit reichlichen Ausläufern sammelte ich sehr spärlich zwischen der Normalform bei Toralpenhütten tief innen im Ardninggraben; eine hohe, grossblättrige, bis auf den einblüthigen Schaft der folgenden sehr ähnliche Waldform häufig an Waldrändern im Strechengraben.

516. H. bifureum MB. Kch. (Pilosella $\times$ praealtum nach Neilreich. Blätter oft ganz gleich denen von Pilosella, aber auch Uebergänge fast bis zu völliger Kahlheit). Auf trockenen Grasplätzen, steinigen Hügeln und Waldräudern an vielen Punkten, aber stets in wenigen Exemplaren, z. B. Am Lichtmessberg neben der Fahrstrasse, an Hïusern bei der Mödringerbrücke, bei Dittmannsdorf, unter der Kemetwand, an Waldsüumen ob der Pfarrerhub bei Lorenzen, beim Teichmeister (Angelis!), im Schwarzenbachgraben.

517. H. amgustifolium Hoppe. Auf hohen Alpentriften der Tanernkette hie nđ́d da: Häufig auf Felstriften ob der Bacheralpe gegen den Grün- und Gemeinsee, rom Mitterstein zur Spitze der Hochhaide, am Bösenstein, besonders der Ostkante entlang (6500 - $\left.7700^{\circ}\right)$, selten am Steinamandl etc.

518. H. Anricula L. Anf Polstern der Torfmoore, an Rainen, Wegen, grasigen Abhängen der Thäler und Berge bis auf die Alpender Kalk- und Tauernkette (z. B. Kalbling, Steinamandl 6400') sehr' gemein; auf Alpen seltener, auch v. miflorum Froel.

519. H. praealtum Vill. Auf trockenen Grasplätzen, steinigen Wegrändern, an sandigen Ufern, anch auf Lehmboden um den Ziegel- 
stadl, sehr hänfig. Diese vielgestaltige Pflanze hommt hier besonders in folgenden Formen vor: o piloselloides (Vill.) Ausläuferlos, sehr zart, kleinköpfig (7. B. an sandigen Ennsufern, auf' Kalkboden im Gesäuss. F Reichemlatchii Rchb. Jc. 'Tfl. 123. Auslänferlos, etwas robuster, Köpfchen noch klein, Hülle sternharig und drüsig, Blätter stark seegrün, ganz kahl oder blos an der Basis bewimpert. (Mit der var. o. und in sie übergehend.) "o olscinlum Rchlb. Stärker behaart, blos am Rande oder auch anf' der Blattfäche, kräftiger. mit grüsseren Küpfchen und schwärzerer, sternhaariger und drüsiger Hülle: bisweilen ist der Blüthenstand gedrungener, der Hüllkelch selır dicht drüsig und ausserlem noch rauhhaarig, so dass fast nm Farbe und Grösse der Blätter einen schwachen Unterschied von pratense bieten: ebenso zahlreiche Uebergänge zu var $\beta$. o lallax Koch lichb. Tafel 121. Grosse, üppige Lehmform mit behlütterten, meist aufstrebenden, blüthentragenden Ausläufern, drüsiger oder auch rauhhaariger Hülle. Blätter an Grösse denen des pratense siclı nälıernd; blos die seegrüne Farbe derselben und der lockere Blüthenstand geben - zweifelhafte, durch Uebergänge rerwischte - Unterschiede. Un den Admonter Ziegelstadl.

520. H. pratense Tsch. Auf Wiesen, an Grasplätzen, Feldrändern, auf Lehmboden, im Enns- und Paltenthale häufig bis auf die Berge, z. B. am Weg in's Gesäuss, am Lichtmessberg, beim Teichmeister (Angelis!), um den Ziegelstarl, bei Dittmannsdorf. Hieher gehört wohl auch: ,H. crmosum I. Im Enns- und Paltenthale" Maly 1868.

521. H. anrantianm L. Auf Alpenwiesen zwischen Krummholz unter den Vormauern des Kalbling riemlich luäufig, ebenso im Triebenthale, in einem W äldchen zwischen Hohentanern und S. Johaun, auf der Südseite des Hochschwung (5600'), am Blahberg in der Strechen; am Pyrgas selter.

522. H. staticifolimm Vill. Auf sandigen, steinigen Stellen der Ebene des Emnsthales bis in die Voralpen selı gemein, aber fast nur auf Kalkschutt, z. B. gegen Mühlau an der Fssling, am Schwarzenbach, um die Grstadtmayrroralpe, am Wege in's Gesäuss, im Gesäuss, Johnsbaclıgraben, Rauchborlen, Laftawald, am Schafwege des Kalbling, hinter der Kaiserau.

523. H. porrifolimm I. Auf Felsen und im Felsschutt der Kalkroralpen bis in die Kalkschluchten der Ebene luäufig: An Scheiblstein, auf der Pitz, im Schwarmenbach- und Bruckgraben, Rauchboden, am Schafweg des Kalbling, im Sunk, um den Gamsstein bei Jolnnsbach etc.: am liäufigsten im Gesäuss und Johnsbachgraben. Neist $\alpha$ armeriaefolium Froel, seltener auf Voralpen $\&$ denticulatum Koch.

524. H. louplenoides Gmel. An felsigen, somnigen Abhängen unter der hohen Kalblingmaner ziemlich hüufig (kleiu, kalıl- oder fast kahlblättrig, Blätter lanzettlicll bis lineal); auf ïppigen Voralpenwiesen zwischen Krummholz ob der Gistadtmayrvoralpe am 
Scheiblstein sehr häufig (hoch, Blätter lanzettlich bis lineallanzettlich, fast kahl bis ziemlich behaart, schwach-bis starkzähnig, aber Blüthenhülle gleichmässig rauhhaarig); sehr selten am Hexenthurm und Steinamandl.

525. H. glabratum Hoppe. Auf trockengrasigen, etwas felsigen Abhängen in der Krummholzregion des Kalkzuges: Am Pyrgas (Zehenter'), Scheiblstein hoch ob der Gstadtmayrvoralpe mit villosum häufig, am Kalbling sehr sparsam (Angelis! Hatzi! Haffner!), in den Johnsbacheralpen (Maly 1868). Uebergänge zu villosum sind nicht selten, indem oft blos einige der unteren Blätter kahl sind; daher wohl Varietät.

526. H. villosum Jcq. Auf trockengrasigen, mehr oder minder felsigen Abhängen der Krummholzregion des Kalkzuges; auch, doch mehr vereinzelt, auf Waldfelsen: Häufig am Pyrgas, Scheiblstein, Kalbling (besonders am Fusse der hohen Mauer), vom Scheibleck zur Schafleithen hinüber, am Natterriegl, Damischbachthurm, in der Johnsbachergruppe; viel seltener im Tanernzuge, z. B. unterhalb der Spitze des Steinamand, auf der Südseite des Hochschwung bei 6000'. Ausser der Normalform findet sich in den Admonter Alpen H. flexuosum W. K., eine Form mit oberwärts kahler Blattfläche (Hatzi!), ferner, z. B. am Pyrgas, var. glabrescens F. Schultz (leg. Oberleitner!), die Uebergangsform zu glabratum, und besonders an Waldfelsen beim Anfstiege zur Scheibleggerhochalpe, die forma elata luxurians Hegetschw. Auch $H$. dentatmm Hoppe: An felsigen Orten der Johnsbacher Alpen (Hatzi!)" Maly 1868 ist nach Ex. des Herb. Hatzi blos die schwächer zottige Form der Voralpenfelsen von villosum.

527. H. Schraileri Schleich. Auf der Scheiplalpe am Rottenmannertauern (Sommerauer); wurde zwar in Maly aufgenommen, wurde aber seither nie mehr gefunden; Angelis bezweifelt auch die Richtigkeit der Bestimmung.

528. H. villoso-murorum Neilr. Ein Exemplar sammelte ich unterhalb der Griesweberalm am Waldwege. Behaarung von villosum, Blattform und Nacktheit des Stengels von murorum $I \quad \beta$ glaucescens. Nlr.

529. H. mnrorum I a silvaticum Nlr. In Wäldern, Holzschlägen, auf Bergen bis in die untere Alpenregion, besonders des Kalkzuges, sehr gemein und ausserordentlich reich an Formen; bemerkenswerth schienen mir folgende:

a. rotundatum $=\alpha$ vulgare Rchb. Jc. Blätter gleichgestaltet, gerundet oder schwach herzförmig, kaum gezähnt, Hülle drüsig bis drüsenlos. In Kalkvoralpenwäldern mit anderen Formen gemischt nicht selten.

b. dentatum. Blätter mässig gross, kurz gestielt, nicht besonders tief gezähnt, Hülle meist drüsig. In Wäldern die gemeinste.

c. incisum. Blätter gross, langgestielt, an der Basis tief eingeschnitten gezähnt, meist etwas länglich, Hülle drüsig bis drüsenlos. 
Auf üppigen Voralpenhöhen, \%. B. Bärnkoppe, Pyrgas, Scheiblstein, Brucksattel, vor der Farchneralm bei Johnsbach; seltener in Wäldern.

d. alpestre firis. oblongum Jord. Blätter schmäler, lïnglich, Blüthenstand 1 bis wenigküpfig, wenig drüsig bis drïsenlos. Auf höheren Voralpenwiesen des Kalkzuges, besonders in Lichtungen zwischen Krummhol\% hïufig, z. B. Schafweg, Kall\}ling, Ardningïbergang, Sulzkahı.

•. Nehile. Schwächlich, mit kleinen, lünglichgermuleten, meist in den Blattsticl zugespiczten Wur\%el- mul 1-:; gleichurestalteten Stengelblättern, 1 _-2 köpfig, eine Uebergangsform \%u \% polyphyllum. In 'Tief- und Hochwälderı \%erstrent, ziemlich lıäulig.

f. pilosissimmm firen. God? Blätter ganz wic bei form. b., aber an der Unter- und Oberseite dicht wollhanrig. Am Schaflerwege unter Fichten im Waldmoose gemeinschaftlich mit form. b.

F. grlancescens Nhr. (Felsenform). An steinigen, felsigen Orten, besonders Waldfelsen, im Kalkschutte, anf Kalksand der Giessbäche fast überall, aber ziemlich vereinzelt. Folgende Formen wären hervorzulleben:

a. Lafifolimm. Blïtter breit, bisweilen herförmig oder eingeschnitten-gezöhnt. lü̈nfig branngefleckt. Stimmt, wenn drüsenlos, mit Rchb. Abbild. von incisum Hoppe überein und ist mit $x$ silvaticum b. dentatum ziemlich analog. Besonders hälutig auf Waldfelsen ron der Bïrnkoppe zur Stumpfnagleralm. Geht über in

b. angustilolinm. Blätter lanzettlich, buchtig gezähnt bis fast ganzrandig. Nach Rehb. Abb. 'Ifl. 163 identisch mit laevigatum W.

c. pymaem = bitidum Kit. nach Koch. Line gabelüstige, drïsenlose $/ /$ wergform der Kalkalpen mit kurgestielten Blättern, theilweise wohl Bastard mit villosmm. Auf felsigen Abbängen unter der holen Kalblingmaner nicht sehr selten: anch im Herb. Hatri!

i polyphyllum Nhr. (vulgatmm Fr.) An Rainen, im Schatten der Wäßder, an Bächen, auf Bergen und Voralpen des Kalk- und 'Tanernzuges häufig, doch scltener, als var. a, nur unter den Linden des Stiftsteiches sehr gemein. Variirt ebenfalls sehr mit elliptischen, länglichen, lanzettlichen, buchtig- bis kaum gezähnten Blättern, drïsigen bis drüsenlosen Hüllen, wenig- bis reichbeblättertem Stengel. Eine kleine Voralpenform erscheint laäufig am Kalbling zwischen Krrummholz bis zur Fichtengrenze herab und anf der Höhe des Hund: eine langblätterige, dichturüsige Varietät simmelte ich auf Felstriften der Hochibaide ob dem Gemeinsec.

530. H. amplexicaule I. An felsigen, buschigen Stellen der Voralpen ïusserst selten, bisher nur auf Schicferfelsen im Strechengraben gefunden.

581. H. alpium I. Auf grasigen Orten der Voralpen und Alpen im Tauernzuge sehr gemein, in der Kalkkette viel seltener (am Kalbling, Scheiblstein bei 6000'): variirt sehr wenig, nur cine rar. longifolia ob dem Scheiplsee und var. macrocephala (mit 23 mal grösseren Köpfchen) am Hochschwung wäre erwähnenswerth. 
532. H. intyloacemm WIf. (albidum Vill.) Auf üppigen Voralpenwiesen des 'Tauernzuges zerstrent: unter der Höhe des Steinamandl und Kampl, ob der Bacheralpe rechts rom Wego zum Gemeinsee auf Felstriften häıfig, am Bösenstein, sehr häufig am Blahberg in der Strechen $\left(4500-5500^{\prime}\right)$.

533. H. prenantloides Vill. Am Rande der Getreidefelder um Hohentauern (4000') sehr häufig, unter Krummholz von der Gstadtmayrhochalpe zum Scheiblstein ziemlich selten.

534. H. rigidum Hartm. In Wäldern am Lichtmessberge, unter Röthelstein, unterhalb Frauenberg, im Wolfsgraben etc. zerstreut, nur auf Schiefer.

535. H. boreale L. An Waldrändern des Lichtmessberges, im Wäldchen unter Röthelstein, im Enns- und Paltenthale selten.

536. H. mmlıellatum I. In lichten Wäldern, an buschigen Abhängen, auf Feldern, Rainen, Mooren gemein, z. B. Lichtmessberg, Hoffeld, Krumau, unter Schilf an den Ennsarmen oft in riesigen Exemplaren.

\section{Fam. Campanulaceae DC.}

537. Jasione moníana L. Auf grasigen, buschigen Rainen, an Wald- und Wegrändern des Lichtmessberges von der Höhe gegen Dittmannsdorf linab stellenweise häufig (Schiefer).

538. Phyteuma pauciflorum L. (nebst der kaum erwähnenswerthen var. $\beta$ globulariaefolium Hoppe) Auf den höchsten Abhängen der Tauernkette ziemlich selten: Am Bösenstein ( $\alpha$ und $\Leftarrow$ ), vom Mitterstein gegen die Hoclıhaide limanf, am Griesstein (Stur, $\alpha$ und $\beta$ ), bei den Felsen des Hochschwung.

539. P'ı. confusum Ker'ner. Auf steinigen Höhen des 'T'uternzuges von 5500' an sehr hänfig, z. B. am Bösenstein, ob der Bacheralpe bis zur Höhe der droi Stecken und der Hochliaide, am Hengst, Steinamandl, Hochschwung etc.; sehr selten im Admonter Kalkgebirge: Am Pyrgas (Strobl sen!), Natterriegl?

NB. Plı. hemisplatericum I. wird ebenfalls am Rott. Tauern angegeben, doch beruht dies anf einer Verwechslung mit der vorigen; ich sammelte es nur auf den Tauern des oberen Ennstliales.

540. Ph. orliculare L. Auf grasigen Orten der Berge, Voralpen und Alpen im Kalkgebirge überall sehr häufig, noch bei $6000^{\prime}$ in einer 1-3" hohen, lanzettblättrigen Zwergform (= v. brevifolia Schl.) anf der Schatleithen; seltener im Tanernzuge, z. B. ob der Bacheralpe gegen den Gemeinsee, an der Hochhaide, vom Rücken des Steinamandl gegen den Globukensee hinab, an Felsen des Hochschwung.

541. Pl. Michclii Bert. a betonicaefolium (Vill.) Kch., \& scorzonerifolium (Vill.) Auf grasigen Abhängen der Berge und Voralpen im T'auernzuge ziemlich häufig, seltener in der Alpenregion: Unter Gesträuch ob dem Scheiplsee sehr häufig, ob der Bacheralpc, am Steina- 
mandl, Kampl, Hochschwung, Blahberg in der Strechen; auch auf Granwackenschiefer: am Lichtmessberg rom Nagelschmied gegen Dittmannsdorf, am Unterkalbling, um liöthclstein, S. Lorenzen etc.; im Sunk auf sil. Kalk. Fast immer var. F.

542. Plı. spicatum I. In Jambluölzern und fenchten Wäldern bis auf die Voralpen häulig: Kalk: Im Rauchboden, zwischen lírummholz ann Seheiblstein, am Anfstiege zum Pitz, zur Scheibleggerliochalpe, am Schafferweg, bei der 'T'reffineralm: Gneiss und Schiefer: Von der Pfarrerhub zur Bacheralm, auf Felstriften des Hochschwung.

543. ('ampanula pulla 1. Auf grasigen und steinigen Abluängen der mittleren Kalkalpen ziemlich lıäıfig, besonders in den Johnsbacherilyen und in Bachbetten von den Felsen der Schafleithen bis in die Waldregion des Kalbling: sowic von der Scheibleggerhochalpe abwärts.

344. Camp. caespitosa Scop. Im Schutt der Kalkbäche, auf steinigen Hïgeln und an Felsen der Kalkvorberge fast überall sehr häufig, schon in der Ebene, z. B. im Mühlauerwäldehen, im Gesäuss, Johnbachgraben; var. albiflora nicht hänfig am Südwestfusse der Kemetwand.

545. Camp. pusilla Hacnke. Auf sandigen, steinigen Orten, besonders in Schuttbetten, auf Felsen der Kalkkette von der Ebene bis auf die Hochalpen gemein, ebenso anf Schiefergeröll, Schiefer- und Gneissfelsen des Tauernzuges; böchster Standort im Kalkzuge auf der Schafleithen bei $6000^{\prime}$; auf der Scheibleggerhochalpe fand ich anch eine winzige, grossblumige Hochalpenform, wahrscheinlich $=$ Hoppeaua Rupr. Rehb. Je.

546. Camp. Schenchzeri Vill. In Bergwäldern, anf Voralpen- und Alpenwiesen des Kalk- und 'Tauernzuges überall sehr lüufig, doch etwas mehr vereinzelt, bis $6000^{\prime}$.

547. Camp. rotumdifolia I. An sandigen Rainen, auf Felsen, alten Mauern, Wiesen, zwischen Gestrüuch hüufig, z. B. Wiesen beim Griesmayr, Raine in der Kruman, Schieferfelsen innerhalb der Klamm; besonders gemein im Werfnerschieferzuge rom Leichenberge bis Liezen; var. Hostii (Bmg.) selten an schattigen Hïgeln vor Frauenberg.

548. ('amp. rapunculoildes L. An wästen Plätzen, unter Bäumen (z. B. im Stiftsgarten, um Admont, Röthelstein) im Ennsthale nicht sehr häufig, gemein aber in Wüldern um Strechau und von der Kilamm einwärts in die Strechenschlucht (Kalk, Schiefer, Alluvium).

549. Camp. patula I. In Feldern, Wiesen, Obstgiarten bis anf die Voralpen höchst gemein; eine winzige Alpenform fand ich noch bei $6200^{\prime}$ am Steinamandl (Gneiss).

550 . Camp. persicifoliat 1. Anf buscligen Hügeln, an schattigen Berglchnen riemlich häufig, besonders anf Werfnerschiefer und Granwacke: Am Leichenberg, gegen Franenberg, bei I)ittmannsdorf, an der Fahrstrasse nach Hohentanern, in den Strechanwälderu, von der Klamm einwärts etc. 
551. (amp. Trachelimm I. Unter Gebiisch, an Zäunen, in Vorhölzern sehr häufig bis anf die Voralpen, zumeist anf Kalk (z. B. Gesïuss, Rauchboden, Sunk), doch auch anf Alluvium und Granwacke sehr verbreitet.

552. Camp. glomerata I. An grasigen Hügeln, Wegrändern, in Wiesen sehr häutig, vorzüglich in der Schultering bei der alten Enms massenhaft.

553. Camrp. alpina Jcy. An steinigen Abhängen und auf Triften der 'Tanernkette von 5-7000' häulig, z. B. ob dem Scheiblsee, von der Bacheralpe gegen den Grün- mod Gemeinsee hinauf, auf der Hochhaide, am Steinamandl, Hochschwung; sehr selten anf Kalk am Kalbling (Altes Verzeichniss).

554. Camp. barloata L. An waldigen und grasigen Stellen der Berge bis auf die Voralpen im Tanern- und Granwackenzuge sehr hänfig, im Kalkgebirge jedoch selten: von der Kemetwand zur Scheibleggervoralpe und var. Hore albo auf' der Treffneralm; es dürften aber selbst diese Standorte noch zur Grauwackenzone gehören.

\section{Fam. Rubiaceae Juss.}

555. Shorardia arvensis l. An Wegen, auf Aeckern und Brachfełdern gemein.

556. Asperula cynanchica 1. An sonnigen, felsigen Orten im Gesüuss gegen Gstatterboden und im Johnsbachgraben häufig.

557. Asp. odorata 1. In sehattigen Bergwäldern stellenweise sehr häufig, z. B. am Aufstieg zur Scheibleggerhochalpe, am Pyrgas, Brucksattel, im Gesïuss ete.

558. Galium Cruciata (L) Scop. An Wegen, Zäunen, zwischen Gebüsch, auf Bergwiesen und an Waldründern fast gemein.

559. (ial. vermum Scop. Am Leichenberg (Altes Verzeichniss).

560. (4al. A parine L. a vulgare Rehb. Je. Zwisehen Hecken, an Käunen und Bretterwänden ziemlich häufig; var. infestum (W. K.) unter Getreide selten.

561. fial. uliginosum L. Auf sumpligen Wiesen und Waldstellen, an Wassergrüben sehr hïutig, z. B. in der Krumau, beim Griesmayr, in den 'Iriebnersümpten, im Bürgerwalde Rottenmann's bei der Brumnenhütte.

562. (ial. palustre I. Auf sumpfigen Wiesen, im Schlamme abgelassener 'T'eiche, an Bächen sehr hïnfig, z. B. in der Kíruman, den 'Iriebnersümpfen, Stiftsteichen, am Pyrgasbacho.

563. Gal. rotmudifolimm I. In Wäldern bis auf die Voralpen sehr hänfig, z. B. an Schaflerweg, Klosterkogel, Pyrgas, im Bürgerwalde Rottenmann's. Hatzi!.

564. Gal. borcale 1. "Un Admont (com. Schaefer)" Herb. 
565. Gal. Verum I. Auf trockenen Wiesen, an Rainen und Wegrändern gemein.

566. Gal. silvaticum I. Auf busehigen Sandhügeln im Gesäuss. in fenchten Schluchten und dunklen Wüldern des Kalk- und Tanernzuges bis $4500^{\prime}$ sehn hänfig, $\%$ B. Am Mïhlauerfall, im Rauchbodenwalde, Aufstieg zum Scheiblstein, zur Seheibleggerhochalpe; im Wolfs-. Strechengriben, unterhalb der "Kothhütten".

NB. Gal. alristatum L. wird von Sommeraner ,am Brïnerüberwurf bei Admont", in einem alten Verzeichnisse "in den Auen an der Enns" angegeben; da jedoch aristatum eine mehr sïdliche Pflanze ist, dürften diese Angraben wohl anf irgend einen Bastard sich beriehen.

567. Gial. Mollugo L. Auf Wiesen, zwischen Gebüsch, an Züunen und Wegräuderı selır gemein, auch auf Sandhügeln im Gesäuss hänfig.

568. Gal. rigidum Vill. (lueidum Koch, non All.) An steinigen Abhïngen, auf Sandhïgeln, in Giessbachbetten der Berge und Voralpen des Kalkzuges sehr häufig; z. B. Gesäuss, Johnsbachgraben, Bruckgraben, Rauchboden, Laffawald, Sulzkahr, Schwarzenbachgraben, am Scheiblstein, Pyrgas, Kalbling.

569. Gal. austriacum Jacy. 1773. (sylvestre Poll. 1776 \% glabrum Kch, $\beta$ scabrum (Jcq.) An trockenen, steinigen, sandigen Stellen, besonders auf sonnigen Rainen und an Waldrändern von der Ebene bis auf die Voralpen im ganzen Gebiete lıäufig, meist $\%$.

570. Gal. anisophyllum Vill. (sylvestre var. alpestre u. r. supinum Koch). Auf grasigen Stellen der Alpen im ganzen Gebiete hïufig, z. B. Pyrgas, Scheiblstein,. Kalbling, Griesweberalm, Johnsbacherkette, Bösenstein, Hochschwung.

571. Gal. baldense Spreng. An grasigen Stellen in der Hochalpenregion des Kalkzuges gemein, z. B. am Pyrgas, Scheiblstein, Natterriegel, Buchstein, Kalbling, Sparafeld, in der ganzen Johnsbachkette von $5000^{\prime}$ aufwärts. Ist helveticum Maly, aber nicht Weigel; letzteres sammelte ich nur am Dachstein.

\section{XXXY. Fam. Lonicereae DC.}

572. Adoxi Moscliatellina L. An feuchten Orten unter Strauchwerk sehr häufig, 7. B. massenhaft unter den Alleeen des Stiftsgartens, zwischen Stiftsgarten und Ziegelstadl, in der Santratte, am Beginn des Schafferweges, an Zäunen bei Büschendorf' und Singsdorf.

573. Sambucus Ehulus L. Anf freien Waldplätzen der Berge hie und da gemcin, z. B. am Aufstieg zum Brucksattel, im Laflawald (besonders in der Nähe des Steinkohlenlagers), am Anfstiege zur Pitz, Plösch, Arling, vol'm Strechengraben; auch an Ackerrïndern vor Weng, am Wege nach Franenberg, von der Klause bis Liezen häufig. 
574. Samb. nigra L. An Zäunen, Wegen, Gebäuden, in Wäldern gemein; var. variegata (mit weissgescheckten Blättern) von P. Otlımal' Berger einmal gesammelt!.

575. Samb. racemosa 1. In Schluchten und Wäldern der Berge des Kalk- und 'Tanernzıges häufig, z. B. Gesäuss, Aufstieg zur Scheibleggerhochalpe, zum Kalbling, um Aigen, im Wolfs- und Strechengraben.

576. Viburmum Lantana I. An Zä̈nnen und Waldränder’n um Admont hie und da vereinzelt, z. B. vol'm Gesänss, an der Essling.

577. Vib. Opulus I. An fenchten Hecken mod Uferstellen sehr häufig, vorzüglich dem ganzen Ennslaufe entlang und in Alleeen des Stiftsgartens; im Stiftsgarten auch kultivirt als var. sterilis DC.

578. Lonicepa Xylostemm L. An /äunen, Hecken, in Wüldern nicht gerade liänfig, z. B. im unteren Stiftsgarten, vor'm Hofmoos, vor'm Gesäuss, unter der Kemetwand; sehr häıfig nur an der Essling.

579. Lonl. nigua I. An buschigen Stellen der Berge und Voralpen im Kalkzuge hie und da, meist vereinzelt: Gesänss, Johnsbachervoralpen, Scheiblstein zwischen Krummholz, Aufstieg zur Scheibleggervor- und -hochalpe, Schafferweg; Kalbling; hommt nach Strobl sen. anch in der Ebene (am Weg zum Heindl und an einem Zanne rol'm Hofmoos) vor, dürfte aber wohl vorige sein.

580. Lon. alpigena I. An buschigen Stellen der Berge und Voralpen im Kalkzuge fast überall lıäufig, auch schon am Bache des Oberhoffeldes, im Gesäuss und Johnsbachgraben.

581. Lour. coerulea I. An felsigen Stellen um den Scheiplsee (Hatzi!, Gneiss): am Hochschwung (Sïdseite, 6200', Gneiss) nicht selten; im Walde unter der Griesweberalm vereinzelt und im Hartlersgraben stellenweise läufig (Kalk).

\section{XxxVI. Fam. Oleaceae Lindl.}

582. Ligustrum vulgare L. In Hecken und Vorhölzern hin und wieder, z. B. am lisslingufer, am Aufstiege von Weng zur Buchau.

583. Syrunga vulgaris $L$. In Gärten sehr hänfig kultivirt.

584. Fraximus excelsior 1. An Bächen, Wegen, Zäunen, in Wäldern bis auf die Voralpen zerstrent oder truppweise sehr hänfig; var. pendula (Vahl) im Stiftsgarten kultivirt.

\section{Fam. A poeyneae Lindl.}

585. Vinca minor 1. An schattigen Waldrändern, anf buschigen Rainen zerstrent: Waldrïnder hinter Grünbüchel bei Rottenmann, bei Frauenberg, im Oberhoffeld, im Waldgraben beim Grabner vor Weng (Hatzi!). 


\section{IXXVII. Fam. Asclepiadeae R. Br.}

586. Vincetoxicum officinale Much. Auf steinigen, buschigen Hügeln, in lichten Wäldern auf Kalk sehr häufig 1 m Strechau, im Gesïluss, Rauchboden und Laftawald; sonst zerstrent.

\section{TXXYIII, Fam. Gentianeae Lindl.}

587. Menyanthes trifoliata L. Anf tieferen Stellen der Moore, in Wassergräben, an Teichrändern sehr hänfig: Hof-, Krumauer-, Wolfsbacher-, Triebnermoor, Griesmayrsumpf, Temmel-, Krumaner-, Tauernteiche, sumpfige Stellen unterhalb der Kothhütten ete.

5SS. Swertia peremis I. Auf sumpfigen Wiesen und an Gräben der Kaiseran gleich hinter der Sägemühle hänfig, an nassen Stellen ob den letzten Almhütten der Strechen am Hochschwung (5000') nicht häufig (Grauwacke, Gneiss).

589. Gentiana punctata l. Auf Voralpen- und Alpenwiesen des Kalkzuges sehr vereinzelt (am Kalbling, Scheiblstein, um die Stumpfnagleralm etc.), viel häutiger anf Schiefer- und Gneissgebirgen: auf der Plösch, ım den Scheiplsee am Bösenstein, ob der Schaunitzeralm im Triebenthal, um den Grün- und Gemeinsee, anf Hochhaide, Steinamandl ete.

590. Gent. pammonica Scp. Auf Voralpen- und Alpenwiesen des Kalkzuges bis zur oberen Krummbolzgrenze häufig (um die Stumpfnagler-, Griesweberalm, am Pyrgas, Scheiblstein, Kalbling, im Sulzkahr, besonders häufig im Walde zwischen Sunk und dem Dorfe Hohentauern (silurischer Kalk): seltener auf Gneiss- und Schieferalpen: Um die Scheiplseen am Bösenstein, you der Bacheralpe aufwärts, um die Felsen der Hochlıaide und des Hochschwung, am Steinamandl etc.

591. Gent. cruciata L. An düren Waldrändern, Waldwegen, trockenen Bergabhängen bis auf die Voralpen der Kalkkette sehr hänfig. z. B. im Wäldchen vor'm Gesänss, vor Mühlan, um die Gstadtmayrvoralpe, im Laffawald, am Brucksattel, Lichtmessberg, Kalbling.

592. Gent. asclepiadea L. Auf Sumpfwiesen beim Griesmayr, an Waldründern und in Bergwäldern des Kalkzuges überall gemein; seltener anf Schiefervorbergen der Tanernkette.

593. Gent. Pnenunnanthe 1. In einer Sumpfwiese beim Griesmayl einmal 1 Exemplar gesammelt.

594. Hent. frigida Haenke. Auf dem Grieskogel im 'Triebenthale, einem Anslüufer der Seckanerkette, sehr häufig (Angelis!).

595. (ient. firma (Neilr.) Kirm. = acaulis Aut. An fenchten felsigen Stellen der Voralpen bis hoch in die Alpenregion des Kalkzuges fast überall sehr hänfig, schon an Mühlanerfall und im Gesāuss. 
596. Gent. alpina Vill.. (excisa Presl.) In der ganzen Tauernkette $\left(4500-6500^{\prime}\right)$ sehr häufig, sowohl an nassen Bachrändern, als auch auf dürren, mit Heidelbeeren bewachsenen Abhängen.

597. Gent. bavarica L. Auf grasreichen Wiesen und Abhängen aller höheren Kalkalpen gemein, im Tauernzuge selten, nur ob der Schaunitzeralm im Triebenthale von Angelis und am Hochschwung von mir gesammelt.

598. Gent. Iracliyplylla Vill. An felsigen oder kurzgrasigen Abhängen höherer Kalkalpen nicht häufig: Zwischen Kalbling und Schafleithen, ob der Scheibleggerhochalpe, am Pyrgas, Scheiblstein, Natterriegel, Buchstein.

599. Gent. verna L. Auf Wiesen im Enns- und Paltenthale streckenweise äusserst gemein; steigt bis auf die höchsten Gipfeln der Kalkgebirge, wo sie oberhalb pumila, bavarica und brachyphylla nicht selten, doch blos vereinzelt, vorkommt, z. B. am Pyrgas, Scheiblstein, Kalbling; zwischen Mühlanerfall und Kochenalm variirte sie mit lichtblaner, dunkelblaner und violetter Krone, letztere mit etwas längerer Blumenröhre; im Tauernzuge nur am Hochschwung ziemlich läufig; auch var. alata Neilr. (verschieden von der südlichen aestiva R. S.) findet sich hin und wieder, Z. B. auf der Kochenalm, am Kalbling.

600. Gent. pumila Jacy. An grasigen Stellen höherer Kalkalpen sehr häufig, meist mit bavarica, oft an den Rändern der Schneegruben und Schneefelder, z. B. am Pyrgas, Schibibtein, Natterriegel, Buchstein, Hochthor, Hund, im Sulzkahr, um die Scheibleggerhochalpe, am Kalbling bis zum Fuss des Sparafeld.

601. Gent. nivalis L. An grasigen Abhängen und auf Wiesen der Voralpen bis zu den höchsten Gipfeln des Kalkzuges fast überall, doch meist nicht sehr bäufig, am häufigsten wohl $\mathrm{nm}$ die Scheibleggerhochalpe; im Tamernzuge sehr selten am Hochschwung.

602. Gent. germanica WV. In trockenen Nadelwäldern, an Waldrändern des Ennsthales, an schattigen und sonnigdürren Abhängen der Berge im ganzen Gebiete verbreitet, auf Kalk, seltener Schiefer und Gneiss.

603. Gent. olutusifolia W. Wie vorige, doch mehr in höheren Lagen, bis über $6000^{\prime}$ im Kalkzuge gemein; im Hochgebirge meist var. pyramidalis (Nees), oft auch var. albiflora und var. uniflora (W), z. B. alle Var. am Kalbling, Hochthor, auf der Scheibleggerhochalm; im Tanernzuge seltener, z. B. am Hochschwung, Grieskogel, ob der Bacheralpe.

604. Gent. ciliata L. An Waldrändem, Rainen, felsigen, buschigen, grasigen Stellen der Berge und Voralpen auf Kalk fast überall und meist sehr häufig; viel seltener auf Schiefer (Plösch) und Gneiss (Steinamandl).

605. Erythraea Centamrinm (L.) Pers. Anf buschigen Plätzen und in Holzschlägen hie und da zerstreut, nur bei Johnsbach nach Angelis in manchen Jahren häufig. 
606. Eir. pulchella (Sw.) Horı. Auf feuchten Wiesen der Krunau, an Grabenrändern und um Lachen (z. B. beim Griesmayr) nicht selten.

\section{Fam. Labiatae Juss.}

607 . Mentha silvestris I. var. vulgaris Kcl. u. v. canescens (Roth). An Quellen, Bächen, Wassergräben, wüsten Stellen, besonders in Holzschlägen bis auf die Toralpen äusserst gemein; var. crispa ('I'en) wird hä̈nfig kultivirt: var. balsamea (Wlhr.) findet sich nach Fürstenwärther (Herb. Johınnei) am Gaishorusee.

608. 1I. piperita K. Häufig kultivirt im Stiftsgarten (Angelis!) ete.

609. N. Inuatica 1. In Sümpfen, Bächen, Wassergräben, sowie an schlammigen, lelımigen Rändern derselben gemein. An trockneren Standorten (z. B. am Nordrande des Hofmoores; an Ufern der Krumaner-Ennsarme) sind Blïtter und Stengel überall ziemlich dicht behaart ( $=$ F hirsuta W.); im Grunde der Griesmayrlache und ihres Ausflusses, sowie soust an ïberflutheten Stellen, sind die Stengel spärlich, die Blätter blos an den Nerven behaart (= var. $\delta$ glabrata Maly): die Normalform ( $\alpha$ genuina G. G.) steht zwischen $\beta$ und $\delta$ in der Nitte; Scheinquirle sind gewöhnlich 2-3, in der Sautratte fand ich aber auch sehr häufig - 15 eine unterbrochene Aehre bildende ( $=$ v. subspicata Weihe).

610. M. \#vensis L. $\propto$ vulgaris Koch. Auf Getreideäckern beim Ziegelstadl, an Wegen, Strassengräben gegen Frauenberg, Mïhla!l etc. sehr häufig: var. glabriuscula Koch: An schattigen, feuchtlehmigen Räidern der Fnusarme in der. Krumau, Schultering ete. sehr laäufig und ïppig mit langen Auslïufern; anch an Gaishornsee (Verbniak im Herb. Johann. als gentilis).

611. M. sativa 1. \% vulgaris Koch. Anf nassen Wiesen um Admont von Strobl sen. gesammelt; ich besitze 1 Ex., das sich von arvensis fast nur durch die längeren Kelchzähne unterscheidet.

612. II. gentilis I Koch. Host. An Gartenzäunen. hie und da (z. B. bei Weng, in der Krumau) als Flüchtling; „in Sumpfwiesen bei Adınont" Vorbniak in Herb. Johannei.

613. Lycopus empopens L. In Gräben, Sümpfen, Mooren, an Teichen schr läufigr, z. B. 'Triebuer-, Frauenberger-, Hofmoor, Kruman, Temmelteich; im Hofmoor auch sehr dicht gran behaarte Fixemplare ( $\vee$. canescens Hausm. = L. mollis Kerner $\%$ ).

614. Salvia rglıtinosa I. An Waldrändern, in Wüldern und Holzschlägen von der Ebene des Enns- und Paltenthales bis auf die Voralpen der Kalk- und Sehieferzone äusserst gemein.

615. S. pratensis 1. Auf Wiesen und an Rainen un Admont ziemlich selten.

661. S. Verticillata I. An Rainen, somnigen Hügeln, Ackerrändern, auf Schuttplätzen schr gemein bis in die Voralpen.

617. Origanum vulgare L. An Wegrändern, auf steinigen 
Hügeln, in Holzschlägen, in der Berg- und Voralpenregion der Kalkzone überall böchst gemein; selten v. albiflora (Hatzi!).

618. Thymus Serpyllum L. p. p. Chamaedrys Fr. Auf Wiesen Rainen, Hügeln, an Weg- und Waldrändern sehr gemein.

619. Th. alpestris Tsch. (pulegioides Lg.) Auf Voralpen und Alpen des Kalkzuges, z. B. am Schafferwege, Kalbling, häufig, selten im Gneissgebirge.

620. Th. lumifusus Bernlı. (Von Serp. verschieden durch allseitige Behaarung des Stengels, weithin niedergestreckte Stengel und kurze Zwischenknotenstücke). An deuselben Standorten, wie Serpyllum und ebenfalls selır hänfig. Variirt \% microphyllus m. (Form der Tiefregion), $\beta$ macrophyllus $m$. (Form der Kalkalpenwiesen, z. B. Kalbling, Buchstein).

621. Calamintha Acinos ( $\mathrm{L}$ ) Claiur. Auf Aeckern, trockenen Hügeln, wüsten Stellen, besonders des Schieferbodens, ziemlieh häufig, z. B. bei Trieben dem Bache entlang, vom Griesmayr zur Enns hinab, innerhalb der Klamm.

622. Cal. alpina (L) Lam. An steinigen Orten der Kalkzone von der Ebene bis auf die Alpen höchst gemein, besonders im Schutt der Giessbäche.

623. Clinopodium vulgare $\mathbf{l}_{\text {. }}$ An steinigen Wegrändern, buschigen Hügeln, Waldrändern und in Holzschlägen bis anf die Voralpen sehr gemein, besonders in der Kalkkette.

624. Nepeta Cataria L. An Zäunen, Wegrändern, wüsten Plätzen, vorzüglich in der Nähe von Häuseru durch das Enns- und Paltenthal bis $4000^{\prime}$ verbreitet, wegen des vereinzelten Vorkommens aber im Ganzen selten: An Hänsern bei Weng, Hall, Dittmannsdorf, Trieben, in der Klamm, zwischen S. Lorenzen und Singsdorf, am Strechanfelsen, anf der Höhe des Leichen- und Lichtmessberges.

625. (ilechoma hederacea I. Auf Hügeln, Mauern, an Wegund Waldrändern, in Gärten sehr gemein.

626. Lamium purpmenm L. Auf Aeckern, in Gemüsegärten äusserst gemein, seltener an Wegrändern und wüsten Plätzen; sehr selten var. albiflora.

627. Lam. maculatum I. An Züunen, wüsten Plätzen, buschigen Hügeln und Bachufern gemein; auch die schöne Spielart var. vittatum hie und da, z. B. am Lichtmessberg, auf feuchtschattigen Rainen gegen Weng gruppenweise häufig.

628. Lam. album L. An Zännen, Wegen, auf Schutt, in Obstgärten sehr häufig, ebenso um die Hütten der Voralpen.

629. Laun. Galeobdolon (L) Cr. var. montanum Pers. In Gebüsch, an Zäunen, Bïchen, in schattigen Wäldern der Ebene hänfig, viel lıäufiger jedoch im Kalkgerölle der Voralpen, z. B. unter den Pyrgasmauern, der Bärnlioppe, am Almsteig des Kalbling, um die Farchneralm bei Johnsbach.

630. Galeopsis angustifolia Lilur. An steinigen, buschigen Orten, in Holzsclılägen, auf Kalkschutt der Voralpen an wenigen 
Stellen, aber in grosser Menge: Wegränder gegen Frauenberg, im Sunk, ob 'Trieben bei der Mauth.

631. Gial. Tetralit I. Auf wïsten Stellen, an Wegen, in Feldern, Aeckern und Holzschlägen sehr gemein, besonders unter Getreide lästiges Unkrant: var. albiflora seltener, \%. B. am Wege in die Krumau, nach Röthelstein.

632. Gal. bifida Biinn. An /äunen, Wegen, auf Feldern unter der Saat bei Admont nicht selten (!, Angelis!); nach Neilr. blos Var. der vorigen.

633. Gial. speciosa Mill. In Holzschlägen, Auen, an buschigen Wegräıdern, vorzüglich aber auf Getreidefeldern schr hä̈nfig.

634. Hal. pubescens Bess. Auf wüsten Plïtzen, an Wegen und Zäumen, schattigen 'Bergabhängen, auf Aeckern und Wiesen häufig, z. B. bei Trieben, Lorenzen, Bärndorf, Admont, vor'm Griesmayr, in der Línmau.

635. Stachys alpina I. An freien Waldstellen der Berge und Voralpen $\left(2500-5000^{\prime}\right)$ durch das ganze Kalkgebiet verbreitet, aber stets in wenigen Exemplaren und daher selten: Am Brucksattel, im Laffia wald, auf den Pitzweiden, vom Mühlauerwäldchen bis zum Pyrgasgatterl, am Schafferweg, Aufstieg zur Scheibleggerhochalpe, im Johnsbachgraben (Hatzi!), um die Farchneralm etc.

636. St. silvatica 1. An Waldrändern, in Hainen, Schluchten und unter Gestrïuch gemein, z. B. Stiftsgarten, Gesäuss, Röthelstein, Wolfsgraben.

637. St. palustris I. In Sümpfen, auf nassen Wiesen und an Wassergräben des Enns- und Paltentbales sehr häufig, auch an quelligen Stellen der Bergregion, z. B. ob Lorenzen.

638. St. recta 1 . Ist aus unserem Gebiete nur durch eine Notiz Hatzi"s "A uf Aeckern bei Admont" bekannt; ich fand sie blos im oberen Ennsthale bei Wörschach.

639. Betonica oflicinalis I. Auf Wiesen, Feldern, an Wegen und buschigen Rainen gemein.

640. Bet. Alopecuros L. Auf steinigen, buschigen Stellen der 'Thäler, Berge, Voralpen und mittleren Alpen (2-6000') äusserst gemein, aber nur auf Kalkboden.

641. Leomurus Cardiaca L. An Häusern, Zäunen, auf Schutt hie und da, selten z. B. bei Admont (Strobl sen!), am Mayrhofe, (Angelis!), ror einem Bauernhause am Wege nach Weng.

642. Scutellaria salericulata J. Auf sumpfigen Stellen der 'Torfmoore (bei Kruman, Admont, Frauenberg, 'Trieben), an Wassergrïben und Ennsarmen, um Teiche und Sümpfe des Enns- und Paltenthales ziemlich häufig.

643. Prumella vulgaris I. Auf Wiesen, Rainen, an Wegrändern, in Wäldern bis auf die Voralpen sehr gemein.

644. Ajugit reptaus I. Auf Wiesen und Grasplützen, an Rainen, Weg- und Waldrändern bis auf die Voralpen sehr gemein, auf Voralpenwiesen (z. B. des Kalbling) meist ausläuferlos = ; alpina (Vill.) Kch. 
645. Aj. genevensis L. Auf Wiesen, Feldern, buschigen Rainen und an Waldrändern stellenweise häutig: beim Ziegelstadl, von der Knappenbrücke gegen Hall gemein, beim Galgen vor'm Griesmayr, ob Dittmannsdorf etc. im Paltenthale (Kalk, Schiefer, Alluvium).

646. Aj. pyramidalis $\mathrm{L}$. In Voralpenwäldern, auf trockenen Weiden und im Haideboden der Tauernkette, sowie des Granwackenzuges häufig, z. B. von der Pfarrerluub bis über die Bacheralpe hinauf, um den Scheiplsee, die Kothhütten, im Oclisenkahr, durch die Strechen bis zum Hochschwung, am Plinten'sattel, Pyrgasgatterl (Werfnerschiefer), an Waldrändern hinter Kaiserau (Silur); sehr selten versprengt auf Kalk (am Schafferwege [Angelis!], ob der Schäferhütte am Kalbling).

647. Tencrimm Botrys L. Auf Kalkschutt ob der Eisenzieh am Wege über die Buchan ziemlich hänfig.

648. T. Chamaedrys L. Auf steinigen Hügeln, an Rainen und Waldrändern am Fusse der Kalkberge lı̈̈ufig, stets auf Kalk: Am Wege von Weng durch den Laffiwald zur Ennsbrïcke, von der Buchau zur Eisenzieh, im Gesäuss etc.

649. T. montanmm I. Auf Felsen, steinigen Abhängen, Schutthalden, an Giessbachrändern im Kalkzuge $\left(2-4000^{\prime}\right)$ sebr lıäufig, meist a majus Vis.: Im Gesäuss, Rauchboden, Laffawald, Johnsbachgraben, ob dem Wolfsbauern zum „unteren Boden “, um den Gamsstein, am Pyrgas, im Sunk, besonders $\mathrm{um}$ den Triebenstein (Sil. Kalk).

(Schluss folgt im nächsten Jahre). 
Flora von Admont.

\author{
Von \\ Professor P. Gabriel Strobl.
}

II. Theil. 



\section{Fam. Verbenaceae Juss.}

650. Verbena officinalis I. An Mauern, Wegen, auf Grasund Schuttplätzen äusserst gemein.

\section{Fam. Globularieae Bartl.}

651. Alohularia mulicaulis I. Auf steinigen Bergweiden, in Voralpenwäldern bis in die Alpenregion der Kalkkette, besonders unter Krrummholz sehr häufig, sowohl in der Kette der Hallermanern, als auch der Johnsbachermanern und der Kalblinggruppe.

652. G1ob. cordifolia L. Ueberkleidet auf Kalkschotter der Ebene (vor'm Griesmayr, vor Hall, MIühlinu) weite Strecken, ist auch höchst gemein an steinigen Grasplätzen, auf Felsen und im Felsschutt der ganzen Dachsteinkette bis über 6000' und auf deu Kalkvorlagen der Tanernkette.

\section{Fant. Asperifoliae Endl.}

653. Echinospermum deflexmm (Whl.) Lehın. Auf waldigen Bergen und in Holzschlïgen des Kalkznges, sowie der Kalkvorlagen des Tauernzuges, ziemlich selten: Am Steinamandl, im Sunk, auf der Spitze des Dörflstein ob Hall (2600', sehı hänfig.)

654. Cynoglossun officinale l. Auf Rainen, Hügeln, an Zännen und Wegen, sowie in Waldlichtungen nicht gemein: Gegen Mïhlium, Hall, Weng, auf freien Waldplätzen unterhalb der Seheibleggerhochalpe.

65.5. Borago officinalis $\mathrm{L}$. Hie und da auf Sehntt, Composthaufen, an Gebäuden und Zäunen rerwildert, besonders in der Nähe des Stiftsgartens.

656. Anchusa officinalis I. Auf Aeckeru und Wiesen, an Wegen, Rainen, Seluttplätzen sehr gemein, z. B. im Frauenfelde, von Bärndorf nach Rottenmann.

657. Lycopsis aprensis 1. Auf Aeckem bei S. Lorenzen im Paltenthale selten (Angelis!, Strobl sen.).

658. Symphytum officinale L. Auf nassen Wiesen, au Bächen, Gräben, 'Teichen, in Obstgälten etc. sehr gemein.

659. Symph. tuberosnm L. An schattigen, feuchten Orten und in Bergwäldern hie und da: Bei der Oberhofinühle (Altes Verzeich- 
niss), am Fahrwege zur Pitz (Strobl sen.), unter Alleeen im Stiftsgarten!, im Gesäuss (Hatzi!), sehr gemein von der Heindlbrücke zum Himbeerstein.

660. Cerinthe major L. Auf sandigen Hügeln (Strobl sen.!); ich besitze ein Exemplarfragment aus seiner Hand, vermuthe aber eine Standortsverwechslung.

661. Cer. minor I. Zwischen Gebüsch, auf Aeckern und Rainen stellenweise sehr häufig, z. B. in der Nähe des Griesmayr, zwischen Getreide unterhalb des Ziegelstadls, im Frauenfelde.

662. Echium vulgare I. An wïsten Wegrändern, auf trockenen Rainen, Feldern, Schutthaufen und steinigen Bachrändern beider Thäler gemein, ebenso auf Kalkschotter im Gesäuss; hier auch selten var. albiflora.

663. Pulmonaria officinalis L. An schattigen Rainen, in Obstgärten, feuchten Wäldern und unter Buschwerk sehr häufig, z. B. bei Mühlau, Hall (Hatzi!), am Fahrwege zur Pitz, von Weng auf die Buchau, vor'm Gesäuss, bei Röthelstein.

664. Lithospermum officinale $\mathrm{L}$. An trockenen Waldrändern, auf steinigen, buschigen Plätzen am Fusse der Kalkberge häufig, z. B. im Mühlauerwäldchen, vor'm Griesmayr, am Aufstieg zur Pitz, Fuss des Lafferwaldes interhalb Weng, neben der Fahrstrasse des Lichtmessberges.

665. Litl. arvense L. Auf Aeckern. Brachfeldern und an Rainen nicht selten, z. B. unterhalb des Ziegelstadls, im Hoffelde, um Rottenmann.

666. Myosotis palustris (L.) Witl. Variirt a vulgaris DC. Stengel abstehend behaart; $\beta$ strigulosa (Rchb.) Stengel angedrückt behaart. An schlammigen Rändern der Wassergräben, Lachen, Sümpfe und Teiche, an Büchen und Quellen, in Sumpfwiesen gemein bis auf die Voralpen.

667. Myos. sylvatica (Ehr.) Hffm. Auf buschigen Rainen, in Gärten, an schattigen Stellen der Berge sehr häufig, besonders im Stiftsgarten, am Lichtmessberge, am Rottenmannertanern; var. lactea (Bönn.) selten im Stiftsgarten (Angelis!) und neben der Fahrstrasse des Lichtmessberges; var. parviflora (mit doppelt so kleinen Blüthen) unter den Linden des grossen Stiftsteiches.

668. Myos. alpestris Schmidt. Auf steinigen, schotterigen, aber auch üppig berasten Abhängen der Voralpen und Alpen (4500-7000') im ganzen Dachsteinzuge sehr häufig (höchster Standort: Gipfel des Pyrgas 7199'); anch in 'Taucrnzuge auf grasigen Felstriften der Hochhaide ob dem Gemeinsee und am Hochschwung (Gl. Schiefer) sehr häufig.

669. Myos. variabilis Angelis. Am Alpenbache, der dem Grünund Gemeinsee entspringt und an der Bacheralpe vorbei nach Schwarzenbach hinabfliesst, in der mittleren Bergregion zwischen Pfarrerhub und Bacheralm - etwa in der Ausdehnung einer Stunde - unter Bäumen sehr häufig, zugleich mit palustris und sylvatica (!, Angelis' Originalstandort). Ueber 7000' im inuersten Winkel des 
¿wischen Gross- und Klein-Bösenstein gelegenen Hochalpenthales unter Cirsium spinosiss. und benacense aut fenchtem Abhange oberhalb eines Schneefeldes 31. Angust 1867 ziemlich häufig gesammelt, 17. Angust 1868 und später aber vergeblich gesucht. Von P. Blitmund nach Angelis' Mittheilung anch in cinem Seitenthale des Strechengrabens gesammelt.

670. Myos. intermedia Link. Auf trockenen Weg- und Ackerrändern, sonnigen Rainen und unter Getreide sehr hänfig, \%. B. vor der Sautratte, neben der Essling, um Mühlau, gegen Franenberg, in der Kruman, bei Lichtmessdorf.

671. Myos. sparsiflop'a Mik. In Gemüsebeeten, sowie anf Grasplïtzen des unteren Stiftsgartens sehr häufig, yon Angelis anch gegen den Ziegelstadl hinab beobachtet. Aus dem Paltenthale (Maly 1868) jedoch unbekannt.

\section{MaII. Fam. Convolvulaceae Vent.}

679. Convolvulus sepinm I. An '/üunen und Gebüsch, an Sumpfrïndern auf Schilf, besonders der kuns entlang sehr häufig.

673. Comr. arvensis L. \% sagittaefolins (M. B.) 'lurez. Auf grasigen Plätzen, an Wegen und Feldrainen hä̈ufig.

674. Cuscuta emropatea L. Auf Nesseln, Labkräntern und Cirsien, an Hecken gemein, überwuchert bisweilen grosse Strecken lüngs des Weges nach Franenberg, durch die Kruman etc.

675. C'use. Epithymun I. Vom Thale bis auf die Voralpen läufig, niedere Kräuter ïberraukend, z. B. Glechoma in der Trirumau, Genista sagittalis am Lichtmessberge, Campanula eaespitosa und Thymus alpestris am Unter-Kalbling, Erica carnea, Pimpinella magna, Lotus corn., Pot. Tormentilla zwischen Krummholz am Scheiblstein, auch bei Unterlıall, im Gesäuss, sehr gemein am Fusse des Gamsstein.

676. Cusc. Epilinum Weilı. Anf Leinäckern zwischen Trieben und Lorenzen häufig (Angelis!), auch im Gesäuss bei Gstatterboden.

\section{Fam. Polemoniaceae Vent.}

677. Polemoninm coernlenm I. ,Auf sumpfigen Wiesen, an Bächeu und Zïunen: Im Einns- und Paltenthale (Angelis)" (Maly 1868), jedenfalls nur sporadisch verwildert: so fand Angelis a coeruleum in der Eichelau, ich var. is lactea DC. vor dem Stiftsgartenthore.

\section{XWV. Solanaceae Bartl.}

678. Solanum nimirum L. \% genuinum Döll. Auf Schutthaufen, wïsten Plätzen, an Zäumen und Häusern hie und da, z. B. am Wegre nach Franenberg, uı Weng, Dittmaunsdorf, Bärudorf hı̈̈ufig. 
679. Sol. Dulcamara L. An schattigen Uferstellen, in feuchten Gebüschen, an Zäunen und Waldrändern, in Holzschlägen überall, doch meist vereinzelt; häufig an der alten Enns in der Schultering. kultivirt.

NB. Sol. tuberosmm L. wird in der ganzen Tiefregion in Menge

680. Physalis Alkekengi I. Auf hügeligen Feldern bei Admont (z. B. Scheibleggerfeld vor dem Schafferwege teste Angelis!) und Johnsbach hie und da, selten.

681. Atropa Belladonna L. In Waldlichtungen und Holzschlägen zerstreut bis 4500': Häufig im Rauchbodenwalde und auf der Höhe des Brucksattels, seltener von Johnsbach gegen die Trefen hin (Hatzi!), im Gesäuss (Angelis!), Lafferwalde, am Leichenberge.

682. Hyoscyamus niger L. Auf Schutt, an wüsten Wegrändern, neben Zäunen und Häusern häufig, z. B. in der Kruman, um Admont, Rottenmann.

683. Datura Stramonium L. Auf Schutt, an wüsten Plätzen und in Gärten hie und da verwildert, besonders im Stiftsgarten.

\section{Fam. Serophulariaceae Lindl.}

684. Verbascum Thapsus L. (Schraderi Mey. Rchb. Ic.) An Ufern, Waldrändern, auf Schutt, an Kalkfelsen der Bergregion: Sehr häufig im Johnsbachgraben und auf silurischem Kalke zwischen Strechau und Lassing, seltener um die Bärnkoppe, in der Kruman etc.

685. Verb. nigrum L. Auf sonnigen Rainen, grasigen Hügeln, buschigen Stellen der Berge. und Voralpen, in Auen und Feldern höchst gemein; einmal auch var. albiflorum.

686. Verb. phoeniceum L. „Im Enns- und Paltenthale (Angelis)" Maly 1868. Sah nie ein Exemplar, ebensowenig die nach Maly in Steiermark gemeinen Verb. Blattaria L. und Lychnitis L., doch dürfte letzteres sich finden.

687. Scrophularia nodosa L. In Vorhölzern, Hainen, Auen, Gärten, an Gräben und Bächen, anf steinigen Plätzen, gemein.

688. Scroph. Neesii Wirtgen. (Wahrscheinlich Ṿarietät von alata Gil. mit mehr horizontal abstehenden Aesten und meist purpurbrannen Kronen.) Auf fenchten Wiesen, an Bächen und Wassergräben häufig: Am Wege nach Frauenberg, Weng, bei der Ennsbrücke, beim Ziegelstadl, vorm Gesäıss; früher anch häufig auf Schutt im Stiftshofe.

689. Scroph. vermalis L. An den Alpenhütten des Rottenmannertauern (bes. bei der Bacher- und Hölleralm, um die "Kothhütten") ziemlich häufig, vom Schwarzbache sogar bis in's Paltenthal herabgeschwemmt; ferner an Zäunen im Alpenthale und beim Obermüller bei S. Lorenzen (Angelis!); in der Ebene bei Hall (Herb. Joannei!); Maly 1868 nennt noch als Fundorte: Armont, Rottenmann und den Kalbling. 
690. Dighitalis ambigna Mur. An steinigen, buschigen Stellen der Berge und. Voralpen auf Kalk und Schiefer fast gemein, z. B. am Pyrgas, Kalbling, Lichtmessberge, unter der Bärnkoppe, Kemetwand, unterhalb Röthelstein, im Gesäuss, Rauchboden, Wolfsgraben, Sunk, Strechengraben.

691. Linaria spuria (L.) Mill. Auf Aeckern in Enns- und Paltenthale selteu (Angelis, Strobl sen. !).

692. Jin. minor. (L.) Dsf. Auf Schuttplätzen, Manern, steinigen und wästen Wegrändern, an Bäichen sehr hälufig: Im Stiftsgarten, Stiftshofe, Gesäuss, am Lichtmessbache unterhalb des Adam, bei Rotteumann, S. Georgen etc.

693. Lin. alpina (l.) Mill. Auf Schutt und an felsigen, steinigen Stellen der Kalkalpen bis $6000^{\prime}$ sehr häufig, in Giessbachrimnen oft bis zur Ebene herabsteigend (z. B. in der Essling, im Gesäuss); selten im Tauernzuge: Ob der Singsdorferalm auf der Hochhaide, auf der Strechenseite des Bösenstein (Gueiss), am Hochschwung (Glimmerschiefer).

694. Lill. rulgaris Mill. An Wegen, Rainen, Sandplätzen, Kohlstätten und in Waldlichtungen bis $4000^{\prime}$ sehr häufig.

695. Verouica scutellata L. \% glabra. In Wassergräben am Rande des Hofmoores häutig.

696. Ver. Anagallis L. Au Wassergräben, Lachen, Bächen und Teichen sehr gemein, z. B. im Schlamme der abgelassenen, kleinerern Stiftsteiche, an Eunsarmen.

697. Ver. Beccabunga L. An Quellen, Bächen, Wassergräben, in feuchtem Sande der Flüsse etc. gemein, z. B. im Veitlgraben, beim Ziegelstadl: steigt bis $4000^{\prime}$.

698. Ver. latilolia L. Kerner Veget. (urticaefolia Icq.) An feuchten, schattigen Plätzen der Vorberge, in Schlnchten, an Waldbächen und den sie umsäumenden Felsen ziemlich häufig. Kalk: Im Gesäuss, Lafferwalde, auf der Buchau, unter der Scheibleggerhochalpe, am Schafferweg, im Sumk. Schiefer: Im Veitlgraben, Wolfsgraben, Strechengraben, an der Tauernstrasse.

699. Vex. Chamaedrys L. An Zäunen, Wegen, in Gärten, Holzschlägen, anf Wiesen der Thäler, Berge und Voralpen bis 5500' im Kalk- und Tauernzuge meist sehr gemeiu.

700. Ver. montana L. „In Laubwäldern bei Admont, im Ennsund Paltenthale" Maly 1868. Ich besitze uur ron Angelis in dem nunmehr verschütteten Apothekergarten gesammelte Exemplare; anch ihm sind andere Standorte unbekannt.

701. Tel. officinalis L. In Wäldern, Holzschlägen und Hohlwegen des Kalk- und Schiefergebietes bis auf die Voralpen höchst gemeiu, besonders in der Tamernkette.

702. Ver. aplyclla L. Auf Felsblöchen und steinigen 'I'riften der Voralpen- bis Hochalpenregion (bis 7000') in der ganzen Haller-, Johnsbacher- und Kalblingkette, doch nirgends gemein; findet sich auch auf der Höhe des Dürnschöberl (Grauwacke, 5400').

NB. Ver. spicata L., nach einem alten Verzeichnisse im Hofmoore, wurde seither niemals daselbst beobachtet. 
703. Ver. saxatilis Jacy. Auf moosigen Steinblöcken, felsigen und trocken-rasigen Stellen der Voralpen und Alpen bis 6000' im ganzen Kalkzuge, sowic in den Kalkvorlagen des Tauernzuges fast gemein, auch am Reiterbache nelsen den Almhütten des Hochschwung (Glimmerschiefer) häutig.

704. Ver. bellillioilles I. Auf Steiublöcken und grasigen Abhängen der 'Tanernkette (5.500-6500', Gneiss, Glimmer'schiefer) ziemlich häufig: Am Hengst, um die Scheiplalm, ob der Bacheralm, im Ochsenkahr, um den Gemeinsee, anf der Hochlıaide, am Steinamandl, Blahberg in der Strechen.

705. Ver. alpina I. Anf' fenchten 'T'riften, an Rändern der Schneefelder und Schneegruben im Kalkgebirge stellenweise sehr häufig, z. B. zwischen Schafleithen und Kalbling, zwischen Kalbling und Sparaleld, von der Gstadtmayrhochalpe zum Scheiblstein, um die Scheibleggerhochalpe, in den Johnsbacheralpen; an Bächen und feuchten Abhängen der 'Tauernkette aber' (5-7000') gemein; auch in der Hochregion des Dürnschöberl (Grauwacke).

706. Ver. serwyllifolia L. An grasigen Wegrändern, auf Grasplätzen, Aeckern, an Bächen bis in die Voralpen gemein, selbst noch um die Scheibleggerhochalpe.

NB. Ver. acinifolia L., von Maly 1868 im Enns- und Paltenthale angegebeu, ist mir und Angelis ans dem Gebiete nicht bekannt.

707. Ver. arvensis L. Auf Grasplätzen, steinigen Wegrändern. Aeckern, in Krantgärten häutig, z. B. an Wegen und in Beeten des Stiftsgartens, vorm Ziegelstadl.

708. Ver. triphyllos L. Auf Aeckern bei S. Lorenzen (Strobl sen.!).

709. Ver. verua L. „Auf Triften, grasigen Hügeln: Im Eunsund Paltenthale" (Maly 1868). Ist mir und Angelis unbekannt, fehlt auch aus dem Gebiete im Joannemnsherbar. Doch ist das Vorkommen nicht so nnwahrscheinlich, da sie auch in einem alten Verzeichnisse aufgeführt wird und an mehreren Punkten Obersteier's (bei Bruck, Pöls Herb. Hatzi!) gesammelt wurde.

710. Ver. agrestis L. In Gartenbeeten und auf Aeckern gemein, z. B. bei Trieben (Angelis!), im Stiftsgarten und ïberhaupt $11 \mathrm{~m}$ Admont.

711. Ver. polita Fr. In Gartenbeeten, an Sandwegen und auf Brachackern sehr läufig, besonders im Stiftsgarten.

712. Ver. Tournefortii (imel. (Buxbaumii Ten.) In Gartenbeeten und auf Brachäckern häufig mit den vorigen, z. B. Stiftsgarten, Hoffeld.

713. Ver. hederifolia I. In Gärten, auf Brachäckern und an Wegrändern höchst gemein, besonders im unteren Stiftsgarten.

714. Limosella aquatica L. An schlammigen Stellen des Eunsthales (Hatzi in Joh. Herb.!), im Ennsthale (Maly 1868), in Lachen bei Hall (Weymayr); dürfte sieh wohl alles anf denselben Standort beziehen.

715. Tozria alpina $L_{\text {. }}$ In einer felsigen, fenchten Schlucht am Bache unter der Scheibleggerhochalpe neben der Kemetwand 
sehr spärlich (!, Angelis), am Wege durch den Gofer nach Johnsbach (Angelis), an der Ardning (Altes Ver\%eichniss), an Scheiblstein (Herb. Hatzi!), an Damischbachthurm häufig (Prolessor P. Pius Strasser mündlich).

716. Melampyrum nemorosum L. Auf dem Hochfelde (Sommeraner und altes Verzeichniss). Sah kein lixemplar.

717. Mel. pratense I. Aut sunpfigen, torfigen Wiesen der Kruman, im 'Torfmoore daselbst und in Wäldern, besonders der 'T'ancrnkette, selı' häıtiğ.

718. Mel. sylvaticum h. In Hainen, Wäldern, an steinigen, buschigen Abhïngen der Berge und Voralpen in Kalk- und l'anernzuge ïherall sehr gemein.

719. Pedicularis postrata I. sp. pl. (non Koch, Jacquini Koch). An steinigen Abhïngen der mittleren Kalkalpen und tiefer herah an Kalkfelsen; steigt sehr selten so loch, wic rosea. Sehr häufig ann Pyrgas, Scheiblstein, Kalbling, an den Folsen der Schafleithen, zicmlich selten an Wald'elsen der Bïrnkoppe, Stumpfnaglerwand, Kemetwand, am Reichenstein, Festkogel, Hochthor, im Sulzkahr.

Nl3. Was rostrata rar. biflora, in einem alten Verzeichnisse rom Hauseck augegeben, sei, konnte ich nicht eruiren.

720. Ped. asplenifolia Floerke. Auf steinigen Alpenhöhen ob dem Seheiplsee am Rottemmannertanern ziemlich hïnfig, \%. B. am Hengst (Hatzi!), Bösenstein (Gueiss b-7000'). Wurde auch am Kalbling (Gassner!, Angelis), also auf Kalk, gesammelt.

721. Ped. Portenschlagii Saut. Ant steinigen Alpenhöhen der Tanernkette (5500-7000') häufig: Am Hengst (Sommeraner), Hauseck, Bösenstein mit voriger, ob der Bacheralpe gegen den Grünund Gemeinsee, im Ochsenkahr, rom Nitterstein zur Hochliaide hinauf, am Hochsehwung.

722. Ped. incarnata Jacy. In der tieferen Alpenregion der Kalkkette, besonders ant ippigen Triften zwischen Krummholz: Am Kalbling sehr gemein bis in die Fichtenwälder herab, sehr hänfig auch am Reichenstein, Pyrgas, Scheiblstein, Natterriegel, Hund bei Johusbach.

723. Pell. foliosa I/. Auf höheren Voralpeu (bis 5000') der Kalkkette an ïppig begrasten, buschigen Stellen sehr spärlich: Am Kalbling (Maly 1868), bei Johnsbach (Angelis), am Hund und unterlialb dè Kochenalm ob Mühlaı.

724. Ped. recutita 1. Anf fenchten hochgrasigen oder buschigen Stellen der Kialk- und Tauemkette (5-(j000') fist ïberall laäntig, z. B. am Pyrgas, Scheiblstein, in den Johusbacheralpen, an Kialbling (Kalk); zwischen Grïnerleu ob dem Scheiplsee, ob der Bacheralpe, um die Felsen der Hochhaide (Gneiss), am Steinamandl, Kampl, Hochschwung (Glimmerschiefer).

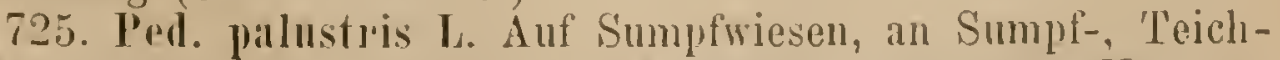
und Moorrändern beider 'Thäler sehr häntig, besonder's in der Krmman, beim Griesmayr, im Hofmoore, neben dem Wolfsbachermoore, am 'Triebnermoore, an sumpfigen Ufern der Palte; anch noch c. $4000^{\circ}$ bei den Fischteichen von Hohentanern. 
726. Ped. rosea Wulf: Auf steinigen und felsigen 'Triften der höchsten Kalkalpen $\left(6-7000^{\prime}\right)$ häufig, besonders von der Schafleithen zum Kalbling und Sparafeld, an Scheiblstein und Natterriegel; seltener am Pyrgas, Hexenthurm, Buclistein. Auch auf Felstriften des Hochschwung (Glimmerschiefer).

727. Ped. versicolor Whlb. $\beta$ unicolor (Helm einfärbig). Auf grasigen Abhängen zwischen den Felsen des Hochschwung häufig (Glimmerschiefer, c. 6000').

728. Ped. verticillata L. Auf grasigen und steinigen Abhängen $\left(5-6000^{\circ}\right)$ in der ganzen Kalkkette fast gemein; häufig auch am Hochscliwung (Glimmerschiefer), selten auf Gneiss: Ob der Schannitzeralm im Triebenthale.

729. Ped. Sceptrum Carolinum L. Auf sumpfigen Wiesen an der Palte bei Gaishorn (Angelis!), bei 'Trieben, Rottenmann (Haffiner im Joh. Herb.!), auf Torf am Triebnersee (Stur). Im Ennsthale (Maly 1868) aber nie beobachtet.

730. Rhinanthus minor Elur. $\alpha$ latifolius, $\beta$ angustifolius Willk. Lange. Auf Sumpf- und Bergwiesen des Enns- und Paltenthales sehr gemein, z. B. Griesmayrwiesen, Kaiserauerweiden.

731. Rhin. uajor Ehrlı. Auf trockenen und feuchten, auch torfigen Wiesen sehr häufig: In der Kirunau, beim Griesmayr etc.

732. Rhin. Alectoroloplıns Poll. Anf Aeckern, Rainen, an Wegen um Admont, besonders in der Näho des Griesmayr, häufig.

733. Rhin. aristatus Čl. Oest. bot. Zeitschrift 1870. alpinus Maly 1868, non Bmg. Der alpinus unserer Alpen entspricht genau der Beschreibung des aristatus C'el., ist auch identisch mit Kerner'schen Exemplaren desselben rom Blaser in Centraltyrol. Der angustifolius unseres Gebietes ist nur eine sehr schmalblättrige, durch die mannigfachsten Uebergänge mit der Normalform verkettete Varietät desselben, von angustif. Gmel. verschieden durch die ausserordentlich feinen Grannen der Deckblätter, stark gewōlbte Oberlippe und abstehende Unterlippe; ron Kerner am Solstein als angust. Gmel. gesammelte Exemplare sind mit unserer Form identisch; habituell ist aber auch der echte angust. aus Baden (com. Döll!) nicht nnterscheidbar. Alpinus Baumg. ist nach Exemplaren Siebenbürgens, der Tatra und der Sudeten in der That von unserem "alpinus" verschieden. Näheres siehe in citirter Zeitschrift. -- Auf Grasplätzen, an Waldrändern, steinigen, buschigen Abhängen der Voralpeu und Alpen des Kalkzuges bis $6000^{\prime}$ überall gemein, doch so, dass die breitblättrige Form vorzugsweise die höheren, var. $\beta$ angustifolius aber vorwiegend die tieferen und tiefsten Lagen (z. B. das Gesïuss, den Schafferweg, Lafferwald) bewohnt; gemein auch auf den Kalkvorlagen der T'auernkette; häufig auch (doch nur a.) auf den Felsen des Hochschwung (Glimmerschiefer), $\mathrm{mm}$ den Gemeinsee und ob dem Scheiblsee (Gneiss).

734. Bartsia alpina I. Auf Triften, felsigen Gehängen, unter Strauchwerk, besonders aber an feuchten Bachrändern (5-7000') des Kalkzuges gemein, doch anch in den Gneiss- und Schieferalpen sehr häufig. 
735. Euphrasia Rostkoviana Hayur (officinalis \% pratensis Fr. Maly 1868). Anf Rainen und Wiesen der Tief- und Bergregion iusserst gemein; steigt bis in die Voralpen, z. B. Johnsbacheralpen (Eelicetti!), Krummholzwiesen des Kalbling! etc.

736. Enplur. stricta Host. W1. Austr. II. 185. An haideartigen Buseh- und Waldrändern, aluf trockenen, kalkschotterigen Rainen (vor Mühlan, vor'm Griesmayr, ror'm Gesïuss, längs der 'Tanerustrasse) sehr häufig und typisch; anch auf Voralpenwiesen des Kalbling etc. in einer viearigen, kleinblüthigen Form, welche der pumila Kerner Fl. anstr. exs. äusserst ähnlich ist, sich aber durch kürzere Kelchz:̈hne und die gelbe Nackel der Unterlippe unterscheidet. Kerner, welcher die Güte hatte, meine Euphrasien zu revidiren, notirte \%u dieser Form: "Scheint pumila".

737. Enphr. versicolor Kerner Fl. austr. exs. Anf Hochalpenwiesen des Kalbling (Kalk, e. 6500') und kurzgrasigen Alpenweiden des Hochschwung (Schiefer, c. 5-6000') sehr häufig.

738. Enphr. minima Schleicher. „Auf Alpenwiesen im Sulzkahr sehr häufig, auffallend durch 'die fast ganz gelben Blüthen." (Herr Oberförster Pachmayr, der mir anch ein Exemplar mitbrachte); häufig anch auf Krummholzwiesen um die Scheibleggerhochalpe in einer schlafferen und einer steiferen Form.

739. Euphur. pulchella Kerner Fl. Anstr. exs. Auf Alpentriften der Gneiss- und Sehieferzone: Am Bösenstein und Hochschwung.

740. Enplir. salisburgensis Funk a genuina. Blätter frendiggrün, dünn, Blüthen grösser, gedrïngtührig. $\beta$ cuprea (Jord.) Kerner Fl. austr. exs. Blätter trübgrün, dick, meist bedeutend breiter, spitzer gesïgt, Sägezähne öfter's zahlreicher, Blüthen kleiner, menr über den ganzen Stengel zerstrent. Auf steinigen, buschigen Abbängen der Kalkvoralpen gemein ; a äusserst gemein im Gesïuss, ${ }^{*}$ ) am Schafferwege, überhanpt vorherrschend in tieferen Lagen; $\beta$ mehr anf sonnigen, trockenen Höhen, z. B. am Pyrgas, Scheiblstein, im Sunk, an del Tauernstrasse, auf der Pitz; beide Formen nur auf Kalk.

NB. Die aufgezählten Euphrasien haben gewiss im Gebiete eine weitere Verbreitung, doch konnte ich nur die bei der Revision rorliegenden Standorte berücksichtigen.

741. Enphr. serotina Lam. Kerner Veget. S. 377. An Mooren, Wassergräben, Lachen, wüsten Plätzen und Wegrändern sehr gemein. Variirt mit langer und mit sehr kurzen Deckblättern.

\section{XWII. Fam. Orobancheae Lindl.}

742. Orobanelie gi:acilis Sul. (cruenta Aut. germ.) Auf Wiesen und grasigen Abhängen vom Thale bis auf die Voralpen sehr hänfig, z. B. neben der Enns in der Kruman, am Lichtmessberg, linter

*) Die Exemplare des Gesiiuses nïhern sich teste Kerner selar der carniolica Kern. und dürften vielleicht ron salisb. spezifiseh rersehieden sein; besonders fïllt ihre grosse, rein weisse Unterlippe anf. 
Kaiseran, am Pyrgasgatterl, beim Griesmayr, im Paltenthale; meist auf Lotus corniculatus.

743. Orob. Epitlymmm DC. Auf Feldern, Haiden, buschigen Kalkhügeln bis in die Voralpen an Thymus-Arten häufig, z. B. im Gesäuss, beim Galgen ror'm Griesmayr.

744. 0rob. caryoplyyllacea Sm. Wird in einem alten Verzeichnisse als Galii Dub. bei der Hackenhuben und als major (ohne Autornamen) am Wege zur Bockmayralpe angegeben.

745. 010b. rubens WIIr. Nach demselben Verzeichnisse (als elatior) auf der Schedelleithen bei Admont. Von mir gleich voriger nicht gesehen.

746. Orob. Scabiosate Koch. Auf Voralpenwiesen: Nicht selten um den Rinnstein bei Johnsbach auf Adenostyles alpina, Carduus defloratus und Knautia sylvatica, auch von Angelis auf Scabiosenwurzeln bei Johnsbach gefunden; auf Card. deflor. am Kalbling (Angelis!, Hatzi), an Waldrändern hinter der Kaiserau.

747. Orob. flava Mart. Auf Petasites niveus im Johnsbachgraben, schon von der Johnsbachbrücke an, häufig, zuerst von Angelis entdeckt; nach Maly 1868 auch auf Petas. albus bei Admont.

748. 0rob. Salviae F. W. Schultz. Auf allen Bergen und Vorlagen der Kalkkette, sowie in Schieferschluchten an Salvia glutinosa meist sehr gemein, 7. B. durch's Gesänss, im Johnsbachgraben, unter der Brucksattelhöhe, am Aufstieg zur Griesweber- und Scheibleggerhochalm, am Schafferweg, im Veitlgraben, junerhalb der Klamm. Znerst vou Angelis entdeckt.

749. Lathraea squamaria L. In Gärten, Hainen und feuchten Wäldern, sowie unter Gebïsch an Wegrändern anf Baumwurzeln (bes. Corylus) hie und da, z. B. im Stiftsgarten, Gesüuss, am Schafferweg, vor Mühlau, auf der Buchau.

\section{XhVIIr. Fam. Utricularieae Endl.}

750. Pingnicula flavescens Schrad. (alpina Maly, non L.) An feuchten, sandigen Stellen, auf nassen Felsen und an Bächen der Berg- bis Alpenregion (bis 6000') im Dachsteinzuge und auf Kalkvorlagen der Tanernkette gemein, steigt im Gesänss, Johnsbachgraben, am Mühlanerfalle bis in die Ebene herab; ich fand sie sogar am Rande eines Ennsarmes in der Santratte; seltener anf Gneiss und Schiefer: Ob der Bacheralpe an Bächen gegen den Grünsee hänfig, an sumpfigen Bachrändern unterhalb der Kothhütten, um die Scheiplseen.

751. Ping. vulgaris L. a. pratensis Koch. A uf nassen Wiesen, an sumpfigen Bachrändern und feuchten Abhängen der Schiefervorberge des Enns- und Paltenthales (bis 5200') ziemlich häufig: Um den Kaiseranerteich, beim Jagdhanse des Kalbling, auf der Höhe der Buchau (2600'), neben der Griesmayrlache, auf der Kater-Hald (Hatzi!), am Schafferweg (Strobl sen.), ob der Messneralm am Dürnschöberl (c. $5200^{\prime}$ ), ob der Reiteralm des Hochschwung. 
752. Utricularia vulgaris $L_{\text {. }}$ In einem Wassergraben am Ostrande des Hofmoores häufig; sonst von keinem Fundorte aus dem "Enus- und Paltenthale" (Maly 1868) bekannt.

753. Utric. minor I. In der 'I'ricbnerlache (Angelis!); sonst sah ich sie nirgends im Enns- mul Paltenthale (Maly). Auch intermedia Hayne wird von Maly 1868 .im linns- und Paltenthale (Angelis)", von Maly 1838 , in den Sümpfen der Palte (Sommerauer)", ron Strobl sen. im Triebnersumpfe angegeben; die Exemplare Sommeraner's im Maly'schen Herbar rom obigen Standorte aber scheinen sich ron minor nicht zu unterscheiden; es bezieht sich wohl die ganze Reihe von Angaben auf das Vorkommen der minor in der Triebnerlache, die ron der Palte durchflossen wird: intermedia Hayne aber fehlt.

\section{Fam. Primulacene Vent.}

754. Androsace alpina Tam. (glacialis Schl., Hppe.) Am felsigen, dürren Rücken der Hochhaide vom Mitterstein anfwärts bis zmr höchsten Spitze (c. 7300', Gneiss) häufig, var. fl. rubro. Ist die ächte alpina. nicht Pacheri Leyb. Die Angaben Maly's 1838 - Rottenmannertauern (Sommerauer) * und , am Wege rom Steinwend (unrichtig statt Steinamandl) auf das Dreisteckengebirge (Gebhard)" beziehen sich auf dieselbe Höhe, da allen Botanikern unseres Gebietes ein zweiter Standort unbekannt ist und man rom Steinamandl nur anf die Hochhaide gelangt. Die Angabe Maly's 1868 "Kalbling" ist gewiss irrig, da alpina nur Gneiss und Schicfer bewohnt.

75j. Andr. Chanalejastite Host. Auf grasigen und steinigen Abhängen am Hund (dem Uebergange von Johnshach in's Sulzkahr) zwischen 5000 und $5500^{\prime}$ selı gemein: nach Strobl sen. und Naly 1868 auch am Kalbling, doch fehlt sie im Herbar beider; wohl Verwechshung mit folgender.

756. Andle olstusifolia All. Auf grasigen Abhängen, an Schneefeldern und Schneegruben des Kalbling von der Schafleithen bis zum Fusse des Sparafeld $\left(6-7000^{\prime}\right)$ sehr häufig; nach Maly 1868 anch am Rottenmannertanern: müglich, weil auch auf benachbarten Gneiss- und Schieferalpen, doch sah ich kein Exemplar.

757. Andr. lactuil L. Anf Felsen und im Felsschutt der Kalkalpen von der Krummholzregion bis gegen 7000' häufig: Am Pyrgas der österreichisch-steyrischen Grenze entlang (5-7000`) sehr häufig, seltener am Scheiblstein, der hohen Kalblingmauer entlang, am Hund mit Chamaejasme; sehr häufig aber auf Kalksand im Gesäuss und Johnsbachgraben (c. $\left.2000^{\prime}\right)$.

758. Primula farinosa L. Auf sumpfigen Wiesen, an lehmigen Flussufern im Ennsthale gemein, z. B. Schultering. Sautratte, Griesmayrwiese (Alluvium), seltener im Gesäuss (Kalk) und im Paltenthale (bei Lichtmessdorf etc.)

759. Pr. acaulis (I.) Jacq. Bisher nur in der Nähe des Oedbauel ron Strobl sen. gesammelt? 
760. Pr. elatior (L.) Jacq. Auf Wiesen, in Auen, Obstgärten, Hainen, Bergwäldern bis auf die Kalkalpen und Kalkvorberge der Tauernkette äusserst gemein; höchster Standort: Schneegrubenränder am Scheiblstein bei $6500^{\prime}$. Eine var. brevicalyx (Kelch nur so lang, als die halbe Kronenröhre, banchig, weit geöffnet mit sehr breiten Kelchzähnen) fand ich selten im nuteren Stiftsgarten, doch mit Uebergängen in die Normalform.

761. Pr. officinalis (L.) Jac\%. Fehlt im Enns- und Paltenthale, tritt aber schon häufig auf um Hieflau und S. Gallen.

762. Pr. Anricula L. $\alpha$ foliis integerrimis, $\beta$ fol. crenatis. Auf Felsen und steinigen Abhängen, sowie im Schutte der Admonter Kalkgebirge von der 'Thalsohle bis $7000^{\prime}$ sehr häufig, jedoch nicht ïberall: Im Gesäuss, Johnsbachgraben, Laffawald, Bruckgraben, in der Bodenlucken, ob der grossen Buchauerschütt am Buchstein (bisweilen neben elatior), am Kalbling, Pyrgas, Scheiblstein, in den Johnsbacheralpen etc.

763. Pr. Clusiana Tausch. Auf Felsen, feuchten, steinigen Abhängen, sowie im Felsschutt der Admonter Kalkgebirge von der Ebene bis auf die Hochalpen $\left(2-7000^{\prime}\right)$ sehr gemein, oft neben voriger, aber noch viel häufiger; variirt $\alpha$ parviflora (meist auf Schutt) und $\beta$ grandiflora (an Felsen). Die tiefsten Standorte sind: Gesänss, Johnsbachgraben, Schwarzenbachgraben, Mühlanerfall, Felsen vor'm Admonter Kalkofen; zuhöchst (bis 7000') steigt sie am Kalbling und Scheiblstein.

764. Pr. glutimosa Wulf. Auf feuchten, steinigen Abluängen, an Schneefeldern $\left(5-7000^{\prime}\right)$ im ganzen Tauernzuge gemein (Gueiss, Glimmerschiefer).

765. Pr. minima L. Auf feuchten, grasigen und steinigen Ablıängen, an Schneefelderu der ganzen T'auernkette (5-7400', Gneiss, Gl. Schiefer) sehr gemein, im Kalkunge nur am Speikboden des Kalbling $\left(6500^{\prime}\right)$ sehr häufig, am Pyrgas, Scheiblstein, Neuburg bei Johnsbach aber selten.

766. Cortusa Matthioli L. In feuchten, schattigen Bergwäldern, in Schluchten, an Bächen und unter Felswänden der Kalkvoralpen bis in die Krummholzregion: sehr häufig am Aufstiege zur Scheibleggerhochalpe, sowie links zur Stumpfnagleralm und rechts dem Fusse der Kemetwand entlang, ferner vom "mittleren Boden" innerhalb Johnsbach gegen die obere Fachneralm und am Rücken des Hund; wurde noch am Scheiblstein von Hatzi! und im Gesäuss von Gebhard und Welden gefunden.

767. Soldanclla montana W. In moosigen Wäldern der Weide Pitz bei Weng anf fettem, feuchtem Boden an Baumwurzeln (Kalk, 2500', Hatzi!); auch neben der Hütte der Pitz und im Walde gegen Hall (Strobl sen.!); ich suchte sie hier zweimal vergebens. Am Kalbling (Maly 1868)?

768. Sold. alpina I. Auf nassen Abhängen, an Bächen und Schneefeldern der Kalkkette $\left(5-7000^{\prime}\right)$ gemein, oft mit minima; steigt bis zu den Triften der Kaiserau nud zum Mühlanerfall herab; 
in der Hochregion oft einblüthig, zwergig; anch ob der Messinerilm ann Dürnschöberl (5)n(1)', Granwacke).

769. Sold. Gamderi Huter üst. bot. Zeitschr. XXII. (alpina $x$ minima) In der Alpenregion des Schuiblstein zwischen den Stammältern selten.

770. Sold. musilla Bumg. Auf lenchten 'Triften, an Bätchen und Schneefeldern der 'T'anernkette $(4-7 n 00)^{\prime}$, Gneiss, Glimmerschiefer) überall äusserst gemein. ob der Bacheralpe und am Hochsehwung anch bisweilen var. biflora: auf Kalk selten, nur an Sehneerïndern im Sulzkahr am Fusse des Hund mit alpiua sehr häutig (c, 4500').

7万. Solul. minima Hopper. Auf feuchten Abhängen, an Bächen, Suhneefeldern und Erdfällen der Kalkkette ron der Vor-bis in die Hochalpenregion ïberall ïnsserst gemein: steigt am Folkernotbache bis zum Mühlanerfalle und an Giessbächen des Buchstein bis zur grossen Buchauerschütt (26um') massenhaft herunter: auch aul' Kalkvorlagen der 'Tauemlette: Bei der Hölleralm häutig (Angelis), im simk.

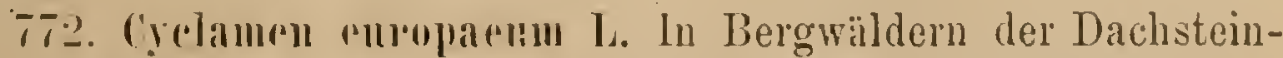
killizone nicht gar häufig: Im Gesïuss, Rauchbodenwalde; sehr häutig aber auf silurischem Kalke um Strechan (besonders im Hauswalde), Rottenmann (Bürgerwald).

773. Namulum thia thrsiflora (I.) Duby. An Rändern der Sümpfe. Teiche und Noore im Enns - und Paltenthale ziemlich häutig: An Scheiblteich und Raithmayrmoore der Kruman, am 'Triebnersumpfe (Sommerauer), im Paltenthale (Gassner!).

77t. Lysimachia vulgaris L. An Bächen und Gräben, auf Sumptwiesen zwischen Schilfrohr, in feuchten Gebiuschen und an Waldründern $₹$ verticillata gemein, \% oppositifolia seltener.

775. Lys. Nummularia l. Auf sumpfigen Wiesen, feuchtlehmigen Ufern, an Bammurzeln, in Hainen gemein, besonders in der Schultering.

776. Lys. nemormm l. An fenchten, schattigen Stellen der Haine, Laub- und Nadelwälder häufig, z. B. im unteren Stiftsgarten, auf der Fuchsweide an der alten Enns, im Gesäuss. Rauchbodenwalde. am Lichtmessberg, hei Röthelstein, in der Waldregion des Rottenmannertauern. Schiefer, Kalk, Alluvium.

777. Anarallis aprensis I. Anf Brachen, Feldrainen, in Gänten sehl hälutigg.

775. An. corrulea Schreb. Wurde nach einem alten Verzeichnisse im Stiftsgarten von Admont gefunden.

\section{Fam. Ericaceate Lindl.}

779. Aretostapuylos alpina (L.) Sorr. An dïrren, steinigen Abhängen der Tamernkette von $60000^{\prime}$ an ïberill gemein. doch anch im Kalkzuge (z. B. Kalblingrïcken. letzte Erhebungen des Scheiblstein, Pyrgas, Hunl, Ostseite der Kemetwanl) selı häutig. 
780. Arct. Inva Lusi (T.) Spr. An Waldründeru, buschigen Stellen der Alpen und Voralpen nach Maly 1868 in ganz Steiermark gemein; aus unserem Gebiete bisher nur von cinem alten Verzeichnisse am Kalbling angegebell.

781. Andromeda polifolia L. Auf allen Mooren des Enns- und Paltenthales höchst gemein.

782. Calluma vulgaris (L.) Sal. In Torfmooren, Haideu und trockenen Wäldern bis auf die Alpen höchst gemein, zumal im Tauernzuge, auf den Grauwacken- und Werfnerschiefer-Gebirgen; ïberzieht z. B. die Plösch bis zu Spitze $\left(5413^{\prime}\right)$; variirt selten flore albo, z. B. Plösch.

783. Erica carnea I. Auf den Hölen der Wegraine, in Wäldern, an steinigen und felsigen Abhängen der Berge und Voralpen im Kalkgebiete (Dachstein- und Grauwacken-Kalk) überall sehr gemein $\left(2-4500^{\prime}\right)$.

784. Loiseleuria procumbens (L.) Dsv. Auf dürren, steinigen Abhängen und Rückenhöhen der T'auernkette von 5000' anfwärts ïberall höchst gemein, doch auch im Kalkzuge, z. B. am Pyrgas, Scheiblstein, Kalbling, gemein; überkleidet oft weite Strecken.

785. Rlododendron ferrugineum I. In der Voralpen- bis Alpenregion der Tauernkette sehr gemein, im Kalkzuge jedoch (aun Pyrgas, Kalbling, in der Kemeten, auf der Ardning, von Johnsbach aut den Hund) nur sporadisch; häufiger auf der Plösch (Werfnerschiefer).

.786. Rlıod. intermedium Tsch. Hie nud da an sabalpinen Abhängen des Kalbling: (Angelis!) : interm. vom Bösenstein im Herb. Maly gehört zu ferrugineum.

787. Rhod. hirsutum I. Im Schatten der Hochwälder, zwischen Krummholz, sowie an steinigen und grasigen Abhängen der Voralpenregion bis 5000' im ganzen Kalkzuge seln gemein; steigt im Gesäuss und Johnsbachgraben bis zur Fahrstrasse herab.

788. Rodothamums Chamaecistus (L.) Rohb. An felsigen Stellen der Kalkvoralpen sehr gemein; steigt seltener bis $6600^{\prime}$ auf (z. B. Spitze des Hexenthurm), geht aber hänfig lüngs der Giessbäche bis zur' Thalsohle (Mülllauerfall, Schwarzembach- und Johnsbachgraben, Gesäuss).

789. Ledum palustre I. Findet sich im Herb. Maly von „Mooren bei Admont" (leg. Sommerauer); wurde von dem Finder nach Angelis' Mittheilung als in Hofmoore häufig angegeben, nach Sommerauer's Aufschreibung aber im Krumanermoore gesammelt; ich suchte es an beiden Standorten vergeblich.

790. Vaccininm Myrtillus L. In Wäldern der Gneiss- und Schieferzone äusserst gemein, steigt hoch in die Alpen auf, bedeckt z. B. die Plösch bis zur Spitze (5413'); anf' Kalkbergen viel seltener, doch auch da bis 6500' (am Scheiblstein).

791. Vacc. uliginosum L. In Torfmooren äusserst gemein; gemein auch auf Abhängen der Plösch (Werfnerschiefer) und der Tanernkette bis $6300^{\prime}$; weit seltener anf Kalkalpen, z. B. bei $6800^{\circ}$ am Rücken des Scheiblstein, bei der Treftineralpe. 
792. Vace. Vitis Idalei l. Anf' 'Torfmooren und in Wäldern der Kalk- mnd 'Tanernkette bis in die Alpenregion gemein; z. B. noch bei $6400^{\prime}$ um die Höhe des Steinamandl an felsigen Stellen.

793. Oxycoccos palustris Pers. Auf Sphagneen der Torfmoore im kinnsthale gemein, ron Angelis mu Stur anch anf' 'lorf 1 m den Triebnersee im Paltenthale gesammelt.

\section{Fam. Pirolacene Lindl.}

794. P'irola rotundifoila I. An schattigen Stellen der Berge, hesonders auf Kalk, stellenweise lı̈̈ufig: Im Gesä̈nss vor Gstatterboden, im Lafferwald, in der Flietzen, am Unterkalbling bis 4500', unter der Kemetwanl: am Wege zur Bockmayralm, zwischen Hohentanern und Scheiplsee selten.

795. Pir. chlorintha Sw. In Wäldern bei Admont (Strobl sen., Angelis), in einem Voralpenwalde des Kalbling.(Angelis): jedenfalls sehr selten.

796. Pir. media sw. Ebenso selten in schattigen Bergwäldern: Am Fusse des Kalbling (Strobl sen., Angelis), in der Flietzen anno 1833 ein Exemplar (Angelis).

797. Pir. minor. L. An schattigen Stellen im 'Thale, in Wäldern der Berge und Voralpen ziemlich häufig: Unter den Linden des Stiftsteiches, unter Gestränch in der Santratte stellenweise seh. häntig, im Laflerwald beim anfgelassenen Kohlenban, im Hartler'sgraben, in den Johnsbacher Voralpen, bei der Treffueralm und am Kalbling Hore roseo, am Lichtmessberge, Hochschwung c. 5500’. Alluvinm, Kalk, Schiefer.

798. Pir. secumda I. In Wäldern der Berge und Voralpen auf' Kalk und Schiefer sehr häufig, z. B. im Gesäuss, vor'm Nïhhlbauerfall, am Aufstieg zur Scheibleggerhochalpe, rom Schafferweg zur Scheibleggerhochalpe gemein, am Unterkalbling, im Bürgerwalde ron Rottenmann.

799. P'ir. uniflor‘a 1. In moosigen Wäldern und an Waldrändern hie und da truppweise, z. B. um Uïhlan, am Schafferweg, neben der Fahrstrasse des Lichtinessberges, am Scliafweg des Kalbling, auf der Pitz, unterhalb der Scheibleggerhochalm (2000-5000', Kalk, Schieter).

\section{Fim. Monotropeae Nutt.}

800. \%. Monotropa Hyjopitis L. 800. F. Mon. glabra Bernlı. In trockenen Berg- und Voralpenwäldern, besonders anf Monsboden, beide Arten gleich selten und vereinzelt: Am Aufstieg zur Scheibleggerhochalnı ( $(\bar{\beta})$, Schafferweg $(\alpha)$, Unterkalbling ( $\%$ und $\%$ ), unterhalb der Pfarrerhub bei Lorenzen, um Strechau unter Fichten, am Bruckstein ror Gstatterboden (Hatzi!), ete. 


\section{Fam. Umbelliferae Juss.}

S01. Sanicula europaea L. In Wäldern des Kalkzuges sehr häufig, z. B. im Rauchboden- und Lafferwalde, am Anfstieg zur Pitz, vor"m Mühlauerfall, am Aufstieg zum Pyrgas, zur Scheibleggerhochalpe, am Schaffer- und Schafweg des Kalbling (bis 4500').

802. Astrantia major L. Anf sumpfigen Wiesen, an schattigen, feuchten Orten der Voralpen im Enns- und Paltenthale sehr hänfig. z. B. um Rottenmann, um das Hofmoor, am Rande der Oberhofwiese, am Schafferweg, ob der Gstattmayrvoralpe; an diesen Standorten meist $\beta$ involucrata (Hpp.) Kch.; an trockenen, kalksteinigen Waldrändern im Gesäuss jedoch ist $\beta$ seltener, $\alpha$ vulgaris Koch aber gemein.

S03. Cicnta virosa L. An T'eichen und in Moorsümpfen häufig: Bei Ardning, Erauenberg, in der Kruman seltener, sehr hänfig aber in den Paltensümpfen bei Trieben und an den Fischteichen von Hohentanern (c. $\left.3800^{\prime}\right)$.

804. Apium graveolens L. Hänfig kultivirt, anch auf einem Schutthaufen am Wege in's Gesänss verwildert angetroffen; schon in einem alten Verzeichnisse angegeben.

805. Aegopodium Podagraria L. An fenchten, schattigen Stellen bis in die Voralpen überall sehr gemein; besonders im Stiftsgarten und um Voralpenhütten.

806. Carum Carvi L. Anf Rainen, Feldern, Wiesen bis in die Voralpen sehr gemein, z. B. noch am Pyrgasgatterl (4300').

807. Pimpinella magna L. Auf Wiesen, Feldern, Hügeln, in Obstgärten höchst gemein ; $\beta$ rubra (Hoppe) in Hochwäldern und auf Voralpenwiesen des Pyrgas, Scheiblstein, Kalbling, der Johnsbacheralpen etc. sehr häufig, selten im Gesäunss.

808. Pimp. Saxifraga L. Auf dürren, sonnigen Rainen bis in die Voralpen sehr häufig. Variirt nach der Behaarung: a glabra, $\beta$ pubescens; nach der Blüthenfarbe: $\%$ albiflora (gemein), \& rosea (selten, z. B. Ennsthal, leg. Angelis!): nach der Blattform: o major Wllr. Blättchen eiförmig, Pflanze höher (Form der üppigeren Standorte); $\beta$ minor poteriifolia Wllr. Blättchen rundlich eiförmig, gekerbt, Pflanze niedrig (Form der dürrsten Raine, z. B. vor'm Mühlanerwäldchen, beim Griesmayr, vor'm Gesänss, am Schafferweg); $\gamma$ alpestris Spr. Blättchen fast handförmig eingeschnitten mit zugespitzten Blattzipfeln (Form der Kalkalpen und angrenzenden Voralpen, z. B. Damischbachthurm, Kalbling); ò dissectifolia Wlli. Blättchen zerschnitten (selten, hie und da mit $\%$ und $\xi$ ).

809. Oenanthe aquatica (L.) Lam. Am Rande stehender Gewässer selten; wird in einem alten Verzeichnisse angeführt und dürfte nach Angelis zwischen - Reitthal (ob Ardning) und Selzthal vorkommen.

810. Acthusa Cynapium L. An Wegen, Zämın, Häusern, auf Schutthaufen und besonders in Gärten sehr häıfig, z. B. um Admont. 
s11. Lihanotis montanal C'r. Aut lelsigen Abhäugen der Kalkvoralpen: Am Scheiblstein (Herb. Hatzi!), sehr hüufig am Fusse des Gamsstein bei Jolnsbach und am Südwestfusse der Kemetwand.

812. Athamanta eretensis I. o hirsuta I)C. Pr. Blättel reichlich kurhaarig, Blattripfeln kïrer und breiter. "snutellinoiles (Lam.) I)C. Blätter fast kahl, Blattzipfeln schmäler und länger. Anf fieröll, Imd an stenigen Abhängen der Kalkzone von der Ebene (\%. B. Gesänss, Jolnsbacligraben, Schwarzenbachgraben) bis 6300' sehr gemein, vereinzelt sogar bis $7000^{\prime}$ : meist $\%$, is seltener, $z$. B. am Kalbling mit ø. Ath. Natthioli "Bei Johnsbach" (Maly 1S68) gehört gewiss auch $z$ \% ; fehlt in Herlo. Maly.

813. Mrum athimanticum .To\%. An rasigen Stellen felsiger Abhänge, nuter Krmmmholz und anf Krmmmholzwiesen $\left(5-65.600^{\prime}\right)$ in der ganzen Dachsteinkette gemein.

S14. Memm Mutrllina (l.) Giartu. Aul Voralpen- und Alpentrilten (5- 650()$\left.^{\prime}\right)$ der 'l'inernkette sehr' gemein: im Kalkzuge mur an einigen Stellen der Johnsbacheralpeu (um die Farchneralm und links am Hand hinauf) selı häutig.

S15. Pachyplemrum simplex ( $\left.\mathbf{I}_{\text {. }}\right)$ Rehlo. An grasigen Stellen der Tanernkette selten: In Ochsenkihn (Altes Verzeichniss), am grossen Griesstein. (Stmr). Gueiss.

S16. Selinmm carvilolia I. Anf einer sumptigen Wiese zwischen Hoffeld und Hofmoos ansserhalb der Eichen sehr häutig; anch in einem alten Verzeichnisse angegeben.

NB. Iseristicum ofticinale Koch wird in allen Hansogitrten bis $4000^{\prime}$ (Hohentanern) kultivirt, verwildert aber tral ich es nirgends.

817. Anundicat silvestris l. Aul" sumptigen Wiesen, an 'I'eichen, in Anen und fenchiten Wähldern sehl gemein.

818. Ing. montana Schleicher. An fenchten, sehattigen Orten der Voralpenregion: Ob der Gstattmayroralpe am Scheib]stein unter Strauchwerk hio mo da (Kalk), in Śtreehengraben (Śchiefer).

819. l'encedanum jalustro (l.o) Mnch. In sumpfiwiesen des Enns- und l'alienthales ziemlich läutig: Un den kirmmanerteich, ausserhalb der Schnltering, an der Palte bei Lorenzen, 'Trieben mud um rlen Gaishorusee.

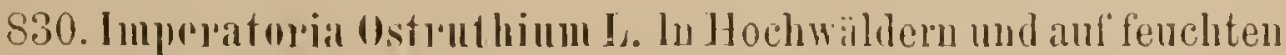
üppigen 'Trilten der 'T'anernkette, besonders am Fusse der Felswände sehr hüutig; \%. B. am Hochschwung, um den Grün-, Gemein- mu Selreiplsee, an Kampl, Blahberg in der Strechen, im 'l'riebenthal bei der Schannitzeralpe; etwas seltener in Dachsteinzuge, \%. B. zwischen Krummholz am Scheiblstein häulig, am Kalbling um das Jagdhaus, ilm Hund.

821. Anetlum suvalens I. Auf wïsten Plätzen rerwildert (Altes Verzeichinss); fand es nie.

822. I'astinaci sativa I. An Rainen in Gstatterboden neben dem Stationsgebindle vereinzelt: sonst im (iebiete noch nicht beobachtet, während sic im oberen Murthale höchst gemein ist. 
s23. Heractenm Sphondylium L. Anf Wiesen, Feldern, an Bächen, in Obstgärten höchst gemein : am üppigsten wohl anf einer Waldwiese des Hartlersgrabens bei $3500^{\prime}$.

824. Her. montanum Gil. (asperum Koch, Maly). An hochgrasigen, feuchtschattigen Stellen der Berg- und Voralpenregion (4-5500') nicht selten: Sehr häufig am Aufstieg zur Scheibleggerhochalpe, vorzüglich muterhalb der Kemetwand; seltener in der Krummholzregion zwischen Scheiblstein und Pyrgas, auf der Ardning, um die Felsen des Hochschwung. Kalk, selten Schiefer.

NB. Die Mannigfaltigkeit der Blattformen an einem und demselben Standorte geht in's Unglaubliche.

825. Her. austriacum Jacq. Auf Wiesen der Voralpen und Alpen bis über $6000^{\prime}$ im ganzen Kalkgebiete sehr häufig, sogar schon im Gesänss sehr verbreitet.

826. Laserpitimm latifolium L. In grasigen Bergwälderu, sowie an bewachsenen Felsterrassen bis anf die Voralpen der Kalkkette und der Kalkvorlagen des Tanermzuges fast iiberall, doch selten in grösserer Menge: steigt im Gesäuss, Johnsbachgraben, längs des Sehwarzenbaches und der Folkernot (bei Mühlan) bis zmr Thalsohle herab.

827. Dancus Carota L. Auf trockenen Wiesen, an Wegen und Rainen sehr gemein bis in die Voralpen.

828. Torilis Anthriscus (I.) Gmel. An Wegen, auf somnigen Rainen und lichten Waldplätzen hie und da hänfig: Bei Weng, am Aufstiege zmr Pitz, vor Frauenberg, um die Klanse ob Ardning, bei Dittmannsdorf, am Fusse der Klammfelsen, un Strechau.

829. Anthriscus silvestris $\left(\mathbf{I}_{\mathbf{L}}\right)$ Hflim. Auf Wiesen, in Grasgärten, an Zäunen und Bachrändern, höchst gemein: F alpestris (W. Gr.), nach Maly auf Voralpen Obersteier's, wurde im Gebiete nicht beobachtet mid fehlt auch im Herb. Maly.

830. Anthr. C'crefoliun (L.) IIflim. An Kä̈unen und Häusern nicht selten verwildert, \%. B. vor den Stiftsthoren, in Hall, beim Ruppgarten.

Chaeropleyllum trunlum L. Bei Admont häutig (Augelis), im Enns- und Paltentlale (Maly 1868). Da Maly seine Angaben znmeist. Angelis verdankt, letzterer alser eine Verwechslung mit aureum zugibt, so ist diese Pflanze für nnser Gebiet sehr fraglich.

831. Charr. anrenm L. An Wegen, /ämnen, Getreidefeldern und Waldrändern bis in die höhere Bergregion sehr häutig, \%. B. in der Kruman, am Pyrgasbache ob der (istadtmayroralpe, un Lorenzen, um die Pfarrerhub ob Lorenzen, um Hohentanern (4000'). Alluvium, Kalk, Schiefer.

832. C'haer. ('icutaria Vill (hirsutum Koch, non L.) An Bilehen, unter Gebüseh, in Obstgärten und Wäldern bis iuf die Voralpen der Kalk- und Tanernkette gemein, auf Voralpenwiesen meist ₹ rubriHorum DC.

833. C'haer. hilsntum I. (Villarsii líoch). An leuchten, grasigen Stellen der mittleren Alpeuregion im Kalk- und Tauemzuge ziem- 
lich häutig, z. B. unter Krummhol\% an l’yrgats, Scheiblstein, Kalbling (Kalk); im Hochalpenthale zwischen Klein- und Gross-Bösenstein his 7000' selten, an Bachrindern ob der Bacheralpe, am Fusse der Hochhaide ob dem Gemeinsee lıäufig (Gneiss); um die Felsen des Hochschwung sehr häıfig (Glimmerschiefer).

834. Myphis odorita ( $\mathrm{I}_{\text {. }}$ ) Scop. An Zämen und Gartenwegen der Ortschaft Hohentauern, vorzüglich imner- und ausserhalb des Pfarrergartens, ebenso hei Admont (Angelis) und im Sattlergarten z.u Hall (Strobl sen.!); scheint blos verwildert.

S35. Conium maculatum L. An Wassergräben bei Ardning (Altes Verzeichniss), um Ardning (Strobl sen!).

S36. Pleurosper'mum anstriacum (L.) Hftm. An schattigen Stellen im Gesäuss und Johnsbachgraben äusserst selten, um den Gamsstein selten (Kalk); ziemlich häufig aber auf üppigen Alpenwiesen an der Suidseite des Hochschwnng (Gl.-Schiefer, 5800').

\section{Fam. Araliaceae Juss.}

837. Hederat Helix 1\% Sehı läufig in Wäldern $\left(2-4000^{\prime}\right)$, theils den moosigen Waldgrund iiberrankend, theils an Bäumen und Felsen emporkletternd; im Gesäuss, von Weng auf die Buchau, vor dem Mühlanerfalle, am Anfstiege zur Scheibleggervor- und Hochalpe etc., besonders häıfigg aber um Strechan.

\section{W. Fam. Corneae DC.}

833. Cormus sanguinea 1. An Zäunen, in Hecken und Vorhölzern sehr häufig, z. B. neben der Essling, im Stiftsgarten.

Corll. mas L. wird im Stiftsgarten etc. kultivirt, ist aber meines Wissens nirgends wild oder verwildert.

\section{WI. Fan. Lomuthaceac Don.}

8:39. Visenm allıum L. Auf Apfelbäumen hie und da um Weng, Hall. Aigen, Admont, im Selzthale etc., von Hatzi auch anf Eichen beobachtet.

\section{WII. Fam. Crassulacene DC.}

840. Scolum Rhodiolia Scop. (roseum (I.) miterscheidet sich nach schwedischen lix. durch viel breitere, kiirmere, fast ganzrandige Blätter). Auf steinigen Ahhïngen und in Gerölle der mittleren $\mathrm{Al}$ penregion: Sehr gemein um die Felsen des Hochsehwung, der Hochhaide, seltener im Ochsenkahr und ob dem Selıeiplsee am Bösenstein; im Kalkzuge in den Johnsbacheralpen. hesonder's rom Nitterboden 
iuf den Hund und gegen das Hochthor sehr häufig, imm Kalbling selten.

841. Sell. maximum Suter. Auf Felsen und Mauern der 'liefregion häufig, z. B. an Stadtmancrn Rottenmanns, an Felsen bei der Melzen, um Strechau.

842. Sed. purpurascens Kocl. An Mauem um Admont von Angelis 1878 gesammelt und mir mitgetheilt.

843. Sed. villosum L. Auf sumpfigen Bergwiesen des Seckaner Zuges bis hart an die Grenze unseres Gebietes nicht selten, für unser' Gebiet aber noch anfzufinden.

844. Sed. atratmm h. Auf steinigen, kimzgrasigen Triften, auf Felsblöcken und Felsen $\left(4500-7000^{\prime}\right)$ in der ganzen Kalkkette seh. hänfig, anch anf Kalkrorlagen der Tanemkette. Variirt o genuinum und $\beta$ carinthiacum (Hpp.) mit gelbgrünen, von einem grünen Mittelnerv durchzogenen Blumenbliittern: letztere fast hänfiger.

845. Sed. anmum L. An Felsen und Mauern der Tauernstrasse von Trieben bis Hohentanern sehr häutig, ebenso von der Klamm bis tief' in den Strechengraben, seltener von Lorenzen zur Pfarrerhube. Schiefer, 2-4000'. Scheint im Ennsthale zu fehlen.

846. Sed. albun L. An Felsen und Manem bis ant die Voralpen des Kalkzuges sehr verbreitet, ebenso auf den silur. Kalklagen der Tauernkette; anf Schiefer aber' nur imnerhalb der Klamm gegen den Strechengraben beobachtet.

847. Sed. dasyplyyllum L. An Felsen in der Klanm, sowie von da gegen Oppenberg und in den Strechengraben ziemlich selten (Glimmerschiefer), auf lialkgerölle in Sunk, Hich dem Herb. Hatzi iluch "aut Alpen un Admont".

848. Sed. sexamgulare L. Auf Mantern, Steinhaufen, Felsen der 'liefregion im Enns- und Paltenthale sehr häufig, z. B. am Wege nach Mühliu, Hall, framenberg, im Gesäuss, am Lichtmessborg, Dittmannstorl', Lorenzen, 'l'rieben. Kialk, Schiefer.

849. Sed. ande L. An denselben Standorten, wic voriges, im ganzen oberen Murthale häufig, lür unser Gebiet aber nur rou einem alten Verzeichnisse angegeben, dessen Verfasser es möglicherweise mit vorigen rerwechselte.

850. Sed alpestre Vill. Auf Felsen unl steinigen Abhïngen der 'T'anernkette (Gneiss, Glimmerschiefer) etwa ron $4500^{\circ}$ an bis zu deu höchsten Gipfeln überall sehr häufig, am Bösenstein bis 7784'.

851. Sempervivum Wulfenii Hpr. Auf'Felsen des Blachberges in der Strechen häutig (Glimmerschieter, 5-5.300').

852. Semp. Funkii Bram. "Auf der höchsten Schneide des Bösenstein mehr vereinzelt" (Schleicher), also auf Gneiss bei 7780': ich fand es aber nie laselbst.

853. Semp. montanum L. $\Lambda$ uf Felsen und Stcinblöcken der 'Tauernkette von 5000 bis über $7000^{\prime}$ überall sehr lıäutig, z. B. Böseustein, Hochlıaide, Steinamandl, Hochschwung; gedeiht auch prächtig an Werfnerschiefer-Platten des Pfarrergartens zu Frauenberg, hier jedenfalls kultivirt. 
85t. Semp. hirtum I. Auf Berglelsen Ner Kalkzone häutig; Auf der Pitz, am Südwestfusse mud auf der Spitze der Kemetwand, zwischen Bärnkoppe und Stumpfnagleralm, am Almsteig des Kalbling und um die hohe Kalblingmaner, am Aufstiege zum Sul\%kahr, am Gamsstein, im Sunk: selten auf Glimmerschiefer am Eingange in den Streehengraben.

\section{Fam. Ribesiaceae Endl.}

85.). Rihes Grossularia I. \% glanduloso - setosum Koch. An Züumen, Hecken und in Wäldern gernein.

8.56. Rih. rulorum I. In Gärten allgemein kultivirt und halb rerwildert: nigrmm L. wird selten gepHanzt, z. B. im Stiftsgarten.

857. Ril. alpinum L. K/wischen Gestränch der höheren Waldbis Krummholzregion zicmlich selten: 'l'ief unter'm Riunstein in len Tohmshacheralpen, muterhalb der Scheibleggerhochalpe und am Wege zu Stumpfiuagleralpe: an letzterem Standorte gibt Gebhard und anl dessen Autorität llaly 1838 petraemm Wlf. an, ich mul Strobl sen, aber haben hier nu alpinum gesammelt: es dürfte somit Ciebhard's Angabe auf irriger bestimmung berulien: anch sonst wurde petraem im Gebiete nirgends heobachtet.

\section{hX. Fam. Saxifrageae Vent.}

S58. Saxiliaga Aizoon Jaeq. Auf' Felsen des Kalkzuges unı der Kalkvorilpen des Tauernzuges $\left(4-7000^{\prime}\right)$ sehr gemein, bisweilen anch bis zur Thalsohle herabgeschwemmt: anch am Hochschwung, besonders miter der Spitze sehr gemein und ob der Bacheralpe unterlalb des Gemeinsee's selı lä̈utig (Glimmerschiefer). Variirt in (iebiete nach den Blüthen: $\%$ immaculati und seltener $\beta$ maculata; nach den Wurzelblittem: o Brevifulia Lingler Mon. (= laeta Schott, wenn die Blumenblätter gross und ungedleckit sind) und \& longifolia Wimmer $=f$. robusta (Schott) Engler. Beide kommen öfter's nebeneinander ror, z. B. rou der T'reflineralpe zum Reiehenstein (Angelis!) und ob der Bacheralpe, wo \% brevif. noch blühte, während 3 schon lange verblüht war: im Allgemeinen lieht $\beta$ tiefere nud $\%$ höhere Lagen.

859. Sax. altissima líprure. "Auf Alpen um Admont" Maly 1868; im Herb. Maly liegen lixemplare mit der Etiquette ,Aimont-: der nächste mir bekiannte, aber schon ansserhalb der (iebietsgrenzen gelegene liundort sind verwitternde Schicferwinde in Hagenbichgraben bei Kalwang.

S60. Sax. mutata L. In Flietzengraben bei Gaishom, an Waldrändern unterhalb der Grieswoberalm ziemlich lı̈̈ılig, selten im Schwallzenbachgraben und im Giristhale am Kahbling. Kalk, Schicfer.

S61. Sax. Bursuriana l. Anf deu lö̈chsten, felsigen $A b$ bängen der Lílkkette: Häntig am Sparaleld $\left(6600-7000^{\prime}\right)$ selten am Hexenthurm, Kalblingrüctien (Angelis), an l'yrgats (Strobl sen.), Scheibl- 
stein (Herb. Joanı.!); auf Kalkfelsen des Sunk und Triebenstein in der Tauernkette schon in der Waldregion häufig.

862. Sax. caesia I. Auf Felsen und im Felsschutt der Kalkkette und der Kalkvorlagen des Tanernzuges $\left(4-6600^{\prime}\right)$ gemein, auch ziemlich häufig herabgeschwemmt am Mühlauerfall, im Schwarzenbachgraben, Gesäuss etc.

863. Sax. 0ppositifolia I. Umkränzt in dichten Rasen die Felsen des Strechaver Schiefergebirges, vorzüglich gemein am Hochschwung; auch am Grieskogel im Triebenthale (Angelis, Gneiss), am Griesstein (Hatzi! Gneiss); auf Kalk nur unter der Spitze des Pyrgas c. $7150^{\prime}$ in einer kleinen Mulde ziemlich häutig und auf der Spitze des Hexenthurm (6618') selten.

864. Sax. blepharophylla Keruer. Auf Glimmerschieferfelsen des Hochschwung c. 6000' mit der vorigen; ob häufig, könnte ich nicht angeben, da ich sie früher nicht unterschied; vielleicht gehört auch "biflora All. am Rottenmannertauern" Maly 1868 hieher; sie fehlt im Herbarium Maly.

S65. Sax. aspera L. "An lelsigen, leuchten Orten des Rottenmanmertauern" Maly 1868; jedenfalls auf' Angelis' Autoritiit, der sie aber nie in unserem Gebiete, sondern nur auf Hochalpen um Kleinsölk sammelte; ich entdeckte sie häufig $\left(4500-5000^{\prime}\right)$ am Blahberg in der Strechen und etwas seltener am Hochschwung ( $\left(6000^{\prime}\right)$. beidesmal auf Glimmerschiefer.

866. Sax. bryoides T. An trockenen, felsigen Abhängen und windigen Rückenflächen der 'Tauernkette, $\left(6-7784^{\prime}\right)$ sehr hïufig: Am Bösenstein gemein, im Ochsenkahr, anf den drei Stecken, der Hochhaide, am Grieskogel, Hochschwung (Gneiss, Glimmerschicfer).

867. Sax. aizoidles I. An feuchten, quelligen Stellen $\left(4-700\left(0^{\circ}\right)\right.$ im Kalkznge gemein, doch auch in der Tanernkette, \%. B. Hochschwung, Bacheralpe, Bösenstein, sehr häıfig. Variirt a. citrina (citrongelb), f crocea Gid. (safiangelb), $\gamma$ atrorubens (Bert) (dmkelsalframroth), oft, z. B. am Kialbling, Hochschwung, ob der Bacheralpe, alle dree Variationen an demselben Standorte und mit Uebergängen; eine selı üppige, grossblättrige Form mit vielen unfruchtbaren Ausläufern (= var. riparia Kerner Herb.) sammelte ich an Gräbeu sumptiger Wiesen vom (iriesmayr gegen die Enns hinab, wohl nur Standortsmodifikation.

S68. Sax. stellaris I. a forma vulgaris Engl. $\beta$ f. glabrata Sternb., of f. hispidula Rochel, ó f. panciflora lingl. An fenchten Stellen, besonders an Bächen und schneefuldern, dor Berg- bis Hochregion des Kalk- und 'Tanernzuges meist sehr gomein, am Bösenstein bis $7400^{\prime}$; a und $;$ an lüutigsten, $\beta$ an den fenchtesten, $\partial$ an den höclisten Standorten; var. comosa I'oir (Aeste mit kleinen Blattrosetten) dürite ebenfalls vorkommen; wenigstens samnelte ich sie in Obersteier zweimal.

869. Sax. hieracifolia W. K. An haideartigen und äpjigeren Abhängen um die Felsen des Hochschwung (Glimmerschieler, 5500') gar nicht selten; sammelte bereits über 60 lixemplare. 
s70. Sax. rotunditolia 1. . forma vulgaris lingler. An Gebirgsbächen, in schattige!n Bergschluchten mol im fenchten Boden der Hochwilder' des Kalk- und 'l'anernzuges fast ïberall, doch nicht gemein und kaum bis in die Alpenregion, etwa bis $5000^{\prime}$; anch schon in der Tiefregion, \%. B. im Gesäuss, Johnsbach-, Veitlgraben, am Mühlanerfall.

871. Sax. prenaica Vill. Fngler. An felsigen, kurzgrasigen Orten der Kalk- und 'T'mernkette (5-7784') sehr häufig, besonders auf Kalk; rariirt ausserordentlich: 1. nach der Blattiorm: a trifida (gemein); $\ddot{F}$ pygmaea Haw = integrifolia Koch (seltener, in ler Hochregion der Kalkalpen): 2. nach der Behaammg: \% lorma rulgaris Eugler (Blitter fast kahı, Stengel unten ziemlich kahıl. Auf Kalkalpen, seltener im 'tinernzuge); $\hat{\beta}$ glandulosa lingl. (= moschata Wlf.. Stengl unten und ohen drïsig, Blättcr dicht drïsig - nur im Tancrnzuge): 3. mach der Rasenform: $\%$ compacta Mert. Lioch, F intermedia lioch, $\because$ laxa Sternb. nud Koch, alle drei oft in nächster Nähe miteinander rorkonmend, \%. B. $\alpha$ und $\ddot{i}$ ant der Spitze des Bïsenstein: endlich wïre noch zn erwähnen, dass manche fixemplare der Tanernkette, \%. B. form. glabrestens laxil rom Büsenstein und f. glandulosa laxa rom Hoclisehwung, fast so stark vorspringende Blattnerven. wie exarata Vill, dabei aber noch die schmalen Blumenb)ätter der lyrenaica besitzen; die echte exaratal mit breiten, verkehrteiförmigen Blumenblättern von doppelter Länge der Kiclchripfeln wurde im Gebiete noch nicht gefunden.

872. Silx. aplyylla Strpul. 1810 (stenopetala Gd. 1818). An steilen, felsigen Abliängen der höchsten Kalkalpen $\left(6-7000^{\prime}\right)$ : Auf del letaten Ehlobmg des Scheiblstein, an Felswänden ler Schafleithen, am liückeri des Sparafold (hicr häutig), muter der Spitze des Kalling, am l'yrgals (S'anter), Natterregl (Hatri!).

87. Sax. soldoiles J. An denselben Standorten, wie vorige und meist mit ilır gesellschaftlich, ann Sparafeld ebenfarls an häufigsten. ausserden noch neben schneefeldern des Hochthor sehr häntig nud mach einem alten Verzeichnss am Buchstein; inn sprarafeld sammelte Angelis auch eine sthlalliasige, höhere rar. dispar (viele blitter dreispaltig, die Blumenbläter etwas schmaler, als bei der Normalform, jedoch Janzettlich und kürzer, als der Kelch); höchst wahrschemilich Bastard mit Aplỵla; ieh möghte ihn zu bhren des bntdeckurs Sax. Angelisii uement.

874. Six. androsiarea I. An leutiten, felsigen Stellen der Voralpen- und Alpenregion des Lalkzuges, vor\%inglich in Schlnchten der Alpenbäche, an Schneefeldern und Schneegrnben (4500-7000') gemein, oft sogar massenhaft: auch $m$ die Felsen des Hochschwmg (Glimmerschiefer) selı häufig.

875) Sax. Scupolii Vill 17s? (controrersa Stemb. 1810) \% f. Jimnae Boiss. Engler (Höher, Blätter meist f'̈̈nltheilig); folia Gd. (zart, einfach, Blätter ungetheilt). Auf einem moosigen Alshange im Sunk unterhalb dre gesprengten Kalkwand rerstrent $(x)$, 
in der Flietzen ob der Flietzenalm, am Wege zur Hölleralm auf Kalk (Angelis!); an letzterem Standorte $\alpha, \beta$ und Uebergänge.

876. Chrysosplenium alternifolium L. An Bächen, Quellen, in Obstgärten und feuchten Schluchten gemein.

\section{Fam. Ramuneulaceae Juss.}

877. Clematis Vitalba L. a. grossedentata, selten $\beta$ integrata DC. An buschigen Stellen und in Bergwäldern zerstreut: Ueberzieht im Rauchbodenwalde von Gstatterboden auf den Brucksattel weithin die Wegränder und das steinige Beet eines Giessbaches, überrankt im Lafferwald am Rande des Reiterbaches Gesträuche; am Wege anf die Buchan, gegen die Pitz hinanf und hoch oben am Dörflstein.

87S. Atragene alpina I. An felsigen und schattigen Stellen der Voralpenregion des Kalkzuges und der sil. Kalkrorlagen des Tanernzuges ïberall bäufig, schr gemein sogar um den Himbecrstein am Ostende des Ennsthales und durch's Gesänss; in Schieferschluchten (z. B. Wolfs- und Strechengraben), sowie anf Sehiefervoralpen (Hochschwung, ob der Pesendorferalpe gegen die Hochlaaide hinauf) spärlich.

879. Thalictrum apuilegifolium L. An Quellen, Bächen und in Wäldern der Kalkzone $\left(3-5000^{\prime}\right)$ überall häufig, viel seltener auf Schieferbergen (beim Stege im Wolfsgraben, unter Felsen des Hochschwung, am Blahberge in der Strechen); var. albiflorm unterlaalb der Scheibleggerhochalm.

880. Thal. mints L. a virens WTlle, F roridum W1lr. (Blïtter intensiv blau bereift), $\gamma$ majus (Jacq.) Kich. $=\beta$ olatuin Nlr. (Eine sehr üppige, hohe, grossblättrige Form; meine lixemplare stimmen genau mit Exemplaren Kerner's und Hafluer's ans der Umgebung Wien's). Anf grasigen, buschigen und felsigen Stellen der Kilkroralpen ziemlich selten: $\Lambda m$ häufigsten ron der Gistadtmalyroralye gegen den Scheiblstein hinaul ( $\%$ und $\%$ ), seltener unter hirmmlnolz um die Ringmaner des Kalbling, ann Wege in die Kruman ob dem Schmidbacher (Angelis), an Wege nach Johnsbach ( $\alpha$ und $\beta$, letztere von P. Rudolf Gersprich gesanmelt und von Angelis mir mitgetheilt).

881. Thal. angustifolium Jacy. $\beta$ heterophyllum Gd. (Die unteren Blittchen länglich - bisweilen einige dreispaltig — die oberen schmal - linear). Auf feuchten Wiesen, besonders zwischen Schilfiohr mnd zwischen Gebïsch anf Kallivorlagen läufig, \%. B. unterhalb der Ziegelbrennerei, in der Krmman, im Grosinss, von Gstatterboden iul den Brucksattel.

882. Thal. nigricans Jacq. Reichb. Jc. 4638 XLIII. Auf feuchten Wiesen, besonders zwischen Schilfrohr, z. B. Imm das Hotmoor, an der Ems in der Schultering, unterhalb der Vicgelbrennerei, an der Palte. Oft mit voriger und wohl kaum spezifisch verschieden.

883. 'Thal. Havum J. Rchb. Jc.! Auf'. Wiesen im Gesäuss von Angelis gesammelt und mir mitgetheilt. 
88t. Hepatica triloba (haix. Unter Laub- und Nadelhol\%, besonders der Bergwälder ant Kalk und Schiefer fast überall gemein $\left(3-4000^{\prime}\right)$ : anch var. albiflora an Schafterwege, an der Falnrstrasse des Lichtmessberges, auf der Buchan etc. nicht selten.

88.). Anrmonn nar nissiflor'a l. f. austriaca Kermer Herb. (KalkRace). An herasten, fenchten Stellen, um Schneegruben (4-7000') in den Hallermanern und Johusbacheralpen sehr häufig, seltener am Kalblingstocke: auf den höchsten Punkten meist einblüthig. Die Form der Urgebirge wurde im Gebiete noch nicht aufgefunden.

886. An. Jaldensis L. Auf Alpenwiesen am Hund bei Johnsbalch (Hatri!): von Strobl sen. auch am Pyrgas angegeben.

887. Au. nemorosa I. In Wälderu, Hainen, Obstgärten, unter Gebüsch der 'Tief- und Bergregion höchst gemein; selten var. rosea.

885. An. ranumculoides L. Zwischen Gebüsch, an Hïgeln und auf Feldern ziemlich selten: Am häufigsten an Zäunen zwischen Bärndorf und Büschendorf, seltener am Leichenberg, am Wege in die Iühlau, am Heindlfeld, vor"m Gesänss, im unteren Stiftsgarten.

889. Pulsatilla alba Lobel. Rchb. Jc. 4653 LI. An fenchten Gehängen und Bachrändern der ganzen Tauernkette $\left(4-6500^{\prime}\right)$ sehr lräutig: häutig auch auf den windigen Höhen und Graten der Hochregion, z. B. am Bösenstein bis $7300^{\prime}$, auf der Hochhaide etc.

890. P'uls. Burseriana Scop. Auf feuchten und felsigen Ablıängen der Voralpen- bis Alpenregion im Kalkzüge fast überall, wenn auch nicht gerade gemein; steigt bis in's Gesäuss und den Johnsbachgraben hinab; ich fand nur \% grandiflora Hpp; $\beta$ sulphurea (L.) wurde von Hatzi am Scheiblstein gesammelt (Herb. Maly), von Strobl sen. am Kalbling und von Welden speziell nam Schneefelde des Speikbodens" angegeben.

891. Idonis aestivalis $\mathbf{I}_{\text {. }}$. Unter Saaten (Strobl sen. Herb. ohne näheren Standort).

892. Myosulıs minimus I. Auf überschwemmt gewesenen Stellen am Gaishornsee (Speckmoser).

893. Ranunculus aluatilis I. var. homophyllus Wlr. (Von paucistam. verschieden durch doppelt so grosse, vieladerige Blumenblätter, gegen die Śpitze verschmälerte Blüthenstiele, zahlreiche Staubgefässe, ausserhalb des Wassers pinselförmig sich vereinigende Blattfä̀den). In stehenden und fliessenden Gewässern gemein, Z. B. Bäche beim Griesmarl', Gräben am 'Temmelteich, Gansmüllerteich, Krumanerteich, Stiftsteiche, Ennsarme, Tanernteiche (c. 400(9'): nach Maly 1868 käme auch \% peltatus und \& tripartitus (Nolte) im Eunsmul Paltenthale vor, doch sah ich keine Exemplare.

894. Rau. pancistamineus Tausch. (identisch mit Diagn. und Exempl. Freyn's in Kerner Flora exs. Austr.). In stehenden Gewässern wahrscheinlich häıfig: ich sammelte ihn in grossen Stiftsteiche und in Enusarmen der Krumau.

895. Raln. circinatus Silotlı. In Krumauerteiche und in den Teichen des Stiftsgartens, besonders den kleineren, nicht selten.

NR. Ran. glacialis I. .Im Gesäuss (Maly 1868) ist jedenfalls ein Ir'thum, weil nic auf Kalk und nie in der Tiefregion. 
896. Ran. alpestris L. Auf felsigen, feuchten Stellen der Kalkkette $\left(4-7000^{\prime}\right)$ sehr gemein, auch auf den sil. Kalkvorbergen der Tanernkette häufig: steigt mit den Giessbächen in die Tiefregion, z. B. Gesäuss, Johnsbachgraben. wo er sehr üppig wird, während die Exemplare der Hochregion kamm 2-:3 cm. Höhe und oft abnorme Blätter zeigen: am Scheiblstein von Strobl sen. anch flore pleno gefunden.

897. Rall. crellitus W. K. In ausgetrockneten Giessbachbeeten, an Rändern der Seeen und Schueefelder $\left(5500-6500^{\prime}\right)$ des Tauernzuges stellenweise höchst gemein: so links ob dem Scheiplsee (wurde hier ,am Hengst" von Sommeraner entdeckt und als vaginatus Som. versendet), um den gefromen See, den Gemeinsee, von dort aufwärts bis zum Sattel zwischen Mitterstein und Hochhaide. um den Grünsee, am Fusse der drei Stecken und an der Weissgulling hinter Oppenberg: wird in Maly 1868 irrig auch rom Sparafeld angegeben. Gneiss, Glimmerschiefer.

898. Rau. aconitifolius L. und $F$ platanifolius (L.) Koch. \%: Auf feuchten 'Triften und zwischen Gestände der Kalk- und Urgebirgsalpen häufig, z. B. zwischen Krrummholz am Kalbling und herabgeschwemmt bis zum Kaiseranerteich, am Steinamandl bis 6400', Kampl, Scheiblstein, in den Johnsbacheralpen ; $\beta$ : An Bächen und feuchten, schattigen Stellen der Tief- und Voralpenregion des ganzen Gebietes zerstreut, noch häufiger als ๘, z. B. um Mühlau, Johnsbach, am Aufstieg zur Scheibleggerhochalpe, im Wolfs- und Strechengraben, bei der Pfarrerhub ob Lorenzen, unter Erlen ob der Bacheralpe, um den Scheiplsee: oft Uebergänge ron $x$ zu $\beta$.

899. Ran. Flammula L. o. lanceolatus und $\beta$ ovatus (Pers.) DC. In Gräben, Sümpfen, an Teichen und Mooren des Enns- und Paitenthales gemein: z. B. an den Rïndern des Hofmoores, an sandigen Ufern der Enns und bei der Griesmayrlache; anch eine weithin liriechende Form mit fast linealen Blättern = reptans L.?: doch sah ich nie so zarte und so schmalblättrige Exemplare, wie ans Norddentschland und der Schweiz.

900. Ran. Lingua L. In tiefen Sümpfen, an sumptigen Teichund Flussrändern riemlich häufig: Ausserhalb der Schultering, in der Krumau zwischen Schilfrohr, an Ennsarmen, an der Palte bei Trieben, am Gaishornsee (Verbniak!).

901. Ran. hybrilus Biria. Auf fenchten Abhängen, an Schneegruben und Schneefeldern der ganzen Dachsteinkette $\left(5-6500^{\prime}\right)$ häufig, besonders am Pýrgas, Scheiblstein, Natterriegel, Buchștein, Kalbling, Hund; selten bis zum Mühlauerfall herabgeschwemmt.

902. Ran. anricomus L. Auf der fenchten Schulteringwiese (Angelis! Hatzi!), an Ennsufern bei Admont (Hatzi), unterhalb der Ziegelbrennerei im Kothgraben (Angelis!).

903. Ran. montanus W. Auf feuchten, gut berasten Abhängen der Voralpen und Alpen des Kalkzuges, besonders auf freien Plätzen zwischen Krummholz gemein, etwas seltener, doch ebenfalls von $4500^{\circ}$ an fast überall verbreitet, im Tauernzuge: auch schon auf Kalksand 
im Gesïuss $\left(\because .20000^{\prime}\right)$ und zwar theils in üppigen bxemplaren der Hauptform, theils in der noch ïppigeren rar. " major Koch, die anch noch hie und da auf Voralpen des Scheiblstein etc. sporadisch anftritt: habituell daron gïnzhich verschieden ist die kaum $3 \mathrm{~cm}$. hohe, kleiublüthige (Durchmesser 11-14 mm.) Form mit schmäleren, tiefer getheilten Blittern, "ie bei $7000^{\prime}$ die Höhe des Kalbling häutig bewohnt: sie sieht dem carinthiacus Hpp. sehr ähnlich, muss aber doch nur als Hochalpenform des montanus aufgefasst werden. Wic in der Ueppigkeit, gibt es anch in der Belıarung von der dichten, abstehenden Stengelbehaarming der var. $\beta$ bis zu fast gänzlicher Kahlheit zahllose Uebergänge.

904. Ran. acris L. Auf Feldern, Wiesen, trockenen Weiden und in Obstgïrten gemein bis auf die Voralpen, wo er in einer niedrigen f. subalpina mihi mit breiteren, weniger tief getheilten Blättern die Almhütten in Menge umgibt.

905. Riu. lamuginosus L. An feuchteu, schattigen Waldstellen, an Bächen und in Schlnchten der Vorberge sehr rerbreitet, doch nicht sehr häufig, z. B. im Gesäuss, auf der Buchau, am Bache les Oberhofteldes, längs der Strasse des Lichtmessberges, am Almsteig, im Wolfsgraben. Kalk, Schiefer; Alluvium.

906. Ran. anreus Schl. 1814 (nemorosus DC. 1828). In Bergund Voralpenwäldern des Kalkzuges auf steiniger Unterlage überall sehr häutig, steigt ron $2000^{\prime}$ (z. B. Gesïuss, Mühlau) bis zur oberen Grenze des Krummholzes.

907. Rall. repens T. An überschwemmt gewesenen Bach- undFlussrändern, an Wegen, iu Gräben und teuchten Wäldern sehr gemein: an trockeneu Stellen öfters aufrecht und ohne Auslänfer.

908. Rail. bulbosus I. Sommerüner hatte ihn im Herbar und gab ihn als Admonter Bürger an (Angelis): auch von Strobl sen. wurde el rom Gebiete angegeben; ich fand ihn nie.

909. Riın. silulous Cr. (Philonotis Ehrh.) An wïsten Plätzen vor Häusern und an Wegen ziemlich gemein, z. B. vor'm Krumauerteiche, am Hoffelde, hinter Johusbach.

910. Ran. scrlepatus 1. Im Gebiete sehr selten: ich fand ihn einmal auf einem Kleefelle im Stiftsgarten, Hatzi an der Sanlache des Stiftsmayrhofes: auch am Stiftsteiche stand er früher.

911. Rill. arveusis L. Ebenso selten, nur in einem alten Verzeiclınisse aufgeführt.

912. Ficaldia 1'inunculoiles Mnch. Aensserst gemein in den Becten der Krautgärten, wo sie ( fürmliche Bestände bildet, gerne auch in der Nähe ron Häusern und Hecken auf fenchter, humusreicher Unterlage.

91:3. C'altha palustris L. In Wassergräben, Sümplen, an Bächen und Teichen höchst gemein, steigt ann Hund bis jogo' (Kalk), ehenso durch den Strechengraben bis in die Alpenregion des Hochsehwung.

914. 'Trollius europaeus L. Auf fetten Triften der Berge, Voralpen und Alpen des Kalkzuges sehr häufig: erscheint auf den 
höchsten Spitzen (Kalbling, Scheiblsteiu bei 7000', Pyrgas bei 7200') als humilis Cr., zieht sich aber am Pyrgas, wo er höchst gemein ist, bis in die Voralpenregion herab und geht allmählig in die Normalform (altissimus Cr.) über; im Tauernzuge traf ich ihn nur um die Felsen des Hochschwung (Glimmerschiefer) häuñg, sonst vereinzelt.

915. Hellebor'us niger L. In Berg- und Voralpenwäldern des Kalkzuges und der Kalkvorlagen des Tanernznges höchst gemein, anch auf Kalkschotter ler Thalsohle: die erste Frühlingspflanze.

916. Isopyrum thalictroides L. In schattigen Laubwäldern bis 3500' nicht selten: Gegen das Gesäuss hinab und im Gesäuss hie und da truppweise unter Laubbäumen häufig, am Leichenberg, Schafferweg, unter der Kemetenmaner, im Sunk (Angelis).

917. Aquilegia vulgaris $\mathrm{I}$. In Bergwäldern und auf Waldwiesen des Kalkzuges zerstrent, aber ziemlich überall, hänfig.

918. Aquil. nigricams Bmg. (atrata Koch). In Bergwäldern und auf Waldwiesen des Kalkzuges: Hüufig vom Dörflstein zu den Pilzhütten hinab und von da zum Natterriegel bis 3500', nicht selten von der Buchau nach S. Gallen, von Angelis noch am Mühlauerfalle und im Fsslingsande gesammelt. Haenkeana Maly 1868 ,anf Abhängen bei Hall (Hatzi) * gehört auch hieher.

919. Delphinium Consolida L. Von Sommeraner bei Weng zwischen dem Grabnerhofe und der Enns, wahrscheinlich auf einem Acker, gesammelt; seither nicht mehr beobachtet.

920. Aconitm Lycoctonmm L. \% Vulparia (Rchb.), \& Thelyphonum (Rchb. Ic.) In Wäldern, Holzschlägen, Schluchten der Berge und Voralpen des Kalk- und Tanernzuges-bis 4500' fast ïberall, $\alpha$ sehr häufig, $\beta$ seltener.

921. Ac. Cammarum Jacø. Rehb. Jc. 4684. $\beta$ judenbergense Rchb. An waldigen und buschigen Stellen der Vorberge in der Dachsteinkette und auf den sil. Kalkvorbergen der Tauernkette überall sehr hänfig; var. albiflorum um die Kemetmaner vereinzelt.

9๕2. Ac. variegatum L. Rchb. 4682. Zwischen Gebüsch am Eingange in's. Gesäuss (Kalk, 2000') ziemlich häufig mit vorigem; vielleiclit gehört hieher anch das ron Strobl sen. am Pyrgas angegebene paniculatum.

923. Ac. speciosim 0tto Rchb. 4690 (? aber Stengel nicht schlaff, Schnabel nicht anfgebogen, Blattstücke an der Basis nicht zusammengeflossen; steht auch dem Stoerkeanum Rchb. 4692 sehr nahe, unterscheidet sich jedoch durçh kanm behaarte Staubfäden und sehr grosse, hohe Blüthen.) Diese prächtige Pflanze fand ich hänfig oberhalb des Alpsteiges an der Südwestseite der Kemetwand zwischen Krummbolz und Gestränch (Kalk, c. 4000').

924. Ac. multifidum Koch, Rchb. 4696. $\beta$ latisectum Rchb. Un die Stumpfnagleralm (Kalk, c. 4000') am 28. September 1868 mit Cammarum und Napellus hänfig und noch blühend gefunden.

925. Ar. Napellus Dod. Lob. Rchb. Jc. s. pubescens mihi (Blüthentraube flaumhaarig), $\beta$ glabrum mihi (die ganze Pflanze völlig kahl). In Voralpenwäldern der Kalkkette: Am Scheiblstein, im Sulzkaln 
(Herb. Hatzi, r. o.), von der Farclneralm bis in's Sulzkahr hinabs häufig, am Fusse des Rimustein sehr häufig (\%), ebenso sehr hälufig um dic Hütte der Stumpfnagleralm mit Camm. und multifid.; was schon reiffrüchtig, während diese noch blühten; hier auch var. $\vec{\beta}$, aber seltener.

920. Ac. laxum Relıl. Jc. 4701 (stimmt genau, aber Staubfiiden dicht langbehaart). Am Alpenbache, welcher ron den Kothhïtten am Rottenmannertauern lierabfliesst, mit der folgenden Art, aber sehr selten.

927. Ac. tamricum Wlf. Rchb. An Gebirgsbälchen und um Almliütten in der ganzen Tanernkette höchst gemein, meist a latisectum m., seltener $\beta$ angustisectum m. (mit schmallinearen Blattzipfeln).

928. Ac. Koelleamm Rchb. In dem hohen Alpenthale zwischen dem grossen und kleinen Bösenstein (Gneiss, 6-7200') sehr häntigg; ist vielleicht nu hochalpine Zwergform der vorigen.

929. Actaea spicata I. In schattigen Bergwäldern und auf Voralpen der Kalk- und Schieferzone überall verbreitet, aber meist vereinzelt, steigt ron der 'Thalsohle (z. B. Wäldchen vor'm Gesäuss, Klamm) bis in's Krummholz (z. B. am Scheiblstein, Kalbling).

\section{Fam. Berberideae Vent.}

930. Berberis vulgaris L. In Hecken, an Zäunen und Waldrändern bis auf die Voralpen gemein.

\section{Fam. Papaveraceae Juss.}

931. Papaver alpinmu L. var. albiflorum Kch. Auf Dachsteinkalk-Gerölle unter den Felsen der Schafleithen am Schafwege und im Kalblingbachbeete abwärts, am Natterriegel (Strobl sen., Hatzi!), in den Johnsbacheralpen (Hatzi!); sehr gemein auf Gerölle und an Giessbachrändern im Johnsbachgraben und im Gesäuss vor Gstatterboden. häufig.

932. Pap. Rlıeas I. Unter Getreide und Lein hie und da

NB. Pap. somniferum L. wird nur in Ziergärten kultirirt.

933. Chelidonium majus L. Auf bebautem und wästem Boden, besonders an Vauern und auf Schutt sehr gemein.

934. Corydalis cava (L.) Schweigr. Auf Feldern, z. B. sehr gemein ob der Kapelle vor Weng, im Heindlfelde vor'm Gesäuss (an beiden Localitaiten auch var. albiflora [Kit]). um Hall; doch auch an steinigen Waldrändern, z. B. lıäufig ob Röthelstein, seltener beim Kalliofen ob Kaiseran $\left(4000^{\prime}\right)$. Meist ïber Kalk.

935. Cor. solida (I.) Sm. Im Scliatten der Laubbäume und Gebüsche; Gemein im Stiftsgarten, sowie im Paltenthale von Bärndorf nach Rottenmann und Gaishorn, sonst scltener. Kalk, Schiefer. 
936. Fumaria officinalis L. In Krantgärten und Kartoffelfeldern, auch auf Schuttplätzen sehr häufig.

937. Fun. Schleicheri Soy. W. Haussknecht Reg. Flora 1873 pag. 411. An ähnlichen Standorten, aber seltener, z. B. auf einem Kartoffelfelde im oberen Stiftsgarten, auf dem im Nordostende des unteren Stiftsgartens sich erhebenden Hügel. Stimmt genau mit Exemplaren Haussknecht's und lässt sich ron Vaillantii Lois., die wohl auch im Gebiete rorkommen dürfte, leicht unterscheiden durch die Bracteen, welche dreimal kürzer sind als die dünnen, kaum nach oben rerbreiterten, $4 \mathrm{~mm}$. langen Fruchtstiele, durch die dunkler gefärbten Blüthen und längeren, breiteren Kelchblätter.

\section{Fam. Cruciferae Juss.}

938. Nasturtium sylrestre (L.) R. Bl. An Gräben, Wegen, lehmigen Ufern der Flüsse und Bäche sehr häufig, z. B. gegen Frauenberg, an Ennsarmen, an der Palte bei Bärendorf, um das Hofmoor.

939. Yast. palustre (Leys.) DC. An überschwemmten Uferm der Enns und Palte. in Wassergräben, abgelassenen Teichen, überhaupt an nassen und sumpfigen Orten gemein.

IB. Nast. austriacum Cr. wird ron Maly 1868 ,im Enns- und Paltenthale (Angelis) - angegeben. Angelis aber erinnert sich nicht, die Pflanze im Gebiete gesammelt zu haben.

940. Barbarea rulgaris $\mathrm{R}$. Br. Unter Gebüsch, an steinigen, sandigen Ufern der Bäche und Flïsse hie und da nicht selten: In der Sautratte, an der Enns unterhalb des Griesmayr und gegen Frauenberg, im Hoffelde, bei Gstatterboden (Angelis!); sehr häutig im Fürstenparke bei Rottenmann.

9.41. Barb. arcuata Rchb. Auf kalkschotterigen Stellen unter Gebüsch in der Sautratte nicht selten.

942. Turritis घrlabra L. Auf grasigen, steinigen Anhöhen, an sandigen Feldrainen hie und da, meist in wenigen Exemplaren: am häufigsten auf buschigen Hügeln vor Frauenberg und auf versandeten Aechern bei Lichtmessdorf.

943. Arabis alpina L. Auf sandigen, steinigen und felsigen, meist etwas feuchten Stellen der Voralpen und Alpen im Kalkruge überall häufig, selten in der Hochregion, wie z. B. am Scheiblstein bei 6800'; sehr oft ron Giessbächen in die Ebene gefüht und auch an steinigen Enusuferu. Häufig auch auf den sil. Kalkrorlagen der Tauernkette, seltener auf sil. Schiefern, z. B. Wolfs- und Strechengraben, noch seltener auf Glimmerschiefer (am Hoclischwung). Aendert bedeutend ab: An ganz trockenen Stellen dichtbehaart und graulich, an feuchten. schattigen Stellen schwach behart, grünlich bis hellgrüu, die Blätter beider Formen manchmal wellig ( $\beta$ crispata W.): ebenso variirt die Schotenlänge.

941. Al. hirsuta (L.) Scop. Auf trockenen, unkultivirten Hügeln, Wiesen und Rainen, an grasigen Abhängen der Berge und Voralpen 
nicht selten: Zwischen Griesmay und Weng, in der Schultering, an Eisenbahndämmen hei Admont (Angelis!), um Gstatterboden, an Unterkalbling: sehr häufig an Wegrainen ror'm Melzner im Paltenthale (sil. Schiefer), ron Lorenzen zum Rothleithner (Angelis).

945. Ar. ciliata R. Br. Auf steinigen, grasigen Höhen der mittleren Kalkalpen bis in die Krummbolzregion herab, wo sie am häufigsten rorkommt: ron den Giessbäclıen in die Ebene geführt, tritt sie auch da an Bachrändern, trockenen Rainen und auf sandigen Wiesen bald sporadisch, bald ziemlich hänfig auf, z. B. ron der linnsbrücke gegen Hall ind Mühlau, um den Griesmarr, stets auf Kalksand. Meist 3 hirsuta Koch, bisweilen aber, besonders zwisclen Kirummholz ob der Jügerhiitte am Kalbling, anch $\%$ glabrata lioch und eine Reihe von Mittelformen.

946. Ar. arenosa (L.) Ścop. Auf sandigen und steinigen Stellen der Tief- bis Voralpenregion, zumal an Bach- uvd Flussrändern, in der Kalkzone sehr hänfig, seltener auf Schiefer (Wolfs-, Veitl-, Strechengraben, unter den Felsen des Hochschwung etc.). Variirt a albiflora, $\beta$ rosea: ferner $\alpha$ simplex $N$ Nr. (in höheren Lagen), $\beta$ multiceps Nlr. (meist an Giessbächen etc. der Tiefiegion).

947. Ar. Halleri L. Auf Feldern, Wiesen, trockenen Hïgeln und in Obstgärten beider Thäler höchst gemein, steigt bis auf die mittleren Alpenhöhen des Kalk- und Tanernzuges: meist \% cordata (Wurzelblätter herzförmig. ohne Oehrchen) und $\beta$ amriculata (mit oft zahlreichen Oehrehen); auf sandigen Stellen in der Sautratte lebt sie gesellschaftlich mit arenosa, wird ranhhaarig, bastardirt? und lïsst sich oft kaum oder gar nicht von derselben unterscheiden.

945. Ar. pumila Jacr. \% scaberrima. Auf felsigen Stellen der Voralpen bis in die höchsten Alpen des Kalkzuges gemein, anch schon auf Kalkschutt im Gesänss, Johnsibach-. Schwarzenbachgraben. am Mühlanerfall: in den niederen Lagen wird sie sehr ïppig und geht oft über in $\beta$ ciliaris (W.) (Pflanze grossblättrig mit mehrblättrigem Stengel. Blätter glänzend, nur oder fast nur am Raude behaart: Habitus sehr ähnlich dem der folgenden); besonders am Mühlanerfall, an Bächen um den Fuss des Kalbling, selten am Bächlein des Schafferweges: eine zur Blüthezeit bewimperte, zur Fruchtreit kahlblättrige Uebergangsform zul bellidif. findet sich sehr häufig anf Moosen am Einflusse in den Kaiseranerteich (kalkhältige Granwacke. c. $\left.4000^{\prime}\right)$.

949. Ar. bellidifolia Jeq. Typisch nur auf Voralpen der Gueissund Glimmerschieferzone: nicht selten an quelligen Stellen am Fusse des Hochschwung, von der Bacheralpe gegen den Grïnsee; nach Angelis auch an einem Bächlein zwischen Sunk und Hohentanern.

950. Arahis Thaliana L. Auf Feldern. Brachäckern, an Rainen, sandigen Wegrändern beider Thäler sehr hänfig, im Fürstenparke bei Rottenmann und im unteren Stiftsgarten sogar massenhaft.

951. Cardamine alpina TW. An steinig-grasigen Abhängen der höchsten Gneiss- und Glimmerschieferalpen: Im Oppenberger Geljirge (Gebhard), am Gemeinsee (Angelis), am Bösenstein ron 7000' 
aufwärts zerstreut und oberhalb des hintersten Schneefeldes gegeu die Scliarte (zwischen Gross- und Klein-Bösenstein) hinauf sogar häufig.

952. Card. resellifolia $\mathrm{L}$. An quelligen, grasigen und steinigen Stellen der ganzen Tauernkette von der Waldregion bis zu den höchsten Spitzen (am Bösenstein über 7700') sehr häufig; auf den höchsten Gehängen des Bösenstein etc. siud öfters alle Wurzel-, manchmal auch die Stengelblätter ungetheilt = var. integrifolia DC.

953. Card. impatiens 1. Im Schatten fenchter Laubwälder und an Bergbächen hin und wieder, nicht selten; unterhalb der Kemetwand, am Lichtmessberg, am Wege nach Frauenberg, Aufstieg zur Pitz, im Johnsbachgraben, bei Dittmannsłorf, im Wolfsgraben etc. Schiefer, Kalk.

954. Card. silvatica Lk. An feuchten, schattigen Waldstellen der Berge und Voralpen; sehr gemein in schieferhältigen Schluchten, z. B. im Veitl-, Wolfs-, Strechen-, Ardninggraben, ob Lorenzen; seltener auf Kalk, z. B. im Gesäuss, Sunk, am Schafferweg, Brucksattel, unter der Kemetwand; auf Voralpen mehr sporadisch.

955. Cart. pratensis L. Auf feuchten Wiesen, an Quellen und Bächen bis auf die Voralpen, besonders der Tauernkette, gemein; in der tieferen Alpenregion des Hochschwung gesammelte Exemplare weichen vou der Normalform etwas ab, daher sie Kerner in litt. "nicht so ohne weiteres mit pratensis identifiziren möchte;" doch gelang es nicht, zur spezifischen Trennung taugliche Unterschierle aufzufinden.

956. Card. amara L. An Wald- und Voralpenbächen, besonders wo sie in kleinere Arme sich zertheilen und klare Sümpfe bilden, sehr häufig, z. B. im Veitlgraben, am Scheiblegger-, Strechen-, Kothhüttenbache, um die Bacheralpe; sehr häufig auch unter den Eichen der Sautratte; nach Kerner Veg. dürften die Pflanzen der Tanernkette grösstentheils f. Opicii Presl sein.

957. Card. trifolia I. In Bergwäldern der Kalkkette überall sehr gemein, steigt vom Gesäuss und Johnsbachgraben bis auf die Voralpen; auch auf Talkschiefer im Veitlgraben sehr häufig, seltener auf' Schieferfelsen bei der Brïcke des Strechengrabens.

958. Jentaria emeaphyllos L. In Berg- und Voralpenwäldern Jer ganzen Kalkzone sehr häufig; bisweilen auch var. alternifolia.

959. Dent. Lulbifera L. In Wäldern und unter Stranchwerk der Kalkvoralpen selten: Am Alpsteig unł Jägerweg des Kalbliug, ron der Kemetwand gegen die Scheibleggerhochalpe.

960. Hesperis inodora L. Rchb. Jc. 4378. An Zïmnen bei Johnsbach (Angelis!, Strobl sen.!); als Gartenflüchtling auf Schutthïgeln im Stiftsgarten.

961. Sisymlurium oflicinale (L.) S'cop. Auf Schutt, an Itanern, Wegen, Zäunen etc. sehr gemein.

962. Sis. Sophia 1. An gleichen Standorten ziemlich selten, 2. B. nebun Stiftsgebäuden, am Zimmeranger.

963. Sis. strictissinmm L. An buschigen Ackerrändern zwischen Dittmannsdorf und der Paltenbrücke ziemlich häutig, bei Trieben 
(Unger); sonst kein Fundort aus dem „Enns- (?) und Paltenthale“ (Maly 1868) bekannt.

964. Erysinum sylrestre (Gro), Cheiranthus Pers. Maly. An der Hartelsbriicke und bei Gstatterboden im Gesüuss spärlich (Kalk, c. 1800').

965. Brassical campestris $\mathrm{L}$. Auf bebanten Feldern und an Wegen sehr häntig. Br. oleracea L., Rapa L. und selten Napus I. werden kultivirt.

966. Sillapis anrensis I. a lejocarpa, retrohirsuta Bess. Anf Aeckern und an Wegränlern beile Var. nit Uebergängen sehr häutig.

967. Nin. nimlar I. Auf Schutt im Stiftshofe mu im Marlite Admont ron Angelis entdeckt und mir mitgetheilt.

968. Mlyssum calycinum L. 969. Berteroa incana (L.) DC. Beide wurden ron Angelis an Eisenbahndämmen bei Admont gesammelt und fehlten ror Ban der Eisenbahn im Gebiete.

970. Junaria rediviva 1. Im Gesäuss an schattigen Orten nahe der Johnsbacherbrïcke nicht selten. Kalk., c. 1900'.

971. Petrocallis pyremaica (L.) K. Mr. An Felsen und steinggrasigen Abhängen der höchsten Kalkalpen $\left(6-6800^{\prime}\right)$ : Am Rückeu les Kialbling bis gegen den Jägerweg hinab, am Fusse der letzten Erhebung des Scheiblstein, an beiden Standorten häufig.

972. Inaba aizoides $\mathrm{J}_{\text {. }}$ \% vulgaris Rehb. Jc. An felsigen Stellen der höheren und höchsten Kialkalpen $\left(6-7000^{\prime}\right)$ häufig, besonders am Pyrgas, Scheiblstein und Kalbling: an den höchstgelegenen Standorten bisweilen schaftlos mit grösseren Rosetten und Blüthen.

973. 1)r. stellata Jacy. Auf Felsen und im Felsschutte der ganzen Kallizone $\left(6-7000^{\prime}\right)$ ziemlich häufig. besonders am Pyrgas, Scheiblstein, Hexenthurm, Festkogel, Falbling und Sparafeld; anch am Hochschwung (Glimmerschiefer, c. 60010').

NB. Dr. frigida Sauter und Jolianuis Host werden von Maly 1868 ebenfalls am Kalbling angegeben, nach meiner und Angelis' Ansicht aber irrthümlich, zmmal beide keine Kalkptlanzen sind. Welden erwähnt rom Sparafeld eine merkwürdige „Var. der stellata mit ganz glattem Stengel und Blättern, die 6- $S^{" \prime}$ lange Ranken aus den Felsritzen treibt."

974. 1). verila L. var. macrocarpa Nlr. Au Abhängen um Dittmannsdorf oft massenhaft, von Angelis auch nahe den Almhütten der Hölleralm ain Rott. T'auern häufig gesammelt.

975. Cochlearia saxatilis (L.) Lam. An Kalkfelsen und im lialkschutte ron der 'Tiefregion bis $6500^{\prime}$ gemein, auch auf' den sil. Kalkrorlagen der 'Tanernkette sehr häufig.

976. Camelina sativa Cr. Rehb. 4292. Auf Feldern und Aeckem ziemlich lıäufig, besonders unter Lein.

977. Thlaspi arvense I. Anf Aeckern, in Gärten und ïberhaupt auf bebautem Boden gemein.

978. Thi. alpinum .Jacy. An fenchten, felsigen Stellen der Kalkkette $\left(4500-7000^{\prime}\right)$ höchst gemein, steigt aher im Gesïuss, Johnsbachgraben, sowie längs der Giessbäche (Folkernot, Schwarzenbach, Scheibleggerbach) auch häufig bis zur Thalsohle. 
979. Thl. rotundifolium (L.) Gd. Auf Kalkgeröll unter der Hochthorscharte bis zum Festkogel (c. 5500-6500') sehr häufig:

NB. In einem alten Verzeichnisse werden auch noch alliaceum L. und montanum L. anfgefülırt, da aber die alte Flora Adm. verbrannte, lässt sich ïber diese und ähnliche Angaben nichts Sicheres behaupten.

980. Biscutella laevigata L. Auf Kalkschotter und steinigen Triften der Kalkzone $\left(1800-5000^{\prime}\right)$ stellenweise sehr gemein, z. B. im Gesäuss, Johnsbachgraben, Mühlanerwäldchen, hinter Kaiseran, am Schafwege des Kalbling bis anf die Schafleithen (c. 6200'): meist a. asperifolia Nlr., selten $\beta$ glabra Gd. (= lucida DC.), noch seltener $\gamma$ hispidissima Koch (Hochalpen 1 m Admont Herb. Hatzi!); auch v. saxatilis Schleich. wird vom Kalkofen hinter der Kaiseran angegeben (Altes Verzeichniss).

981. Hutchinsia alpina (L.) R. Bł. Auf steinigen Abhängen, in Felsspalten, auf Gerölle und an Schneegrubenrändern der Kalkalpen $\left(5-7000^{\prime}\right)$ sehr gemein, von den Giessbächen häutig in die Ebene geschwemmt (z. B. Mühlanerfall, Schwarzenbachgraben, Gesäuss). stein (Stur).

982. Hatch. brevicaulis Hpp. Auf Gneiss am grossen Gries-

983. Capsella bursa pastoris (T.) Mnch. Auf Aeckern, Grasplätzen, an Wegen, Rainen bis mm die Hütten der Voralpen höchst gemein, vorzïglich var. sinuata und v. piunatifida Koch, seltener a. integrifolia (Schl.), diese sogar noch um die Scheibleggerhochalpe.

984. Aethionema saxatile ( $\mathrm{H}_{\text {. }}$ R. Rr. Auf Kalkschutt im Gesäuss selten; „am Kalbling" (Maly 1868) ist nach Angelis umrichtig.

985. Neslia paniculata (L.) Dsv. Auf Aeckern unter der Saat hie und da: Bei Gaishorn (Verbniack), 1 mm Admont be'sonder's anf Leinäckern von Angelis und Strobl sen. mehrunals gesammelt.

986. Raphamus Raplianistrum J. Auf Aeckern, unter Saaten var. $\alpha$ arvense (Rchb.) und $\gamma$ segeturn (Rchb.) häufig. -- R. sativus L. wird häufig knltivirt.

\section{Fam. Resedaceae DC.}

987. Resela lutea $I_{\text {. }}$ Mit der Bahn eingeschleppt, jetzt hie und da an Eisenbahndïmmen (Angelis!).

\section{Fam. Nymphaeaceae DC.}

988. Nymplatea alba L. In Lachen und 'Teichen der Krumau höchst gemein, seltener' im 'Triebnersee, Gaishornsee etc.

989. N. biradiata Sommeraner. In 'Triebner- und Gaishornsee sehr gemein, besonders in ersterem. 


\section{LXY. Fam. Cistineae DC.}

990. Helianthemun alpeste (Jaeq.) Anf dürren und felsigen Abhïngen der Kalkalpen von $5500^{\prime}$ an bis zu den höchsten Spitzen sehr gemein, \%. glabratum DC. mit vielen Uebergïngen zu \& hirtum (Nlr.). Anch zwischen den Sehieferfelsen des Hochschwung findet sich loüulig eine wenig behaarte mud wegen des f'euchten, hochgrasigen Standortes schlalle. fast krantige Form, wahrscheinlich i elougatum DC. Pr.

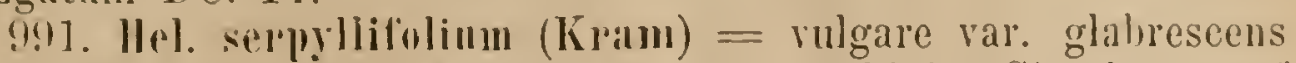
Nlr. Auf Kallhïgeln bei Almont, ob Weng, hinter Strechau, aul" Ahhängen der Kalkvoralpen: geht hier über in die weit gemenere var. grandiflorm (Scop.) Kioch, welche in der Krummholzregion und höher hinanf bis zum Verbreifungshezirke des alpestre iilurall in den Kalkalpen anftritt.

\section{LXYII. Fam. Nroseraceae DC.}

992. Inoserar rotundifolia I. In allen T'orlmooren des Enmsminl Paltenthales liöchst gemeiu.

993. Dros. ohovati M. K. (rot. $\times$ longifolia Rehb.). Anf'Torfmocren mit den Stammälter'n seltever: Im Hofmoore, am Rande cines grösseren Tümpels im Südostende des unteren Krumanermoores.

994. Mros. longilolia L. Auf Torfmooren und torfigen Sumplwiesen des Enns- und Paltenthales sehr gemein.

99\%. Parllassia palustris I. Auf feuchten Wiesen und Hïgeln der Ebene bis auf die höchsten Alpen der Kalk- und Tauenkette gemein.

\section{Fam. Violarieae DC.}

996. Viola palustris l. Auf Moorwiesen und in Mooren des Enus- und Paltenthales sehr gemein, z. B. Hol-, Krumauer-, Wolf'sbacher-, Triebnermoor, iil der Schultering: auch aut trockeneu Hügehn am Nordrande des Holleldes gegen die Enns hin.

997. V. lıirta 1. \% minima mihi (Blütlse blïsser und lileiner als bei $\beta$, die Blätter kurz-herzförmig-dreieckig, wenig behaart, zur Bliithezeit fast gar nicht entfaltet). Am Uler dor Enns anf einem Felde unterhalb des Ziegelstadls mit $\beta$; $\beta$ parrula $(O p)=$. r. fratema Rehb. Jc. 4493. (Blitter kur-herzförmig-dreieckig, wenig behart, Blüthen geruchlos, blasshila, nach dem Mittelpunlite zu weiss odel seltener ganz weiss.) Anf Wiesen, Hügeh, Raineu in der ganzen 'Tiefregion sehr gemein; rar. grandifolia Rehb. Je. (Blätter grösser, lïnglich-herzlörmig.) Im Hohlwege lev Au bei Gaishorn mit $\beta$.

!98. V. collina Bess. Auf Hïgeln bei Gaishorn (Angelis), Trieben, an Wegrändern im Paltenthale (Sommeraner), am Oberhoffelde bei Admont (Ang.!); Strobl sen. und ich fimden sie an 
Wegrainen des Hofweges bei Au zwischen der daselbst gemeinen und sehr variablen hirta, deren kleinere Formen ihr sehr ähnlich sind, sich aber durch Geruchlosigkeit und die Nebenblätter unterscheiden, ziemlich selten.

999. V. styriaca mov. spec. Von voriger versehieden durch grössere Blumen, gelbgrüne, lichtere, breitere Blätter, kahle Kapselı, von sciaphila Koch durch lichtere, viel stärker behaarte Blätter und Blattstiele, stärker gefranste und ausserdem noch stark rauhhaarige Nebenblätter und grössere, inwendig sehr zierlich verästelt geaderte Blumen; Blıme wohlriechend, blassblan, inwendig weiss, Sporn weiss, Fransen sehr lang, entfernt, gewimpert, Blätter breitherzförmig, stumpflich, langestielt. Von den übrigen Arten meines Herbar's noch stärker verschieden. Ob dem Admonter Kalkofen am Wege zur Weberalm an Waldrändern gegen den Bach zu selten (Kalk c. $2500^{\prime}$ ).

1000. V. odorata L. In Grasgärten, an Feldrainen, Hecken, Waldsäumen etc. selı hänfig.

1001. V. alba Bess. An der Mauer des Pfarrergartens hinter Frauenberg.

1002. V. arenaria IOC. und f. rupestris Schm. (Kahler, mit grössereu Blüthen). Auf Kalkschotter im Johnsbachgraben, gegen Hall, Mühlaı, beim Griesmayr; hüufig an Strassenrainen zwischen Rottenmam und Gaishorn, sowie im Hohlwege bei Au.

1003. V. canina I. var. ericetorum Rchb. Je. Auf sonnigen, sandigen Hügeln und Wegrainen nicht häutig: Hohlweg der Kruman, unterhalh, Röthelstein, am Lichtmessberge (Angelis), im Paltenthale und ob der Plinrerhub bei Lorenzen (Ang.); letztere Standorte gehören wohl theilweise zu v. lucorum Rehb. Je., die ich auch vou Strobl sen. aus dem Gebiete besitze.

1004. V. Riviniana Rehb. Jc. 4502. Anf buschigen Wegrainen, an 'Läunen und in Lanbwäldem des ganzen Gebietes ungemein häufig. Kalk, Alluvium, Schieler.

1005. V. silvatica Fr. G1. God. (sylvestris Rehb. 4503, non Lam.) Wie vorige, aber seltener, z. B. an Zännen oberhalb des Hoffeldes, am Schaflerweg, häufig von Weng auf die Buchau.

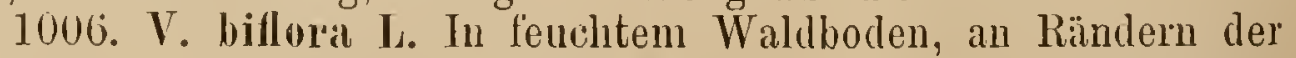
Wald- und Voralpenbitcho, vorzüglich aber an und unter triefenden Felswänden von der Ébene bis hoeh in die Alpen der Kalkzone gemein, z. B. schon im Gesäuss, Johmsbachgraben, am Schafferweg; anch in Schieferschluchten (Wolfs-, Strechen-, Veitlgraben) und auf Voralpen der T'auerukette (Hochschwung, ob der Bacheralpe ete.) nicht selten.

1007. V. arvensis Muru. Anf Feldern und in Gärten sehr hänfig.

1008. V. tricolor L. Auf Aeckern, Feldern und in Gärten seln' gemein; die mamigfachen libenvarietäten lassen sich auf drei Grundformen zurïckführen: $\alpha$ lutea (die vier oberen Blumenblätter weissgelb, das untere gelb). Die oberen Blätter fürben sich allmählig, vorerst an den Rändern, hellblan und so geht $\alpha$ ïber in $\beta$ tricolor 
(die zwei oberen Bliitter sammtartig violett, die zwei mittleren weissgelb, das untere gelb, im Fratienfelde auch häufig goldbraun). Allmälilig werden anch die mittleren und das untere Blumenblatt von den ländern einwärts violett, bis die mit Ausnahme des Nagels des unteren Blattes ganz schwarzviolette var. \% violacea entsteht. Oft wachsen alle Nuancen durcheinander, $\beta$ am gemeinsten, $\gamma$ rorziiglich auf fetter Gartenerde.

1009. V. lutri Sur. \%. grandiflora Rchb. Je. 4519. Auf fenchten, steinigen Triften am Hengst und Hauseck, zwei Vorbergen des Bösenstein (Sommerauer, Hatzi, Angelis!). Gneiss, e. 6000'.

\section{Fam. Cucurbitacene Juss.}

1010. Bryounial alba I. An Zäunen und in Gärten hie und da, selten: In der Nïhe des Stiftsmayrhofes, im Sehlossgarten von Strechan.

Häufig kultivirt 'werden Cucumis sativus L., Melo [... Cueurbita Pepo L., letatere anch anf Feldern.

\section{Fam. Portulaceae Juss.}

1011. Momlia rivularis (imel. (fontana $\beta$ major Schrd.) In Bächen und Wasserbecken der 'T'anernkette $\left(4-5500^{\prime}\right)$ : Sehr häufig in den Salmlingteichen beim Dorfe Hohentanern, seltener an einem Alpenbache unterhalb der Kothhïtten, im Bache der Sclaunitzeralm des Triebenthales und a:n Steinamandl.

\section{Fam. Caryophylleae Endl.}

1012. Herniaria glabra L. An trockenen, sandigen Stellen, besonders Wegrändern, in der Sautratte, an der Enns, von der Marktbrücke zur Essling, vor'm Griesmayr häufig; sehr häufig anch an Bachrändern im Veitlgraben.

1013. Sclerinthus immuns L. Auf Aeckern unter Getreide gemein, z. B. im Hoffelde (die Exemplare dieses Standortes determinirte Rehb. sen. als arenarius Schur), am Lichtmessberge ob Dittmannsdorf; auch an grasigen Wegrändern gegen Frauenberg und von der Klause bis Liezen.

1014. Sagina procumbens 1. Auf Aeckern, Weiden, feuchten Abhängen, an Waldwegen, anf' Sumptwiesen häufig, z. B. am nördlichen Hoffeldrande, auf torfigen Weiden im Hofmoore, Sumpfwiesen linter'm Wolfsbachermoore, an Waldründern bei Lorenzen, Rottenmann, Trieben, an Schaflerwege, auf der Kaiserau.

1015. Sigg. Limmaci Presl. (saxatilis. Wimm.) An feuchten Wegrändern (im Sumk, hinter Hohentanern, bei Lorenzen, im Stiftsgarten), 
lehmigen Grabemrändern (am Lichtmessberg etc.), Quellen (am Brucksattel etc.), auf dürren Alpenhöhen: sehr gemein am Gipfel der Plösch (5400', Werfnerschiefer), selten am Kalbling bei der Schäferhütte (c. 5000'), zwischen Kalbling und Sparafeld (c. 6500').

1016. Sag. nodosa (L.) Fenzl $\beta$ glandulosa (Bess.) Rchb. „Im Enns- und Paltenthale (?)" Maly 1868. Jedenfalls sehr selten: Angelis sammelte einige Exemplare bei der Griesmayrlache, suchte sie aber seitdem dreimal vergebens: auch von Strobl sen. besitze ich Exemplare.

1017. Spergula arvensis L. $\beta$ vulgaris (Bönn.) Kch. Auf Lehmboden der Ziegelbrennerei, auf Aeckern bei Lorenzen, Dittmannsdorf, Frauenberg, Admont (besonders im Hoffelde) gemein.

1018. Sperigularia rubra (L.) Pers. Anf lehmigen und sandigen Plätzen, an Häusern hie und da, z. B. häufig bei der Ziegelbrennerei, bei Schwarzenbach im Paltenthale, seltener am Lichtmessberge.

1019. Cherleria sedoides L. An steinigen Abhängen der ganzen Kalkzone $\left(5-7000^{\prime}\right)$ sehr gemein, auch selır häufig am Hochschwung (Gl.-Schiefer).

1020. Alsine aretioides (Port.) M. K. Auf trockenen HochalpenGehängen $\left(6500-7100^{\circ}\right)$ der Kalkalpen : Häufig am Festkogel, Sparafeld, Scheiblstein, seltener am Hexenthurm, Buchstein (Hatzi!), Pyrgas (Sauter).

1021. Als. austriaca (Jacq.) M. K. Auf Felsschutt und an Felsen der mittleren Alpenregion im Kalkzuge ziemlich häufig, besonder's am Kalbling, Pyrgas, Scheiblstein, Hund; sonst meln vereinzelt.

1022. Als. Gerardi (W.) Whl. Auf steinigen Hochalpentriften $\left(6-7000^{\prime}\right)$ im ganzen Kalkzuge sehr häufig, selten herabgeschwemmt; nach Sommeraner (Herb. Maly!) auch am Wege vom Steinamandl zu den drei Stecken (Gneiss).

1023. Moehringia muscosa L. Auf fenchten Sandriesen, an beschatteten Felsen und bemoosten Steinblöcken ron der Ebene bis in die Voralpen der Kalkzone sehr gemein, doch auch in Schieferschluchten (Veit]-, Wolfs-, Strechengrabeu etc.) sehr häufig; an dürren Stellen der Kalkvoralpen, z. B. am Pyrgasgatterl, unter der Scheibleggerhochalpe, sind dic Blätter kürzer und steifer = var. acifolia Rchb. Jc.

1024. Moehr. polygonoides (Wlf.) M. K. Auf steilen, felsigen und geröllbedeckten Höhen der Kalkalpen (z. B. am Uebergange vom Scheibleck zur Schafleithen, um die hohe Kalblingmaner, Kemetenwand, auf den Hallermauern) ziemlich selten, häufig aber von den Giessbächen herabgeschwemmt bis in die Thalsolıle (besonders des Gesäusses und Johnsbachgrabens, des Schwarzenbachgrabens).

1025. Moehu. trinervia (L.) Clairv. In fenchten, schattigen Wäldern und Bergschluchten, vorzüglich auf Schieferboden sehr häufig, z. B. Ardninger-, Veitl-, Strechengraben, von Lorenzen zur Pfarrerhub, von Hall zur Pitz.

1026. Arenaria serpyllifolia L. A uf sandigem Bodeu der Aecker, Wegränder, Wälder bis in die Voralpen sehr häıfig; Kalk, seltener Schiefer. 
1027. Ar. multicaulis (L.) Wull. Auf steinigen Hochalpentriften $\left(6-7000^{\prime}\right)$ an Kalbling, Sparafeld, Scheiblstein sehr hüufig (Kalk), seltener am Hochschwung (Gl.-Schiefer).

1028. Ar. biflora I. An feuchten, sandigen Rändern der Alpenbäche und Alpenseeen, doch auch auf dürren, steinigen Höhen der 'Tauernkette (5-7000') gemein. Gneiss, Glimmerschiefer.

1029. Stellaria cerastoiles 1. An feuchten Stellen der T'auermkette $\left(5-6500^{\prime}\right)$ sehr spärlich: Am Scheiplsee, Gemeinsee, Grünsee (Angelis), an einem Bache der Hochhaide ob der Singsdorferalm.

1030. Stell. nemorum L. In schattigen Bergschluchten nud fenchten Wäldern, vorzüglich auf Schieferkrume: Lichtmessberg, Veitl-, Wolfs- und Strechengraben, hier sehr gemein.

1031. Stell. mellia L. Auf Aeckern, wüsten und bebanten Plätzen, in Gärten sehr gemein bis um die Hütten der Voralpen.

10:30. Stell. graminea L. Auf Wiesen, Raineu, Waldplätzen bis in die Voralpen sehr liäutig.

1033. Stell. uliginosa Murr. In Wassergräben und an sumpfigen Stellen sehr häufig, z. B. im Hofmoore, Bichlmayrnoore, bei Aigeu, Hall, am Lichtmessberg, auch aul' Voralpen der 'Tauernkette (um dic Kofhhütten, höchst gemein an den Fischteichen bei Hohentallern).

1034. Malachinum alquaticum (Scop.) Fr. An nassen und sumpfigen Stellen der 'T'iefregion häutig, besonder's in abgelassenen Stiftsteichen.

1035. C'erastium viseosum I. (glomeratum Thuill.) An feuchten Weg- und Grabenrïndern, anf Feldern und um die Hütten der Voralpen; an vielen Standorten, doch stets in wenigen Exemplaren: varirt $\alpha$ glindulosum, $\beta$ eglandulosum Kich., $\gamma$ apetalum (Dum.) Kch.

1036. Cer. jmmilum Curt. (glutinosum Fr.). Auf Lehmboden bei der Ziegelbremnerei einmal gesammelt.

1037. Cer. rulgatum I. (triviale Lk). An wïsten und bebanten Plützen, im Schlanme der Sümpfe mul trocken gelegten Teiche, auf Voralpentriften schr gemein, $\%$ hirsutum Nlr. und \& glaudulosum (Bönn.) Kch.

1038. Cer. arvense I. a hirtum Nlr. An trockenen Hügeln und Rainen, steinigen Plätzen der Tiefregion nicht häutig: $\beta$ ciliatum (W. K. Rchb. Jc. 4981, nach meinem Urtheile eine kahlere, breitblattrige Voralpenform). Aul Voralpentriften des Pyrgas, Scheiblsteiu, Kalbling, der Scheibleggerhochalpe häufig; ; strictum (Haenke) Koch (wie F, aber noch kahler, Blätter schmäler); im Kalkgebirge selten (Spitze des Scheiblstein 6930'), sehr häufig an Bächrüuderı und auf' 'Tritten des Hochschwung (Gl. - Sehicfer).

1039. Cer. alpimm L. \% villosum, \& glanduliferum Kch. Im Gebirte sehr selten: Ich sah beide Var. Vom lanernzuge in Herb. Strobl. sen., Stur. gibt die Art ron der Peewuzalpe an Bösenstein auf Glimmerschiefer und körnigem Kalk an.

1040. Cer. lanatum Lam. o. eglandulosum, fi glutinosum lioch. Beide Var. häutig auf Felsterrassen des Hochschwung, ob der Bacheralpe rechts vom Gemeinsee und rom Mitterstein gegen die Höhe der Hochhaide hinanf. Glimmerschiefer $6-7000^{\prime}$. 
1041. Cer. uniflorum Murr. Stein in öst. bot. Ztschr. XXVIII. Auf steinigen, haideartigen Höhen der Tanernkette: Am Bösenstein, Grieskogel, ob dem Ochsenkahr, auf der Hochhaide sehr häufig, zumal längs der windigen Kanten. Gneiss, Glimmerschiefer.

1042. Cer. latifolimm L. Stein. Am Buchstein auf Dachsteinkalk (Herb. Kerner teste Stein).

1043. Cer. carinthiacmu Vest 1808 (ovatum Hpp. 1818). Auf steinigen und schuttbedeckten Stellen der Kalkalpen, und zwar $\alpha$ ovatum mit Uebergängen zu $\beta$ lanceolatum Britt. - sehr hänfig, sodann aber herabgeschwemmt als $\beta$ im Gerölle der Alpenbäche sehr gemein, besonders im Gesäuss, Johnsbach-, Bruck-, Schwarzellbachgraben etc.

1044. Gypsophila pepens L. Auf Felsen und im Felsschutte der mittleren Kalkalpen $\left(4-6000^{\prime}\right)$, sowie auf Kalkvorlagen der Tanerukette hänfig: Kalbling, Bärukoppe, Kemetenwand, Pyrgas, Scheiblstein, Hochthor, Sunk etc.; selten auf Gneiss am Bösenstein.

1045. Gylus. muralis L. Anf Schieferkrume des Lichtmessberges (an Wegränder'n ob Dittmannsdorf) nicht selten; soll auch an Sandwegen im Stiftsgarten gefunden worden sein.

1046. Dianthus Carthusianorum h. Auf trockenen Wiesen, somnigen Hïgeln, grasigen Bergabhängen zerstrent, z. B. um Admont, am Pyrgas, Scheiblstein, Leichenberg, Damischbachthurm, Gamsstein, im Sulzkahr, sehr häufig hinter Johnsbach; in winzigen Exemplaren (v. nanus DC. Pr.) sehr häufig auf Pignolithfelsen im Sunk; eine sehr schmal- und grasgrünblättrige Form (v. graminicolor Rchb. Jc.) selten auf einer Kalkschütt vor der Schäferhütte am Kalbling.

1047. D. alpinus L. Auf Alpen- und Voralpenweiden der Dachsteinkette, vorzüglich auf krummbolz-umschlossenen, nicht zu üppig berasten Stellen sehr gemein; steigt am Kalbling bis $6500^{\prime}$.

1048. 1). plumarius L. An steinigen Stellen und im Gerölle der Giessbäche: Im Johnsbachgraben (Angelis), am Aruningbache (Altes Verzeichniss), ziemlich hünfig in der grossen Schütt unterhalb des Brucksattels, sehr häufig am Leierbache, seltener am Buchstein. Kalk, 2-4000'.

1049. Saponaria of'licinalis L. An Bachufern unterhalb des Adam sehr häutig, seltener am Wege in's Gesäuss und an Ennsufern in der Sautratte.

1050. Silene inflata Sm. a vesicaria (Schrd.). (Blätter ziemlich gross, elliptisch, gewimpert oder ungewimpert, Kelch gross, kugelig). Auf Wiesen der 'Tiefregion, an grasigen Abhängen der Voralpen und Alpen im Kalk- und 'Tauernzuge sehr häufig, z. B. Hochschwung, ob der Bacheralpe bis zur Hochhaide, am Scheiplsee, Scheiblstein zwischen Krummbolz, in der Sautratte, gegen Frauenberg; var. latifolid Koch und angustifolia ('T'en.) wurden noch nicht gefunden.

1051. Sil. alpina Thom. (infl. Y alp. Koch). Auf Schutt und Gerölle der Kalkzone (1800-6000`) sehr gemein, besonders im Gesäuss, Johnsbachgraben, Bruckgraben, am Kalbling.

1052. Sil. P'umilio Wulf. Auf dürren, mit Flechten bewachsenen 
Höhen der 'Tauernkette, besonders auf windigen Kanten und Rücken der Hochregion (6--7700`) überall gemein. Gneiss, Glimmerschiefer.

1053. Sil. acaulis L. Auf trockenen Vor-bis Hochalpenweiden der Kalkkette $\left(5-7000^{\prime}\right)$ sehr gemein: meist \& vulgaris Rehb. Jc. und in tieferen Lagen $\rho$ dianthifolia Rehb. Jc.; seltener $\%$ pedunculosil Rehb., welche Strobl sen. in einer f. albiflora ziemlich häufig am Kalbling sammelte.

1054. Sil. excapa A1l. Bei $7700^{\prime}$ am Bösenstein gemein, ebenso aluf dürren Abhängen $u m$ die Felsen des Hochschwung (c. 6000'). Ist wohl als Urgebirgstace der vorigen aufzufassen.

1055. Sil. nutaus I. Auf trockenen Wiesen, steinigen Hügehn, sonnigen und buschigen Bergabhängen der Kalk-, vorzingglich aber der Schieferzone bis $4000^{\prime}$ sehr gemein.

1056. Sil. rmpestris I. In allen Gneiss- und Schiefergebirgen ron der 'Thalsohle bis $6500^{\prime}$ an felsigen Stellen gemein, auf Kalk niemals beobachtet; im Ennsthale nu an Werfnerschieferbergen. Blüthe gewöhnlich weiss, seltener sehön rosa, z. B. ob der Bacheralpe, Blïtter bald ziemlich grasgrïn, ball intensiv blangrïn.

1057. Sil. quadrifida I. An feuchten, sandigen Stellen, vorzüglich in den Giessbachbeeten der Kalkzone überall, bald vereinzelt, bald gemein; steigt von der Hochregion (z. B. Spitze des Scheiblstein) längs der Giessbäche bis zu' Thalsohle, ist z. B. im Gesïuss und Johnsbachgraben gemein; auch auf sil. Kalk der Tauernkette und an feuchten Glimmerschieferfelsen des Hochschwung nicht selten.

1058. Sil. alpestris Jacf. An schattigen, feucbten und steinigen Stellen der Kalkthäler bis in die Voralpen überall sehr häufig, besonders an moosigen Kalkblöcken; schon auf Kalkschotter vor'm Griesmayr, im Gesäuss und Johnsbachgraben.

1059. Sil. Armeria L. Aus Gärten verwildert, hie und da.

1060. Lychnis Viscaria L. Auf grasigen Hügeln, in lichten Wäldern der Grauwacken- und Werfnerschieferzone: Vor Frauenherg häufig, am Lichtmessberg ob Dittmannsdorf sehr gemein, ob S. Lorenzen und im Strechengraben hänfig.

1061. L. floscuculi L. Auf feuchten Wiesen, besonders Waldwiesen ron der Ebene bis in die Voralpen höchst gemein. Kalk, Schiefer, Alluvium.

1062. 1. Vesperrtina Sibth. Auf Wiesen und Feldern, an Zäunen und Wegen sehr häufig.

1063. L. dintna Sibth. An Gräben, Bächen, auf Wiesen bis in die Voralpen sehr gemein.

1064. Igrostemma Githago L. Unter Saaten häufig.

\section{Fam. Malvaceate Br.}

106.5. Alıhatea oficinalis L. Auf Wiesengrumel nehen dem Jägerhause der Krmman, aul Schntt im Stiftshote, gegen Liczen hinauf an Wegränden; wohl nur verwildert. 
1060. Malva Alcea L. An Zäunen. auf steinigen Hügeln und Feldrainen hie und da, z. B. ausserhalb der Stiftsmauer ror dem Ziegelstadl, beim Korubauer, ror Weng. in der Eichelau.

1067. M. silvestris L. An wästen Plătzen, rorzüglich auf Schutt und an Wegrändern häufig, z. B. im Stiftsgarten, neben der Marktbrücke, gegen Weng.

1068. M. vulgraris Fr. An Wegen, Zäunen, Yaueru und auf Schutt sehr häufig. z. B. Stiftsmauern, Häuser beim Temmelteich, Zülune bei Teng.

\section{Fam. Tiliaceae Juss.}

1069. Tilia parvifolia Elnlı. Häufig kultivirt im Stiftsgarten, uralte Bäume auch bei Weng, Hall und Ardning nebeu den Kirchen, kleinere um Rottenmann etc.

1070. Til. grandifolia Elırh. In den Alleen des Stiftsgartens hie und da, auch um den grossen Stiftsteich mit der rorigen, ebenfalls kultivirt.

\section{LXIT. Fam. Hypericineae DC.}

1071. Hỵpericum lumifusnm L. Auf schieferhältigem Boden an schattigen Wegrändern hie und da: Am Lichtmessberg ob Dittmannsdorf, bei Lorenzen, am Wege nach Frauenberg, am Aufstiege zur Plösch, im Hoffelde.

1072. Hyp. perforatum L. Auf Wiesen, buschigen Wegrainen und Hügeln ziemlich häufig, z. B. längs der Enns, am Wege gegen Frauenberg.

1073. Hyp. quadrangulum L. Anf Wiesen, Hügeln, an Wald- und Ackerrändern bis in die Voralpen äusserst gemein.

1074. Hỵp. tetrapterum Fr. In Sümpten, Wassergräben und an Teichrändern ziemlich häufig, z. B. am Temmelteich, am Wege nach Frauenberg, am Rande des Hofmoores, in Waldsümpfen gegen die Scheibleggerhochalpe, beim Reitmeier.

1075. Hỵp. montanum L. An Waldrändern von der Klause gegen Liezen hinauf vereinzelt (Werfnerschiefer). nach einem alten Verzeichniss auch am Weg zur Scheibleggerhochalpe.

1076. Hyp. hirsutum L. An feuchten und trockenen buschigen Stellen, in lichten Wäldern hie und da, ziemlich selten: An Wegrändern im Gesäuss, zwischen Gebïsch am linken Ennsufer unterhalb des Griesmayr, in Giräben am Rande des Hofmonres, am Essling- und Oberhoffeldbache.

\section{LXXV-LXXVII. Fam. 'Tamarisc., Arerin., Hippocastaneae.}

1077. Myricaria germanica (J.) Dsv. An sandigen Uferstellen der Enns sehr hänfig, besonders in der Sautratte und Krumau, auch an der Essling und Palte (bei Gaishorn). 
1078. Acer Psendoplatanus L. In Lanbwädern ron der Thalsohle bis in die Kalkvoralpen sehr häutig, bisweilen noch unter Krummholz: auch auf Grauwackenschiefer ron Lorenzen bis zur l'arreralm ete. nicht selten: zwei uralte Bäume stehen rol"m Heindl.

1079. Arsculus Hippocastamum L. Eine prachtrolle Allee im Stiftsgarten: sonst wenig kultivirt. Anch Paria L. wird im Stiftsgirten gezogeu.

\section{ICXVIII. Fam. Polygaleate Juss.}

11880. Polygala vulgaris L. Auf Feldern, Hügeln, Wald- und bergwiesen luäutig, z. B. bei Lorenzen, am Lichtmessberge, Aufstiege zur Pitz, zur Hölleralm. Scliefer. Kialk.

1081. Pol. comosa Schk. Wie vorige, aber viel häufiger, z. B. Oberhofwiese, Schultering, Griesmayr-Sumpfwiesen, Esslingufer, Abhänge bei Hall, Aufstieg zur Pitz.

1082. Pol. amara Jacy. In lichten Wäldern ma an steinigen Ahhäugen ron der Thalsohle bis in die Hochregion der Kalkkette sehr häufig: in der Hochregion meist die Form mit breiteren Trurzel- und Stengelblïttern $=;$ alpestris Koch ( $F$ alpina Rchb., non alpestris Rchb. 146 III): ron dieser Form fand ich am Kalblingbache ob der Schäferhütte auch r. rosea.

10S3. Pol. anstriaca ('r. Auf Sumpfwiesen, Schotterbänken. fenchten und trockenen Bergabhäugren bis 4500' sehr häufig: rariirt Hore albo (diese am häufigsten. zumal auf Kalkschotter ror Mühlau, ror"m Gesäuss, in der Sautratte, hinter Kaiserau ete.). fl. roseo (selten z. B. in der Santratte), H. coeruleo (meist anf Sumpfiriesen und feucliten Bergwiescn): ferner mit abgermuleter lind keilförmiger Kapsel: letztere ist, wenn die Blïtle blan, uliginosa Rehb.

1084. Pol. ('hamachuxus L. Auf steinigen Högeln und in lichten Wähleru der Killizone $\left(1800-.5000^{\prime}\right)$ gemein: anch auf sil. Kalk del Tamerukette: rar. purpurea scheint zu fehlen.

\section{IXIIX. Fam. Celastrineate R. Br.}

1085. Evon!mus puropaens l. An Zäumen, Bachufern und in Laubgebïsch sehr gemein.

1086. Er. reprucosus L. Im Herb. lelicetti liegen zwei Exemplare mit der Ftiquette: Admont.

1087. Er. latifolins L. ,Im Euns- und Paltenthale- Maly 1868. lch sih Exemplare ans dem Gehiete und fimd ihn selbst zivisehen Ciestränch unterhalb der Kochenalın (Kalk, e. fouv') spärlich.

\section{IXIX. Fam. Rhammeate R. Br.}

1085. lihamuns cathautica I. An Zämnen, Bachnfern. zwisehen Stranchwerk: bei Weng sehr hälfig. alm Hofmoore, Wege nach Mühlan, in der Kruman, Santratte etc. nur rereinzelt. 
1089. Rh. saxatilis L. An steinigen, felsigen Abhängen im Gesäuss hie und da ein Stranch, besonders am linken Ennsufer (!, Gebhard, Strobl sen.!); im Paltenthale wohl nirgends.

1090. Rh. Frangula L. In den Alleeen des Stiftsgartens, an feuchten Wiesen- und Moorrändern, sowie in Vorhölzern selır gemein.

\section{Fam. Empetreae Nutt.}

1091. Empetrum nigrum L. Auf trockenen, felsigen Höhen der Gneiss- und Glimmerschieferberge $\left(5-6500^{\prime}\right)$ stellenweise ïusserst gemein: Von der Höhe des Enzianplonspitzes in der Strechen gegen die Simonbanternhütte hinab, in der Schlucht zwischen Gross- und Klein-Bösenstein, auf der Rückenhöhe des Steinamandl : nie auf Kalk gefunden.

\section{Fam. Euphorbiaceae R. Br.}

1092. Buxus sempervirens L. In aufgelassenen Gartenanlagen (besonders vor dem Schlosse Strechau) und auf Friedhöfen gleichsam verwildert.

1093. Euphorbia lıelioseopia L. Auf Schutt, an Wegränderı, wüsten Stellen, besonders aber in Gürten und Getreidefeldern gemein.

1094. Euph. platyphyllos L. An Wegen, Schuttplätzen, Bachrändern und in Waldlichtungen sehr verbreitet, aber selten in grösserer Anzahl: Gegen Hall, Mühlau, Franenberg, vor'm Griesmayr, gegen die Pitz hinauf, im Lafferwald, vor dem alten Admonter Kalkofen, an der Lichtmessbergstrasse etc.

1095. Euphl. dulcis (L.?) Jacq. a. lasiocarpa Nlr. In Wäldern, feuchten Bergschluchten und an Bächen hie und da, ziemlich selten: Im Buchenbestande vor der Kochenalm ob Mühlau, im Lafferwald, am Oberhoffeldbache (Angelis!), am Bächlein des Schafferweges etc. Meist auf Kalk.

1096. Euph. verrucosa Lam. Anf üppigen Grasplätzen am Rande der Gebüsche und Wälder bis in die Kalkvoralpen nicht selten, z. B. im Gesäuss (besonders am linken Ennsufer), am Fusse des Gamsstein und gegen den "oberen Boden" hinauf, am Futterweg ob der Gstattmayrvoralpe des Scheiblstein.

1097. Euph. pilosa L. \% trichocarpa Nlr. An Waldlichtungen, Giessbächeu und auf hochgrasigen Voralpentriften, besouders aum unteren Rande der Krummholzregion im ganzen Dachsteinzuge sehr häufig, schon im Gesäuss und Johnsbachgraben.

1098. Euph. amygdaloides L. In Vorhölzern, Wäldern und Holzschlägen von der Ebene bis auf die Voralpen des Kalkzuges sehr häutig, seltener auf S'chiefer.

1099. Euph. Cyparissias L. Auf dürren Rainen mit SchotierUnterlage, verwahrlosten Grasplätzen und Wegrändern stellenweise in grosser Menge, z. B. vor'm Griesmayr, unterhalb des Adam, am Brucksattel $\left(4000^{\prime}\right)$. 
1100. Euph. Esula I. Auf einem Krautacker ausserhalb der alten Marktschiessstïtte spärlich, ron Angelis auch nächst dem Griesmayr angegeben.

1101. Fuplı. Peplus I. Auf Aeckern, wïsten Plützen und in Gemüsegärten sehr liantig.

1102. Mercurialis perenuis $\mathrm{T}_{\text {. }}$ An buschigen Stellen, in Hainen und schattigen Wäldern bis anf die Kalkroralpen, wo sie oft im Gerölle truppweise wurzelt, sehr häufig: var. latifolia mihi (Blätter eiförmig, wie bei orata Strub. aber langgestielt) einzeln unter der Normalform, z. B. unterhalb der Scheibleggervoralpe.

N13. Die in anderen Gebieten Steicrmarks so gemeinen Euph. exigria L. und Merc. annua L. wurden hier noch nie gefunden.

\section{Fam. Juglandeae DC.}

110:3. Tuglaus regia I. Selten an Wegen und in Obstgärten kultivirt, in Franenberg wild oder doch verwildert.

\section{Fam. Geraniacene DC.}

1104. Geranium l'hicum I. In Obstgärten, Auen, Waldlichtumgen, in den Futtergärten der Voralpenhütten etc. sehr häufig.

1105. fiel. sylvaticum I. Auf buschigen Berg- und Voralpenwiesen bis zur Strauchgrenze les Kilk- und 'Tanernznges sehr bäufig. Variirt A graudiflormu (Blumenblïtter von doppelter Kelchlänge (14 mm.), verkehrteiförmig), die gemeine Form, die sich wieder theilt in a glandulosum und seltener $\beta$ eglandulosum; B. parviflorum (Blumenblätter nur $7 \mathrm{~mm}$. lang, kaum länger, als der kleine Kelch, rerkehrteifürmig - keilig, der Nagel stark bebartet.) Kommt ebenfalls ror als \% glandnlosum (Voralpenregion des Kalbling) und "s eglaudulosum (tlaumig, fast kahl), (Waldregion des Pyrgas inmitten einer ïppigen Vegetation).

1106. (ier. pritemse, l. Auf Feldern und Wiesen im Paltenthale zu heiden Seiten der Landstrasse sehr häufig, im Enusthale nur bei den Fichen des Hoffeldes ron Hatzi gesammelt; findet sich auch uicht selten an hochgrasigen Stellen ob dem Gemeinsee um die Felsen der Hochhaide (Gneiss, c. 6000').

1107. Ger. palustre 1. An Gräben, Zäunen mnd zwischen Gebïsch anf sumpfigen Wiesen nicht häufig, z. B. in der Krumau, ror"m Hofmoore, anf der Fuchsweide.

1108. Grr. pusillım L. An Häusern, 'Zäınen, Wegen, auf Schutt hie und da häntigg, \%. P. um die Manern des Stiftsgartens, bei Weng, Hall, beim Farchner, Griesmayr.

1109. Vier. molle $\mathbf{I}_{\text {. }}$. Wird in einem alten Verzeichnisse angegeben.

1110. Arr. columhinum I. Auf steinigen, trockenen Rainen, an Wegrïndern und Kännen hie und da, selten, z. B. um Admont (Hatri!), Dittmannsdorf. ror St. Gallen. 
1111. Ger. dissectum L. Anf Aeckern nuter Getreide und anf Schutt selten: Im Hoffelde, bei der Ziegelbrennerei.

1112. Ger. robertianum L. An alten Manern. auf Steinhaufen, feuchten Kalk- und Schieferfełsen, im Schatten der Wälder und Bergschluchten auf nassem Sandgerölle, bis anf die Voralpen, wo es den Kalkschntt der Giessbäche liebt, sehr gemein.

1113. Erodium cicutarium (I.) Her. var. chaerophyllum (Car.) Rchb. 4864. Auf sandigen Aeckern und Rainen hie und da sehr häufig, z. B. unterlıalb des Griesmayrhauses, um Dittmannsdorf, an sandigen Ufern des Triebnerbaches; v. pimpinellifolium (Cav.) form. pilosa (Thıill) Relıb. Jc. fand Angelis am Pfarrhofe zu Gaishorn.

\section{Fam. Lineae DC.}

1114. Linnm usitatissimum L. Nicht selten kultivirt, hie und da anch verwildert.

1115. Lin. alpinum Jacq. Anf Geröll nnd steinigen Abhängen der Kalkzone (1800-6000') ziemlich häufig: Im Gesänss bei der Hartelsbrïicke (Augelis), beim Amtmannsgalgen vor Johnsbach, bei der unteren Farchneralm, an Fusse des Reichenstein ob der Treffineralm, von der Kalblingvormauer bis zur hohen Kalblingmaner häufig, am Scheiblstein (Hatzi!) und Natterriegel.

1116. Lin. catharticum L. Auf trockenen Wiesen, Rainen und Hïgehn der Ebene, Berge und Voralpen sehr verbreitet; steigt bis auf die höchsten Alpen der Kalkkette.

\section{LXXXV.-VII. Fam. Oxalideae DC. U. Balsamineae Rich.}

1117. Oxalis Acetosella I. Unter Gebïsch, an Baumwurzeln und auf Moosen in Nadelholzwäldern, auf' fenchten, moosigen Gneissblöcken der Bergschlnchten ete. äusserst gemein. Blüthe weiss mit röthlichen Adern oder lila geadert bis liła (= v. lilacina Rchb.).

1118. Ox. corniculata I. Wurde im Stiftsgarten verwildert als Unkraut beobachtet.

1119. Inplatiens noli tangere I. An Quellen, Bächen, überliant an schattigen, fenchten Orten der 'Thïler mu Bergschluchten äusserst gemein.

\section{Fam. Oenothereae Endl.}

NB. Alle Epilob. wurden von Prof. Hanssknecht revidirt.

1120. Epilobium angustifolimm L. Auf freien Waldplätzen und Holzschlägen zumal der Schieferberge bis anf die Voralpen überans gemein; riesige Flächen werden von ihren Blïthen roth gefärbt. 
1121. E1. hirsutum 1. An den Wassergräben der Fuehsweide (Altes Verzeichniss).

1122. Ep. parvillor'um Schreh. An feuchten Wegrändern, in Grüben, Mooren und Sumprwiesen bis 4000' sehr hänfig.

1123. Ep. montanum I. An Gräben, fenchten, schattigen Orten, roüüglich, in Wäldern, bis aul die Voralpen sehr gemeiu ; var. verticillatum Sturm rom Sulykihr gegen den Hartlersbach hinab am Grunde einer liallifelswand häulig; anch v. minns Hansshecht (det. ipse!) wurde vou Angelis um Admont gesammelt.

1124. Elo. collimm Gimel. Anf trockenen, somnigen Hïgehn miterhally lï̈thelstein, alm Lichtmessberg, Stemamindl, in der Strechen. vor Franenberg etc. sehr häulig.

1125. lip. collinmm $\times$ montamm IIansskn. let. ipse; An Bächen und kohlstätten in der höheren Bergregion der 'l'anernkette bäutigg, z. B. am Steinamandl, bei der Hölleralm.

1126. Ep. collimum Х rosem Hansskn. det. ijse! An der Anssenseite des ehemiligen Kaltenbrunnerischen Kohlenbarens ron Angelis gesammelt.

11:3. E). rosenum Schreb. \% genninum G. G. (Aestig, BlattZähne genähert). An Wassergriaben und Bächen häutig; fo simplex G. G. (Winzig, einfich, Blattzïhne entfernt, schwach.) Auf den steinernen, der Mittagrssonue sehr ansgesetaten Stufen des P'avillons im Stiftsgarten häufig, oft kaum "2" hoch: auch sonst 1 m Admont: "tetragonum $I_{2}$. am Höphlinger Fluder" (Altes Verzeichniss) gehört wohl alleh zul roseum.

112S. H. paluste 1. Auf Sumpifwiesen und Mooren sehr häufig, z. B. in der Krrumall, beim Griesmayr, im Hofinoore, vor Flatuenberg ete: anch am Lichtmessbache minterhallb des Adam.

1129. Fu. trigonum Schrk. An schaltigen, hochgrasigen Stelleu der Kalkvoralpen lis 5sou fust in ganzen Gubiete, doch nirgends häutig; sehr hänlig an Ackerrainen um diss Dorf Hohentanern; var. $\beta$ oprositilolium nicht selten mit der Normalform.

1130. Ep. Alsinclolimm Vill. Hausskn. An Quellen, Bäthen und Seeen im Gueiss- mol Schiefer\%uge hörhst gemein, aber anch in der Kalkzone häntig: steigt bis zur Thalsohle, z. B. Gesäuss, Schwarzenbachgraben, an der Griesmatrache.

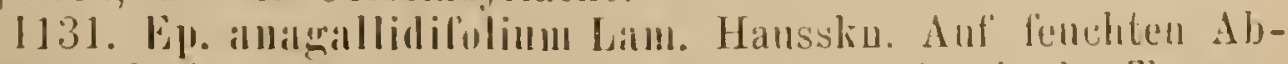
längen, an kleincn bïchen und Seeen der Alpenregion in der T'incrnlette häutig, \%. B. am Bösenstein, Hochsehwmy, un den Geneinsee. dic Bacheralpe, die Hëllerahn, anf ler Hochhaide: im Kallzonge nur hein briimnl des Kalhling und am Hochkilbling: an letzterem Standorte sind die Frïchte ziemlich stark flammigg, in der 'Tamernkette aber kahl.

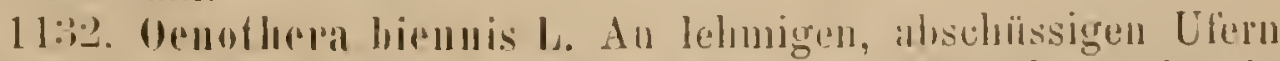
der Eums und ihrer Arme, sowie an Wegen nieht selten: häutig

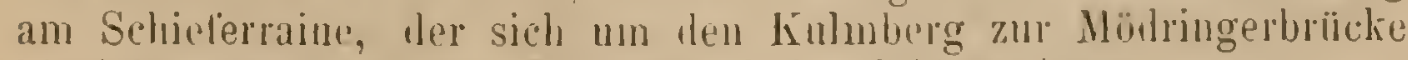
hinzieht: auch anf lem Schutthïgel des Stiltsgartens. 
1133. Circaea alpina L. An feuchten, schattigen Abhängen der Schieferschluchten sehr gemein, z. B. im Veitl-, Ardning-, Wolfs-, Flietzen-, Strechengraben, am Lichtmessberge überhaupt und auf den Voralpen der Tauernkette; seltener und nie in solcher Menge auf Kalk: Am Brucksattel, um die Stumpfuagleralm, Kemetwand, im Sunk etc.

1134. Circ. intermedia Ehrh. An Bächen, fenchten, schattigen, Stellen der Ebene und der niederen Bergwälder häufig: Im Gesäuss vor der Johnsbachbrücke, am Wege nach Weng, von Hall zur Pitz hinauf, im Walde vor'm Mühlauerfalle, am Oberhofteldbache, Lichtmessbache, um Rottenmann (Stur); meist in dichten Trupps.

1135. Circ. Iutetiana L. An ähnlichen Standorten ziemlich hänfig, lieht aber grössere Trockenheit: Am Eingang in's Gesäıss, von der Johnsbachbrücke gegen Gstatterboden, in Wäldern zwischen Weng und der Pitzweide, am Schaflerweg, am Heindlgnt (Hatzi!), im Johnsbacher Friedhofe (Angelis!).

1136. Isuardia palustris L. In regenwasserhältigen Vertiefungen am Westende des Hoffeldes gleich am Wege gegen die Eichen hinab (Hatzi).

\section{Fam. Halagoreae R. Br.}

1137. Hippuris vulgaris L. Sehr häufig in der Griesmayrlache und in Ennsarmen der Krumau; gewiss auch in den Sümpfen der Palte.

1138. Myrioplyllum verticillatum $\mathbf{L} . \alpha$ und $\beta$ intermedium Koch. In stagnirenden Gewässern sehr häufig, z. B. bei Trieben, in der Krumau, in Ennsarmen, in einer Lache ausserhalb des Hofmoores. häıfig.

1139. Myr. spicatum L. In den Admonter Stiftsteichen sehr

1140. Trapa natans I. Im Krumauerteiche wahrscheiulich häufig; beim Reinigen desselben wurden viele Nüsse gefunden.

\section{Xc. Fam. Lythrarieae Juss.}

1141. Lythrum Salicaria L. An Gräben, Bächen, in Sümpfen sehr häufig.

1142. Peplis Portula L. An Gräben im Hofmoore (Altes Verzeichniss), um Admont (Herb. Gebhard!).

\section{IXC. Pomaceae Juss.}

1143. Crataegus Oxyacautla L. In Hecken, Vorhölzem mit Berberis, Prunus spin., Alnus ine. ete. sehr häufig.

1144. Crat. monogyna Jacr. An ähulichen Orten, z. B. ror"in Griesmayr, à der Essling, ebenfalls sehr lıäutig. 
1145. Cotomrister tommontosa lindl. Von der Bärnkoppe den Kalkwänden entlang gegen die Stumpfnagleralm spïrlich, rom Gamsstein zum Hochthor ziemlich häulig.

1146. Pyrus communis L. In Gebüschen und Wäldern sehr häufig will.

1147. PYr. Malıs 1. In Vorhölzern mad Wäldern hä̈ufig; wie vorige auch in zahlreichen Spicharten kultivirt.

1148. Aronia rotumbilolia l'er's. In Berg- und Voralpenwäldern des Kalkznges iiberall hïuligr, z. B. in Gesïuss, Brnckgraben, am Dürflstein, Scheiblstcin, Iyrgas, Kalblingr, um den Mōhlanerfall.

1149. Sorbus Ancuparia I. In Berg- und Voralpenwäldern des Kalk-, sowie des Tamernzuges schr gemein; anch in schönen Alleecu beim Ausuginge des Paltenthales, in der Kilamm, vor Kaiserau ete. kultivirt. kultivirt.

1150. Sorb. domestica L. Um Admont (Angelis!), wohl tü

1151. Surb. scandica (L.) Fr. In Wähdern bei Liezen (Praesens) Maly 1868. lch sah die Exemplare im Herb. Maly; sie zeichnen sich ror den anderu Arten mnseres Gebietes durch liederlappige, unten weissfilzige Blätter aus, doch wäre noch zu untersuchen, ob es nicht intemedia Schult. Kerner Veget, eine Bewohnerin der Kalliterrassen, ist.

1152. Sorl). Aria (L.) r'r. In Bergwäldern des Kalkzuges bis zur Krummholzregion überall, doch sehr zerstreut, bisweilen sehr schöne Bäume; an häufigsten im Gésäuss, zwischen Gamsstein und Hochthor, am Scheiblstein.

1153. Sorlo. Chamaremespilus (L.) Cr. \% glabra Nhr. In der höheren Berg- und Voralpenregion des Kalkzuges zwischen Gesträuch und Krummbolz zerstrent: Am Pyrgas, Kalbling, unterhalb der Scheibleggerhochalpe : häutig vou der Gstattmayrvorilpe den Futterweg entling zum Scheiblstein und rom Gamsstein zum Hochthor.

\section{VIIC. Fam. Sanguisorbeate 'T. Gr.}

115. Alchemilla vulugaris $\mathrm{L}$. o glabra DC. Pr. Aul nassen Wiesen und an Bächen bäufig, auch noch unterhalb der Kemetwand und sehr hïlfig mit Rumex arifol. mol Alonicum scorp. in Schneegruben am Selieiblstein (Kalk, c. $6200^{\prime}$ ): $\beta$ pilosa Nlr. Auf Wiesen, Feldern, Waldplätzen, um Voralpenliütten gemein.

1155. Alch. hybrida ( $\boldsymbol{H}_{\text {. }}$ ) Kern. Veg. nontana W. Auf sonnigen Hügeln der Eibeue selten (z. B. vor (ler Ziegelbremerei), sehr häufig aher auf trockenen Berg- und Voralpenweiden bis über' $6000^{\prime}$, z. B. am Bruclisattel, Scheiblstein, Kalbling, in den Johnsbacheralpen (Kalk), um die Scharte des Hochschwung mit pubescens (Glimmerschiefer).

1156. Alch. pubescens MB. Um die Scharte des Hochschwung (Gl.-Schiefer, 5600') ziemlich häufig; von Strobl sen. anch am Pyrgas angegeben, aber wohl Verwechshng mit voriger. 
1157. Alch. pyrenaica Dnf. 1821, fissa Schum. 1827. Auf feuchten Alpenweiden: Am südwestlichen Aufstiege vom Speikboden auf den Gipfel des Kalbling (Herb. Hatzi!), am Pyrgas (Brittinger!), an Bachrändern zwisehen der Bacheralm und dem Gemeinsee (Gl.Schiefer).

1158. Alch. alpina L. Auf sounigen und steinigen Triften der mittleren Kalkalpenregion überall sehr häufig, besonders in den Johnsbacheralpen, am Pyrgas, Scieiblstein und Kalbling; auch nicht selten lierabgeschwemmt bis Mühlau.

1159. Singuisorba officinalis $L$. Auf sumpfigen Wiesen des Enns- und Paltenthales läulig, anch $\beta$ anriculata (Scop.) All.

1160. Poterium polygamum W. K. pl. rar. 11. 117, muricatum Spach. (Ansgezeichnet durch die list gellïgelten, sehr erhabenen, an meinen Exemplaren wellig gezähnten Kinten und die tief grubigen, stachelig-höckerigen Felder des Fruchtkelehes.) An Eisenbahndämmen bei Adnnont voll Angelis gesammelt.

1161. Pot. Sanguisorba L. (dictyocarpum Spach). In der Schulteringwiese ron Angelis gesammelt.

\section{VIIC. Fam. Rosaceae Juss.}

1162. Rosa arvensis Hds. Am Abhange eines tiefen Grabens, der S. Gallen von der Ruine Gallenstein tremnt. - Allerdings schon etwas ausserhalb der Gebirgsgrenzen, doch wahrscheinlich anch in Gebiete.

1163. Ros. alpina L. $\beta$ pyrenaica (Gou.) Ser. Blättcheu einfach gesïgt, Blüthenstiele (oder anch Kelch) drüsig steifhaarig. \% monspeliaca (Gour.) Koeh. Blättclıen doppelt gesägt, Blüthensticle (oder anch Keleh) driisig steifharig. An buschigen, waldigen Orten der Berge und Voralpen bis in die Krummholzregion der Kalkkette überall, doch ziemlich vereinzelt; sehon im Gesiuns, Johnsbachgraben, am Sehwarzenbach. $\beta$ am gemeinsten, $\gamma$ seltener, z. B. unter der Bärnkoppe (mit kahlem Kelehe), am Fusse les Gamsstein bei Johnsbach (mit drïsigem Kelehe). var. $\alpha$ vulgaris Dsr. mit einfach gesïgten Blättern und kihlen Blüthenstielen scheint zu fehlen.

1164. Ros. cinerascens Dum. l'. subadenophylla Borbás (det. Heinr. Braun!) Auf Hügeln, an Waldründern rereinzelt: Fingang in's Gesäuss, unterhalb Röthelstein, am Fahrwege unterhalb Fraueuberg, im Strechengraben, naeh Nlaly Fl. anch an Lichtmessberge (als toment.).

NB. Dieselben Exemplare, welche Braun vorlagen, determinirte mir Christ als tomentosa Sn.

1165. Ros. canescens Déségl. (non Backer see. Borbás) f. subatrichostylis Borbás (Gruppe der Caninae pubese, det. H. Brann!). An Zäunen um Admont hie und da.

1166. Ros. canima L. $\alpha$ genuina W. Log. (= Lutetiana Lem.) An Zïunen, Wegen, in Hecken, Bergwäldem gemein. 
1167. Rus. ohlonga Rip. (let. H. Brann. Dieselben Exemplare determinirte Christ als canina l. dumalis Bechst., Brann schreibt jedoch: "Griflel kahl oder fisst kahl, Kelchröhre verlüngert-cllipsoidisch, daher dumalis absolut ausgeschlossen!). An '/äunen um Admont und an Wegrändern der Buchan (e. 2600').

1168. Ros. rubiginosa I. (det. Christ). Am Wege ron der Klamm mach Oppenberg selten (Grauwackenschiefer, 3000').

NB. Ros. graveolens Gr. God. (det. Christ). Im oberen Ennsthate bei Oeblarn, gewiss anch im Gebiete.

1169. Rulus libtus W. K. a genumus Gr. Gor., W. Isge. (Stimmt mit der Beschreibung W. K. vollkommen überein, nur dass meine Hxemplare lauter dreizählige Blätter besitzen, ist anch mit Fxemplaren Wirzbicki's aus dem Banate identisch). In Wäldern mod Holzschlägen sehr häufig, z. B. gegen die Pitz hinauf sehr gemein, am Eingange in den Schwarzenbachgraben, am Brucksattel, im Gesïuss, um Aigen, am Lichtmessberge.

1170. Rub. plicatus Weile (teste Dr. Halacsy). An den mit Strauchwerk bewachsesın Rändern des Krumauer 'T'orfmoores dem Ennsarme entlang sehr gemein, auch an anderen Stellen der Kruman ind in Holzschlïgen häufig.

1171. Rub. bilpous Vest. Neben einer verlassenen Voralpenhütte heim Aufstiege ron Gistatterhoden zum Brucksattel ein sehr üppiger Stork.

NB. Dr. Halacsy bemerkt zu meinem Exemplare: "Kann nicht reinel bifrons sein, da vereinzelte Stieldrüsen in Blüthenstande rorkommen"; da ich jedoch weit umher ausser hirtus keinen Rubus traf, so möchte jch doch nur an eine Variation denken.

1172. Rub. vestitus W. N. (teste Dr. Halacsy.) An Wegrändern oberhalb Grünal bej Spital am Fusse des Pyrgas sehr häufig (Werfinerschiefer, 2500॰).

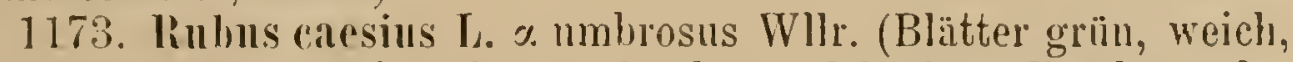
fast kahl). Unter Buschwerk an feuchten, lehmigen Rändern der linns und ihrer Arme sehr gemein, chenso um Aigen, an schattigen Wegrändern gegen Franenberg, Weng, im Stiftsgarten ete.

1174. Rul. sixatilis I. In steingen Wäldern bis auf die Voralpen der Kalkkette ïberall zerstreut, schon im Gesäuss, Jolnnsbachund Schwarzenhachgraben, anf Felsen der Klamm.

1175. Kul. Ilacus T. In Holzschlägen der Tief- und Bergregion höchst genein bis anf die Voralpen; meist mit plicatus und verwandten, den Felsen der Bärnkoppe entlang anch häufig mit vorigem.

1176. Agrimonia Eupatoria I. Anf sonnigen Hügeln beim Griesmayr, bei Aigen, gegen Frawenberg, am Aufstiege zum Brucksattel etc. häufig; öfter's sind, z. B. gegen Franenberg, die Frïchte genau halbkugelig, also auch Agr. odorata Mill?

1177. Geum urlanum I. An Zïunen, Scheunen, zwischen Gebüsch hie und da, nicht häufig, z. B. im Stiftsgarten, Frauenfelde, am Wege zur Pitz, an der Essling. 
1178. G. rivale L. An sumpfigen Rändern der Grüben und Bäche, zwischen Gebüsch, in fenchten Schluchten und Bergwäldern ziemlich häufig: Alleeen des Stiftsgartens, Umgebung des Hofmoores, ror der Kaiserau, vom Wolfsbanern zum Hund, im Strechengraben bis auf die Voralpen, um dem Scheiplsee am Rott. Tauern (2-5500', Alluvinm, Kalk, Schiefer, Gneiss).

1179. (*. peptans I. Am Rottenmannertanern (Strobl sen!), am Griesstein (Gersprich im Herb. Hatzi!). Gneiss.

1180. (*. montanum L. Auf grasigen Alpenhöhen des Tauernzuges sehr gemein, auch im Kalkzuge nicht selten, z. B. am Scheiblstein $\left(5-6000^{\prime}\right)$, anf der Speikwiese des Kalbling (c. 6500'), $1 \mathrm{~m}$ die Farchneralm vor"m Hund sehr häufig.

1181. Dryas octopetala L. An fenchten, felsigen Abhängen, auf steinigen, windigen Triften und Kanten der Kalk- und Tauernkette $\left(6-7700^{\prime}\right)$ äusserst gemein, steigt auf Felsschutt und längs der Giessbäche des Kalkznges auch sehr oft bis zur Thalsohle herab, z. B. im Gesäuss sehr gemein, seltener am Mühlanerfall, im Schwarzenbach-, Johnsbach-, Bruckgraben etc.

1182. Sibbaldia procumbens L. Auf den höchsten Gipfehn der Oppenberger Gebirge (Gebhard), an kurzgrasigen, steinigen Abhüngen unter den Felsen des Hochschwung (Gl.-Schiefer 5-6000').

1183. Comarum palustre L. Auf Mooren, Sumpfwiesen, an Teichrändern beider Thäler bis auf die Alpen ( $\left.2-5500^{\prime}\right)$ hänfig: Krumaner-, Hof-. Ardninger-, Triebnermoor, um die Höllcralm, $m$ die Tamrer-Fischteiche und die Scheiplseeen.

1184. Fragaria vesca L. An Raineu, Hügeln, in Holzschlïgen mnd Waldlichtungen bis anf die Voralpen äusserst gemein.

1185. Frag. moschata Duch. (elatior Ehrh.) An schattigen Orten der Ebene und in lichten Bergwäldern stellenweise sehr häufig, z. B. am Anfstiege zur Pitz, von der Heindlbrïcke zum Himbeerstein, beim Kohlenban des Lafferwaldes, unter Alleeen des Stiftsgartens. Meist auf Kalk.

1186. Potentilla Fragariastrum Rhrlı. Auf Waldhügeln am Aufstiege zur Scheibleggerhochalpe.

1187. Pot. allıa I. „In Gesü̈ss (Weimayr)“ Fürstenwärther.

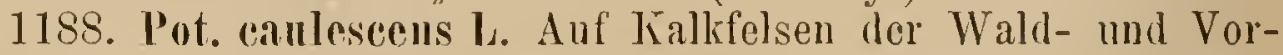
alpenregion stellenweise sehr häufig, 7. B. im Gesäuss, Jolnnsbachgraben, am Gamsstein, unterhalh der Scheibleggerhochalpe, am Sïdwestfusse der Kemetwand; anch anf sil. Kalkvorlagen der 'Tauemkette und anf Pignolithfelsen im Sunk.

1189. Pot. Clusiana Jacy. An Felsen und steinigen Abhängen der ganzen Kalkzone $\left(5-7000^{\prime}\right)$ gemein, selten herabgeschwemmt im Gesïnss, Johnshach- und Schwarzenbachgraben; hänfig anch in Felsspalten muter der Höhe des Stemamandl (Cineiss, c. (6400’).

1190. Pot. minima IIall. Auf' kurggrasigen, steinigen 'Triften der Kalkalpen $\left(4500-7000^{\prime}\right)$ ziemlich häulig: Hinter der Kaiseran, in der Nöhe der Hölleralm (Angelis), $n$ m die Strumpfuagleralm (Hatzi!), mm die Scheibleggerhochalm, am Kalbling, Pyrgas, Scheiblstein, Hexenthurm, Natterriegel. 
1191. Pot. maculata Pourr., salisburgensis Hnk. Auf ïppig begrasten Alpenwiesen zwischen den Schieferfelsen des Hochschwung häutig, auch am Hund im Sulzkahr (Herb. Hatzi!).

1192. Pot. verna L. Anf trockenen Rainen, Hügeln, an Waldrindern, oft mit Globul. cordif.; rorzüglich gemein vor"m Griesmayr, ror Hall, ror'm Mühlanerwäldchen, gegen Franenberg zu.

1193. Pot. allea I. Auf Triften und haideartigen Abhängen von der höheren Waldregion bis $6500^{\prime}$ in Kalk-, vorzüglich aber im Tanernzuge sehr gemein.

1194. Pot. reptans I. An Gräben, Wegräudern, Ackerrainen sehr gemein.

1195. Pot. Tormutilla Nostl. Anf Sumpfwiesen, Torfmooren, nasseu Waldlichtungen, triefenden, folsigen Ablïngen der Schieferschluchteu, aber anch in trockenem, haideartigem Waldgrunde mit Vaccinien bis hoch in die Urgebirgsalpen äusserst gemein.

1196. Pot. argentea 1. A uf sandigen Bachrändern bei Trieben häıfig, ant einer alten Maner unterhalb Grünbüchel (ob Rotteumann), an Wegräudern gegen Fraueuberg, am Sandwege zwischen Kolılmayer und Klamm, sowie ron da in den Streclengraben stellenweise hïufig. Grauwacke und Werlinerschiefer.

1197. Pot. ansurina L. a sericea Hayne, $\beta$ discolor Nlr. Auf Wegräuderı, Rainen, Weiden, an fenchten und sandigen Uferstellen iilusserst gemein.

1198. Spirata salicifolia L. Am Ufer der Palte bei Trieben (Hatzi!), beim Aubrugger bei Trieben an einem Zanne (Sommeratrer in Herb. Maly!), bei der Schanpenziegelbrennerei (Angelis!).

1199. Spir. Aruncus L. An feuchten, schattigen Waldstellen, in Schluchten, auf steilen, Schiefer- und Kallifelsen im Wald- bis Voralpengebiete häufig, \%. B. Gesïuss, Aufstieg zum Brucksattel, zur Scheibleggerhochalpe, am Schafferwege, auf der Eggerleitheu, im Wollis- und Strechengraben, zwischen Krummhol\% am Scheiblstein.

1200., 1201. Spir. VIuraria L. und demdata Presl. Auf Sumptwiesen, an bach- mud 'eichränderu, bald zwischen Sehilf und Gosträuch, bald frei grosse Strecken bedeckend, beide Arten äusserst gemein.

\section{VIC. Fam. Amygdaleae Juss.}

1202. Prunus spinosal L. Anf' dürrev, somnigen Plätzen, an Käıne ॥, Waldsäumen sehr lä̆ıfig, meist nit Crataegus und Berberis.

120:3. L'run. insititia L. In Hausgärten, an Häusern und Zïımen um die biorlere häutig knltivirt und verwildert.

1 201. Prun. domestical L. In Obstgïrten, auf Ackerrainen und an '/äl nen selır hïufig angephllant.

120.5. L'run. avium L. In Bergwälderu und Vorhölzern häufig wild, in Obsträlrten sehr häntig kultivirt in vielen Fruchtrarietïten.

1206 . P'un. ('n'asus L. In Obstgïrten länfig knltivirt, hie und da gleich sam rerwildert: nach Angelis auch wirlilich wild. 
1207. Prun. Padus L. In Hecken, Vorhölzern, an Bachuferm und Wiesenzäunen sehr häutig strauch-, bisweilen auch baumförmig.

NB. Prun. Armeniaca L. und Persica vulgaris Mill. wird nur hie und da an Staketen gezogen.

\section{VC. Fam. Papilionacene L.}

1208. Genista tinctoria I. Auf buschigen Hügeln und an grasigen Waldsänmen selten: Am Rücken des Strechauer Kalkznges gegen Lassing zu, ob Dittmannsdorf am Waldwege (Hatzi!).

1209. Gen. germanica I. In einem Wäldchen zwischen Hohentauern und S. Johann.

1210. Gen. sagittalis L. An Waldrändern und anf Rainen auf der Passhöhe des Lichtmessberges bei der Sägemühle selten, häufig von da gegen Dittmannsdorf hinab, oft von Cuscuta Epithymum übersponnen; häufig auch an Wegrainen zwischen Hohentanern und S. Johann. Grauwacke.

1211. Ononis spinosa L. Auf Wegrändern, trockenen Wiesen, Rainen und in lichten Nadelwäldern bis auf die Voralpen hänfig, z. B. am Wege zum Gesäuss, beim Griesmayr, im Mühlanerwäldchen, um die Gstattmayrvoralpe sehr häufig.

1212. 0n. procurrens Wllr. $\alpha$. vulgaris Lge. und $\beta$ mitis Lge. Auf Sumpfwiesen beim Griesmayr häuffig ( $\alpha$. und $\beta$ ), am Raine der Griesmayrlache, auf' Wiesen zwischen Admont und dem Gesäuss.

1213. Anthyllis Vulneraria L. a. aurea Nhr. (Blüthen einfärbig goldgelb.) Auf trockenen Wiesen, Hügeln und Rainen ron der Ebene bis auf die höchsten Kalkalpen (hier kleiner $=$ f. alpestris Heg.) äusserst gemein; $\beta$ rubrocarinata $m$. (goldgelb, oberer Theil des Schiffchens blutroth). Selten mit $\alpha$, z. B. am Aufstieg zur Kochenalm, mit $\gamma$ auf einer Ennswiese östlich von der Sautratte; $\gamma$ ochroleuca Nlr. p. p. (Blüthe gelblichweiss, Schiffchen wie bei $\beta$ ). Auf Rainen und Feldern des Ennsthales, z. B. in der Santratte selır häufig, auf der Oberhofwiese sehr gemein.

NB. Anth. montana L. wird in einem alten Verzeichnisse am Kalbling angegeben; bezielit sich wohl auf die Alpenform von Vulneraria.

1214. Medicago sativa L. Auf Feldern und trockenen Wiesen hie und da kultivirt, eben da, sowie an Wegen, anch öfters verwildert.

1215. Med. filcata L. Auf trockenen Wiesen, Feldern, an Rainen und Wegrändern nicht selten; anch $\gamma$ major Kch., z. B. im Frauenfelde, auf Steinhaufen gegen Mühlau.

1216. Mel. lupulina L. $\alpha$ vulgaris Kch., $\beta$ Willdenowii Bünn. Auf Wiesen, Grasplätzen, Rainen und Wegrändern beide Var. selır gemein bis in die Voralpen, $\beta$ noch nnter Krummlılz am Káalbling.

1217. Melilotus officinalis (L.) Dsr. $\Lambda \mathrm{m}$ Tichtmessberge ( $\mathrm{nn}$ gelis), bei Dittmannsdorf (Strobl sen.), auf Schntt und an Wegen um Admont bie und da. 
121S. Mel. alba Dsr. Auf wüsten und steinigen Stellen, vorzüglich an Wegrïndern und den Ennsufern entlang zwischen Gebüsch sehr häufig.

N1B. MIel. crierulea (I.) Ianu. „Auf Wiesen im Enns- und Paltenthale (Angelis) " Maly 1868; ich fand sic immer nur in Hausgärten liultivirt.

1219. Trifolium prateuse I. Auf sumpfigen und trockenen Wiesen, Feldern, Grasplïtzen äusserst gemein, wildwachsend und linltivirt; $\gamma$ nivale (Sieb.) Kich. Auf Alpentriften im Kalk- und 'T'anernzuge häufig, \%. B. um die Farchnersim vor'm Hund, am Kalbling. Stadlfeld bei Jolnsbach (Ǩalk), ob dem Gemeinsee sehr hänfig, am Hochsehwong bis (j400' äusserst gemein (Gl.-Sehiefer).

1220. 'Trif'. medium 1. Unter Schilf bei der Euns und am Stiftsteiche, an Oberliofielde, an Ackerrändern des Lichtmessberges ob Dittmannsdorf häıfig, noch lı̈̈ıfiger auf den Weiden der Pitz; in den Johnsbachervoralpen (Herb. Hatzi!).

1221. Trif. arvense I. An Wegrändern bei Aigen (Angelis!), auf sandigen Aeciem bei Gaishorn.

1222. 'Trif. monfanum $\mathrm{J}_{\text {. }}$ Auf Wiesen von der Ebene bis auf die Voralpen, zumal der Schieferzone, sehr häufig, oft sogar gemein.

1223. 'T'rif'. repens I. Auf Wiesen, Feldern und Grasplätzen äusserst gemein.

1224. Trif. Iyyluidum l. Auf sumpfigen Wiesen bei Admont und 'Trieben häufig, auch an Wegrändern gegen Krumau, im Stiftshofe und auf Feldern der Klamm.

12.25. T'19if. whilreosum Schl. 1821. pallescens Kch. non Schreb. An felsigen Stellen des Hochschwung (Nordseite, c. 6000') ziemlich häufig. Gl.-Schiefer.

1226. Trif'. badium Schreh. Anf grasigen, feuchten Abhängen der Kalk- und Urgebirgsalpen ziemlich hänfig: Bei der Treffneralpe, am Hund, Hochthor, Kalbling, Pyrgas, Seheiblstein (Kalk), auf Alpen bei Trieben (Angelis), am Hochschwung bis 6000' sehr häufig (Gl.-Schiefer).

1227. 'Trif. allreum P'oll. Auf Sumpfwiesen der Krumau, auf Rainen gegen Frauenberg, am Wege ron Bärndorf gegen Büschendorf und sonst noch im Enns- und Paltenthale häufig.

1228. Trif. camprestre Schreb. Auf Weiden, Aeckern und Wegrändern sehı häntig.

1229. Tril., procumbens Schreb. Wie voriges und ebenfalls häufig.

1230. 'Tlif. miuns Sm. Auf nassen Wiesen um Admont von Augelis gesammelt, ich selbst fand es nur im oberen Ennsthale.

1231. Iotus corniculatus I. a vulgaris Koch. Auf Wiesen, Feldern und Rainen äusserst gemein bis hoch in die Alpen, wo sio oft weit höher aufsteigt, als Hippocr. comosa.

1232. Tetragonolobus siliquosus (L.) Rth. An Lisenbalındämmen im Gesäuss bei Hieflau von P. Plac. Baclinger gesammelt und mir mitgetheilt.

1233. Phaca frigida I. Auf üppigen Alpenwiesen: Aın Hund im Sulzkahr (Strobl sen. nud Hatzi!), luäufig an Hochsehwung mit Hedys. obscurum. Kalk, Glimmerschiefer, 5500-6000'. 
1234. Phac. anstralis L. a glabra. An sehr felsigen Stellen des Hochschwung hie und da liäufig (Nordseite, 6400', Gl.-Schiefer).

1235. Plıc. astragalina D(!. Von diuren Abhüugen unter den Felsen des Hochschwung bis zu den üppigen Felstriften hinauf sehr häufig (5500-6000', Gl.-Schiefer); nach einem alten Verzeichnisse auch im Snlzkahr (Kalk).

1236. Oxytropis campestris (L.) DC. "Auf Alpen bei Strechan" (Maly 1838), am Bösenstein auf Gueiss (Stur).

1237. 0x. montana (L.) DC. Auf trockener Erde an steinigen und felsigen Abhängen der Kalkalpen (5-7000') lü̈ufig: Am Südwestfusse der Kemetwand, auf der Höhe des Scheibleck, am Kalbling, Scheiblstein, Pyrgas, im Sulzkahr etc. „Auf der Peewurzalpe am Bösenstein (körniger Kalk) und verändert anf Hornblendeschiefer" Stnr; die verïnderte Form ist wohl $0 x$. triflora Hoppe.

1238. Astragalus leontinus Jacq. Auf dem Strechaner und Schwarzullingergebirge (Gebhard), fehlt im Herh. Maly.

1239. Astrag. Cicer L. Auf Ründern von Getreidefeldern an der Landstrasse des Paltenthales zwischen Singsdorf und dem Walzenhanse hänfig.

1240. Astrag. glycyphyllos L. Anf buschigen Hügeh, freien Waldstellen, Beig- und Voralpenwiesen hie und da, nicht selten: gegen Franenberg, unter der letzten Erhebung des Dörflstein, unter Strechan, im Strechengraben, am Aufstieg zur Scheibleggerhochalpe, bei der Bichelmayralmhütte, unter Krummholz auf der Ardningalpe (Strobl sen.) etc.

1241. Coponilla vaginalis Ian. Auf Kalkvoralpen um Admont selnr selten (Altes Verzeichniss); ich fand sie nur im oberen Emnsthale.

1242. Cor. varia L. Anf Rainen, Hügeln, zwischen Gebüsch, selten.

1243. Hippocrepis comosa L. Auf trockenen, sonnigen 'Triften und über Kalkschotter von der Thalsohle bis 6300' im Kalkznge und auf sil. Kalkvorlagen der Tauemkette selı gemein.

1244. Hedysarmm ohsertim L. Auf grasigen Ablü̈ngen der Kalkhochalpen $\left(6000-7100^{\prime}\right)$ nicht häutig: Am Pyrgas, Scheiblstein, in den Jolnsbacheralpen (besonders von der farchneralm anf den Hund), am Stadlfeld (Hatzi!); sehr gemein aber auf ïppigen Felstriften des Hochschwing (Gl.-Schiefer).

1245. Onobrychis sativa L. Nicht selten kultivirt und verwildert, \%. B. im Oberhoffelde, Stiftsgarten, an Rainen um Admont und Johnsbach.

1246. Pisum arvense I. Auf Aeckern unter Getreide hänfig; sativum L. wird im Stiftsgarten etc. kultivirt.

1247. Ervum hirsutum I. $\alpha$ eriocarpon G. G. Auf sandigen Aeckern bei Dittmannsdorf, in Kileefeldern $11 \mathrm{~m}$ Admont.

1248. Vicia silvatical I. Unter Gebüsch und in Gebirgswäldern stellenweise in Menge, z. B. vom innersten Winkel des Schwarzenbachgrabens zur Griesweberalm hinauf, von der Pitz zum Natterriegel (Kalk), unter der Kemetwand auf einer Rutschfläche (4000', Werfnerschiefer); seltener am Bache des Oberhoffeldes (Angelis), in Walde nuter der Bockmaieralm (Hatri!). 
1249. Vic. Cracea L. Auf Wiesen, an Hecken und Züunen sehr häufig.

1250. Vic. sepimm I. In Hainen, an Waldrïndern, Zämnen und Hecken gemein.

1251. Vic. sativa I. B obcordata Rchb. Auf Aeckern unter Getreile sehr häufig.

125. Vic. allgustifolia Rth. Anf Steinhanfen bei Trieben von Strobl selı. gesammelt!

1253. Latlyus sativus I. Auf Aeckern verwildert (Strobl sen.!).

125t. Latl. pratensis L. Auf Wiesen, unter Gebuisch rind an 1/situnen gemein.

125. Lath. silyestris L. Unter Gebiisch beim Sausteiger (Sallpichler Angelis) am Lichtmessberge (Strobl sen.!), an sonnigen Waldrïndern um Admont (Hatzi!).

1256. 0robus laevigatus W. K. Ob rem Pyrgasgatterl (c. 4500', Kalk) zwischen Gebiisch an alten Fenerstätten ziemlich häufig.

\section{Nachträge und Berichtigungen.}

Herr' Professor Hackel hatte die Güte, die Gramineen der Flora Admont. 7.u revidiren, wobei sich folgende Veränderungen der Nomenclatmr ergaben:

Poa nemoralis of firmula ist var. rigidula Godr., var. subuniflora ist V. alpina G. G.: der Standort: Hatlersgraben ist bei Poa hybrida 7.11 streichen; denn die hier gesammelte Pflanze ist Festuca sylvatica Vill: anch die Exemplare des Blahberges gehören theilweise dazn.

Glyceria fluitans ist plicata Fr.

Festucal orina rom Stiftsgarten ist var. psendoovina Hackel, die übrigen sind rubra var. fallax Thuill.

Fest. Halleri ist rupicapmina (Hackel als Var. von orina).

Fest. duriusc. var. alpestris hat den älteren Namen dura Host. 7.1 fühıren.

Fest. heterophylla a laxa ist rubra var. fallax Thuill, $\beta$ rigida ist rubra var. alpina Parl, violacea $\beta$ major ist violacea var. picta Kit., alpestris ist nur eine Voralpenform von varia.

Nen für das Gebict wurde von Hackel F. arundinacea Schreb. auf Schutt und Grasplaitzen im Stiftshofe entdeckt.

Zı 197. Tofieldia horealis wurde von mir am 26. Juli zwischen Kallbling und Sparafeld an mehreren Punkten gesammelt.

Zi1 240. Anacamptis pyramidalis ist nach Professor Strasser am Damischbachthurm häutig.

7u 254. Cephalanthera rulura fand ich im Hinterwinkel bei Gstatterboden selten.

Zn 286. Callitriche verna (L.) ist anch in subalpinen Lachen des Dürnschöberl ob Aigen hïufig. 


\section{Cryptogamae.}

\section{IVC. Fam. Equisetaceae Rich.} gemein.

1257. Equisetum arvense $\%$. Auf Feldern im ganzen Gebiete

1258. Eq. Telutateja Ehrh. An sumpfigen Waldrändern spärlich: Am oberen Ausgange des Schafferweges (Angelis!), im Käferwäldchen ob dem Franenfelde.

1259. Eq. silvaticum L. An Feldrändern, Waldbächen und auf feuchten Bergabhängen bis $4500^{\prime}$ sehr häufig, besonder's in der Schiefer- und Gneisszone.

1260. Eף. palustre L. In Thal- und Bergsümpfen gemein; anch var. polystachyon Milde.

1261. Eq. limosmm L. In tiefen Sümpfen des Enns- und Paltenthales sehr hänfig, sowohl o. Linnaeanum Döll, als auch $\beta$ rerticillatum Döll mit f. leptocladon Döll.

1262. Eq. variegatum Schleich. An einer sumpfigen Stelle des Schafferweges häufig.

\section{IIIC. FaII. Lycopodiacene DC.}

1263. Lycopodium Selago L. $\alpha$ imbricatum Nlr., $\beta$ recurvum (Kit.) Milde. In trockenen Wäldern bis anf die Alpenhöhen des Grauwacken- und Tanernzuges beide Var. zerstrent, aber im Ganzen hänfig, z. B. im Strechengraben, am Dürnschöberl, Bösenstein, Grünsee der Hochhaide, Steinamandl, Hochschwung (-6000').

1264. Lyc. inumdatum L. An sumpfigen Stellen im Bürgerwalde ron Rottenmann (Grauwacke).

1265. Lye. annotinmu L. In Wäldern und Schluchten der Gneiss- und Schieferzone bis in die Voralpenregion sehr hänfig.

1266. Lye. clavatum $\mathrm{L}$. Wie roriges, doch etwas seltener, z. B. am Dürnschöberl, Hochschwung, ob Lorenzen.

1267. Ly'c. alpinum L. Anf trockenen Alpenhöhen $\left(5-7000^{\prime}\right)$ der Tauernkette sehr häufig, z. B. am Bösenstein, Steinamandl, Hochschwung; anch auf der Spitze des Dürnschöberl (Grauwacke $\left.5400^{\prime}\right)$.

1268. Selaginella spinnlosa A. Br. Auf steinigen Voralpenund Alpenweiden $\left(4-6000^{\prime}\right)$ der Kalkzone gemein, aber anch im Grauwacken- und Tauernznge ziemlich häufig, z. B. Spitze des Dürn- 
schüberl, Raine um Hohentauern, Bachränder ob der Bacheralpe, um die Kothhütten, an Bösenstein und Hochschwung; steigt auch hïufig bis in's Gesïuss linab.

1269. Sel. helrotica (l.) Syr. An schattigen Ránen und Bergabhïngen vom 'Thale (\% B. Hohlwege ror Mühlau) bis in die Voralpenregion (\%. B. Spitze des Dürnschöberl s400') nicht selten. Kiaik, Grauwacke, Gneiss.

\section{IIC. Fam. Ophioglosseae R. Br.}

1270. Oplitoglossum vulgatum L. Auf subalpinen und alpinen Abhängen des Damischbachthurm nach Professor Strasser häunig, am Düruschöberl c. 52200' zwischen Grauwackenblücken seltener.

1271. Botrychinm Virginiamm Sm. Auf Waldwiesen des Pyrnpasses selur selter (Presl als anthemoides); ich suchte es vergebens.

1272. Botr. Lumaria (L.) Sw. Zwischen 4000 und 6000' auf haideartigen Abhïngen im ganzen Gebiete, aber nicht hiunfig, z. B. am Pyrgas, Kalbling, Natterriegel, auf der Scheibleggerhochalpe (Kalk), am Düruschüberl (Grauwacke), Hochschwung (Gil.-Schiefer).

\section{IC. FaII. Filices L.}

1273. Polypodium vulgare L. a. commune Milde. Auf schattigen Kalk-, Schiefer- und Gneissfelsen der Waldregion sehr zerstreut, z. B. am Aufstieg zum Dürnschöberl, zur Scheibleggerhochalpe, um Rottenmann, im Strechengraben.

1274. P'ol. calcaremu Sm. In Wäldern und Schluchten der Kalkzone bis gegen $5000^{\prime}$ gemein.

1275. Pol. Dryopteris L. In Wäldern und Schluchten der Schieferzone sehr hä̈utig, besonders im Wolfsgraben.

1276. P'ol. P'legopteris I. In Wälderu und Voralpen des Kralk-, Schiefer- und Gneissgebirges häufig.

1277. Aspidium Lonchitis (L. L. $_{\text {) }} \mathrm{Sw}$. In Wäldern der Kalkzone bis $5000^{\prime}$ hälufig; T/wergformen sogar noch bei $6500^{\prime}$ am Scheiblstein.

1278. Aspiul. aculeatum (L.) Döll. a. vulgare Döll. In Bergund Voralpenwäldern der Kalkzone bis $4500^{\prime}$ iiberall häufig.

1279. Aspid. Filix mas (J.) Sw. 1. genuinum Milde. In Bergwäldern, besonders der Kalkzone, sehr häufig, z. B. am Pyrupass, Brucksattel, im Bruckgraben, Gesäuss, am Schatferweg: doch auch häufig anf Ciranwacke des Lichtmessherges ete.

1280. Aspid. rigidum (Hfin.) Sw. Auf Kalkblöeken an Fusse des Hund (c. 4.500') und am L'usse der letzten Erhebung des Scheiblstein $\left(5-6500^{\prime}\right)$ sehı häntig.

1281. Aspiil. spimulosum (Müll.) Sw. $\alpha$ typicum und $\beta$ dilatatum (Sm.). An Rändern des Hofmoores häntig ( $\alpha$ ), an Ränderu des Krumanermoores sehr gemein ( $\%$ und $\beta$ ); seltener in Berg- 
wäldern, z. B. beim Kohlenbau des Lafferwaldes ( $\beta$ ), am Pyrnpass, Unterkalbling ( $\alpha$ Angelis !), bei der Brunnstube des Lichtmessberges $(\beta)$.

1ะ82. Aspid. montamm (Vgl.) Aschs. Oreopteris Sw. Am Beginn des Schafferweges unter Fichten hänfig (Sil. Schiefer, 2300'), auch sonst am Lichtmessberge bis zum Unterkalbling (Angelis!).

1283. Cystopteris tragilis (L.) Bruh. a lobulatodentata Milde. An feuchten Felsen der Berg- und Voralpenregion ziemlich hänfig, z. B. am Scheibleggerbach, unter der Kemetwand, am Aufstieg zum Natterriegel. $\beta$ alpina (Dsv.) Milde. Auf Kalkfelsen der Voralpenund Alpenregion: Sehr luäufig am Scheiblstein bei 6500', seltener um die Kemetwand mit o, unter der Schaffeithen des Kalbling; selten auf Grauwackefelsen des Dürnschöberl (5430').

1284. Cyst. montana (Lam.) Bernl. Sehr läufig auf Kalkfelsen unter der Kemetwand (c. $4500^{\prime}$ ).

1285. Asplenimu Filix femina (L) Brnh. In feuchten Wäldern und an Moorrändern des ganzen Gebietes sehr häufig, am Scheiblstein sogar noch unter Krummholz; meist v. multidentatum Döll, seltener (z. B. an steinigen Wegrändern bei Lorenzen, an Hohlwegen um Admont) a dentatum (Hffm.) Döll.

1286. Aspl. Halleri (L.) DC. "Auf Alpen bei Rottenmann (Zahlbruckner)" Maly 1868; fehlt im Herb. Maly.

1287. Aspl. tissum W. K. In Felsritzen zwischen Pyrgas und Scheiblstein, besonders an Schneegruben hänfig, ebenso zwischen Geröll am Fusse des Gamsstein bei Johnsbach. Kalk, 4-6000'.

1288. Aspl. Ruta muraria L. Anf Felsen und alten Manem der Tiefregion gemein, am Buchstein und Scheiblstein noch in der Voralpenregion.

1289. Aspl. septentrionale (L.) Sw. Auf Gueiss- und Schieferfelsen selten: um Oppenberg (Gebhard im Herb. Maly!), in der Strechen. häufig.

1290. Aspl. viride Hds. Auf Kalk bis in die Alpenregion seh:

1291. Aspl. Trichomanes L. An Manern und Felsen im ganzen Gebiete sehr häufig. Kalk, Grauwacke etc.

1292. Scolopendrium oflïciuarum Sw. Im Hartlersgraben zwischen Kalkblöcken $\left(2-3000^{\prime}\right)$ stellenweise hänfig, selten im Gesäuss.

1293. Blechnum Spicaut (L.) Rth. In feuchten Wäldern der Kalkzone zicmlich häufig, sehr gemein aber in der Schicler- und Gneisszone.

1294. Pteris aquiliua I. Aeusserst gemein in Wäldern und Waldlichtungen der 'Tiel- bis Voralpenregiou, anch an Kändern der Torfmoore.

1295. Allosmrus crispus (L.) Bruh. Am Rottemmannertauerı (Maly 1868); ich fand ihn selten auf Glimmerschieferblöcken etwa eine Stunde oberhalb der letzten Plintenalm (hinter Oppenberg).

1296. Struthiopteris germanica W. Unter Waldbäumen im Gesäuss, besonders nahe der Johnsbachbrücke, sehr häufig. 


\section{Fam. Musci frondosi. a. Acrocarpae.}

NI. Sämntliche von mir seit 1862 gesammelte Laub)- und Lebermoose wurden ron Dr. Poetseh, Herm Jurat\%ka mnd nach dessen 'Tode von Herrn Breidler in zurorkommendster Weise revidirt und determinirt. Her Breidler. stellte mir überdies unfassende Mittheilungen über die Verbreitung der Laul)- mal Lebermoose im Gebiete zur Verfügung, die meiner Arbeit selu zn Statten kamen. Str. = Strobl, Br: = Breiller.

1297. Ephemerum serratum (Schreh.) Ifampe. Auf Brachäckern und Errlblüssen der Wiesen in den Thïlern; zwar im Gebiete noch nicht beobachtet, aber nach $\mathrm{Br}$. gewiss cinheimisch.

1298. P'hascum cuspidatum S(chreb. Anf Aeckern, Erdblüssen der Wiesen und Grasplätze in den 'Thalgrïnden: Bei Dittmanusdorf (Br.).

1299. Pleuridimn alternifolium Br. em: Auf Wiesen, grasigen Abhängen, Weglehnen, Grabenrändern der 'Thalgriunde und der unteren Bergregion: In 'Torfgruben bei Selzthal, an einem Ackerraine bei Dittmanusdorf (Br.). thal (Br.).

1300. Sporledera palustris Br. eur. In Torfgruben bei Selz-

1301. Hymenostomm mierostommu (Hdw.) R. Br. Anf nackter Erde der Wiesen, Aecker, Waldliehtmigen, Weg- md Grabemränder bis in die Bergregion sehr verbreitet: Gaishorn, Trieben, Strechengraben, Jiezen, Admont.

1302. Gymmostomm rupestre Seliwg. Aul fenchten Kíalk- und Schieferfelsen bis in die Voralpenregion verbreitet, aber luäufig steril; seltener in der Alpeuregion: Nordabhang des Schober bei Wald, im Sunk, Flitzengraben bis 4000', an vielen Stellen im Gesäıuss (Br.).

1303. Gymu. curvirostmm (Ehrh.) Hdw. An fenchten und überrieselten Felsen, vorzüglich auf Kalk, von den Thäleru bis in die Toralpenregion verbreitet, seltener in der Alpenregion, häufig steril: Gesäuss (Br., Str.), Seeboden, Natterriegel (-5500'), von Raittlal gegen Liezen, Sunk, Flitzengraben, von Eigelsbrunu gegen den Leobmerberg (Br.).

130t. Eucladiun rerticillatum (L.) Br. eur. An nassen Kalkfelsen der Wurzenalm ob Liezen (Str.), wahrscheinlich auch in der Thal- und Bergregion der Kalkzone.

1305. Anoectangium compactum (Schlch.) Schwg. An feuchten Gneiss- und Glimmerschieferfelsen im Tanernzuge, besonders in den Bachschluchten: Vom 'Triebenthal gegen den Griesstein (38-5000' Br.), im Strechengraben (3000', Str.).

1306. Weisia viridula Brid. Auf nackter Erde allgemein verbreitet in den Thälern und in der Bergregion, selten auf Alpen, z. B. Abhang des Natterriegel gegen Seeboden (-5500' Br.).

1307. Dicranoweisia crispula (Hdw.) Lindb. Anf Felsblöcken des Schiefer- und Urgebirges (2500--7700') höchst gemein. 
1308. Rhabdoweisia fugax (Hdw.) Br. eur. An beschatteten Schiefer- und Gneissfelsen, in Felsspalten und an steinigen Abhängen von 3-6800': Im Walde am Wege von Wald gegen Eigelsbrunn, im Triebenthale, an den Abhängen des Griesstein und Bösenstein (Br.).

1309. Rhabd. denticulata (Brd.) Br. eur. An feuchten, beschatteten Schieferfelsen und in Höhlungen an steinigen, moosigen Abhängen ziemlich selten: Bei Wald $\left(2850^{\prime}, \mathrm{Br}\right.$.).

1310. Cynodoutium gracilescens (W. M.) Sch. An Gneissfelsen des Griesstein (55-6300', Br.).

1311. Cyn. polycarpum (Ehrlı.) Seh. An kalkarmen Felsen und beschatteten steinigen, moosigen Abhängen des Schiefer- und besonders des Urgebirges sehr häufig, von den Thälern bis in die Alpenregion, z. B. Flitzen-, Wolfs-, Strechengraben, Wagenbänkalm, Leobner (bis 6000\%).

1312. Cyu. virens (Hdw.) Br. eur. Auf Humus über Dachsteinkalk $\left(5-7000^{\prime}\right)$ am Pyrgas bis zur Spitze, aim Kalbling, Sparafeld (Str.), aber auch auf Erde, Steinen, faulem Holze in der Schieferund Gneisszone: Leobnerberg, Bösenstein von der Gamsgrube gegen den Scheiplsee $\left(5-6000^{\prime}, \mathrm{Br}\right.$. $)$.

1313. Dichodontium pellucidum (L.) Sch. Auf feuchter, steiniger, sandiger und lehmiger Frde, an nassen Felsen, in Bachschluchten der Tief- und Bergregion verbreitet, z. B. am Fusse des Schober bei Wald, von Trieben gegen Hohentanern und im Triebenthal (Br.), im Strechengraben (Str.); seltener und meist steril in höheren Lagen: Dürnschöberl (5430', Str.), Seeboden bei Admont (5000 bis $\left.5400^{\prime}, \mathrm{Br}.\right)$.

1314. Trematodon ambiguns (Hdw.) Hornsch. Auf einer von Eunsschlamm bedeckten Stelle des Selzthalermoores im Jahre 1869 ausgezeichnet schön und reichlich (Br.).

1315. Dicranella Schreberi (Hdw.) Sch. Auf feuchter Erde, an Weg- und Grabenrïnderi: Bei Gaishorn (Br.), in der Waldregion des Dürnschöberl (Str.), im Gesäuss (Erdinger teste Jur.).

1316. D. squarrosa (Schrd.) Sch. An quelligen Stellen der Voralpen- und Alpenregion des Tauernzuges gemein, im Grauwackenzuge nur am Dürnschöberl (Str.); höchst selten mit Frucht.

1317. D. cerviculata (Hdw.) Sch. In den Gräben der Torfstiche bei Selzthal und Admont stellenweise massenhaft, z. I3. im Hofmoore (Br., Str.), auch auf Walderde am Fusse des Rottenmannertamern bei Lorenzen (Str.).

1318. D). varia (Hdw.) Sch. Auf lehmiger, sandiger Erde, an Weglelnen, Grabenrändern etc. bis $4000^{\prime}$ allgemein verbreitet.

1319. D. rufesceus (Turm.) Sch. An ähnlichen Standorten in der Tauernkette selten: Von 'Trieben nach Hohentautrn längs der Fahristrasse (Str.).

1320. D. suluulata (Hdw.) Seh. Auf kalkfreier Erde an Waldweglehnen etc. in der Berg- und Voralpenregion des Taueruzuges allgemein verbreitet.

1321. D. leteromalla (Hdw.) Scl. Mit der vorigen in Obersteiermark zerstreut, im Gebiete bisher nur im Selzthalermoore (Br.). 
132.). Dicranmm Stankii W. II. Anf funchter, steiniger linle und anf felsigem Boden des Schiefer- and Urgebirges von den höchsten Gipfeln bis herab in die Voralpenregion (7700-5500'), z. B. I.cobnerberg, Flitzengraben, Laargang ob der Wagenbänkalm (Schiefer: Br.), Griesstein (Br.), Bösenstein, Hochılıaile ete. (Gueiss, Str.).

1323. I). falcatum IIdw. Auf feuchtem, steinigem und felsigem Boden der Alpen- bis Hochalpenregion ziemlich selten: Nordabhang les leobnerberges (Schieler, 6000', 13r.), Bösenstein (Gneiss, 6000 bis $7700^{\prime}$, Str.).

1324. 1). Blyttii Br. cur. An steinigen, felsigen Abhängen in der Alpenregion des Rottenmannertanern (Str. teste Jur.).

13:5. 1). montanum Hdw. An alten Stimmen, faulen Strünken, anf' Waldboden, seltener auf kalkfreien Felsen (2-5500') sehr verbreitet, besonders in Wäldern des Schieler- und Gneisszuges, doch auch im Ciesïuss, am Pyrn, im Hofmoore ete.

1326. 1). flagellare Hdw. An ähnlichen Standorten von ien höheren Thälern bis zur Voralpenregion Obersteiermarks nicht selten; im Ciebicte bisher ïbersehen, aber nach Br. gewiss vorhanden.

1327. D. Iongifolium IIdw. Auf kalktreiem Gestein und dessen Detritus, seltener an alten Stämmen $\left(25-6000^{\prime}\right)$ im Schiefer- und Gneisszuge gemein, oft steril.

132S. D. alhicans Br. eur. Auf' kalkfreiem, steinigem Boden der 'Tauernkette $\left(6-7000^{\prime}\right)$ nicht selten, bisher nur steril: $A m$ Steinamandl (Str.), Griesstein, Bösenstein (Br., Str.); Wurzenalm ob Liezen (Kalk, Str.).

1329. D. elongatum Schwg. An Felsen, steinigen, moosigen Abhïngeu und anf 'Triften $\left(5-7600^{\prime}\right)$ nicht 'selten, aber meist steril: Natterriegel, Krummholzregion des Kabbling (Kalk, Br.); rom Griesstein gegen die Seifriedalm (Br.) am Bösenstein (Br., Str.), Gneiss.

1330. 1). f'uscescens 'T'urı. 'Auf faulen Stämmen, Waldboden und kalkfreiem Gesteine von 4-7000' allgemein verbreitet, anch nicht selten fruehtend: Dürnschöberl bis zur Spitze, Eigelsbrunnalm, Triebenthal gegen den Griesstein, ron Hohentanern zum Scheiplsee (Br., Str.): var. flexicaule (Brd.) und form. integrifolia am Bösenstein (6-7006', Str.); gewiss anch in der Kalkkette, da ich es anf der Speikwiese des nahen Warschenegg sammelte.

1331. 1). neglectum Jur. Auf felsigem und lumosem Boden der Hochalpen $\left(6-7700^{\prime}\right)$ : Bösenstein (Br., Str.), Nordseite des' Griessteingipfels (Br.), nur steril; Kalkfelsen anf der Höhe des Pyrgas (Jur.).

1332. 1). Miullenbeckii Br. enr. Anf steinigen Triften der Kalkalpen: Am Pyrgas (Jur., Str.), rom Seeboden gegen den Natterriegel steril $\left(5-6000^{\prime}, \mathrm{Br}^{\circ}\right)$.

1333. D. scoparium (I.) Hww. In Wüldern, auf Moorgrïnden, Haideplätzen, Bammstrünken, Erde und Felsen bis 7700' äusserst gemein, häufig fruchtend; rar. alpestre Milde anf der Spitze des Dürnschöberl (Str.). 
1334. D. palustre Lap. Auf dem Stücklermoore bei Wald mit Früchten, auf dem Moore bei Trieben steril (Br.).

1335. D. Schraderi Schwgr. Auf Moorgründen ziemlich gemein, oft steril: Krumauermoor (Str.), Selzthaler- und 'Triebnermoor (Br.); seltener auf humosem Boden der Alpenregion, z. B. auf der Kuppe des Leobnerberges steril $\left(6300^{\prime}, \mathrm{Br}.\right)$.

1336. D. undulatum Voit. Auf Moorgründen, Berg- und Waldwiesen, auf Erde in Wäldern bis zur Voralpenregion verbreitet, läufig fruchtend: Hof-, Krumauer-, Selzthalermoor, Lichtmessberg, bei Trieben, Gaishorm, Wald ete.

1337. Dicranodontium longirostre (W. M.) Br. eur. Anf Waldund Moorboden, faulen Stäınmen, beschatteten, humusbedeckten Felsen bis in die Voralpen sehr verbreitet, meist steril: In Wäldern bei Wald, Gaishorn, 'Trieben, Hohentanern, im Strechengraben, am Lichtmessberg, Saalberg, in Mooren bei Selzthal, Admont ete.; var. alpinum (Sch. als Camp.) Milde: Auf nassem Humus der Wagenbänkalm $\left(5000^{\prime}, \mathrm{Br}^{\circ}\right)$, Spitze des Dürnschöberl (5430', Str.).

1338. Campylopus flexnosus (L.) Brid. Auf Waldboden am Lichtmessberg ob Dittmanusdorf steril (3160', Br.).

1339. C. framilis (Dcks.) Sch. In Ritzen und Spalten der Schieferfelsen im Flitzengraben selten, steril $\left(310^{\circ}, \mathrm{Br}.\right)$.

1340. C. Schimperi Milde. An steinigen Abhängen in Vertiefungen zwischen Gräsern und Kräutern des Bösenstein von der Gaunsgrube gegen den Scheiplsee zu selten (Br.).

1341. Leucoloryum grancum (L.) Sch. Sehr häufig in Torfmooren, z. B. Hofmoor (Str.), Selzthalermoor (Br.); seltener in Wäldern, wie am Schafferweg, Lichtmessberg (Str., Br.), bei Wald an der Nordseite des Schober (Br.); nur steril.

1342. Fissidens bryoides Hdw. An Erdabhängen, Grabenränderı, besonders in Wäldern bis zur Voralpenregion: Lichtmessberg, am Fusse des Fötleck längs des Gaishornsee's (Br.), an der Tauernstrasse ob Trieben (Str.).

1343. 1:. incurvus (IV. M.) Schwg. An gleichen Standorten, aber etwas seltener in Obersteier; nach Br. gewiss anch im Gebiete.

1344. F. osmundoides (Sw.) Hdw. In Schluchten und auf fenchten Abhängen bis in die Alpenregion der Kalk- und 'T'auernkette zerstreut: Strechengraben, Bösenstein (Str.), Höhe des Pyrgas (Jur.).

1345. F. taxifolius (L.) Hdw. In Hochwäldern unterhalb der Scheibleggerhochalpe und im Strechengraben (Str.), sonst im Gebiete nicht beobachtet.

1346. 13. Iecipiens Not. Auf humoser Erde an Felsen, steinigen und buschigen Abhängen bis gegen die Voralpenregion, besonders des Kalkznges, verbreitet, meist fruchtend: An vielen Stellen im Gesänss, am Lärcheck; selten löher, z. B. rom Seeboden gegen den Natterriegel $\left(5-6300^{\circ}, \mathrm{Br}.\right)$, am Pyrgas (Str.).

1347. 1. aldiantoides (Dill.) Hdw. Auf fenchten Stellen der Wiesen und Wälder, in Moorgründen, besonders aber an nassen 
Felsen bis 4500': in Strechengraben, an der 'T'anernstrasse (Str. Schiefer), am Alpsteig im Gesïluss (Angelis i. litt., wenn nicht voriger).

1348. Anodus Donianus (Gingl. Bot.) 131. eur. und Seligeria tristicha (Brill.) Br. eur. Beile teste Br. in Obersteier ziemlich rerbreitet mul höclsst wahrscheinlich auch im Gebicte.

1349. Sel. pusilla (Hdw.) Br. emr. In Höhlungen und an schattigen Stellen vou Kalkfelsen: Im (iesäuss gegen Gstatterboden hinab an einigen Punkten spürlich $\left(19-2200^{\prime}, \mathrm{Br}\right.$.).

1350. Blindia acuta (Dicks.) Br. eur. An fenchten, steinigen Stellen und anf lelsen des Sehiefer- und Tanernzuges, in letaterem ron der Berg- his in lie $A$ lenegregion allgemein verbreitet, rou ersterem nur aus dem Flitzengraben $\left(31-4000^{\prime}\right)$ bekamnt (Br.); olt steril.

1351. Ceratodon purpureus (l.) Brid. Auf den verschiedensten Substraten ron der 'liet'- his in die Hochregion gemein, z. B. am Pyrgas und Kalbling (Kalk) bis 6800', am Bösenstein (Gineiss) bis $7780^{\prime}$ : luäufig fruchtend.

1352. Leptotrichum homomallum (Hew.) Hmp. An Erdbrïchen und Waldweglehnen des Schiefur- und Urgebirges bis in die Volalpenregion rerbreitet, meist fruchtend: Saalberg bei Liczen, Düruschüberl bis $5400^{\prime}$, unterhalb ligelsbrunu bei Wald; in 'Tauernzuge gemeiu, am Böseustein steril sogar noch bei $6800^{\prime}$.

1353. L. flexicanle (Schwg.) Hmp. Auf steiniger Erde, an Felsen, buschigen und moosigen Ablüngen bis in die Hochregion, zumal des Kalkzuges, gemein, aber meist steril; im 'Taueruzuge bis auf den Gipfel des Bösenstein $\left(7780^{\prime}\right)$.

1354. L. tortile (Schrl.) Hupe und glancescens (Hdw.) Hmpe wurden zwar noch nicht im Gebiete, wohl aber nahe den Grenzen desselben von Br. mehrfach beobachtet und sind gewiss auch einhoimisch.

1355. Distichium capillaceum (L.) Br. eur. Auf Humus, steinigen, moosigen Ablängen und au Felsen des Kalk-, Schieferund Ưrgebirges $\left(3-7000^{\prime}\right)$ gemein, ineist fruchtend: vall. brevifolia Sch. auf der Höhe des Pyrgas (Jur:).

1356. 1). inclinatum (Hdw.) Sw. Auf humoser Erde an Felsen und steinigen Abhängen der Alpenregior ziemlich selten: Natterriegel (6300', Br.), Pyrn (Niessl teste Jur.), Dürnschöberl (5+30', Str.), Leobnerberg $\left(6-6300^{\prime} \mathrm{Br}\right.$.) ; ïberall fruchtend.

1357. Pottia lanceolata (Dcks) C. Müll. Auf Erde an einem Raine bei Dittmannsdorf spärlich (Br.); an anderen Punkten wohl nur übersehen.

1358. P. intermedia (Turn.) Fürur. = truncata $\beta$ major Br. eur. Auf Lehmboden eines Ackers in der Santratte bei Admont im April 1S71 häufig gesammelt (Str:); wahrscheinlich nebst P. truncata (L.) Fürnr. in der ganzen Tiefregion rerbreitet.

1359. Didymodon rubellus (Roth) Br. eur. Auf Erde, Humus, steinigen, moosigen Abliängeu, an Manern und Felsen bis in dic 
Hochregion des Kalk-, Schiefer- und Tanernzuges gemein, meist reichlich fruchtend.

1360. D. ruber Jur. (rubellus var. cavernarum Mldo.). Anf steiniger und humoser Erde zwischen Kalkblöcken an der Nordseite des Leobnerberges $\left(55-6000^{\circ}\right)$ selten, steril, $q$ (Br.).

1361. D. cylindricus (Bruch) Br. eur. Auf feuchten Schieferfelsen im Strechengraben mit Encal. ciliata steril (Str.).

1362. Trichostomum crispulum Bruch. An Kalkfelsen in Gesänss $\left(19-2200^{\prime}\right)$ und vom Seeboden gegen den Grabnerstein und Natterriegel (5-5500') steril (Br.).

1363. Desmatodon latifolius (Hdw.) Br. eur. Auf humoser Erde, steinigen 'Trilten, erdbedeckten Felsen des Kalk-, Schieferund Urgebirges $\left(6-7780^{\prime}\right)$ : Natterriegel, Leobnerberg, Griesstein, Bösenstein bis zum Gipfel (Br.).

1364. Barbula muralis (L.) Hdw. An alten Manern, sonnigen Kalkfelsen der 'Tief- und unteren Bergregion gemein.

1365. B. unguiculata (Dill.) Hdw. Auf' fenchter Erde, an steinigen, buschigen Abhängen, Weglehnen, Manern, erdbedeckten Felsen der Tief- und Bergregion im ganzen Gebiete gemein.

1366. B. fallax How. An denselbeu Standorten und noch gemeiner.

1367. B. recurvifolia Sch. Auf feuchtem, sandigem und steinigem Boden, an Weglehnen, Kalk- und Schieferfelsen bis $4500^{\prime}$ nicht selten, fast immer steril: Gesäuss, von Admont gegen Weng (Br.), bei Aigen und am Pyrn (Niessl teste Jur.), um Wald (Br.), an der Tauernstrasse (Str.), auf einem alten Bletterdache in Hohentanern (Br.).

1368. B. rigidula (Dcks.) Sclı. (Trichostomum ed. I.) Auf alten Mauern, steinigen Abhängen, beschatteten Kalk- und Schieferfelsen bis in die Voralpen sehr häufig, z. B. Gesäuss, Stiftsgartenmanern, Aigen, Saalkogel und Pyrn, Wolfs-, Strechen-, Flitzengraben, Tauernstrasse, um Wald.

1369. B. paludosa Schwg. Auf feuchtem sandigem, und steinigem Kalkboden, sowie an kalkhältigen Felsen $\left(16-4000^{\circ}\right)$ ziemlich häufig: Von Wald gegen Eigelsbrunn, im Flitzengraben (Br.), häufig im Gesäuss (Br., Str.), am Pyrn (Str.); oft steril.

1370. B. convoluta Hdw. Auf kalkiger und sandiger Erde, Humus und Torf: im alten Enusbette bei Admont, im Torfstiche bei Selzthal (Br.).

1371. B. flavipes Br. eur. Auf humosem Kalkboden im Gesäuss (Erdinger Herb. Jur.).

1372. B. inclinata Schwgr. Auf Kalkboden im Gesäuss und an der Strasse yon Admont gegen Weng (Br.).

1373. B. tortuosa (L.) W. M. Auf steiniger und humoser Erde, alten Bretterdächern, in Wäldern, an Felsen und buschigen, moosigen Abhängen bis $6500^{\prime}$ im ganzen Gebiete gemein, vorzüglich auf Kalk; oft steril. 
1374. B. fragilis Wils. Auf nassen, steinigen, felsigen und erdigen Alpenhöhen selten: Am Griesstein (Gneiss, c. 6300', Br.), Höhe des Pyrgas (Kalk, Jur.).

1375. 13. subnlata (L.) Brid. Auf Schieferfelsen und steinigen, humosen Abhängen in Strechengraben und Oppenbergerthale nicht selten (Str.); wolll weiter vorbreitet.

1376. B. aciphylla $\mathrm{Br}$. enr. Anf Dachsteinkalk und blosser Erde $\left(5-6300^{\prime}\right)$ : Leobnerberg, vom Seeboden gegen den Natterriegel c. fr. (Br.), am Pyrgas häufig (Str.).

1377. 13. Pluralis (I.) Hdw. Auf steinigen, buschigen Grasplätzen und Abhängen, an Felsen, Mauern, alten Stämmen, auf Dächern bis in die Alpenregion gemein, meist steril; mit Früchten an Lindenstämmen im Stiftsgarten (Str.), an Kalkfelsen im Sunk (Br.) etc.

1378. B. intermedia (Brid.) Sel. An Mauern und trockenen, sonnigen Kalkfelsen im oberen Ennsthale, höchst wahrscheinlich anch im Gesïuss oder am Fusse der Hallermauern (Br.).

1379. Geheebia cataractarum Sch. Syn. ed. II. (Grimmia gigantea ed. I.) An feuchten, beschatteten Felsen, besonders kalkhältigen : Wolfsgraben, Sunk $\left(2500-3500^{\prime}\right.$, (Str.).

1380-82. Cinclidotus fontinaloides ( $\mathrm{Hdw}$.) P. B. und riparius (W. M.) Br. eur., in der Enns bei Steyr von Sauter gesammelt, finden sich gewiss auch iunerhalb des Gebietes, ebenso dïrfte aquaticus (Dill.) Br. eur. in der Enns oder ihren Zuflüssen vorkommen; Br. fand f. und aq. im Pass Stein (ob. Ennsthal).

1383. Grimmia apocarpa (L.) Hdw. Auf Kalk-, Schiefer- und Gneissgestein bis in die Alpenregion gemein; var. gracilis $\mathrm{N}$. et Hrnsch. bei Admont und am Pyrn (Niessl teste Jur.), am Dürnschöberl c. $5430^{\prime}$ mit der Normalform (Str.) ; var. rivularis N. et H. an Steinen im kleinen Bache unterhalb der Gamsgrube des Bösenstein $\left(6000^{\prime}, \mathrm{Br}^{\circ}\right)$; v. alpicola (Sw.) N. Im Dachsteinzuge ron 6000' aufwärts, z. B. Spitze des Hexenthurm (Str.).

1384. Gr. pulviuata (I.) Sm. Auf einem Grauwackenblocke neben dem Heustadl der Schulteringwiese bei Admont mit Doniana (Str.).

1385. Gr. contorta (Whlb.) Sch. In Felsklüften und an Felstrümmern des Schiefer- und Urgebirges $\left(6-7780^{\prime}\right)$, meist steril: Leobnerberg $\left(6000^{\prime}\right.$, Br.), sehr verbreitet im Tauernzuge, z. B. Griesstein (Br.) Bösentein bis zur Spitze (Br., Str.).

1386. Grr. tor (utata Grev. Auf feuchten Gneissfelsen an der Nordseite des Griessteingipfels (7300', Br.).

1387. Gr. funalis (Sclıwg.) Sch. An Felsen und Blöcken der Gneissalpen: Abhänge und Gipfel des Griesstein, Bösenstein (6300 bis $\left.7780^{\circ}, \mathrm{Br}.\right)$; nur steril.

1388. Hr. Hartmani Sch. An beschatteten Felsen und Blöcken der Berg- bis Voralpenregion des Schiefer- und Gneisszuges zerstrent: Am Fusse des Schober bei Wald, in Triebenthal (Br.), Wolfsgraben (Str.). 
1389. Gr. Doniana Sm. An Schiefer- und Gneissblöcken der Berg- bis Alpenregion ziemlich häufig, z. B. Bösenstein, Steinamandl (Str.); anch auf der Kirchhofmaner bei Rottenmann und an Feldmarken bei Admont (Str.).

1390. Gr. ovata W. M. In der Schiefer- und Gneisszone von der Tief- bis in die Alpenregion allgemein verbreitet, z. B. bei Dittmannsdorf, im Strechengraben, am Aufstiege zum Steinamandl, Bösenstein, zur Bacheralpe.

1391. Gr. alpestris Schlch. An Gneissfelsen und Felstrümmern des Tauernzuges nicht selten, gewöhnlich steril: Griesstein (6300 bis $\left.7300^{\prime}, \mathrm{Br}.\right)$ Bösenstein $\left(6-7780^{\prime}, \mathrm{Br} .\right.$, Str.).

1392. Gr. sulcata Saut. An feuchten, erdbedeckten Gneissfelsen und Felsblöcken des Bösenstein mit Früchten $\left(6-7600^{\prime}\right.$, Str.).

1393. Gr. elongata KIf. An Gueissfelsen und Felsblöcken der Tanernkette: Griesstein (63-7300' Br.), an Bösenstein hänfig $\left(6-7700^{\prime}\right.$, Str., Br.); bisher nur steril.

1394. Rhacomitrium patens (Dcks.) Sch. Auf nassem, steinigem Boden und an Felsen der 'Tauernkette in der Voralpen- bis Alpenregion zerstrent: Am Rott. Tanern (Str. teste Jur.), von der Gamsgrube des Bösenstein gegen den Scheiplsee herab steril $\left(6000^{\circ}, \mathrm{Br}\right.$.).

1395. Rh. aciculare (L.) Brid. Anf nassem, steinigem Boden und an ïberrieselten Felsen der Berg- bis Alpenregion des Tanernzuges zerstreut: Im Strechengraben mit Früchten, in Bächen ob dem Scheiplsee $\left(6400^{\prime}\right)$ steril (Str.).

1396. Rh. protensum A. Br. An feuchten Schieferfelsen der Berg- bis Voralpemregion zerstreut: Im Strechen- und Wolfsgraben mit Früchten (Str.).

1397. Rh. sudeticum (Funk) Br. eur. An Gneiss- und Schieferfelsen der Tauernkette von den Voralpen bis auf die höchsten Gipfel sehr gemein (Str., Br.), seltener im Grauwackenzuge, z. B. Nordseite des Leobnerberges $\left(6000^{\prime}\right.$. Br.); var. validior Jur. an nassen Stellen des Bösenstein $\left(5-6000^{\prime}\right.$, Str.).

1398. Rh. Heterostichum (Hdw.) Brid. An Felsen und Felsblöcken der Tanernkette von der Tief-bis zur Voralpenregion häufig; Calvarienberg bei Rottenmann, Wolfs-, Strechengraben (Str.), Triebenthal (Br.); nicht selten auch auf Alpenhöhen: Oberhalb der Bacheralpe, der" "Kothhïtten", am Bösenstein bis über 7000' (Str.).

1399. Rh. fasciculare (Schrad.) Brid. An feuchten Felsen und Felsblöcken der'Tanernkette: Abhang des Griesstein gegen das Triebenthal (5-5900', Br.) steril; Bösenstein (5-6000', Str.) steril.

1400. Rh. microcarpum (HWw.) Brid. An Gneissblöcken der Tauernkette $\left(4-6500^{\prime}\right)$ : Aufstieg zur Bacheralpe, Bösenstein (Str.).

1401. Rh. lanuginosum (Hdw.) Brid. An Gneiss- und Schieferblöcken der Tauernkette $\left(5-7500^{\prime}\right)$ hänfig, besonders am Griesstein und Bösenstein (Br., Str.); seltener im Granwackenzuge, wie am Leobnerberge $\left(59-6300^{\prime}, \mathrm{Br}.\right)$, noch seltener auf humusbedecktem Kalke: vom Seeboden gegen den Grabnerstein (5-5900', Br.); stets steril. 
1402. Rh. danescens (Hdw.) Brid. Auf Saml- mul Haideboden, Schotterpliit\%en, verwittertem Gestein lis in die Hochalpen des Sehiefer- mul Gneisszuges selır lı̈ulig: seltrner im Kalk\%uge: in der Alpenregion des Sparaleli, Büsenstein ete.; meist $\gamma$ ericoides (Deks.); oft steril.

140\%. Iledwigia ciliata (Mcks.) Ehrh. An trockenen Felsen und Felshlücken des Sulicfer- mnd Urgebirges bis anf die Voralpen sehr gemein, selten liüher; nie anf Kialk.

1404. Coscinodon pulvinatus Spreng. An Schiefer- mol Gneisssteinen anf Mauern mon Rottenmam (Str.).

140.. Amphoridimm lipponicum (Hdw.) Seh. In Felsspalten der Norlostseite des Bösenstein $\left(68--7600^{\prime}\right)$ fruchtend (Br.).

14106. A. Mongrotii (Br. Mur.) Seh. An beschatteten, kalkfreien Felsen des Schiefer- und Urgebirges von den Thälern bis in die Alpenregion gemein, hesonders in Bachschluchten; nur steril.

1407. Clota Ludwigii Brill. An Buchen, Erlen, Fichten und 'Ianuen von den hüheren Tlü̈lern bis zur Voralpenregion nicht selten: Klosterkogel, Lichtmessberg, Fuss des Schober bei Wald (Br.), beim alten Kalkofen ol, Armont (Angelis i. litt.).

14nS. L. Brncliii llousch. An Tamb- und Nadelholzstämmen in Bergwildern zicmlich selten: Vom Schlosse Röthelstein gegen den Kilosterliogel c. :31.,o' (Br.).

1409. V. (apispa (IIIw.) Brid. An Lanb- und Nadelholzstimmen in Wïllern bis anl die Voralpen sehr lö̈ufig, z. B. am Rande des Krumanernoores, am Aufstieg zur Scheibleggerhochalpe, zum P'yrgas, Büsenstein (Str.), im Gesäuss (Niessl), am Lichtmessberg, Klosterlogel, Selober bei Wald (Br.).

1410. C. intrimedia Sch. An Janb- nnd Nadelholz in Wäldern: Lichtmessberg ob Dittmannselorf $\left(3150^{\prime}\right)$, Fiss des Schober bei Wald (Br.).

1411. I. crispula Bruch. Wie crispa und ebenso häufig: Klosterlogel, Lichtmessberg (Br., Str.), Schober (Br.), Birken des Hofmoores, Gesäuss, Wälder des Pyrgas, Steinamandl etc. (Str.).

1412. I. Rehmanni Jur. An jungen Fichten und Taunen am Lichtmessberge ob Dittmannselorf und am Klosterkogel sehr selten (c. 3150 , Br.).

1413. I. IIntchinsiac (Sm.) Seh. An kalkfreien Schiefer- und Urgebirgsfelsen der Berg- bis Voralpemegion zerstrent: Im Flitzengrabeu, gewiss auch in Tauernzuge (Br.).

1414. Orthotriclum anomalum Hdw. An sonnigen Kalkblöcken und Kaikfelsen der 'Tief- bis Bergregion gemein.

1415. 0. cupulitum IIflm. Auf Kalksteinen am Aufstieg zum Pyrgas (Str.).

1416. 0. rupestre Schlch. An beschatteten, kallifreien Felsen und Felsblöcken der Berg- bis Voralpenregion des Tauernzuges: Im Triebenthale und am Wege von Hohentauem gegen den Griesstein (38-.)nu(), Br.); gewiss noch weiter rerbreitet im T'anernzuge. 
1417. 0. obtusifolimm Sclurad. An Pyramidenpappeln bei Liezen, an Eschen bei Gaishorn (Br.), an Baumstämmen um Rottenmann (Str.).

1418. 0. affine Schrad. An Laubholzstämmen bei Liezen nnd Gaishorn (Br.), an Kastanien und Waldbäumen um Rottenmann nicht selten, auch noch auf dïren Aesten bei der Bacheralpe (Str.).

1419. 0. fastigiatum Bruch. An Lanbholzstämmen am Nordabhang des Klosterkogels $\left(2850-3160^{\prime}\right)$ und im Sunk (3160 bis $4000^{\circ}, \mathrm{Br}$.).

1420. 0. speciosmu Nees. Auf Felel- und Waldbäumen verschiedener Art bis in die Voralpenregion gemein.

1421. 0. pateus Brch. Auf Feld- mol Waldbäumen am Nordabhang des Klosterkogels ob Röthelstein (2850', Br.).

1422. 0. straminemm Hrusch. An Laubholzstämmen der 'T'halund Bergregion in Obersteier nicht selten, gewiss anch im Gebiete.

1423. 0. pumilum Sw. An Pappelstïmmen bei Liezen (Br.), an Laubhölzern in einer Waldschlucht ob dem Franenfelde und an Pappeln des Stiftsgartens (Str.).

1424. 0. pallens Brich. An Eschen bei Gaishorn (Br. in z. b. G. 1871 irrig als Rogeri).

1425. 0. leiocarpum Br. enr. An Feld- mol Waldbämmen his anf die Voralpen im ganzen Gebiete gemein.

1426. Fucalypta commutata H. N. Auf Humus in Kalkfelsspalten $\left(6-6500^{\prime}\right)$ zerstrent: Pyrgas (Str:), Natterriegel (Br.); anch am Leobnerberg (Br.).

1427. F. vulgaris Hdw. Anf steiniger, kalkiger Erde, an erdbedeckten Felsen und Manern der Tiefregion; bisher nu' im Gesäuss beobachtet (Str.).

1428. E. rlablocarpa Schw. Anf Humus in Felsspalten und an steinigen Ablüngen (5-7780') im ganzen Gebiete: Häufig am Pyrgas (Kalk, Str.), auf der Spitze des Dürnschöberl (Granwacke, Str.), noch hänfiger im 'Tanernzuge, z. B. Griesstein und Bösenstein bis zur Spitze (Br.).

1429. E. ciliata Hdw. Auf Frde und Humus, an beschatteten Felsen, steinigen Ablängen der Tief- bis Alpenregion im Schieferund Tanernzuge allgemein verbreitet.

1430. E. streptocarpa Holw. Auf Humus, an Manern, Felsen, steinigen Abhängen der T'ief- nnd Bergregion dos Kalkzuges gemein, oft reichlich fruchtend, z. B. Gesänss, Pyrgas, von Admont gegen Weng, Sunk (Str., Br.); seltener im Tanernzuge: Strechengraben, Tauernstrasse (Str.), anf einem alten Bretterdache in Hohentanern (Br.).

1431. Tetpaphis pellucida (I.) Hdw. An schattigen Stellen, auf Humus, Torf, faulem Holze, kalkfreier Frde bis in die Voralpenregion sehr gemein, meist reichlich fruchtend.

1432. Schistostega osmmndacea (Dcks.) W. M. In Erdhöhlungen, unter überhängenden Rasendecken, an Waldwegründern der 'Tiefund Bergregion zerstreut: von Röthelstein gegen den Klosterkogel, von Wald gegen Eigelsbrunn (3150-3800', Br.). 
1433. Dissodun Froclichianns (Ildw.) Grev. Auf Humus an steinigen, moosigen Ablüngen und auf Triften der Alpenregion: Natterriegel $\left(6330^{\prime}\right)$, Nordseite des Griesstein und Bösenstein $\left(68-7600^{\prime}, \mathrm{Br}.\right)$.

14:34. Tayloria serrata (Hdw.) Sel. Aul' Humus und verwitterten Exerementen der Wiederkinucr in der Alpenregion ziemlich selten: Burgstalleralm ob Liezen (Kalk, Str.), Griesstein gegen das Seifriedthörl (6S-7200', Br., Gneiss).

1435. T'. tennis (I)icks.) Sch. ed. II. Am Uebergang von Wald nach Johnsbach aul einer sumpfigen Stelle nihe dem Antonikreuz (c. $5900^{\prime}, \mathrm{Br}^{\mathrm{r}}$.).

1436. Tetraplodon mnioides (L. fil.) Br. em. Am Gipfel des Bösenstein (Gueiss, 7780', Br.).

1437. Splachun sphatericum I. lil. Auf halbverwitterten Excrementen der Wiederkäuer, an f'uchten Abhängen, in Moorgründen der Voralpen und Alpen zerstrent: Leobnerberg $\left(57-6000^{\prime}, \mathrm{Br}\right.$.), in der Plinten hinter Oppenberg und am Hochschwung herrich fruchtend (Str.).

1438. Sp. ampullacenm L. Auf halbverwitterten Excrementen der Rinder in den Moorgründen der 'Thüler selten: Bei 'Trieben (Br.), beim Mühlauerwasserfalle (Angelis i. litt.).

1439. Plysseomitrium pyriforme (l.) Brid. Auf einer Moorwiese bei l'rieben (Br.), anl feuchten Grasplätzen im unteren Stiftsgarten ziemlich hïutig (Str.).

1440. Funaria hygrometrica (Is.) Hdw. Auf nackter Erde, an Brandstellen, erdbedeckten Felsen, in Sand der Bäche bis zur Alpenregion überall gemein, von Jur. sogar noch auf der Höle des Pyrgas gesammelt.

1441. F. calcarea Whlb. Im Hofmoore (Angelis i. litt.); unwahrscheinlicher Standort.

1442. Mielichloferia nitida Hrusch. Am Speikboden des Kalbling (tiefer Humus, 6500', Aug. i. litt.).

1443. I (Pptobryum priforme (L.) Sch. An Mauern, erdbedeckten Felsen, auf 'lorlimooren, schattigen und tenchten Erdabhingen bis zur Voralpenregion nicht selten: Gesäuss, Johnsbacherthal, Sunk, Selzhialermoor (Br.), Maucrn um Rottemmann, Admont, Kolılstätte am Westrande des Hofmoores (Str.).

1444. Weberal polymorphal (Hp).) Seh. Aul humoser Erde, an steinigen, moosigen Abhängen, in Felsspalten des Griesstein und Büscenstein $\left(57-7600^{\prime}, 131^{\circ}\right.$.).

1445. W. clongata (1)cks.) Schwg. An beschatteten Erdabhä̈gen, Weglehmen und exdbedeckten Felsen ron der 'lief- bis Hochregion des 'Tauernzuges allgemein rerbreitet, seltener in der Grauwackenzone.

1446. WV. Iongricollis (Sm.) Hdw. Anl Hide, Humus, an steinigen, moosigen Abhüngen, erdbedeckten Felsen der Vor-bis Hochalpenregion des 'Tauernzuges riemlich selten: Abhang des Griesstein gegen dis Suifrielthörl (Bro), an der 'T'anernstrasse, anf 
der Höhe des Steinamandil zwischen Cladon. grac. und Cetrar. cuc. (Str.).

1447. W. nutans (Schreb.) Hiw. Auf Humus, Mooren, faulen Strünken, in Wäldern etc. bis hoch auf die Alpen allgemein verbreitet; var. longiseta und sphagnetorum Sch. in Torfgruben bei Selzthal (Br.), Uebergänge zn v. long. anch im Krumauermoore länfig (Str.).

1448. W. cruda (Schreb.) Seh. An steinigen und moosigen Abhängen, auf erd- und humusbedeckten Felsen von der Tief- bis in die Hochregion des Kalk-, Schiefer- und Tanernzuges allgemein verbreitet.

1449. WV. ammotina (Hdw.) Sclıwg. Wegränder am Fusse des Fötleck längs des Gaishornsee's, steril (Br.).

1450. W. Breidleri Jur. (= Ludwigii Sch. Syn. ed. II.). Auf fenchter Gneiss- und Glimmererde der Urgebirgsalpen: Am Rottenmannertanern c. $6500^{\prime}$, Bösenstein $\left(6-7000^{\prime}\right.$, Str.), nur steril.

1451. W. Lundwigii (Spreng.) Br. cur. (= commutata Sels. ed. Il.) Auf fenchter Gneiss- und Glimmererde der Urgebirgsalpen allgemein verbreitet, z. B. an don Ahhïngen des Griesstein und Bösenstein (54-7200', Bri., Str.); meist steril.

1452. W. albienus (Whll.) Sch. An schattigen, fenchten Stellen, an Quellen, auf Erde und erdbedeckten Felsen von der Tief- bis Alpenregion im ganzen Gebiete verbreitet, aber meist steril; mit Frucht an quelligen Stellen im Walde ob Kaiseran gegen Laargang und den Uebergang in die Flitzenalm (c. 4800', Br.).

1453. Bryum pendulnm (Hrusch.) Sch. Anf Humus, fenchter Erde, sandigen Ufern bis in die Hochalpenregion zerstrent: Leobnerberg, Abhänge des Griesstein, Bösenstein $\left(57-7600^{\prime}\right)$ und sonst noch in der Tanerukette (Br.); anch im Dachsteinzuge, z. 1 . Pyrgas (Str.).

1454. Br. inclinatum (Sw.) Br. eur. Wie voriges, aber seltener: Dürnschöberl (5430', Str.), Bösenstein (57-6300', Br.).

1455. Br. cirrhatum Hpp. und Hrnsch. An ähnlichen Standorten, doch aluch auf 'Torf, an Felsen und Manern von der T'isebis in die Alpenregion ziemlich häufig: 'Torf'gruben bei Selzthal $\left(\mathrm{Br}^{\circ}\right.$.), Hofalpe am Pyrgas (Jur:), Strechengraben, Aulstieg zur Bacheralpe, längs der Tauernstrasse (Str.), im Kar an der Nordseite des Leobner (c. $5700^{\circ} ; \mathrm{Br}^{\circ}$ ).

1456. Br. bimmu Schreb. Im Selzthaler Moore (Br.).

1457. Br. pallescens Schlch. An glcichen Standorten, wie cirrh. (doch nicht anf 'Torf), bis in Alpenregion ziemlich häufig, besonders im Strechengraben und längs der 'l'auemstrasse (Str.), an der Nordseite des Leobnerberges $\left(5700^{\prime}, \mathrm{Br}^{\circ}\right)$, auf der Höhe des Steinamandl (6200', Str.), am Griesstein (6800', Br.).

1458. Br. Santeri Br. cur. Auf einer mit Enusschlamm bedeckten Stelle des Selzthaler Moores selten. (Br.).

1459. Br. erythrocarpum (Schwgr.) Mit vorigem, aber minder selten (Br.). 
1460. Br. versicolor (A. Bir.) Jir. elu. Aul schlammigem und sandigem Boden im alten limsbette unterhalb $A$ dmont solten (Br.).

1461. Br. Mildeanmm Jur. An Steinen mo anf nasser Erde längs des Baches im 'Lriebentlale (35-3800') steril (Br.).

1462. Br. alpinum I. An nissen Felsen, anl' steiniger Erde des Sehiefer- und Urgebirges ron den 'J'hällem bis in die Voralpen in Obersteier nicht selten, gewiss anch im Gebiete (Br.).

1463. Br'. Calespiticium I. Anf Wrde, an Felsen, Manem, alten Dächern, auf 'Torfmooren, Brandstellen, Schotterplätzen etc. bis in die Alpenregion im ganzen Gebiete sehr gemein.

1464. Br. Dadlium Bruch. Auf schlammigem und sandigem Boden im alten Fmsbette unterhalb Admont (Br.).

1465. Br. Funkii Schng. Anf Kalksand im Gesänss an liande der Strasse unweit der Johnsbachbrücke steril (Br.).

1466. Bbr. sregenteum I. Auf fenchter, simdiger Hide, in Grüben, an Felsen, Manern, alten Däichern ete. bis in die Alpeuregion gemein, olt steril.

1467. Br. appillure 1. Auf Humus, an fanlen Strünken, steinigen, huschigen Abhüngen, aln Mancru, Felsen, in Wähdern bis in die $\Lambda$ penregion gemein und formenreich: olt steril.

1468. Br. alexans Nors. lon liar an der Nordsoite des leobuerberges $\left(5700^{\circ}\right)$ mit Frucht, am Natterriegol (57-63:00') steril (Br.).

1469. Bir. pallens Ku. Aul denselluen substraten, wie eirhat,

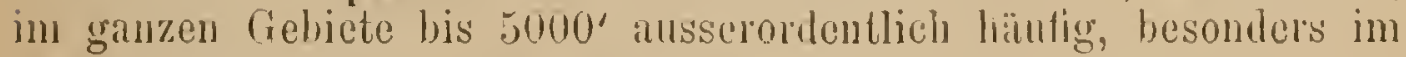
(iesïluss und an der Tamernstrasse.

1470. In. triste be Not. In Bürgerwalde bei hottenmann sehr selten (Str. Herb). Jur.).

1171. Br. Invalii Vuit. An einer Quelle an der Nordseite des Leobnerberges $\left(57-6000^{\circ}\right)$ steril (Br.).

1172. Br. psendotrigurtum (How.) Schwg. Auf nasser bilde,

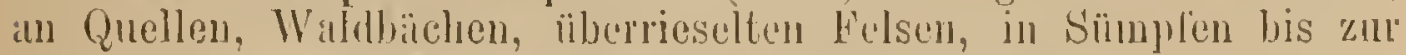
Alpenregion (-6500') sch rerbreifet, ancl häntig fruelitenul.

1473. IBr. furbinatun (Hdw.) Suhwg. Wie voriges, aber viel seltener: S'mmpfiviesen bei 'l'rieben c. fr., Gesïnss, Natterriegel (c. 6000') steril (Br.), uncllige Stellen and Anfsticge zur Sucheibleggerlochalpe (Str.).

1474. Br. Schleicheri selıw. An gleichen standorten, noch seltener: Aufstieng zur Ścheibleggerhochalpe, steril (Str.).

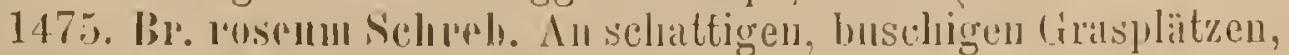
in Wäldem unl Bachschluehten: T/war im Gebiete noch nicht, wohl

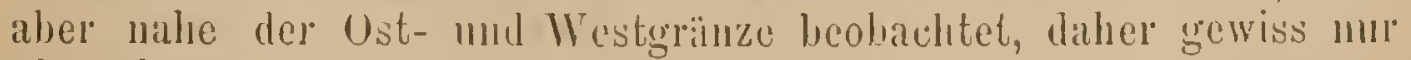
ïl)ersehen.

1476. Br. concinnatum H. Sir. Anf lenchten, verwitterten Glimmerschieferfelsen in Strechengraben mit Didym. rubelhus steril (c. 3000 ', Str.).

1477. Kieria julacea (I)cks.) Seh. Anf lenchten, moderuden Brïckubrettern und nassen Glimmerschieferfelsen im Strechengraben c. fr. (3000', Stro), an Schiefirfelsen im Flitzengrahen (2850-3160', 
Br.), an Grauwackefelsen der Spitze des Dürnsehöberl reichlich fruchtend $\left(5430^{\prime}\right.$, Str.).

1478. Mnium cuspidatum Hdw. Auf Walderde, an Baumstämmen, schattigen Grasplätzen und quelligen Stellen der Tiefregion: Im Gesäuss häufig, bei der Schiessstätte von Rotteumanu (Str.), im Holmoore (Angelis i. litt.).

1479. Mn. affine Bland. Wie voriges, bis in die Voralpen allgemein verbreitet, z. B. Krumauer-Moor, Wälder ob Röthelstein, bei Trieben, Gaishorn, Wald, um Kaiserau, Hohentauern; oft steril.

1480. Mu. undulatum (L.) Hdw. An gleiehen Standorten der lief- und Bergregion gemein und oft reichlich fruchtend.

1481. Mn. rostratum (Sehrd.) Schwg. An feuchten, schattigen Stellen, steinigen, buschigen Abhängen, in Wäldern und an Bächen bis $4000^{\prime}$ verbreitet, meist fruchtend.

1482. Mı. serratum (Schrl.) Brid. An buschigen, steinigen und moosigen Abhängen, erdbedeckten Felsen und in Felsspalten von $1600^{\prime}$ (z. B. Gesïuss Br., Str.) bis auf die Voralpen - zumal des Kalkzuges - allgemein verbreitet, selten löher (Leobnerberg, $57-6000^{\prime}, \mathrm{Br} \cdot$.).

1483. Mn. orthor hynchum Br. enr. Wie voriges, doch mehr in der Berg- und Alpenregion (38-6800') und meist steril : Vom Lüreheck bis anf den Natterriegel, am Fusse des Kalbling ob Kaiserau, von der Eigelbrunner-Alm gegen den Leobner, im Sunk, am Griesstein (Br.), Wolfşraben, Spitze des Dürnschöberl (Str.), Pyrn (Niessl Herb. Jur.), F'uss des I'yrgas (Jur.).

1484. Mn. spinosinn (Voit.) Schwgr. In Berg- und Voralpenwäldern auf humoser Erile zerstrent: Von Hohentauen gegen den Scheiplsee fruchtend (Str.), in Triebenthale, am Nordabhang des Schober bei Wald (Br.).

1485. Mn. stellare Hiw. An schattigen, feuchten, steinigen Abhängen, erdbedeckten Felsen, Bachründern, besonders in Bergwäldern $\left(16-5000^{\prime}\right)$ allgemein verbreitet, seltener in der Alpenregion, z. B. am Bösenstein (c. 6000', Str.).

1486. Mu. pumctatum How. Auf Hede, Humus und Steinen an feuchten, sehattigen Stellen, besonders an Quellen und Waldbäehen bis aul die Voralpen des Śchiefer- und Urgebirges gemein, meist fruehtend; var. $\beta$ elatum Sch. in Bösenstein ob dem Scheiplsee an quelligen Stellen steril $\left(63-6800^{\prime}, \mathrm{Br}.\right)$.

1487. Mn. hymenophylloiles IIbı. In Höhlungen und Spalten von Kalkfelsen in Kar an der Nordseite des Leobuerberges sehr selten $\left(5700^{\prime}, \mathrm{Br}.\right)$.

1488. Amblyodou dealbatus (Deks.) P'. Bv. Vom Seeboden gegen Grabnerthörl und Natterriegel $\left(5-5700^{\prime}\right)$ spärlich, gewiss noch an vielen Stellen im Kalkzuge (Br.).

1489. Catoscopinm nigritum (Hdw.) Brid. Auf leuchtem, humosenı und kalkhälttigen Boden, sowic anf Kallifelsen an der Nordseite des Leobnerberges und boim $\Lambda$ ntonikreuz an Uebergange rou Wald nach Johnsbach (57-6000', Br:). 
1490. Meesia uligiunsa Ilıw. Auf 'Torf, Humus, an fenchten unl steinigen Stellen der 'T'ief- bis Ilochalpenregion selur verbreitet, auf allen Cesteinen, meist als r. $\beta$ alpina Sch. z. B. Moore bei 'Tricbeu, Selzthal, im Gesänss, am Leobner, Natterriegel, Hexenthurm, Pyrgaı, Diimschüberl, Griesstein, Bösenstein bis 7001)'.

1491. M. tristicha (Funk) Br. cur. Auf Sumplwiesen und Moorgründen Obersteier's ziemlich verbreitet, felılt sicher anch in Gebiete nicht (Br.).

1492. Paludella squarrosa (L.) Fhrh. In Sümpfen am Gaishorusee ziemlich häufig steril (Br.).

1493. Anlacommimu palustre (I.) Schwg. Auf Sumperiesen mol Moorgrïnden des Emns- mil Paltenthales gemein, seltener anf Voralpen mol Alpen z. B. Brumnsteineralm ob Liezen (Str.), vou Hohentanern gegen die Scheiplsefen (Br.): mit Frïchten im Krumaller Moore (Str:).

14!4. Aul. turgidum (Whih.) Scluwg. Anf fenchten, steinigen ımi felsigen, mosicichen Abhängen des Hochschwung ziemlich hälnfig (6000', Str.), wahrscheinlicb noch anderwärts im Tanernzuge.

1495. Bartramia ithyphylla Brid. Auf Erde an steinigen, buschiggen und moosigen Ablüngen, in Felsritzen der Berg-bis Hochregion des $\mathrm{Ur}$ - und Schiefergehirges allgemein verbreitet, meist aber nur in kleinen Räs'chen; hïufig und reichlich fruchtend am B̈̈senstein bis 7500 .

1496. B. pomiformis (I.) Hdw. An schattigen, steinigen Abhängen, in Wüldern und Felsklïften der Tief- bis Bergregion nicht selten: Strechengraben, Bürgriwald bei Rottemmamn (Schiefer), Gesä̈lss (Kalk, Str.); F crispa Sw. Gesïlsss (Str.).

1497. B. Halleriana H»w. Wie vorige, aber sehr häufig, zumal im Tanernzıge, 7. B. Gesïnss, Pyrgas, Strechen-, Wolfsgraben, Tanernstrasse, Triehenthal, Schober liei Wald; steigt bis in die untere Alpenregion und fruchtet meist reichlich.

149S. B. Oederi (Gum.) Sw. Mit der vorigen im ganzen Gebiete bis anf die Alpen sehr verbreitet, im Kalkzuge sogar gemein, meist reichlich fruchitenl: steigt am Griesstein und Büsenstein his 7000'.

1499. Pliilonotis fontana (L.) Bril. An quelligen, sumpfigen Stellen, nassen Felsen mul steinigen $\Lambda$ bhängen von den Thälern bis gegen 7000' sehı häufig, vorzüglich im Schiefer- und Urgebirge, oft in ansgerlehnten, reichfrïchtigen Rasen, z. B. am Lichtmessberg, Dürnschöberl, am Nordrande des Hoffeldes, $1 \mathrm{~m}$ den Schciplsee ete.; if falcata Sch. im Tancruzuge (Str.).

1500. Plı. calcarea B31. emr. An gleichen Standorten bis 5000' häufig, aber vorwiegenl im Dachsteinzuge: Gesïuss (Br., Str.), Sïmpfe am Gaishornsee (Br.), Brucksattel, Aufstieg zur Sclieibleggerhochalpe, Voralpenbäche des Pyrgas, hier oft in prachtrollen, reichfrüchtigen Rasen, Dürnschöberl (Str.), Pyrn (Niessl teste Jur.).

1501. Timmia austriaca Hdw. An beschatteten felsigen, steinigen Ahhïngen, in Felsklüften der Kalkalpen riemlich selten: Natterriegel $\left(57-6000^{\circ}, \mathrm{Br}.\right)$ : steril. 
1502. T. bavarica Ilessl. Anf beschattetem, humusbedecktem Kalkboden nud in Höhlungen zwischen Felsblöcken: Im Kar an der Nordseite des Leobnerberges c. fir. (57-6000', Br.).

1503. T. Honvegica Yett. Auf hmmusbédeckitem Kalkboden, an felsigen, steinigen Abhüngen $\left(57-6300^{\prime}\right)$ zerstrent: Nordseite des Leobnerherges, Natterriegel, wohl im gan\%en Kalkzuge (Br.).

1504. A trichnm milulatum (L.) Bv. In Wällern, an Hohlweglehnen, Erdansstichen ete. bis $4000^{\prime}$ sehr gemein, selten höher.

1505. A. tenellum (Röhl) Br. eur. Ant lehmiger Frde an Waldweglehnen und Frdansstichon solten: Hochwaldregion des Dürnschöberl, fruchtend (Str.).

1506. Oligotrichum lepeynicum (Ehrh.) Lam. Auf erdigen und steinigen Alhängen der Tamernkette (54-7780') sehr hänfig, überzieht zwischen dem grossen und kleinen Bösenstein weite Flächen; anch auf den büchsten Spitzen Ier Granwackenkette: Dürnschöberl (5430', Str.), Leolmerberg (54-6000', Br.); hänfig finchtend.

1507. Pogonatum aluiles (Hdw.) Bv. Auf thoniger, steiniger Frde an Wrglehnen, Frdbrichen des Schiefer- mol Urgebirges bis fast in die Alpenregion überall gemein.

1508. P. uniggrum (L.) Hiv. An denselhen Standorten und noch gemeiner; seltener in Kalkuge.

1509. P. alpinnm (1.) Rhl. An lusehigen, steinigen Abhäugen, in Wäldern und anf' Felshläeken der Berg- his Ilochalpenregion des 'Tanernznges sehr hänfig (3-7780'), 7. B. Strechengraben, Tlochschwnng, Bacheralpe, Steinamandl, Büsenstein (Str.), Griesstein (Br.); in Granwackenzinge am Leobnerberg (Br.).

1510. Polyfudum sexangulare Fl. Anf feuchtem, kalkarmen, steinigem Boden in der Alpenregion: Nordseite des leobnerberges $\left(6000^{\circ}, \mathrm{Br}\right.$.), Büsenstein $\left(6-6800^{\prime}\right.$, Br., Stro), beidesmal fruchtend.

1511. P. gracile Menz. Im Torfmoare bei Selzthal lıünfig (Br.).

1512. P. formosum lldw. Auf Mooren, in Wälderu und an humosen Abhängen bis 7000' allgemein verbreitet, besonders in Bergwäldern.

1513. P. piliferum Schreb. Auf lehmigen, sandigem und steinigem Boden, auf Haideplätzen und in Waldlichtungen vom Thale bis in die Hochalpen, besonders des Sehiefer- und Urgebirges, rerbreitet; steril noch am Gipfel des Bösenstein (7780', Str.).

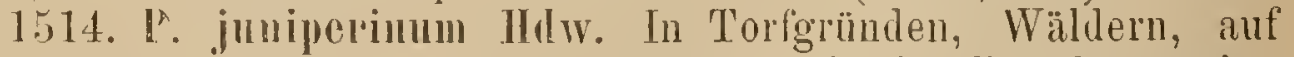
Haideplätzen und buschigen Bergabhängen bis in die Alpenregion allgemein verloreitet; var. strictum (Banks.) gemein im Selzthalerund Krumaltermoore (Br., Str.). gemein.

1515. P. commme L. Wie roriges, bis auf die Voralpen

1516. Diphyscium foliosum (T.o Molur. Auf trockenem, festem Boden in, lichten Wäldern, an steinigen, buschigen Abhängen bis 4500' zerstrent: Wald unterhalb Eigelsbrunn, Lichtmessberg, längs der Tanernstrasse (Br.), Bürgerwald bej Rottenmann (Str.). 
1517. Buxbaumia indusiata Brid. An fanlen Strünken in Bergund Voralpenwilderu zerstrent: Am Iichtmessherg gegen den Kleeriedel $(3150-3801)^{\prime}$, Br.).

1518. B. aphylla llall. Aul' Walderle des 'Tanernzuges zerstrent: Hohlwegrïnder an Austiege zur Bacheralm, am Aufstiege in die Globuke des Steinamandl (Str.).

\section{b. Pleurocarpae.}

1519. Fontiualis antipyretica I. In Quellen, Wassergrïben und Bichen bis $4000^{\prime}$ allgemein verbreitet: Bei Wald, Gaishorn, im 'Triebenthale (Br.), sehr häulig in den Fischteichen bei Hohentimern (Str.).

1500. Neckera pentuta Ildw. An Linden- mod Buehenstämmen des Stiltsgartens nelen der Kegelstätte nicht selten (Str.).

15:1. N. punila Hdw. An Tannen im Walde zwischen Röthelstein und dem K’losterkogel selten, steril (c. 3150', Br.).

1522. N. Mispa (1.) Hdw. An alten Baumstïmmen, beschatteten Kalk- mul Schieferfelsen bis anf die Voralpen allgemein verbreitet, sogar noch anl' der Spitze des Dürnschöherl (5430', Str.).

1523. N. ('omplamata (1.) Hüb. Wie volige und ebenfalls sehr hänfig, besonders im Kalkznge; nur steril; steigt nicht bis anf die Voralpen.

1524. Homalia trichomanoirles (Schreb.) Seh. An ähnlichen Standorten selten; bisher nur im Bürgerwalde bei Rottenmann zwischen Metzg. pub. (Str.).

1525. Tancodon sciumoides ( $\left.J_{.}\right)$Schwg. $\Lambda n$ alten Bämmstïmmen, kallifreien Felsen, steinigen, buschigen Abhäugen der 'Tief- bis Voralpenregion gemein, meist steril; seltener in höheren Lagen, z. B. Spitze des IÖ̈ruschöberl (5430', Strr.).

1520. Antitrichia curtipendula (J.) Bril. An beschatteten, kalkfreien Felsen und alten Banmstämmen bis in die Voralpenregion: Eichen in der Silntratte, Fichten in der höheren Waldregion des Pyrgas (Str.), lüufiger auf Waldfelsen des Tanemznges; meist steril.

1527. Myurella julacea (Vill.) Br. eur. An steingen, moosigen und buschigen Abhängen, in Felsspalteu vou 5-7200' des Kalk-, Schiefur- und T'anernzuges allgemein verbreitet, meist andere Hoose durchwachsend: Seehoden, Natterriegel, Kalbling, Leobnerberg (Br.), Dürnschöberl (Str.), besonders häufig am Griesstein und Bösenstein; ïberall steri].

1528. Leskea polycarpa Ehrlı. An Eichenstämmen in der Sautratte bei Admont (Str.).

1529. L. Herrosa (Schwg.) Myr. Auf Brettern in der Sautratte (Str.), bei Admont (Niessl), an Baumstïmmen bei Wald und Trieben, an Steineu unter Gebüsch im 'Triebenthal (Br.), längs der Tauernstrasse an Rainen, in den Hochwïldern unterhalb des Scheiplsee's an Fichten (c. $5000^{\prime}$, Str.); iiberall steril. 
1530. Anomodon Jongifolius (Schlch.) Hrtm. An alten Stämmen, beschatteten Felsen, buschig-steinigen Abhängen bis 3000': Gesiunss, Weg von Wald gegen Eigelsbrunn (Br.); nur steril.

1531. An. attenuatus (Selıreh.) Hrtm. An ähnlichen Standorten der Tief- und Bergregion im ganzen Gebiete gemein, aber meist steril.

1532. An. vitieulosus (L.) Hk. et Tl. An beschatteten Felsen und alten Stämmen in der Tief- und Bergregion, vorzüglich des Kalkzuges, gemein, meist steril.

1533. Psendoleskea atrovirens (Dicks.) Br. eur. An Felsen, Felsblöcken, steinigen, buschigen Abhüngen (4-7700') im Kalk-, Schiefer- und Urgebirge gemein, selten in der 'Tiefregion; häufig steril.

1534. Ps. catemulata (Brid.) Br. enr. An gleichen Standorten $\left(2-5700^{\circ}\right)$ nicht selten, zumal auf Kalk: Gesïnss, Pyrgas, Sunk, Dürnschöberl $\left(5430^{\prime}\right)$, von der Figelsbrunneralm anf den Leobner $\left(4700-5700^{\prime}\right)$ etc.

1535. Heterocladimm dimorplımm (Brid.) Br. cur. Auf Walderde, an alten Stämmen und beschatteten Felsblöcken des Schiefer- und Urgebirges bis auf dic Voralpen: Unterhalb der Eigelsbrunneralm, an der Nordseite des Schober, am Fusse des Fötleck, im Triebenthal, bei Hohentauem (Br.), am Anfstieg zur Bacheralpe (Str.); meist mit Früchten.

1536. Het. heteropterum (Bruch) Br. emr. An beschatteten Schieferfelsen im Strechengraben steril (3000', Str.).

1537. Thuidium tamariscinmu ( $\mathrm{Hdw}$.) Br. enr. Am Grumde alter Stämme, anf Erde in Wäldern bis zur Voralpenregion im ganzen Gebiete sehr häufig; meist steril.

1538. Th. delicatulum (Hdw.) Sch. ed. II. Anf Mooren, Grasplätzen, Baumstrïnken, fenchter Walderde his in die Alpenregion ziemlich häufig, 2. B. Gesänss, Krmmanermoor, lïngs der Tanernstrasse, am Kalbling bei $6000^{\prime}$ (Str.).

1539. Th. recognitum (Hdw.) Sch. ed. II. Anf Humus und am Grunde alter Stämme in Wüldern, auf Waldwiesen und buschigen, steinigen Grasplätzen bis in die Voralpen des ganzen Gebietes verbreitet; meist steril.

1540. Th. abietinmm (T.) Br. eur. Auf somnigen Abhängen und in lichten Wäldern der 'Jief- bis Voralpemegion gemein, seh" selten fruchtend.

1541. Pterigynandrum filiforme (Timm.) Hdw. An Baumstämmen (besonders Buchen und Ahoruen), kalkarmen Felsen etc. bis in die Voralpenregion überall gemein, oft steril; $\beta$ heteropterum (Brid.) Sch. An Steinen, Felsen der Voralpen- und Alpenregion des Taneruzuges allgemein verbreitet, seltener im Schieferzuge; meist steril.

1542. Leseuraea striata (Schwg.) Br. eur. An Baumstämmeu, Krummholz und Wachboldergesträuch der Kalkkette wahrscheinlich ziemlich verbreitet, bisher nur von der Hochalpe am Pyrgas (Jur.) bekannt. 
151:3. L. saxicola Milde (striatal P sidxicolat Sch.) An Gneissund Schieferblöcken des Griesstein und Bösenstein $\left(57-7100^{\circ}\right)$ steril ( $\mathrm{Br}$.).

1544. Platygrimu repens (Brid.) Br. emr. An Fichtenstämmen in einen Wäldehen (Viehweile) nordwestlich ron Admont steril (Br.).

1.545. Pylasisia polyantha (Selueh.) Br. enr. An Batumstämmen und Strünken der 'lief- unl Bergreggion gemein, stets fruchtend; seltener auf Steinen und Felsen, \%. Bs. bei Aigen (Niessl), in der Klamm (Str.).

15.16. Cylindrothreinm roucimum (Not.) Sch. Auf' somnigen Abhäagen, steinigen Grasplätzen bis in die Apenregion zerstreut: Gesïuss, lärclieck, von Hall gegen das Grabnerthörl (32-3800', Br.), Spitze des Dïrnschöberl (5 (:30), Str.); überall steril.

1547. Climacinm dendroiles (I.) W. M. Auf nassen Wiesen, in Wäldern, Mooren und Sïmpfen bis $4000^{\prime}$ überall verbreitet, selten fruchtend.

1548. Isothreimm mynum (Poll.) Brid. An Steinen, Felsen, alten Stïmmen der Berğ- und Voralpeuwälder gemein, häufig finchlend.

15.19. Orthothecimm intricatum (Hrt.) Br. emr. An beschatteten, steinigen Abhängen und aul' Felsen der Berg- bis Alpenregion zerstreut: Gesäuss, Sunk (Br.), Diiruschöberl (5430', Str.), Nordseite des Leobner (6000', Br.).

1550. 0. rufuscens (Dcks.) Br. eur. Au beschatteten, steinigen Ablïngen und anf Felsen der Kalkkette $\left(2-4000^{\circ}\right)$ nicht selten, seltener in der Alpenregion und im Granwackenzuge: Im Gesäuss lüıfig (Br., Str.), Sunk, Flitzengraben (Br.), Dürusehöberl (5430', Str.), Natterriegel $\left(6300^{\prime}, \mathrm{Br}\right.$ ) : meist steril.

1551. 0. chryseum (Schwg.) Br. eur. An feuchten, steinigen und felsigen Abhängen der Kalkalpen $\left(63-70000^{\prime}\right)$ : Auf Humms an der Nordseite des Natterriegel spärlich (Br.), auf der Höhe des Pyrgas (Jur:).

1552. Homalothecium sericen!n (L.) Br. eur. An Eelsen, Naneru, Laubholzstïmmen der 'Tief- und Bergregion überall häufig, meist steril.

15.53. II. P'hilippeanum (R. Spr.) Br. emr. An beschatteten Liallefelstrümmern und am Crumde aller Buchen: Ostabhang des Lïrchek bei $A$ dmont $\left(9150-3500^{\prime}\right)$, fruchtend (Br.).

15.万. ('amptolhreimm lutescens (Hds.) Br. emr. An steinigen, buschigen Abhïngen, an Waldrändern der 'Tief- und Bergregion verbreitet, lïufig steril.

155.). C. nifens (Schreb.) Br. eur. Auf Sumplwiesen und Moorgrïnden des Enns- nnd Paltenthales gemeiw, meist steril.

15.56. Ptychodium plicatum (Sehl.) Seh. Auf steinigem Boden, an Felsen, Felsblöeken der Voralpen mi Alpen sehr verbreitet, besonders im Kalkznge: PJrgats, Natterriegel, Dürnschüber, Leobuer, Griesstein bis $6300^{\prime}$ ete. ; meist steril. 
1557. Brachythecium salebrosum (Hftm.) Br. eur. Auf Waldboden, an Baumstämmen, Mawern, alten Brettern, steinigen, buschigen Abhängen bis in die Voralpen sehr häufig, oft reichlich fruchtend.

1558. Br. Mildeamm (Sch.) $=$ salebr. $\gamma$ palustre Sch. ed. Il. An Grabenrändern gegen Krumau und an waldigen Rändern des Krumanermoores (Str.).

1559. Br. glareosum (Bruch) Br. eur. An Manern, Felsen, trockenen, steinigen Abhängen, anf Grasplätzen und in lichten Wäldern bis in die Alpemregion allgemein verbreitet, meist steril.

1560. Br. velutinum (L.) Br. eur. Auf Erde, Steinen, Bäumen, faulen Strünken etc., besonders aber in Wäldern, bis $5000^{\prime}$ gemein. $\beta$ sericeum Funk am Pyrgas (Str.).

1561. Br. reflexum (W. M.) Br. eur. In der Voralpen- und Alpenregion nahe den Grenzen von Br. melumals gesammelt, gewiss auch einheimisch.

1562. Br. Starkii (Brid.) Br. eur. In Wäldern der oberen Bergund Voralpenregion an Erde, Steinen, Baumstämmen und fanlen Strünken zerstreut, am bäufigsten im Tauernzuge: Wolfsgraben, $1 \mathrm{~m}$ den Scheiplsee (Str.), Triebenthal, von Hohentauern gegen den Griesstein, Nordabhang des Schober (Br.); meist fruchtend.

1563. Br. glaciale Br. enr. Anf feuchter, steiniger Erde, an Felsen und Bachrändern des Tanernzuges zerstrent: Vom Scheiplsee. auf den Bösenstein (6-7000', Br., Str.), am Griesstein (63-7300', Br.); meist steril.

1564. Br. rutabulum (L.) Br. emr. Auf Erde, an Steinen, Brettern, Baumstämmen, faulen Strünken etc. bis in die obere Bergregion sehr lï̈ufig, oft reichlich fruchtend.

1565. Br. livulare Br. eur. Auf fenchtem Waldboden, in Quelleir, an Bächen, überflutheten Feisen, auf nassen Wiesen etc. bis in diø Voralpenregion gemein; meist steril.

1566. Br. populeum (Hdw.) Br. eur. Bis in die Voralpenregion, besonders des Schiefer- und Urgebirges gemein, meist reichlich fruchtend; am Dürnschöberl noch bei $5430^{\circ}$.

1567. Br. plumosum (Sw.) Br. eur. Auf fenchter Erde, an nassen Steinen und Felsen, besonders längs der Bäche des Schieferund Urgebirges $\left(25-6000^{\prime}\right)$ nicht selten, z. B. Triebenthal (Br.), Wolfs-, Strechengraben, Alpemregion des Hochschwung (Str.).

1568. Eurliyuchium strigosum (Hffm.) Br. eur. Auf Erde, an Felseu, alten Stämmen, steinigen, buschigen Abhängen, in Wäldem etc. bis in die obere Bergregion allgemen verbreitet, seltener in der Alpenregion, z. B. am Böseustein bei $6000^{\prime}$ fruchtend (Str.).

1569. E. striatum (Schreb.) Sch. In Wälderu der Tief- und unteren Bergregion nicht selten: Wald am Krumauermoore, Bürgerwald bei Rottenmann, im Wolfsgraben häufig (Str.).

1570. E. crassinervium (Tayl.) Br. enr. Dürtte nach Br. an beschatteten Felsen und buschigen, steinigen Abhïngen der Kalkkette vorkommen; nächster Standort Pürgg im oberen Ennsthale (Br.). 
1571. L. Tommasinii (Sendtu.) $=$ Vancheri Sch. An ähnlichen Standorten der Kalkkette $\left(2-400()^{\prime}\right)$ nicht selten: Im Gesïuss an mehreren Stellen, am Läreheck ol, Hall (Bro); sehr selten linchtend.

1572. E. histrio Mlldo. (Vauch. v. julaceum Sch., Vauch. v. cirrhosum Jur. ex pte). Aul Humus, an steinigen Abhängen, in Felskilülten der Voralpen und Alpen zerstreut: Alpenrugion des Kalbling (Str.), Spitze des Dürnschöberl $\left(5430^{\prime}\right.$, Str.), Leobnerberg $\left(6300^{\prime}, \mathrm{Br} \mathrm{r}^{\circ}\right.$ ).

1573. E. pilifermm (Schreh.) Br eur. Auf Waldwiesen, feuchten, grasigen Abhängen und in Wäldern bis zur Voralpenregion zerstrent: Nordrand des Hofleldes, Strechengraben, an cler 'Tauernstrasse (Str.), Wald unterhalb Eigelsbrumn, Fuss des Fötleck bei Gaishorn, von Kaiserau gegen den Kalbling - 4800' (Br.).

1574. H. pritelongmm (L.) Br. eur. Auf Erde, Steinen, Rainen, in Wäldern ete. der 'l'iel- und Bergregion gemein; anch noch oberhalb der Krummholzregion des Pyrgas (Poetsch Crypt.).

1575. Khynchostegim depressum (Bruch.) Br. eur. Im Liesingund oberen Enusthale von Br. gesammelt, fehlt wohl anch in Gebicte nicht.

1576. Rh. murale (How.) Br. enr. Anf fenchten Steinen, Felsblöcken, Manern, an Bächen und in Schluchten bis in die Bergregion : Bachsteme in der Kruman, Eichenwurzeln in der Santratte (Str.), Kalkblüche gegen Weng, im Gesäluss (Br.), am Pym (Niessl teste Jur.).

1577. Rh. rusciforme (Weis) Br. eur. An überflutheten Steinen und Felsen bis in die Voralpenregion gemein, oft steril.

1578. Thammimm alopecu'mu (L.) Br. em. An beschatteten Fulsen und in Bachsehluchten, vorzïglich auf Kalk: Fenchte Abhänge ob der alten Enns ann Nordrande des Hofteldes, im Bürgerwalde bei Rottemmann (Str., bloss notirt).

1579. Plagiothecium polchellum (Helw.) Br. eur. A uf humoser Erde, an steinigen und folsigen Abhängen der Vor- bis Hochalpen im Kalk-, Schiefer- und Urgebirge zerstreut: Flitzengraben (3.,00' Br.), Dürnschöberl (5430', Str.), Griesstein und Bösenstein (57-$7300^{\prime}$, Br.); gewöhulich fruchtend.

1580. P’. Merams (llook) Sch. ed. If (Schimperi Jur.) Auf trockenem, festem Boden der Bergregion: Lichtmessberg ob Dittmanusitorf, von lï̈thelstein gegeu den Kilosterkogel $\left(2850-3150^{\circ}, \mathrm{Br}\right.$.).

1581. Pl. denticulatum (L.) Br. eur. Auf Erde, Baumwurzeln, fanlen Stämmen, erdbedeckten Felsen, an steingen, huschigen $\Lambda$ bhängen bis in die Voralpen allgemein verbreitet, meist fruchtend.

1582. Pl. sylvaticum (L.) Br. eur. Wie voriges, bis in die Alpenregion gemein, häutig steril: $\beta$ carifolim Jur ( $=$ Pl. Roeseanum (Hmp.) Sch. im Bürgerwalde bei Rottemmann (Str.).

155:. Pl. Imdulitum (L.) Br. eur. Auf Hride in feuchten Wïldem der Berg- mol Voralpenregion: Von Röthelstein gregen den Kilosterkogel, von Kaiserau gregen Laargang und die Flitzenalm üppig (Br.) von Rïthelstein anl den Dïrnschöberl gemein und reichlich firuchtend, am Lichtinessberg, Steinamandl (Str.), Schober bei Wald (Br.), Saalkogel bei Liezen (Niessl teste Jur); firchlet meist spärlich. 
1584. P'. silesiacum (Sel.) Br. eur. An faulen Strünken in Wäldern bis anf die Voralpen des Kalk-, Schiefer- und Urgebirges allgemein verbreitet, meist reichlich fruchtend.

1585. Amblystegium subtile (Hdw.) Br. em: An Laublıolzstämmen der 'Tief- und Bergregion nicht selten: Von Hall gegen das Lärcheck (Br.), im Gesäuss und Stiftsgarten (Str.).

1586. A. serpens (L.) Br. Auf Erde, Steinen, Manern, Baumstämmen, Brettern etc. bis in die obere Bergregion überall gemein und meist fruclitend.

NB. Auch radicale, irrigium, Kochii und riparium dürften im Gebiete vorkommen.

1587. Hypnum Halleri L. f. Auf Kalkfelsen und Kalksteinen bis in die Voralpen gemein, viel seltener im Schiefer- und Tauemzuge, z. B. Spitze des Dürnschöberl $\left(5430^{\prime}\right)$, längs der 'Tanernstrasse (Str.), im Flitzengraben, von Wald gegen den Leobner $\left(-5700^{\prime}, \mathrm{Br}.\right)$; meist reichlich fruchtend.

1588. H. Sommerfelti Myr. Auf Erde, Steinen, Holzwerk, an steinigen, grasigen Abhängen der 'Tief- und unteren Bergregion im ganzen Gebiete verbreitet, oft in Mischrasen; gewölnnlich fiuchtend.

1589. H. chrysophyllum Brid. Auf' Erde, feuchten, steinigen, buschigen Abhängen, erdbedeckten Felsen, Moorgründen, seltener an alten stämmen bis auf die Alpen allgemein verbreitet, zumal im Kalkzuge; meist steril.

1590. H. stellatum Schreb. Wie roriges, bis in die Alpenregion aller Züge gemein, meist steril.

1591. H. aduncum Hdw. In Sümplèn, Wassergräben und Mooren: Bei Selzthal (Br.), im Hofmoore bei Admont (Str.); meist steril.

1592. II. intermedium Ludll. (Cossoni Sch.). In Sümplen des Paltenthales bei Wald, Gaishorn, 'Trieben, anf dem Selzthaler Moore, von Hohentanern gegen den Scheiplsee in einer Versumptung (414400', Br.), auf der Höhe des Pyrgas (Jur.); selteu fruchtend.

1593. H. vernicosum Lindh. In Sïmpfen bei Gaishorn steril (Br.).

1594. H. exammulatum Gïulb. In Sümpfen, Wassergräben, an quelligen Stellen bis $5700^{\prime}$ nicht selten: Umgebung der Scheiplseeen, Wagenbänkalm, Uebergangshöhe von Wald nach Johnsbach und Radmer (Br.); selten fruchtend.

1595. H. Hhitans h. Ebenso, bis in die Voralpenregion : Sümpfe bei Gaishorn, um die Scheiplseeen, auf der Wagenbänkalm (47$5000^{\prime} \mathrm{Br}$.), am Dürnschöbcrl (5000', Str.); oft reichlich firuchtend.

1596. II. uncinatum Hıw. Auf Erde, Feisblöcken, fanlen Stämmen, steinigen Ablängen, in Wäldern des Schieler- nnd Urgebirges bis aul die höchsten Giptel gemein, z. B. Spitze des Bösenstein $\left(7780^{\prime}\right.$, Str:) ; seltener und nur auf Humus oder lanlem Holze im Kalkzuge; var. plumosum Sch. an faulen Stämmen im Walcle unterhalb Ligelsbrumn $\left(38-4400^{\prime}, \mathrm{Br}\right.$. $)$.

1597. II. curvicinle .Jur. Anf' humosen und felsigen 'Triften der Kalkrette $\left(5-6000^{\prime}\right)$ : Pyrgas (Jur.), Kalbling (Str.), vom Seeboden gegen den Grabnerstein (Br.); nur steril. 


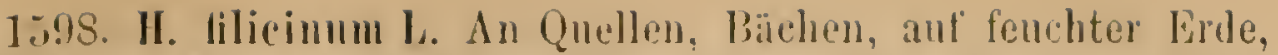
an Holzwerk, Siteinen md Felsen bis in die Alpenregion in vielen Formen gemein. oft reichlich fruchtend.

15)!!. H. decipiens (De Not. als 'Thuid.) Limp. An quelligen

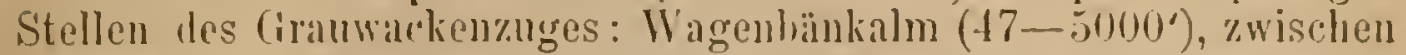
Kaiseran und f'lit\%enalm im Walde (4700, Br.); meist steril.

1600. H. commutatum Hdw. Ln Qnellen, S'ümpfen, Bächen bis anf die Voralpen überall gemen, zomal im Kalkzuge; oft reichlich firminteurl.

1601. I1. faleatum Brid. Mit rorigem, his in die Alpenregion allgemein verbreitet, oft fimchtent: var. gracilescens Sch. an trockneren Stellen: lisalkborlen im fiesïuss (19-2200' Pri.), S'pitze des Dïrnschöberl. hänfig (Granwacke, 5430', Str.).

1602. II. sulcatum Sch. Auf' erdigen, steinigen mul felsigen Alpenhühen der Kallizone ziemlich selten: Wnronalm ob liezen (Str.), Höhe des Jyrgas (Jur.), rom Seehoden gegen den Nattelriegel $\left(5-5700^{\prime} \mathrm{Br}\right.$. $)$; steril.

1603. Н. गuggosmm Ehluh. An trockenen luschigen und steingen Ahlïngen, sonnigen Wallisämmen der Tiel- mal Bergregion selı. hïulig, etwas seltener anf' Alpenhöhen, 7. B. Dïlmschöberl (5430'), Kalluing $\left(6000^{\circ}\right)$, Bösenstein his $7780^{\prime}$ (Str.); nur steril.

1604. H. inchrvatum Soluad. Auf Baumstämmen in der Eichelatu, an Banmstrünken. $\mathrm{mm}$ die Bacheralm (Str.), hïufiger anf Steintrïmmern in Wïldern: Sunk (Str.), Lichtmessherg, Fuss des Lïlreheck bei Itall (Br.); meist reichlich fruchtend.

160\%. H. reptile Rich. An Fichten in einem Wïldehen am rechten Emmsufer westlich von Admont mul in Wählem von Hall gegen das lürcheck (c. 3160', Br.); meist liuchtend.

1606. II. fastigriatmu Brid. An Steinen mol Felsblöcken der Berg- his Alpenregion des Kalliznges gemein, \%. B. Gesänss, Grabnerthïr, Kalbling (Br.), Pyrgas bis zur Spitze (Jur., Str.), Scheibleggerlochalpe, Smk (Str.); bäufig anch am Dïmschüberl (5430', Str.), ron ligelsbrum gingen den Leolmer $\left(47-6000^{\prime}, \mathrm{Br}\right.$.), Sil. Schiefer: meist finclitend.

1607. H. Sinteri Br. eur. An beschatteten Steinen mad Felsen rom Sceboden gegen den Natterriegel (c. $5400^{\circ}$, Kalk) spürlich (Br.).

1608. H. hamulosmu Br. emr. An fenchten, steinigen Ablängen mnd anf Felsen des Büsenstein $\left(68-76000^{\prime}, \mathrm{Br}\right.$.) ; steril.

1(j09. II. calliehromu Brill. In Wäldern, an fenchten Stellen, anf stemigen, felsigen 'Triften $(4 \overline{7}-6000$ ') zerstrent: Wald ob der' Kaiseran gegen den Kalbling, Leobnerberg, Seifriedalm an Griesstein, Abhänge des Bösenstein (Br.), Steinamandl (Str.); meist steril.

1610. H. cupressilorme L. Aul Hide, Holz, Gestein ete. bis in die Alpenregion höchst gemein und lormenreich; rar. filiforme Brid. z. B. hänfig im Wolfs-, Strechengrahen, Bürgerwalde bei Rottenmann (Str.) : r. orthophyllum in der Alpeuregion des Kalbling, Düınschöberl, Bösenstein bis $7780^{\prime}$ (Str.); oft steril. 
1611. H. Vancheri Lesq. Anf ler Höhe des Pyrgas (Jur.); wahrscheinlich anch in der Tief- und Bergregion der Kalkkette.

1612. H. Bambergeri Sch. Anf erdbedeckten Felsen des Dürnschöberl (5430،, Granwacke, Str.); wahrscheinlich anch im Kalkund 'Tanernzinge.

1613. H. alcuatnm Ldl\%. Anf nassen Wiesen. buschigen Abhängen, fenchter Erde mud in Wiildern bis zur Voralpenregion: Eichenwurzeln in der Sautratte, am Dürnschöberl, längs der Tanernstrasse (Str.), Selzthaler Moor, Wiesen hei Gaishorn (Br.).

1614. H. Henfleri Jnr. An steinigen und felsigen Abhängen der Alpenregion: Nordscite des Griesstein (7200', Br.), Höhe des Pyrgas (Jur.).

1615. H. procerrimum Mld. Am benachbarten Zeiritzkampl mol Hochwart (Br.); gewiss anch im Gehiete.

1616. H. molluscum Hdw. Auf Erde, Humns, Steinen etc. bis in die Alpenregion überall gemein, vorzüglich im Kalkzuge: meist steril.

1617. H. (rista-castrensis I. In fenchten Wïldern auf Erde md Felsböcken: in den Thälorn ziemlich selten (z. B. an Waldrändern des Krumanermoores häntig, Str.): hänfiger in der Bergund Voralpenregion: von Rötluelstein anf den Dürnselı̈̈herl gemein und fruchtend, im Strechengraben, am Hochschwung his 6000', mnterhalb der Bacheralpe (Str.), am Schober, K'losterlogel, mm Hohentanem (Br.); selten fruchtend.

1618. II. palnstre L. Anf Erde, Steinen, an Bächen, Quellen ete. bis in die Toralpen sehr verhreitet. z. B. im Gesïuss md Johnshachgraben hänfig, bei Aigen, Trieben, Gaishorn, an der 'T'anernstrasse, im 'Triehenthale bis 4200': meist fruchtend; o suhsphaericarpon (Schl.) an Bachsteinen bei Admont (Str.).

1619. H. dilatatum Wils. An Bächen und nassen Felsen der Urgebirgsalpen nicht selten, hesonders rom Suheiplsee gegen die Gamsgrube dos Bïsenstein (Br., Str.); meist steril.

1620. H. giganterm S(h. In Sümpfen und Wassergräben bei Trieben und Gaishorn steril (Br.).

1621. H. cuspidatum L. Anf nassen Wiesen, in Mooren, Sümpfen, an quelligen Waldstellen etc. der 'T'ief- mul Bergregion gemein; meist steril.

1622. H. Schreheri W. In Wäldern, anf Bergwiesen, Imschigen, steinigen und moosigen $\Lambda$ bhängen his $6000^{\prime}$ gemein, besonders in Berg- und Voralpenwäldern: hö̈ufig steril.

1623. 11. julım I. Anf Pergwiesen, buschigen Grasplätzen, an Waldsälumen und in Wäldern nicht gemein und meist steril: Gesäuss (Br.), Dürnschöberl (Str.); ich notirte es noch vom Nordabhange des Hoffeldes, rom Bürgerwalde bei Rottenmann und rom Aufstiege zum Steinamandl.

1624. II. straminenm Joks. In Sümpfen und Mooren bis $5600^{\prime}$, nicht selten: Moore bei Selythal und 'Trieben, Wagenbänkalm, Uebergangshöhe zwischen Wald und Johnshach, Umgebung der Scheiplseeen (Br.), Voralpensümpfe am Iö̈rnschüberl (Str.); überall steril. 
16:- H. trifirium W. M. Auf dem selzthalemoore mit seore. spärlich und steril, in einer Versmmpling am Nordalhang des Schober und im Stïelilerminore bei Wald steril, in Sïmpfen bei 'l'rieben fruchtend (Hir).

1626. H. scorpioides I. In Sïmplen und Mooren hei S'eltothal, Triehen. Gaishorn, Waht ziemlich gemein: hie und da anch liruchtend (Br.).

1627. Hylocominu splendens (Hdw.) Br. eur. Lu Wäldern, and 'Triften. Haidepläte'n ete. lis in die Hochalpenregion sehr gemein, nicht selten reichlich fruchtend; imn Büsenstein steril noch bei 7rSo'.

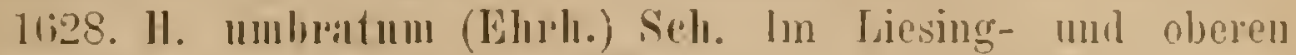
Eunsgebiete nicht selten (Br:), gewiss anch in unserem Tauernuge.

1629. It. Oakrsii (Sull.) Sch. In Wäldern, anf stuingen, moos-

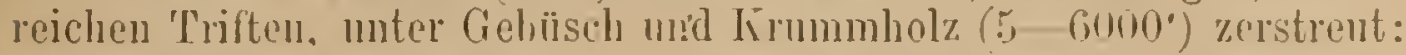
Pyrgas (Jur.), rom Seeborlen gegen den Grabnerstein, ron Hohentanern gegen den Griesstein, rom Seifriedthörl gegen das 'Trobnerthal (Br.), auf der Spitze des Diimschüberl (Str:) : un steril.

16:80. H. squarusum ( $\mathrm{I}_{\text {. }}$ ) Seh. An feuchten, schattigen GirasMätzen, auf Burgwiesen, in feuchten Wïldern his 5000 gemein, aber meist steril: rar. subpiunatum (Lindh.) an Raule ron Waldsümplen hie und da mit der Normalform.

1631. Il. trigurtlum (1.) Scli. Wie roriges, his 5000', zumal in Wïlde'm. höchst gemein; meist steril.

163:. H. Ioreum (L.) Scl. In Bergwäldern und unter Krummlool\% allgemein rerhreitet, aber meist steril: sclten in der 'Tiefregion, z. B. Waldige Ränder des Krumanermoores (Str.).

\section{r. Andreaene.}

1633. Andreatea petpophila Ehulı. An Felsen und Felsblücken des Taucrnzuges vou den hüchsten Gipfeln his in die höheren 'Thäles" herab gencin: im Schiclerzige nur an Leobnerberge $\left(6000^{\prime}, 131^{\circ}\right.$ ); var. homomalla Sicl. am Bösenstein (Niessl teste Jur.).

1634. A. Nivalis Hook. An tenchten Stellen des Büsenstein (Gamsgrube) auf Erde und Felsblücken (6-7200', Br., Str.).

\section{d. Sphagninae.}

1635. Sphagum acutifolium Ehu. In Stimpfen. Mooren, feuchten Wäldern, an nassen Felsen bis roo0', sehr gemein und formenreich: valr. dellexm, rar. Jurpureum und fusemm Seh. in Mooren mud Sümpfon des Limns- und P'iltenthales: var. roseum limp. am Nordabhang des Scholer bei Wald (B1.) : var. fallax Warnst. anf Alpen lıühcn um den Scheiplsee (Str.).

1636. S. Gionensolnuii liuss. Wie rorjges, bis in dic Voralpenregion des Schicfur- und Urgebirges allgemein rerbreitet und olt massenhaft, aber last immer steril: Wälder am Nordabhange des 
Klosterkogel, des Schober bei Wald, an Fusse des Fötleck, bei Hohentauern (Br.), Alpenhöhen $n$ m den Scheiplsee, sich nähernd der var. strictum (Str.).

1637. S. recurvum Bv. In Sümpfen und Mooren bei Gaishorn, Trieben, Selzthal, Admont gemein.

1638. S. cuspoilatum Ehrh. mit den var. submersum und phumosum Sch. In Sümpfen, Mooren, Wassergräben des Euns- und Paltenthales gemein ; var. majus Russ in T'orfgrmben bei Selzthal (Br.).

1639. S. squarposum P'ers. In Sumpfwiesen, Moorgründen und feuchten Wäldern zerstrent: Nordabhang des Schober bei Wald, Fuss des Fötleck am Gaishornsee (Br.), Lichtmessberg, Bürgerwald bei Rottenmaun (Str.).

1640. S. teres Augst. In der Berg- und Voralpenregion des Tauernzuges gewiss aufzufinden (Br.).

1641. S. rigidum Sch. Anf Mooren, Sumpfwiesen, in fenchten Wäldern bis 6000` zerstreut: Krmmanermoor, Dürnschöberl (5000'), Umgeloung des Scheiplsee's (Str.); $\beta$ compactum Sch. In der Voralpen- und Alpenregion des Tanernzuges nicht selten: um den Scheiplsee (Str., Br.), vom Seifriedthörl gegen das Triebenthal (Br.), oberhalb der Kothhütten und im Ochsenkar am Bösenstein (Str.).

1642. S. subsecundum N. et H. In Sümpfen, Mooren, Wassergräben des Enns- und Paltenthales gemein, anch um den Scheiplsee bis $6000^{\prime}$; var. $\beta$ contortum (Schulz) an denselben Standorten und ebeuso häufig.

1643. S. cymbifolium Ehrh. In Sümpfen und Mooren der Tiefregion sehr gemein, anch noch bis $5000^{\prime}$ am Dürnschöberl und $\mathrm{um}$ die Scheiplseeen; var. $\beta$ congestum Sch. Auf Torfmooren bei Selzthal (Br.) und Admont (Br., Str.).

\section{Cl. Fam. Musei hepatici.}

1644. Riccia sglauca L. Auf Schlamm der Emms bei Selzthal und Admont, in Wiesengräben bei Trieben (Br.).

1645. R. Lindenbergiana Sant. Ueber kalkhältiger Modererde bei 6000' am Pyrgas (Santer Flora 1845).

16t6. Reboulia hemisphaerica (L.) Rdd. Auf humoser Frde bei Gstatterboden (c. $1900^{\prime}, \mathrm{Br}^{\circ}$ ).

1647. Fegatella conica (L.) Rdd. An Bammurzeln, fouchten, schattigen Abhängen und Felsen allgemein verbreitet, besonders in Wäldern der 'l'ief'- und Bergregion.

1648. Santeria alpina Nees. Auf fenchtem Humus des Kalbling (c. 6000', Str.); wohl im ganzen Kalkzuge.

1649. Preissia commutata (Whilb.) Nees. Auf fenchter, humoser und steiniger Erde, an Felsen und Manern bis in die Voralpen des Kalk-, Schiefer- und Urgebirges häufig; ani Pyrgas und Kalbling bis $6500^{\prime}$ (Str.).

1650. Marchantia polymorpha L. In Sümpfen, Aeckern, an Quellen, Felsen, anf fenchter Erde der Tief- und Bergregion gemein, 
seltener in hüheren Lagen, z. B. Dürnschöberl (5:301', S'tr.), Leobnerberg $(6300$, , Br.).

16i)1. Metrencia furcata (I,) Nees. An schattigen Abhängen, auf bemoosten Felsen unl Bammstämmen, besonders in Wäldern bis zur Voralpenregion gemein: var. prolifera Nees. An der Tanemstrasse, im Wolfs- und Strechengraben (Str.).

1652. M. pubescens (Schrk.) Rdd. An denselben Standorten, besonders in Berg- md Voralpenwäldern, durch das ginze Gebiet rerhreitet: seltener in der Alpenregion.

16.53. Anemua palmata (Hdw.) Dum. Anf modermden Strünken in Wäldern bis \%ur Vorilpenregion allgemeiu verbreitet

16.54. A. pinguis (1.) Dum. Anf fenchteu Erdabhängen, an nassen Felsen, in Quellen his zur Voralpenregion zerstrent: Wegrïmler im Gesïuss anf nassem Kalkboden (Br.), Nordabhang des Holleldes, hei der Brumnhütte im Bürgerwalde von Rottenmann (Str.).

16.5. Bhasia pusilla (I.) Mich. An fenchten, beschatteten Erdablü̈ıgen, Graben- unı Wegrändern, besonders in Wüldern, bis anf die Voralpen des Schiefer- und Urgebirges alligemein verbreitet; seltener mit Frucht.

1050. Pellia epiplyylla (Dill.) Gitt. An gleichen Standorten bis in die Alpenregion zerstrent; auch anl dem Selzthalermoore (Br.).

1657. P. Neesiana (Gtt.) Limp. An gleichen Standorten bis anf die Toralpen sehr verbreitet: Wälder des Tanernzuges bei Wald und 'Trichen (Br.), Strechengraben, Düruschüberl (5430'), ob dem Sulceiplsue (6300', Str.).

] 6.58 . P. calycina (Tayl.) Nees. An fenchten, sehattigen Stellen, vorzüglich auf kalkbältigem Gestein, bis in die Alpenregion zerstrent: Lichtmessherg ob Dittmannsiorf (Br.), Strechengraben, Bürgerwald hei hottenmann, Bösenstein (Str.).

1659. Moerkia norvegica Gtt. Auf fenchter, humoser Erele, zwischen Kräuteru auf Alpentriften: Nordseite des Leobner $\left(6-6300^{\prime}\right)$, rom Scheiplsee gegen die Gamsgrube des Bösenstein $\left(6300^{\prime}, \mathrm{Br}\right.$.).

1660. Lejernia ealcarea Lil. Auf Humus und absterbenden Moosen an lieschatteten lialkfelsen bis in die Voralpen: Gesïnss, Ostabhang des Lïrcheck, unterhalb der Figelsbrum-Alm, im Sunk (Br.), Dürnschüberl (Grauwacke, 5430', Str.).

16ii1. L. serpyllifolia (Dcks.) Lib. An fenchten, schattigen Abhïngen, kalkarmen Felsen, anf Humus und Baunstämmen bis $5000^{\prime} \mathrm{jm}$ 'tanenzuge allgemein verbreitet, anch im Schieferzuge nicht selten, z. B. Dürnschöberl, Aufstieg zur Scheibleggerhochalpe (Str.) ; seltener im Kalkzuge: Auf Humus und Moosen im Gesäuss, auf dem Sceboden (5400') bei Admont (Br').

1662. Frullania dilatata (L.) Nees. An Balumståmmen und Felsen der Tief- mel Pergregion allgemein verhreitet.

1663. F. T'Tunarisei (L.) Nees. Wie rorige unh noch häufiger; steigt his 5430' am Dürnschöberl.

1664. Madotheca platyphylla (L.) Nees. An Laubholzstïmmen und Eelsen his inf die Voralpen im ganzen Gehiete gemein. 
1665. M. litevigata (Schrd.) Dum. An Felsen, steinigen Abhängen ma Baumwmreln wahrscheinlich im ganzen Gebiete rerstrent; in der Radmer (Br.).

1666. Radula germana Jack. An Felsen nnd absterbenden Lanbmoosen am Ostabhang des Lïrcheck (4100', Br.).

1667. R. complamata (1.) Dum. Anf Moosen mnd Bamnstäınmen der Tief- und Bergregion sehr gemein, seltener an feuchten, lialifreien Felsen und in der Alpenregion, \%. B. ob dem Scheiplsee $\left(6000^{\prime}\right)$.

1668. Ptilidimm ciliare (I.) Nees. Auf Mooren, Walderde, faulem Holze und humusbedeckten Felsen bis in die Alpenregion sehr häufig; ob dem Scheiplsee noch bei 6500'.

1669. Trichocolea Tomentella (Ehrh.) Nees. An nassen Stellen ob dem Franenfelde unter Laubholz, am Fusse der Hallermaneru und im Gesïnss (Str.).

1670. Mastigolnyum deflexmm (Mart.) Nees. An Büchen, feuchten Felsen, moosigen, steinigen Abhängen (5-7000') des Tanernzuges gemein, seltener im Granwackenznge: Leobnerberg (Br.). Saalkogel bei Liezen (Niessl teste Jur.); im Kalkznge nur anf Humus und Moosell: Seeboden bei Admont (5400', Br.).

1671. H. trilobatum (I.) Nees. Anf Humus, Mooren, fanlen Strïnken etc. der Tief- und Bergregion allgemein verbreitet, besonder's in Wïldern und am Nordwestrinde des Krumanermoores.

1672. Lepidozia reptans (J.) Nees. Wie voriges, bis in die Voralpenregiou ïberall gemein.

1673. Calypogeia Trichomanis (Dill.) Cord. Wie vorige, bis in die Voralpenregion gemein; seltener bis 6000 , z. B. oberhalb des Scheiplsee's am Bösenstein (Br.).

1674. Shiloscyplns polyanthus ( I.) Anf Humus, fanlen Strönken, feuchten, schattigen Erdabhängon der Tief- und IBergregion allgemein verbreitet, seltener in der Voralpenregion: var. pallescens (Schrad.) an mehr trockenen Standorten, \%. B. am Dürnschöberl, an der 'Tanernstrasse, im Bürgerwalie vou liottenmann (Str.); ral. rivnlaris Schrad. an Bächen und 'l'ümpehn der T'ancrnkette, z. B. im Triebengraben (Br.).

1675. Harpanthus Jotovianus Tees. Auf moorigen, sumpfigen und quelligen Stellen $\left(47-65000^{\prime}\right)$ : Im Walde \%wischen Kaiserau und der Flitzenalun, aul der Wagenbänkalm, an Nordabhang des Schober, Umgebung iles Scheiplsee's (Br.), vou den Kothhintten zum Bösenstein c. $651100^{\circ}$ (Str.).

1676. Tophoeolea hoteropliylla schlnd. In Wïldern des Tamernzuges auf Frde und an faulen Stämmen $\left(2-50000^{\prime}\right)$ allgemein verbreitet, anch im Grauwackenmge nicht selten, \%. B. Lichtmessberg, Dürnschöberl.

1677. I. hidenta1a (L.) Nees. An schattigen, feuchten Stellen, an Baumstrünken, auf Gras-, Wald- und Moorboden bis 5000' gemoin.

NB. Auch L. minor dürfte nach $\mathrm{Br}$. einheimisch sein.

1678. Jungermannia curvifolia Dicks. Auf morschem Holze bis $5000 \%$, zumal in Wüldern, nicht selten: Gesäuss, ob dem Franen- 
felde, am Pyrgas, Dürnschüberl, im Strechengraben (Str.), am Jichtmessberg gegen Laargang und Wagcnbänkalm (Bro).

1679. .. (onnivens Dicks. Anf Humus und faulen Stïnmen in Wäldern und Mooren bis zur Voralpenregion verbreitet; selten höher, \%. B. Seehoden (5)(10)', Br.).

1081. .I. Licuspilata I. An ähnlichen Standorten bis in die Alpenregion gemein, am Bösenstein sogar bis 7700 '.

1681. I. catenulata Hiil. Auf morschem Holze in Wäldern des Dïrnsehüberl (Str.).

1682. J. setacea Wel. Anf Bergen des Liesing- und oberen Ennsthales (Br.), gewiss anch im Ciebiete.

1683. J. trichoplyylla I. Anf faulen Stämmen, lumoser Erde, in Wïldern, Mooren ete. bis in die Alpenregion sehr gemein.

1684. J. julacea Lightif. Auf feuchtem Humus mol ardbedeckten Felsen (b3-7600): Griesstein und Bösenstein (Br., Str.), Höhe des Pyrgas (Jur.); letrterer Standort bezieht sich nach Br. wohl auf dic folgende Art.

1685. J. Jumatzkina Jimu. (julacea v. claruligera Nees.) Wie rorige, in der Alpen- und Hochalpenregion des Tanernzuges selır verbreitet, im Kallizuge seltener und un auf festem Humus, z. B. am Natterriegel $\left(6300^{\prime}, \mathrm{Br}\right.$.).

1686. J. Floerkei Wr. II. Anf Moorgründen, fenchten, steinigen und moosigen Ablängen der Voralpen und Alpen nicht selten: 1)ïrnschüberl (Str.), Griesstein, Bösenstein (Br., Strr.).

1687. J. quimpuedentata Wel. An feuchten, sehattigen Abhïngen, auf Felsblücken, steiniger und humoser Frde der Voralpenregion gemein, seltener anf Hochalpen, z. B. am Bösenstein (7000 lis $7700^{\prime}$, Str.), ron Br. f. minor alpina benamt.

1688. J. barbata Schmid. Auf Erele, Humus. faulen Strünken nicht selten, vorzïglich in Berg- und Voralpenwäldern: Von Röthelstein z.mm Klosterkogel, alm Weg in die Kiaseran, Norlabhang des Schobers, im Wolfsigraben, Triebenthal.

1689. J. polita Nees. Am Bache von der Gamsgrube des Bösenstein gegen den Scheiplsee herab $\left(\mathrm{Br}^{\circ}\right.$ ).

1690. .I. incisil Schliul. Auf Humus, 'Tolf, faulen Stïmmen, fenchter Erde etc. bis zur Alpenregion; in den Wöldern gemein und häufig fruchtend, anl' Alpen seltener, z. B. am Griesstein und Bösenstein bis 7700$\}^{\prime}$ (Br., Str.).

1691. J. intermedia Nees. Bisher nur bei $7000^{\prime}$ am Bösenstein (Str.), wahrscheinlich aber auch in der Tief- nud Bergregion.

16:92. J. ventricosil Mckis. An feuchten, schattigen Stellen, auf Erde, Humus und morschem Holze bis zur Voralpenregion nicht selten, \%. B. am Dürnschöberl, in Strechengrahen (Str.); var. porphyrolenca (Nees.) lüufiger, als die Normalform, zumal in Ẅ̈ldern, bis zur Alpemegion.

16!3. J. alpestris Schlch. Auf' Erde, Felsen, steinigen, moosigen Abhängen des 'T'anernzuges (5- $\left.5780^{\prime}\right)$ z. lıäufig, besonders am Griesstein (Br.) mul Bösenstein (Br. Str.): seltener im Granwackenzuge: Wageubänkalm (Br.). 
1694. J. oreallensis Hook. Wie vorige, aber selten : Nordseite der Spitze des Griesstein (c. $7200^{\prime}, \mathrm{Br}$.).

1695. J. inflata IIts. In einer Versumpfung auf der Wagenbänkalm $\left(47-5000^{\circ}\right)$, am Scheiplsee ( $5-5700^{\prime}$, Br.).

1696. J. albescens Hook. Wie alpestris, an den Ablängen des Bösenstein $\left(6-7700^{\prime}\right.$, Br., Str.).

1697. J. acuta Limd. Auf Erde an der Tanemstrasse (Str.), an anderen Stellen wohl mur iibersehen.

1698. J. Miilleri Nees. Auf fenchter Erde, steinigen Abhängen, rerwitterten Kalk- und Schieferfelsen bis in die Voralpen z. häufig: Gesäluss (Br., Str.), vor Weng, im Sunk (Br.), Strechengraben, Hochschwung, Dümschöberl $\left(5400^{\prime}\right)$ Str.

1699. J. obovata Nees. Auf Erde, Steinen, Felsen am Rande der Quellen, Seeen und Bïche des Tauernzuges $\left(5-7000^{\circ}\right)$ nicht selten: Am kleinen Scheiplsee, am Bache unterhalb der Gamsgrube des Bösenstein (Br.), am Hochschwung (Str.).

1700. J. hyalina Ilo0k. Auf feuchter Erde, an Hohlwegrändern der Tief- mol Bergregion zerstrent: Tauernstrasse, Wolfsgraben (Str.), längs des Gaishornsee's am l'usse les Fötleck (Br.).

1701. J. tersa Nres. Wie obor., im Tanernzuge (57-7700') z. häufig: Abhang rom Seilrielthörl gegen das Triebenthal (Br.), rom Scheiplsee iiber die Gamsgrube anl den Büsenstein (Br., Str.); selten im Granwackenzuge: Nor'dseite des Leobner $\left(6300^{\circ}, \mathrm{Br}^{\circ}\right.$ ).

1702. J. confertissima Nees. Auf feuchter Erde an der Tanernstrasse (Str. teste Limpricht), an Kallitelsen anf der Höhe des Pyrgas (.Tur:).

1703. J. cremulata Sm. Bei Kalwang und im oberen Emnsthale nicht selten (Br.): gewiss anch in der Tief- mul Bergregion des Schiefer- und Urgebirges.

1704. J. pumila With. An fenchten, beschatteten Kalkfelsen im Gesäuss $\left(1900^{\prime}\right)$ und am Ostabhange des Järcheck $\left(4300^{\prime}, \mathrm{Br}\right.$.).

1705. J. riparia Tayl. Im Gebiete noch nicht gesammelt, kommt aber gewiss im Gesäuss, Johnsbachgraben, höchst wahrscheinlich auch in Bergschluchten des Tauernzuges ror (Br.); auch lanceolata Nees. ist fast gewiss einheimisch.

1706. J. subapicalis Tees. Von Röthelstein gegen den Klosterkogel $\left(25-285\left(0^{\circ}\right)\right.$ anf hmmoser Walderde mod an Steinen selten (Br.).

1707. J. Taylori Hook. An feuchten, kalkfreien oder humusbedeckten Felsen, auf Walderde, faulen Stämmen und Mooren $\left(32-6300^{\prime}\right)$ nicht selten: Nordabhang des Schober bei Wald, vom Seifriedthör] gegen das Triebenthal, vom Scheiplsee gegen die Gamsgrube des Bösenstein (Br.); var. $\beta$ anomala (Hook.) Nees: Auf Mooren bei Selzthal und Admont nicht selten (Br., Str.).

1708. J. minuta Crantz (mit v. protracta Nees.) Auf Humus, Felsen, steinigen Abhängen und faulen Stïmmen bis $7700^{\prime}$ im ganzen Gebiete verbreitet, am häufigsten in der Berg- bis Voralpenregion des Schiefer- und Urgebirges.

1709. J. Reichardti Gtt. u. Jur. An feuchten, steinigen Abhängen und in Felsklüften des 'T'anernzuges: Vom Gipfel des Bösen- 
stein herab gegen den siheiplsee (T-So-6ismor, Br., Str.), an der Norlseite des Griesstein (7201), Br.).

1710. I. Mielanuxi Wro. An fanlen Stummen der Berg- und Voralpenevion sehr wahrscheinliclı einheimisch (Br.): chenso dürfte obtusifolia Ilonk. im Schirar- und Urgebirge gewiss rorkommen (Br...

1711. I. exsecta Schunil. Aul Erihlössen, fanlen Stämmen, Weglehnen, lumnsbedecliten Felsen lis in die Alpenregion sehr rerbreitek, \%. B. ob Rï̈thelstein, am lichtmessberg, Dïruschöherl, hinter Líliseran, im Wolfsgraben, am Schober bei Wald, unterbalb der Ligelsbrumnalm.

171:. J. albicans L. Auf Erde, feuchten Felsen, steingen Abhïngen. in Wïldern der Berg- bis Alpenregion des Schiefer- nnd Urgebirges gemein; var. taxifolia (Whlb.) ebenso gemein, vorzüglich in der Alpen- und Hochalpenregion.

1713. S(apantia nubrosa (S'chrd.) Nees. Auf fenchter, kalkarmer Erde, an Steinen und morschen Strünken $\left(9-4-4400^{\prime}\right)$ nicht selten: Nordabhang des schober, 'Triebenthal, Dürnschöberl, rom Lichtmessberg gegen die Wagenbänkalm.

1714. Se. curta (Marr.) Nees. Auf lehmiger und steiniger Erde, an Felsen, in lichten Wüldern his zur. Toralpenregion zerstrent, seltener auf Alpenhöhen: Fon Wald gegen Figelsbrumn, am Lichtmessberg (Br.), Spitze des Dürnschöberl, Büsenstein (7000 bis $7700^{\prime}$, Str.).

1715. Sc. acquiloba (Schwg.) Nees. Wie rorige $\left.(2-5401)^{\prime}\right)$, stellenweise luäulig; besonders im Kalkzuge: Wollisgraben, Dürnschöberl bis zur Spitze, Pyrgas (Str.), miterhalb Ligelsbrun, Ostabhang des Lärcheck, Seeboden, Gesïnss an vielen Stellen (Br.); var. dentata major Gottsch. Gesäuss, Wald unter Eigelsbrunn (Br.), Strechengraben (Str.).

zuge (13r.).

1716. Sc. uliginosa (Sw.) Nees. Wahrseheinlich im 'Taueru-

1717. Sc. Imdulata (L.) Mnt. u. Ness. In Quellen, Bäichen, Sïmpfen, auf übrrieselten Steinen und Felsen, auf Holz und nasser Erde ron der Berg- bis in die Alpentegion des Schiefer- und besonders des tanernzuges gemein und formenreich.

1718. Sc. nemorosil (L.) Nees. Auf feuchter Lrde, steinigen, moosigen Abhïngen, an Felsen des Schicfer-und Urgebirges bis in die Alpenregion häufig; selten im Kalkzuge: an Pyrn (Poetsch.).

1719. Placiochilit interupta Yees. Anf Felsen, steingen und busehigen Abhängen des Kallizuges: In Gesänss an einigen stellen, Ablï̈nge des Lärcheck (38-4100', Bro).

1720. P1. asplenioides (L.) Nees. Auf Erde, Felsblöcken, steinigen Abängen, in Wäldern his \%ur Voralpenregion höelıst gemein, seltener in der Alpenregion, \%. b. Sjitze des Diurnschöberl (mit $r$. hummlis Ne'es.), Biisenstein bis $70100^{\prime}$.

1721. Alicularia scalaris (Schrl.) Cord. Wie rorige, bis in die Hochatpenregion im gan\%en Cicbicte gremein, am Bösenstein noch bej $7700 \%$. 
1722. Al. compressa (Hook). An nassen Stellen und in Quellbächen am Rande des kleinen Scheiplsee's (5000') in grossen Polstern (Br:).

1723. Sarcoscyphus Funlii (W. M.) Nees. Auf lehmiger und steiniger Erde, an Felsen der Schiefer- und Tanernkette: Lichtmessberg ob Dittmannsdorf $\left(25-3100^{\prime}, \mathrm{Br}\right.$.), unterhalb der Eigelsbrunn-Alm $\left(3-3800^{\prime}\right)$, im Triebenthale $\left(3800^{\prime}, \mathrm{Br}\right.$ ), rom Scheiplsee auf den Bösenstein $\left(6-7000^{\prime}\right.$, Br., Str.).

1724. S. sparsifolius Lindb. Auf Felsen und Erdflächen des Bösenstein (6-7600', Str.).

1725. S. commutatus Limpr. Mit vorigem am Bösenstein (77700', Str.); Blattrand nicht immer umgeschlagen.

1726. S. revolutus Nees. An feuchten Gueissfelsen und deren Detritus am Bösenstein (7780', Br.).

1727. S. Ehrlharti Corda. Anf feuchter Erde, Steinen, Felsen der Voralpen- und Alpenregion des Tauernzuges gemein, selten in tiefen Lagen (Bürgerwald bei Rottenmann, Str.) und im Grauwackenzuge (Wagenbänkalm, Br.); $\beta$ aquaticus Nees. am Rande des kleinen Scheiplsee's und in Bache unterhalh der Gamsgrube des Bösenstein $\left(5-6000^{\prime}, \mathrm{Br}.\right)$.

1728. S. spltacelatus (Giesk.) Nees. Auf nasser Erde, in Quellen und Bächen des Taneruzuges: An einer Quelle nahe dem Scheiplsee (c. 5000'), in Bächen des Bösenstein (65-7000', Str.), rom Seifriedthörl gegen das Triebenthal $\left(5-5700^{\prime}, \mathrm{Br}.\right)$.

1739. Gymmomitrium corallioides Nees. Auf steiniger, humoser Erde und an Felsen der Tanemkette: Nordseite des Griessteingipfels (7370', Br.), am Bösenstein von $6800^{\prime}$ bis zum Gipfe! (Br., Str.).

1730. G. concinnatum (Ligtf.) Cord. Wie roriges, aber viel hänfiger, z. B. am Griesstein und Bösenstein von $5400^{\prime}$ bis auf die Gipfeln (Br., Str.); seltener im Schieferzuge: Leobnerberg bei Wald $\left(6-6300^{\prime}, \mathrm{Br}\right.$. $)$. 


Ex 